\title{
As gerações e o HIV/Aids : análise de três décadas da epidemia de HIV/Aids no estado de São Paulo
}

Dissertação apresentada à Faculdade de Medicina da Universidade de São Paulo para obtenção do título de Mestre em Ciências

Programa de Dermatologia

Orientador: Prof. Dr. Jorge Simão do Rosário Casseb

(Versão corrigida. Resolução CoPGr 6018/11, de 1 de novembro de 2011. A versão original está disponível na Biblioteca da FMUSP) 


\section{Dados Internacionais de Catalogaçăo na Publicação (CIP)}

Preparada pela Biblioteca da

Faculdade de Medicina da Universidade de São Paulo

\section{Greprodução autorizada pelo autor}

Alves, Wagner da Silva

As geraçöes e o HIV/AIDS : analise de três

décadas da epidemía de HIV/AIDS no estado de são

Paulo / Wagner da Silva Alves. -. São Paulo, 2018.

Dissertaçăo (mestrado)--Faculdade de Medicina da

universidade de săo Paulo.

Programa de Dermatologia.

orientador: Jorge Simão do Rosário Casseb.

Descritores: 1.HIV 2.Sindrome da imunodeficiencia adquirida 3 .Geraçбes 4. Populaçăo chave 5. Epidemias 6. Incidencia

USP / FM/DBD - $358 / 18$

Responsável: Erinalva da Conceição Batista, CRB-8 6755 


\section{DEDICATÓRIA}

A todos que contribuíram direta ou indiretamente nessa pesquisa.

A equipe do Ambulatório ADEE 3002.

A toda a trajetória de vida. 


\section{AGRADECIMENTOS}

À minha família, apoio fundamental para construção do que hoje sou.

Ao meu orientador, Prof. Dr. Jorge S do Rosário Casseb, pela confiança e apoio em todos os momentos dessa trajetória.

À Lívia Bueno, por ser uma grande amiga e conselheira de sempre.

Ao Programa de Pós-graduação de Dermatologia da FMUSP e todos os colaboradores dedicados.

Aos meus amigos, por darem sentido à vida. 
Esta dissertação está de acordo com as seguintes normas, em vigor no momento desta publicação:

Referências: adaptado de International Committee of Medical Journals Editors (Vancouver).

Universidade de São Paulo. Faculdade de Medicina. Divisão de Biblioteca e Documentação. Guia de apresentação de dissertações, teses e monografias. Elaborado por Anneliese Carneiro da Cunha, Maria Julia de A. L. Freddi, Maria F. Crestana, Marinalva de Souza Aragão, Suely Campos Cardoso, Valéria Vilhena. 3a ed. São Paulo: Divisão de Biblioteca e Documentação, 2011.

Abreviaturas dos títulos dos periódicos de acordo com List of Journals Indexed in Index Medicus. 


\section{SUMÁRIO}

Lista de Siglas e Abreviaturas

Lista de Tabelas

Lista de Figuras

Resumo

\section{Abstract}

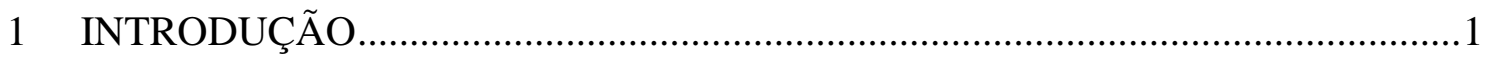

2 CRITÉRIOS DE DEFINIÇÃO DE AIDS .................................................................9

3 PROBLEMATIZAÇÃO E JUSTIFICATIVA ……………………………........11

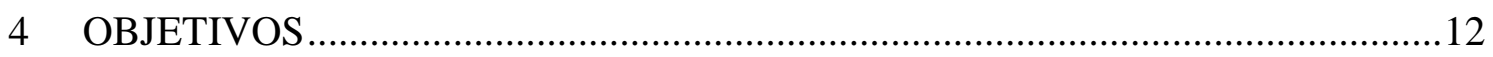

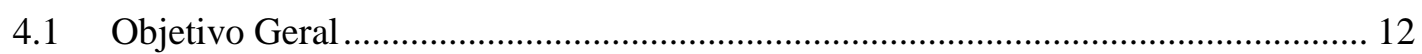

4.2 Objetivos Específicos ..................................................................................... 12

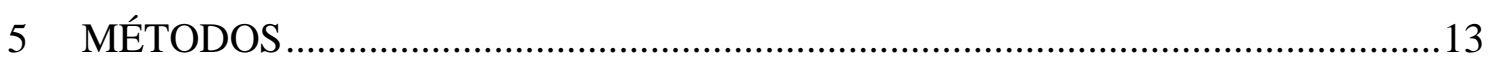

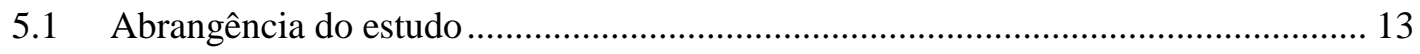

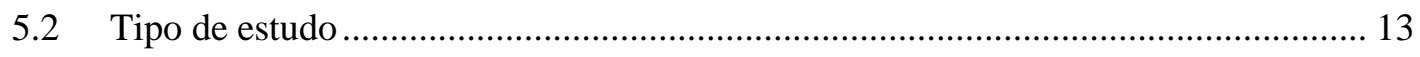

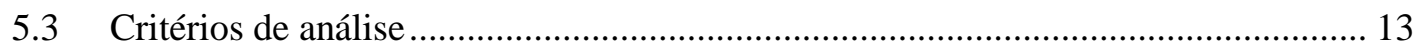

5.4 Procedimentos .............................................................................................. 14

5.5 Análise descritiva .................................................................................... 15

5.6 Teste de associação ………………………………………………………….... 15

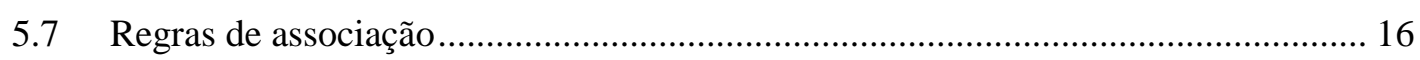

5.8 Análise da Incidência ........................................................................................ 16

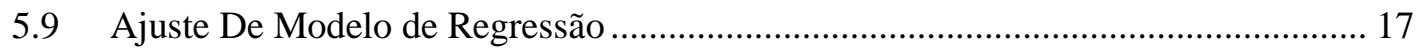

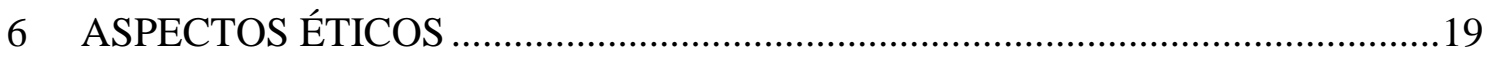

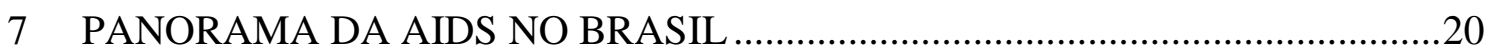

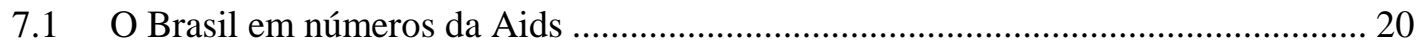

7.2 O Brasil no front contra a epidemia. …………………………………………….... 29

8 PANORAMA DA AIDS NO ESTADO DE SÃO PAULO …………………….........

8.1 Um retrato do Estado nos dados da Aids .............................................................. 32

8.2 O Estado de São Paulo e a Aids em síntese ……………………………………….. 39

8.2.1 Teste de associação ............................................................................. 42

8.2.2 Regras de associação ……………………………………………….. 43 
9 UM PANORAMA DA AIDS NA REGIÃO METROPOLITANA DE SÃO

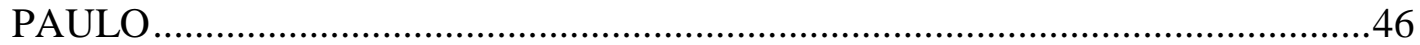

9.1 Um recorte da Região Metropolitana Paulista. ......................................................... 46

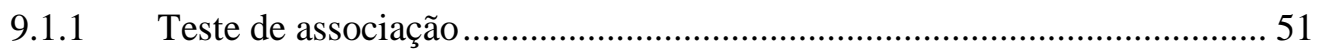

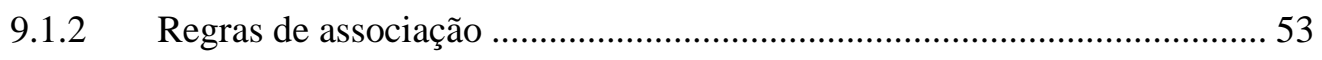

10 PANORAMA DA AIDS NO MUNICÍPIO DE SÃO PAULO ..............................55

10.1 O cenário da Aids na Capital Paulista.......................................................................... 56

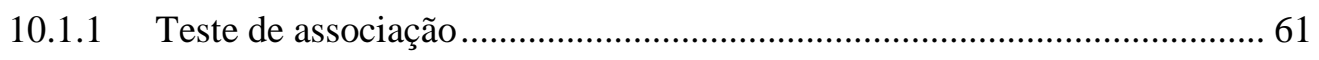

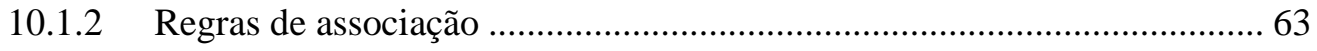

10.2 Análise da Incidência de Aids no município de São Paulo ......................................... 65

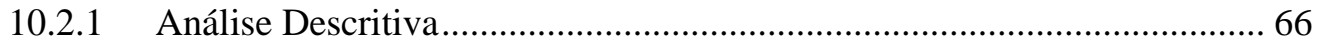

10.3 Tabelas de análise para incidência de Aids na Cidade de São Paulo .............................. 67

11 RESULTADOS DO MODELO DE REGRESSÃO .........................................73

12 REFLEXÕES E PRINCIPAIS DESAFIOS PARA O ENFRETAMENTO

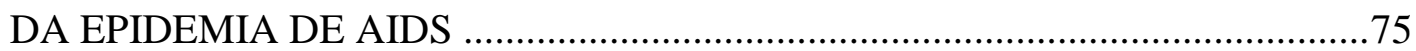

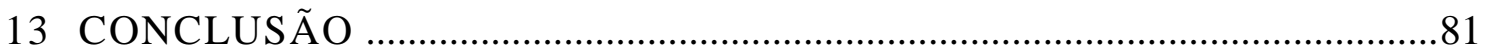

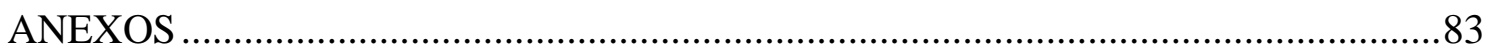

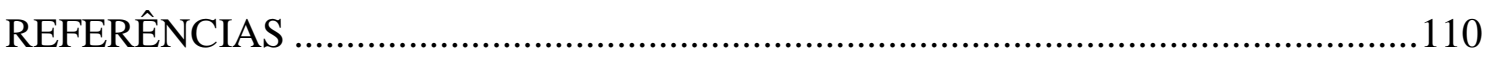




\title{
LISTA DE SIGLAS E ABREVIATURAS
}

\author{
AIDS - SÍNDROME DA IMUNODEFICIÊNCIA ADQUIRIDA \\ CRT - CENTRO DE REFERÊNCIA E TRATAMENTO DTS/AIDS \\ GAM - GENERALIZED ADITIVE MODEL \\ HIV - VÍRUS DA IMUNODEFICIÊNCIA HUMANA \\ HSH - HOMENS QUE FAZEM SEXO COM HOMENS \\ HSM - HOMENS QUE FAZEM SEXO COM MULHERES \\ HT - HETEROSSEXUAL \\ IBGE - INSTITUTO BRASILEIRO DE GEOGRAFIA E ESTATÍSTICA \\ IST - INFECÇÕES DE TRANSMISSÃO SEXUAL \\ OMS - ORGANIZAÇÃO MUNDIAL DA SAÚDE \\ PAHO - ORGANIZAÇÃO PAN-AMERICANA DA SAÚDE \\ SEADE - FUNDAÇÃO SISTEMA ESTADUAL DE ANÁLISE DE DADOS \\ SINAN - SISTEMA DE INFORMAÇÕES DE AGRAVOS DE NOTIFICAÇÃO \\ SISCEL - SISTEMA DE CONTROLE DE EXAMES LABORATORIAIS \\ SNVE - SISTEMA NACIONAL DE VIGILÂNCIA EPIDEMIOLÓGICA \\ TARV - TERAPIAS ANTIRRETROVIRAIS \\ UDI - USUÁRIOS DE DROGAS INJETÁVEIS
}




\section{LISTA DE TABELAS}

Tabela 1 - Cronologia e distribuição das gerações ........................................................2

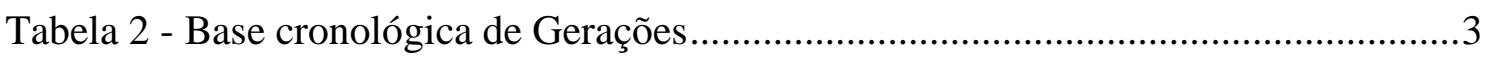

Tabela 3 - Resumo das Políticas Públicas e principais fatos históricos da Aids no Brasil

Tabela 4 - Frequência de palavras nas Campanhas sobre HIV/Aids e outras IST ............7

Tabela 5 - Número e taxa de detecção (por 100.000 hab.) de casos de Aids notificados no Sinan, declarados no SIM e registrados no Siscel/Siclom por sexo e razão de sexos, segundo ano de diagnóstico. Brasil, 1980-2016.

Tabela 6 - Taxa de detecção de Aids por ano e sexo, Brasil 2011 a 2015

Tabela 7 - Taxa de detecção de Aids por ano e sexo, Brasil 1980 a 2015

Tabela 8 - Comparativo percentual de casos de Aids ao longo dos anos de 2010 a 2015, faixa etária de 15 a 24 anos, Brasil.

Tabela 9 - Casos de HIV (percentual) notificados no Sinan segundo faixa etária por ano do diagnóstico. Brasil, 2007-2016

Tabela 10 - Casos de Aids notificados no Sinan, declarados no SIM e registrados no Siscel/Siclom(1) segundo faixa etária por ano de diagnóstico. Brasil, 1980-2015 .

Tabela 11 - Percentual de Casos de Aids notificados no Sinan, declarados no SIM e registrados no Siscel/Siclom(1) segundo faixa etária por ano de diagnóstico. Brasil, 1980-2015

Tabela 12 - Resumo de dados de Boletins Epidemiológicos do Ministério da Saúde, Brasil

Tabela 13 - Percentual de crescimento de casos de Aids em relação ao ano anterior, São Paulo, 1983 a 1987

Tabela 14 - Distribuição de sexo por Geração em casos notificados de Aids, faixa etária de 15 a 24 anos, Estado de São Paulo, 1980 a 2014

Tabela 15 - Distribuição de escolaridade por geração em casos de Aids no Estado de São Paulo, período entre 1980 a 2014, faixa etária de 15 a 24 anos.

Tabela 16 - Distribuição de meio de contato por geração em casos de Aids no Estado de São Paulo, período entre 1980 a 2014, faixa etária de 15 a 24 anos.

Tabela 17 - Distribuição de frequências e resultados do teste qui-quadrado das variáveis socioeconômicas e demográficas em relação as gerações dos casos notificados de Aids, faixa etária de 15 a 24 anos, Estado de São Paulo, 1980 a 2014....42

Tabela 18 - Regras de associação e suas respectivas medidas dos casos notificados de Aids, faixa etária de 15 a 24 anos, Estado de São Paulo, 1980 a 2014.

Tabela 19 - Regras de associação por geração e suas respectivas medidas dos casos notificados de Aids, faixa etária de 15 a 24 anos, Estado de São Paulo, 1980 a 2014...45

Tabela 20 - Número de casos notificados de Aids no Estado e Porcentagem de casos da Região Metropolitana. 
Tabela 21 - Distribuição de sexo por Geração em casos notificados de Aids, faixa etária de 15 a 24 anos, Região Metropolitana de São Paulo, 1980 a 2014.

Tabela 22 - Distribuição de frequências e resultados do teste qui-quadrado das variáveis socioeconômicas e demográficas em relação as gerações dos casos notificados de Aids, faixa etária de 15 a 24 anos, Região metropolitana de São Paulo, 1980 a 2014

Tabela 23 - Regras de associação e suas respectivas medidas dos casos notificados de Aids, faixa etária de 15 a 24 anos, Região metropolitana de São Paulo, 1980 a 2014.

Tabela 24 - Regras de associação por geração e suas respectivas medidas dos casos notificados de Aids, faixa etária de 15 a 24 anos, Região metropolitana de São Paulo, 1980 a 2014.

Tabela 25 - Número de casos notificados de Aids no Estado, Porcentagem de casos da Região Metropolitana e Município de São Paulo

Tabela 26 - Notificações para o sexo Masculino, Razão Heterossexual: HSH, Município de São Paulo, 1983 a 2014.

Tabela 27 - Distribuição de sexo por Geração em casos notificados de Aids, faixa etária de 15 a 24 anos, Município de São Paulo, 1980 a 2014.

Tabela 28 - Distribuição de frequências e resultados do teste qui-quadrado das variáveis socioeconômicas e demográficas em relação as gerações dos casos notificados de Aids, faixa etária de 15 a 24 anos, Município de São Paulo, 1980 a 2014.... 62

Tabela 29 - Regras de associação e suas respectivas medidas dos casos notificados de Aids, faixa etária de 15 a 24 anos, Município de São Paulo, 1980 a 2014.

Tabela 30 - Regras de associação por geração e suas respectivas medidas dos casos notificados de Aids, faixa etária de 15 a 24 anos, Município de São Paulo, 1980 a 2014.... 65

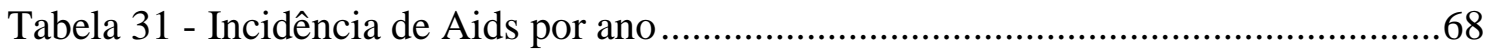

Tabela 32 - Incidência de Aids por sexo e ano............................................................69

Tabela 33 - Distribuição percentual da Taxa de Incidência de Casos de Aids no

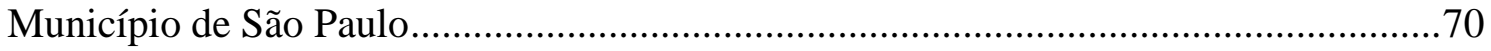

Tabela 34 - Incidência de Aids por faixa etária e ano .................................................71

Tabela 35 - Incidência de Aids por faixa etária, sexo e ano da Cidade de São Paulo.....72

Tabela 36 - Resumo dos coeficientes paramétricos do modelo.......................................73

Tabela 37 - Resumo das Últimas 10 Edições do Boletim Epidemiológico de São Paulo. ... 78

Tabela 38 - Resumo das Campanhas de Prevenção do Ministério da Saúde - 1998 a 2004

Tabela 39 - Distribuição de meio de contato por geração em casos de Aids no Estado de São Paulo,

Tabela 40 - Notificações para o sexo Masculino, Razão Heterossexual: HSH, Município de São Paulo, 1983 a 2014. 


\section{LISTA DE FIGURAS}

Figura 1 - Legenda de identificação das gerações para Tabela 1

Figura 2 - Resumo dos critérios de definição de casos de Aids em indivíduos com 13 anos de idade ou mais.

Figura 3 - Razão M:F - Casos de Aids notificados no Sinan, declarados no SIM e registrados no Siscel/Siclom por razão de sexos, segundo ano de diagnóstico. Brasil, 1980-2015

Figura 4 - Taxa de detecção (por 100.000 hab.) de casos de Aids notificados no Sinan, declarados no SIM e registrados no Siscel/Siclom por sexo, segundo ano de diagnóstico. Brasil, 1980-2015.

Figura 5 - Número de casos de Aids notificados no Sinan, declarados no SIM e registrados no Siscel/Siclom por sexo, segundo ano de diagnóstico. Brasil, 19802015

Figura 6 - Casos de HIV (percentual) notificados no Sinan segundo faixa etária por ano do diagnóstico. Brasil, 2007-2016.

Figura 7 - Georreferenciamento da Epidemia de Aids. Brasil, 1995 a 2004 ...................28

Figura 8 - Georreferenciamento da Epidemia de Aids. Brasil, 1995 a 2004 ...................28

Figura 9 - Georreferenciamento da Epidemia de Aids. Brasil, 2005 a jun/2015 ............28

Figura 10 - Casos de Aids no Estado de São Paulo por ano de nascimento e ano de diagnóstico de indivíduos de 15 a 24 anos. Estado de São Paulo - 1980 a 2014 ...

Figura 11 - Diagnósticos de Aids por ano de notificação da população entre 15 a 24 anos do Estado de São Paulo, 1980 a 2014

Figura 12 - Distribuição de casos de Aids por sexo de indivíduos entre 15 a 24 anos, Estado de São Paulo, 1980 a 2014

Figura 13 - Distribuição de casos de Aids por sexo e categoria de exposição hierarquizada de indivíduos entre 15 a 24 anos, Estado de São Paulo, 1980 a 2014 .......35

Figura 14 - Distribuição de casos de Aids do sexo masculino e categoria de exposição hierarquizada de indivíduos entre 15 a 24 anos, Estado de São Paulo, 1980 a 2014

Figura 15 - Distribuição de sexo por Geração em casos notificados de Aids, faixa etária de 15 a 24 anos, Estado de São Paulo, 1980 a 2014.

Figura 16 - Distribuição de escolaridade por geração em casos de Aids no Estado de São Paulo, período entre 1980 a 2014, faixa etária de 15 a 24 anos ....

Figura 17 - Distribuição de meio de contato por geração em casos de Aids no Estado de São Paulo, período entre 1980 a 2014, faixa etária de 15 a 24 anos.

Figura 18 - Quadro resumo dos dados do Banco de Dados Relacionado da Vigilância Epidemiológica - CRT-SP, 1980 a 2014, São Paulo

Figura 19 - Casos de Aids por Geração por ano de notificação, Estado de São 
Figura 20 - Diagnósticos de Aids por ano de notificação da população entre 15 a 24 anos da Região Metropolitana de São Paulo, 1980 a 2014

Figura 21 - Distribuição de casos de Aids por sexo de indivíduos entre 15 a 24 anos, Região Metropolitana de São Paulo, 1980 a 2014

Figura 22- Distribuição de casos de Aids por sexo e categoria de exposição hierarquizada de indivíduos entre 15 a 24 anos, Região Metropolitana de São Paulo, 1980 a 2014

Figura 23 - Distribuição de casos de Aids do sexo masculino e categoria de exposição hierarquizada de indivíduos entre 15 a 24 anos, Região Metropolitana de São Paulo, 1980 a 2014

Figura 24 - Distribuição de sexo por Geração em casos notificados de Aids, faixa etária de 15 a 24 anos, Região Metropolitana de São Paulo, 1980 a 2014 ......................50

Figura 25 - Distribuição da população por sexo, segundo os grupos de idade, Município de São Paulo, 2010

Figura 26 - Diagnósticos de Aids por ano de notificação da população entre 15 a 24 anos do Município de São Paulo, 1980 a 2014.

Figura 27 - Distribuição de casos de Aids por sexo e categoria de exposição hierarquizada de indivíduos entre 15 a 24 anos, Município de São Paulo, 1980 a 2014

Figura 28 - Distribuição de casos de Aids do sexo masculino e categoria de exposição hierarquizada de indivíduos entre 15 a 24 anos, Município de São Paulo, 1980 a 2014

Figura 29 - Notificações para o sexo Masculino, Razão Heterossexual: HSH, Município de São Paulo, 1983 a 2014

Figura 30 - Distribuição de sexo por Geração em casos notificados de Aids, faixa etária de 15 a 24 anos, Município de São Paulo, 1980 a 2014 .......................................60

Figura 31 - Taxa de Incidência de Aids por 100.000 mil habitantes..............................66

Figura 32 - Taxa de Incidência da Aids por 100.000 mil habitantes..............................67

Figura 33 - Taxa de Incidência de Aids na cidade de São Paulo, por ano, população

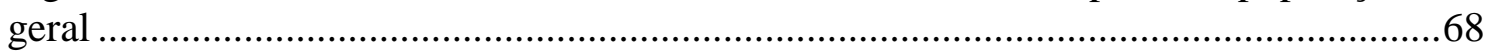

Figura 34 - Taxa de Incidência de Aids na cidade de São Paulo, por ano e sexo ............70

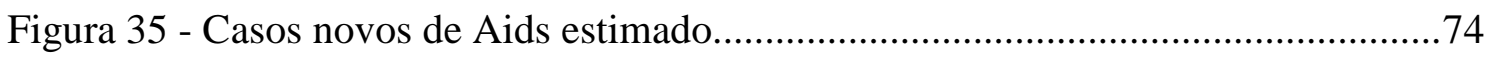

Figura 36 - Total de diagnósticos de Aids de 1980 a 2014 brasil ..................................78

Figura 37 - Total de diagnósticos de Aids de 1980 a 2014 São Paulo .............................79

Figura 38 - Total de diagnósticos de Aids de 1980 a 2014 São Paulo - Faixa etária de 15 a 24 anos 


\section{RESUMO}

Alves WS. As gerações e o HIV/Aids: análise de três décadas da epidemia de HIV/Aids no estado de São Paulo [dissertação]. São Paulo: Faculdade de Medicina, Universidade de São Paulo; 2018.

Objetivos: Esta Dissertação teve como objetivo avaliar os índices de notificação de Aids e as divisões geracionais, considerando fatores históricos e Políticas Públicas em Saúde voltadas para a Aids no estado de São Paulo. Metodologia: Trata-se de um estudo retrospectivo e descritivo de caráter epidemiológico, analisando os dados de notificação de Aids do estado de São Paulo. Para descrição dos resultados foram utilizadas frequência absoluta e a porcentagem para as variáveis categóricas; Regressão Logística; Teste de Associação e; Análise de incidência. Resultados: Foram analisados 25.693 participantes de pesquisa com notificação para Aids entre os anos de 1980 a 2014 e idade entre 14 a 25 anos. O principal achado refere-se ao período dentre 1989 a 2004, em que os casos notificados do sexo masculino com categoria de exposição heterossexual foram maiores que os caso notificados do sexo masculino com categoria de exposição HSH (Homens que fazem sexo com Homens). Quando analisado por gerações, a maioria dos notificados de Aids são referentes aos indivíduos do sexo masculino, sobretudo para a geração baby boomer. A Geração X foi a mais acometida por notificações no geral, tendo $63 \%$ do total de casos registrados para esse recorte de dados. Conclusões: No período de 1980 a 1998 as gerações que tiveram como categoria de exposição foram HSH, predominantemente. É observado aumento de casos para o sexo masculino heterossexual entre os anos de 1989 a 2004. Entretendo, não é observado nas ações de políticas públicas avaliadas qualquer ação mais fundamentada para alertar esta população em específico. Faz-se necessário, a partir dos dados coletados, que ocorra maior investimento em conscientização da população como um todo, principalmente das consideradas menos vulneráveis.

Descritores: HIV; síndrome da imunodeficiência adquirida; gerações; população chave; epidemias; incidência. 


\begin{abstract}
Alves WS. The generations and HIV / Aids: analysis of three decade of the HIV / Aids epidemic in the state of São Paulo [dissertation]. São Paulo: "Faculdade de Medicina, Universidade de São Paulo"; 2018.

Objectives: This dissertation aimed to evaluate the AIDS notification indexes and the generational divisions, considering historical factors and Public Health Policies focused on AIDS in the state of São Paulo. Methodology: This is a retrospective and descriptive epidemiological study, analyzing the AIDS notification data from the state of São Paulo. Absolute frequency and percentage for categorical variables were used to describe the results; Logistic Regression; Association Test e; Incidence analysis. Results: A total of 25,693 research participants with AIDS reports were analyzed between 1980 and 2014 and aged between 14 and 25 years. The main finding refers to the period from 1989 to 2004, where notified cases of males with a heterosexual exposure category were higher than the reported cases of males with MSM exposure category (Men who have sex with men). When analyzed by generations, the majority of reported AIDS are male, especially for the baby boomer generation. Generation X was the most affected by notifications in general, with $63 \%$ of the total cases registered for this data cut. Conclusions: In the period from 1980 to 1998 the generations that had exposure category were predominantly MSM. There is an increase in cases for heterosexual males between 1989 and 2004. Among the actions of public policies evaluated, it is not observed any more grounded action to alert this specific population. It is necessary, from the data collected, that occurs a higher investment in awareness of the population as a whole, especially those considered less vulnerable.
\end{abstract}

Descriptors: HIV; acquired immunodeficiency syndrome; generations; key population; epidemics; incidence 


\section{INTRODUÇÃO}

A questão dos crescentes casos de Infecções Sexualmente Transmissíveis (IST), da vulnerabilidade e do risco, em relação ao vírus da imunodeficiência humana (HIV) e sua evolução para a Síndrome da Imunodeficiência Adquirida (Aids), é um tema bastante atual, controverso e foco de diversas pesquisas científicas e de políticas públicas na área da saúde. Nossa sociedade encontra-se diante de uma epidemia persistente (1), completamente ligada ao contexto sociocultural e aos comportamentos de risco dos indivíduos e de suas concepções sobre saúde, prevenção e doença (2). Ao analisar estudos recentes, podemos verificar o crescimento dos índices de infecção de HIV, principalmente na faixa etária de jovens adultos, com idade entre 18 a 25 anos (3), apesar de todos os esforços de conscientização promovidos pelos órgãos mundiais de saúde, como a OMS (Organização Mundial da Saúde) (4), o PAHO (Organização PanAmericana da Saúde) (5), Ministério da Saúde (6), demais organizações sociais.

A transmissão do HIV está intrinsecamente ligada à conscientização dos indivíduos em relação à prevenção, observando que, quanto à exposição, entre “indivíduos com 13 anos ou mais de idade, a principal via de transmissão é a sexual. Tanto entre os homens quanto entre as mulheres, em 2013, esta categoria de transmissão corresponde a $94,9 \%$ entre os homens e $97,4 \%$ entre as mulheres"(3), o que permite a possibilidade de uma análise dos elementos e características sociais que podem estar envolvidos neste processo, ou que possam influenciar. Por meio desta avaliação pode-se propor ações mais efetivas para a promoção da prevenção visando a diminuição da exposição ao HIV e outras infecções de transmissão sexual (ISTs), mais próximas aos anseios e os modos de pensar das diferentes gerações.

Para contextualizar essa questão, define-se como gerações o conjunto de indivíduos nascidos em determinados períodos históricos, que compartilham particularidades e experiências semelhantes, constituído pela subjetividade, alteridade e valores sociais, entre outros aspectos que marcam e fundamentam o modo de ser de cada indivíduo, além da concepção do pensamento inseridos em cada geração $(7,8)$. Diversos autores se debruçam sobre o tema, não apenas delimitando os períodos correspondentes de nascimentos, mas, principalmente, analisando atributos da personalidade, padrões socioculturais e visão de mundo que são alimentados por acontecimentos históricos, 
conjunturas políticas e econômicas, principalmente com base na sociedade norteamericana (9). Como condição teórica, considerando a realidade brasileira e a distinção entre cultura, considera-se para esse estudo as categorizações das gerações por faixas cronológicas, utilizando a delimitação temporal para a segmentação de cada geração.

Para ilustrar esse processo de categorização das gerações, com base em alguns estudos, apresenta-se na Tabela 1, cronologicamente, a identificação de gerações das pesquisadoras Yelkikalan e Ayhun(10), em uma versão revisada e ampliada para essa pesquisa.

Tabela 1 - Cronologia e distribuição das gerações

A UTORES

Alves, 2015

Kyles, 2005

Lancaster e Stillman, 2002

Seçkin, 2005

Tulgan e Martin, 2006

Salahuddin, 2010

Yelkikalan e Altın, 2010

Tsui, 2001

Spitznas, 1998

Washburn, 2000

Crumpacker, 2007

Senbir, 2004

Haeberle vd., 2009

Keleş, 2011

Matthews, 2008

PERÍODO 1900

\section{Fonte adaptada: (10-24)}

CRONOLOGIA

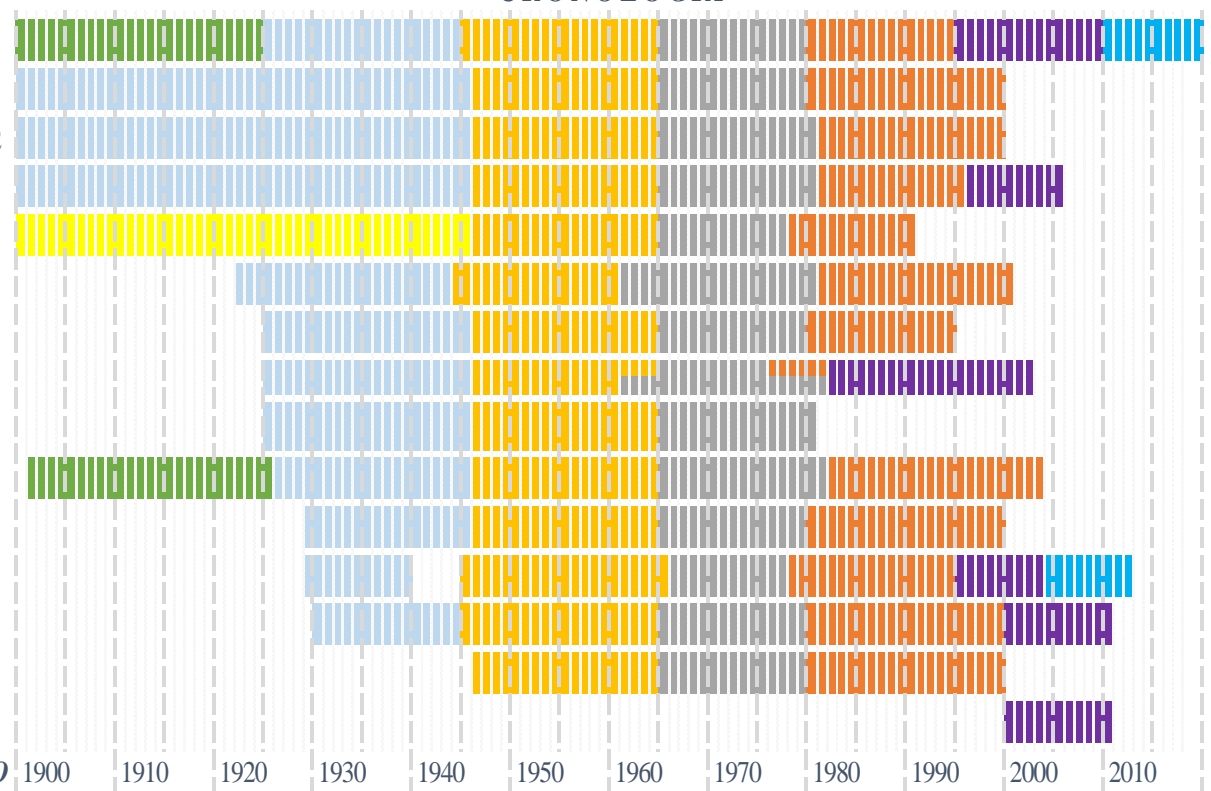

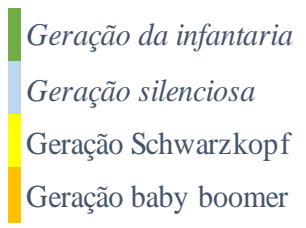

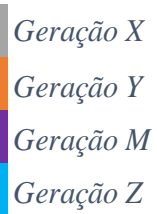

Fonte: O Autor

Figura 1 - Legenda de identificação das gerações para Tabela 1

Cada geração possui questões predominantes e condutas características, mas considera-se aspectos cronológicos para este atual estudo, deste modo, para justificar o posicionamento apresentado na Tabela 1, na Figura 1 são apresentadas as legendas referentes a Tabela 1 . 
Na Tabela 2 estão delimitados os períodos que compreendem cada uma das gerações. Tal delimitação ocorrerá por meio de análises dos aspectos relevantes e levantamentos bibliográficos que sustentarão a divisão das gerações adotada para as observações propostas nessa pesquisa.

Tabela 2 - Base cronológica de Gerações

\begin{tabular}{ll}
\hline PERÍODOS & GERAÇÕES \\
\hline $1900-1925$ & Geração da Infantaria \\
\hline $1926-1944$ & Geração Silenciosa \\
\hline $1945-1963$ & Geração Baby boomer \\
\hline $1964-1979$ & Geração X \\
\hline $1980-1989$ & Geração Y \\
\hline $1990-2003$ & Geração M \\
\hline $2004-$ atualidade & Geração Z \\
\hline
\end{tabular}

Fonte: o autor

Em estudo similar ao proposto por essa pesquisa, Kilsztajn(25) caracterizaram indivíduos nascidos entre os anos de 1955 e 1970, que para o presente estudo compreendem a meados do período geracional Baby boomer e início da Geração X, como a Geração Vulnerável. Ao analisar a incidência e os óbitos decorrentes da infecção pelo HIV no Estado de São Paulo, nesse estudo, Kilsztajn concluiu que, em 1985, ocorreu o evento que quadriplicou os números de incidência de notificações e que em indivíduos com idade entre 15 e 30 anos esses índices eram mais acentuados.

Como fonte de análise, o interesse nesse tema das gerações se desenvolve em diferentes ramos da ciência, principalmente nas áreas de ciências sociais aplicadas, com o objetivo de perceber como cada geração vislumbra o ambiente de trabalho, suas aspirações sobre as atividades que executam e as relações sociais em diversos ambientes(26). Na área de ciências humanas, como a Psicologia, Sociologia, Antropologia e Política o intuito percorre a compreensão de como essas gerações se articulam, se organizam e promovem ações diversas em sociedade(27-29). De fato, todas as gerações convivem ao longo dos anos, mas suas formas de perceber e agir no mundo podem ser distintas (30) e merecem uma compreensão diferenciada e estratégias distintas para conscientização em qualquer tema proposto. 
Analisar as ações governamentais em relação à prevenção de infecções sexualmente transmissíveis (IST) ao longo dos anos, associando-as aos índices de detecção de Aids (31) no decorrer desses períodos é uma das possibilidades para compreender a dinâmica dos indivíduos frente à utilização de métodos preventivos(32) e aos cuidados com a saúde após o diagnóstico. Este estudo possibilita traçar um perfil dos indivíduos com diagnóstico de Aids, e proporcionar possíveis interpretações da relação entre prevenção, infecção e conscientização sobre o HIV.

Ao comparar dados estatísticos com o contexto histórico, ao longo das últimas décadas, é possível compreender características das diferentes gerações que têm sido diagnosticada com Aids e, dessa forma, refletir sobre as atuações necessárias para intensificar ações efetivas de prevenção que atenuem os números atuais em relação ao contato com a doença, aos aspectos de risco e vulnerabilidade, ao incentivo da testagem e, em casos positivos para HIV, a consequente adesão ao tratamento.

A presente análise tem como base os dados apresentados nos Boletins Epidemiológicos do Ministério da Saúde(31); o banco de dados da Vigilância Epidemiológica do Centro de Referência e Tratamento DTS/Aids (CRT) do Estado São Paulo; o banco de dados do Sistema de Informações de Agravos de Notificação (SINAN) e da Fundação Sistema Estadual de Análise de Dados (Seade)(33), buscando não só apresentar os dados objetivos, mas também contextualizá-los temporalmente no contexto histórico e no ambiente que permeava cada um dos momentos analisados. Para tanto, algumas questões norteiam as análises desta pesquisa, entre elas a diferença da incidência de Aids em relação às diversas gerações no decorrer das últimas décadas; dos indivíduos com idade entre 15 a 24 anos; elementos sócio históricos associados à ações preventivas elaboradas pelo Poder Público na contemporaneidade; análise das Gerações $\mathrm{X}$ e $\mathrm{Y}$ buscando compreender os principais elementos que tornam esses jovens mais suscetíveis a contrair HIV e evoluir para um quadro clínico de Aids; e os principais elementos que corroboram com essas constatações.

Assim, o presente estudo busca traçar aspectos relativos à epidemia de Aids ao longo das últimas três décadas, com base nos marcadores históricos das gerações, buscando servir como apoio para a tomada de decisão de futuras campanhas de prevenção e conscientização da população dessas diferentes gerações e das PopulaçõesChave(34). Debruçar-se sobre os aspectos sociais da Aids exige uma leitura sobre os dados estatísticos de sua evolução no Brasil (35). e em diferentes regiões. 
Ao longo dos anos o Ministério da Saúde passou a adotar diferentes nomenclaturas para as Categorias de Exposições Hierarquizadas, sendo a última modificação em 2001 (36) (37). Essa adequação é ponto importante para as análises que esta pesquisa segue. Mesmo não sendo a base para as modificações dos termos do Ministério da Saúde, ao acompanharmos a evolução sócio histórica, a mudança de nomenclatura não modifica os tipos de exposição encontrados nos dados de HIV/Aids, como, por exemplo, indivíduos que fazem sexo com pessoas do mesmo sexo, a terminologia ao longo dos anos também se modifica, (homossexualismo, homossexual, HSH (Homem-sexo-Homem), homoerotismo, Gays, por exemplo), mas não muda o fato em si (38), e auxilia no entendimento de alguns dados apresentados.

Outro termo que apresentou evoluções é o que atualmente chamamos de População-Chave, que compreende "gays e outros HSH; pessoas trans; pessoas que usam álcool e outras drogas; pessoas privadas de liberdade e trabalhadoras(es) sexuais" (34), substituindo o conceito de Grupo de Risco que era reducionista e reprodutora de preconceito e estigmatização (39). A abordagem sobre risco para HIV é, de fato, o principal norteador para estudos epidemiológicos. Esta concepção permite compreender o acontecimento por diversos ângulos, pois o:

“(.) risco é central nos estudos de epidemiologia: conecta-se à ideia de identificação de pessoas e de características que as colocam sob maior ou menor risco de exposição a eventos de saúde, com comprometimento de ordem física, psicológica elou social. Integra, desta forma, a probabilidade e as chances de grupos populacionais de adoecerem e morrerem por algum agravo de saúde(40)"

A vulnerabilidade é outra questão que deve ser compreendida ao analisarmos a evolução histórica do HIV no Brasil, pois levanta aspectos associados ao adoecimento dos indivíduos $(2,40,41)$. Os estudos sobre Vulnerabilidade:

“(...) buscam compreender como indivíduos e grupos de indivíduos se expõem a dado agravo à saúde a partir de totalidades conformadas por sínteses pragmaticamente construídas com base em três dimensões analíticas: aspectos individualizáveis (biológicos, comportamentais, afetivos), que implicam exposição e suscetibilidade ao agravo em questão; características próprias a contextos e relações socialmente configurados, que sobredeterminam aqueles aspectos $e$, particularizado a partir destes últimos, o modo e o sentido em que as tecnologias já operantes nestes contextos (políticas, programas, serviços, ações) interferem sobre a situação - chamadas, respectivamente, de dimensão individual, social $e$ programática"(42) 
Tais estudos, que envolvem o comportamento humano e a vulnerabilidade, são conduzidos ao longo dos anos e apresentam em seus resultados impactos diferentes e significantes em diferentes populações (39), o que exige ações distintas para cada população-chave identificada. Dessa forma, aspectos de Risco e Vulnerabilidade devem estar sempre envolvidos nos estudos sobre HIV/Aids considerando seus principais conceitos.

Como subsídio para as análises propostas nesse trabalho, é importante apresentar as principais Políticas Públicas voltadas para a questão do HIV/Aids. Tais ações e iniciativa estão apresentadas na Tabela 3:

Tabela 3 - Resumo das Políticas Públicas e principais fatos históricos da Aids no Brasil

\begin{tabular}{|c|c|}
\hline ANO & Políticas Públicas \\
\hline 1975 & $\begin{array}{l}\text { Sistema Nacional de Vigilância Epidemiológica (SNVE) é instituído pela recomendação da } 5^{\text {a }} \text { Conferência } \\
\text { Nacional de Saúde (CNS). (43) }\end{array}$ \\
\hline 1982 & Aids passou a ser um problema de saúde pública (caráter endêmico e elevada letalidade)(44) \\
\hline 1983 & Criada o Programa Estadual de DST/Aids (PE- DST/Aids) no Estado de São Paulo. (43) \\
\hline 1985 & $\begin{array}{l}\text { Reconhecimento oficial como um problema de saúde pública. As políticas brasileiras se iniciaram no estado de } \\
\text { São Paulo }(44,45)\end{array}$ \\
\hline 1985 & $\begin{array}{l}\text { primeira Organização Não Governamental (ONG) com atividade em HIV/Aids no país - Grupo de Apoio à } \\
\text { Prevenção da Aids (GAPA)(45, 46) }\end{array}$ \\
\hline 1985 & Criação dos Programas Estaduais de DST/Aids $(45,46)$ \\
\hline 1986 & $\begin{array}{l}\text { Ministério da Saúde estabeleceu: universalidade (medicamentos e insumos para prevenção), a equidade (grupos } \\
\text { vulneráveis e estigmatizados) e a integralidade (por agregar prevenção, assistência e tratamento) }(44,45)\end{array}$ \\
\hline 1986 & VIII Conferência Nacional de Saúde (reforma sanitária)(46) \\
\hline 1986 & Implantação do Programa Nacional de DST/Aids (PN-DST/Aids)(44-46) \\
\hline 1986 & $\begin{array}{l}\text { Aids entra na relação de doenças de notificação compulsória do Brasil (Portaria n }{ }^{\circ} 1.100 \text { de } 24 \text { de maio de } \\
\text { 1986). (46) }\end{array}$ \\
\hline 1987 & Início do tratamento com inibidores de transcriptase reversa (44) \\
\hline 1987 & incentivo ao uso de preservativos, como ação da vigilância epidemiológica. (44) \\
\hline 1988 & Proposição do Sistema Único de Saúde (SUS) (46) \\
\hline 1988 & $\begin{array}{l}\text { A Organização Mundial da Saúde (OMS) institui o dia } 1^{\circ} \text { de dezembro como o dia internacional de luta contra a } \\
\text { Aids. (46) }\end{array}$ \\
\hline 1990 & Período de retrocesso do Programa Nacional de DST/Aids. $(44,45)$ \\
\hline 1993 & $\begin{array}{l}\text { Convênios entre o governo brasileiro e o Banco Mundial para o primeiro acordo de empréstimo, denominado } \\
\text { "Projeto Aids I", que priorizava a implantação e a estruturação de serviços assistenciais. (46) }\end{array}$ \\
\hline 1996 & Advento do acesso universal e gratuito aos medicamentos antirretrovirais, lei federal $\mathrm{n}^{\circ} 9.313 / 96(43-45)$ \\
\hline 1998 & $\begin{array}{l}\text { O governo brasileiro negociou e aprovou, junto ao Banco Mundial, o "Projeto Aids II", tendo "como objetivos } \\
\text { reduzir a incidência de casos de HIV e DST, assim como expandir e melhorar a qualidade do diagnóstico, } \\
\text { tratamento e assistência às pessoas com DST/HIV/Aids". (46) }\end{array}$ \\
\hline 2000 & Ministério da Saúde torna compulsória a notificação de gestantes infectadas pelo HIV. \\
\hline 2003 & $\begin{array}{l}\text { Programa Nacional de DST e Aids (PN-DST/Aids), foi considerado referência mundial por diversas agências } \\
\text { internacionais. (46) }\end{array}$ \\
\hline 2003 & $\begin{array}{l}\text { "Projeto Aids III" tendo como objetivo "o aprimoramento dos processos de gestão nas três esferas de governo e } \\
\text { na sociedade civil organizada; o desenvolvimento tecnológico e científico, qualificando a resposta brasileira à } \\
\text { epidemia, especialmente no controle das DST; a ampliação do acesso ao diagnóstico precoce do HIV e a } \\
\text { melhoria da qualidade da atenção às DST/Aids oferecida pelo Sistema Único de Saúde no País" (46) }\end{array}$ \\
\hline 2002 & $\begin{array}{l}\text { O Plano de Ações e Metas (PAM) é instituído com o objetivo de ser "um instrumento de planejamento, } \\
\text { monitoramento e avaliação das ações a ser implementado pelas Secretarias Estaduais e Municipais de Saúde } \\
\text { selecionadas para receber recursos do incentivo". (46) }\end{array}$ \\
\hline 2005 & $\begin{array}{l}\text { Com a Portaria } \mathrm{n}^{\circ} 33 \text {, de } 14 \text { de julho de } 2005 \text {, passa a ocorrer a Notificação Compulsória para doenças e } \\
\text { agravos de interesse nacional. (43) }\end{array}$ \\
\hline 2005 & $\begin{array}{l}\text { Ministério da Saúde adotou o licenciamento compulsório de um dos antirretrovirais de segunda linha (quebra de } \\
\text { patentes) (46) }\end{array}$ \\
\hline 2009 & Portaria n $^{\circ} 151$, de 14 de outubro de 2009, regulamenta o diagnóstico laboratorial da infecção pelo HIV. (43) \\
\hline 2013 & $\begin{array}{l}\text { Revogada Portaria n }{ }^{\circ} 151 \text { e substituída pela Portaria no } 29116 \text {, de } 17 \text { de dezembro de 2013, resultante, então o } \\
\text { "Manual Técnico para o Diagnóstico da Infecção pelo HIV em Adultos e Crianças"(43) }\end{array}$ \\
\hline
\end{tabular}


Como mais uma fonte de análise, em um levantamento de frequência de palavra nas campanhas (Tabela 4), podemos encontrar os principais focos das campanhas realizadas a partir do ano de 1998, ano do primeiro registro de campanhas no portal do Ministério da Saúde, conforme apresentado no Anexo 4.

Tabela 4 - Frequência de palavras nas Campanhas sobre HIV/Aids e outras IST

\begin{tabular}{|c|c|c|c|}
\hline Posição & Palavra & Porcentagem & Ocorrências \\
\hline 8 & campanha & $1.55224 \%$ & 279 \\
\hline 10 & Aids & $1.51886 \%$ & 273 \\
\hline 16 & dia & $0.62312 \%$ & 112 \\
\hline 19 & contra & $0.57304 \%$ & 103 \\
\hline 22 & prevenção & $0.5341 \%$ & 96 \\
\hline 30 & mundial & $0.44508 \%$ & 80 \\
\hline 31 & luta & $0.42839 \%$ & 77 \\
\hline 32 & preservativo & $0.41726 \%$ & 75 \\
\hline 33 & carnaval & $0.40057 \%$ & 72 \\
\hline 36 & população & $0.37832 \%$ & 68 \\
\hline 37 & camisinha & $0.3505 \%$ & 63 \\
\hline 38 & hepatites & $0.33937 \%$ & 61 \\
\hline 39 & mulheres & $0.33937 \%$ & 61 \\
\hline 42 & ministério & $0.31156 \%$ & 56 \\
\hline 45 & uso & $0.30043 \%$ & 54 \\
\hline 46 & homens & $0.29487 \%$ & 53 \\
\hline 48 & casos & $0.28374 \%$ & 51 \\
\hline 50 & jovens & $0.27261 \%$ & 49 \\
\hline 51 & virais & $0.26705 \%$ & 48 \\
\hline 54 & ano & $0.23367 \%$ & 42 \\
\hline 55 & cartazes & $0.2281 \%$ & 41 \\
\hline 56 & pessoas & $0.22254 \%$ & 40 \\
\hline 57 & sexo & $0.22254 \%$ & 40 \\
\hline 58 & materiais & $0.21141 \%$ & 38 \\
\hline 62 & ações & $0.20028 \%$ & 36 \\
\hline 64 & nacional & $0.18916 \%$ & 34 \\
\hline 68 & profissionais & $0.17247 \%$ & 31 \\
\hline 73 & preconceito & $0.1669 \%$ & 30 \\
\hline 79 & dezembro & $0.15578 \%$ & 28 \\
\hline 80 & mensagem & $0.15578 \%$ & 28 \\
\hline 81 & preservativos & $0.15578 \%$ & 28 \\
\hline 82 & relação & $0.15578 \%$ & 28 \\
\hline 84 & distribuição & $0.15021 \%$ & 27 \\
\hline 90 & tratamento & $0.13908 \%$ & 25 \\
\hline 91 & epidemia & $0.13352 \%$ & 24 \\
\hline 93 & sociedade & $0.13352 \%$ & 24 \\
\hline 94 & veiculação & $0.13352 \%$ & 24 \\
\hline 96 & teste & $0.12796 \%$ & 23 \\
\hline 97 & ação & $0.12239 \%$ & 22 \\
\hline 98 & mulher & $0.12239 \%$ & 22 \\
\hline 100 & país & $0.12239 \%$ & 22 \\
\hline
\end{tabular}


Essa distribuição das 100 palavras mais utilizadas para as descrições das campanhas realizadas pelo Ministério da Saúde, sem considerar palavras instrumentais, como artigos, pronomes, preposições, conjunções, etc., apresenta os principais focos de atenção ao longo dos últimos anos, conforme considerado na apresentação da Tabela 4, e serve como subsídio de análise para a atual pesquisa.

Ao considerarmos todo o contexto apresentado, há de notar que o caminho para o enfrentamento do HIV/Aids ainda é longo, mas cheio de oportunidades de atuação em diferentes áreas, desde a saúde, como em investimento. 


\section{CRITÉRIOS DE DEFINIÇÃO DE AIDS}

Desde o surgimento do HIV, com os primeiros relatos datados no início dos anos 1980(48), o mundo tem se dedicado à busca da cura deste agravo que marcou a história da humanidade, que inicialmente foi identificada a partir de pacientes que apresentavam sarcoma de Kaposi e um comprometimento no sistema imune. O termo Aids (Síndrome da Imunodeficiência Adquirida) foi definido em 1982(48) delimitando assim a doença que ataca o sistema imunológico, estágio mais avançado causado pelo vírus da imunodeficiência humana (HIV).

Com o advento das terapias antirretrovirais (TARV), o comportamento epidemiológico da epidemia de Aids se alterou quando comparado à história natural da doença até então observado, tanto nos indicadores de morbidade e mortalidade, quanto na qualidade de vida desses pacientes (49).

Para definição dos casos relatados neste estudo, observe o resumo dos critérios de definição de casos de Aids apresentados pelo Ministério da Saúde do Brasil, Figura 2, para fins de vigilância epidemiológica.

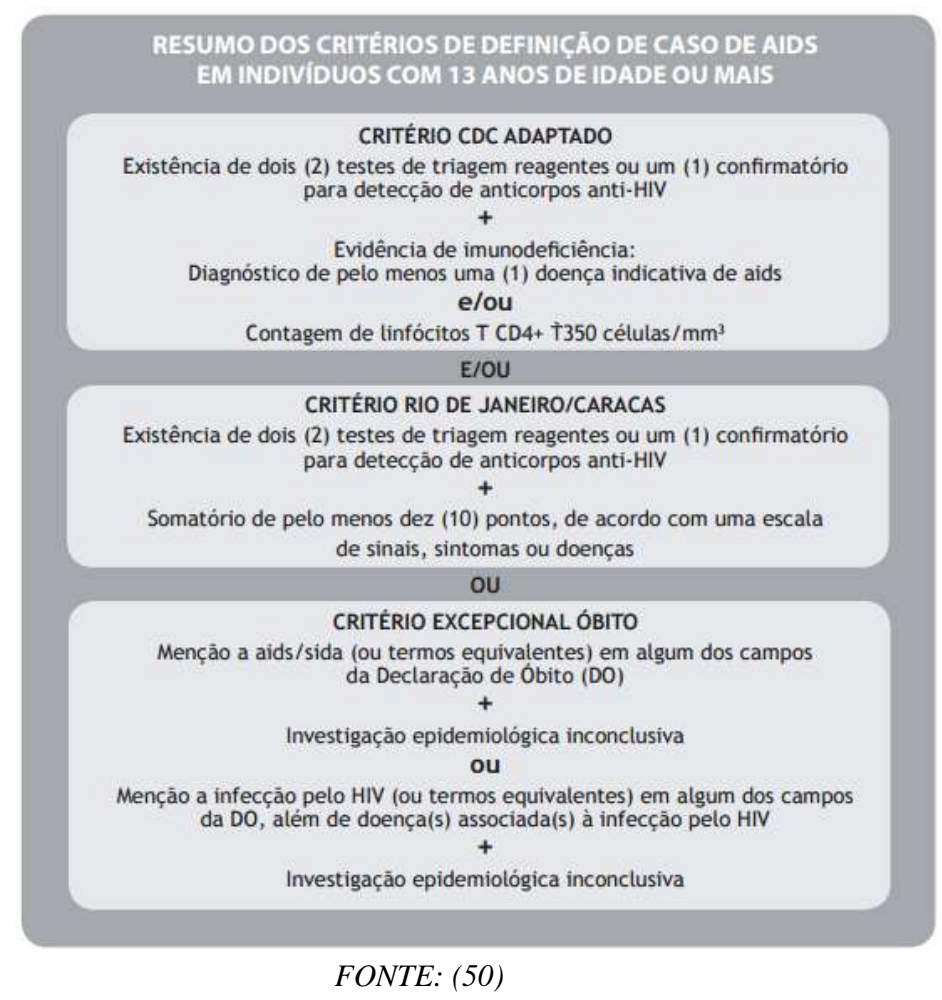

Figura 2 - Resumo dos critérios de definição de casos de Aids em indivíduos com 13 anos de idade ou mais 
Desta forma, considera-se Aids uma condição caracterizada por uma série de manifestações de doenças oportunistas ou neoplasias ou alterações laboratoriais que apontam para imunodeficiência $(43,50)$. 


\section{PROBLEMATIZAÇÃO E JUSTIFICATIVA}

Em estudos recentes sobre detecção da Aids, verificamos que sua ocorrência é distinta em diferentes gerações, porém constante ao longo dos anos $(3,51)$.

Compreender os elementos socioculturais envolvidos nesse processo é de suma importância quando buscamos promover ações mais efetivas de prevenção e redução dos índices de infecção pelo HIV, alinhando os anseios e modos de pensar das diferentes gerações que hoje coexistem em ambientes diversos aos objetivos de Saúde Pública e Prevenção de Doenças.

Algumas reflexões são propostas quanto aos papéis governamentais, da mídia e da sociedade no enfrentamento da problemática das Doenças Sexualmente Transmissíveis (DSTs), atualmente denominadas de Infecções Sexualmente Transmissíveis (IST), e das metas internacionais de combate à doenças, como a Cascata de Cuidado Contínuo, que consiste em uma meta que estabelece que $90 \%$ de pessoas vivendo com HIV/Aids devem estar diagnosticadas, $90 \%$ destes indivíduos devem estar em tratamento e $90 \%$ com carga viral indetectável, também conhecido como Meta 90-90-90, sendo estabelecidas pelo UNAIDS com foco de alcance até 2020(1). Para tanto, o presente estudo analisa os dados fornecidos pelo Centro de Referência e Treinamento DST/AidsSP por meio da Gerência de Vigilância Epidemiológica do Estado de São Paulo.

Em 2014, ano de concepção da proposta desta pesquisa, o aumento de casos em Aids entre os jovens e jovens adultos era alarmante (3), as faixas etárias posteriores também apresentavam crescimento nos números, a dispor de toda as informações disponíveis e acessíveis a população. As campanhas focadas em populações-chave também foram fatores de relevância para a escolha deste tema, pois, mesmo analisando os dados históricos, o foco para campanha deveria ser muito mais abrangente. Em 2006 e 2007 casos de Aids foram quase um caso masculino para um caso feminino (52).

O HIV/Aids tem impacto na vida dos infectados e seus próximos, a busca pela cura é incessante, e a precaução com prevenção deve ser constante, para diagnosticados, não diagnosticados e não portadores do vírus. Abordar o tema tem impactos em diversos setores da sociedade, na saúde pública, nos investimentos em saúde e a prevenção deveria ser o foco principal de qualquer movimento público ou privado. 


\section{OBJETIVOS}

\subsection{Objetivo Geral}

Avaliar os índices de notificação da Aids e as divisões geracionais, com base nos anos de nascimento e data de notificação.

\subsection{Objetivos Específicos}

- Descrever a incidência de notificações de pacientes com Aids compreendendo o período histórico entre os anos de 1980 até 2014, que compreende 4 Gerações (Baby Bommers, Geração X, Geração Y e Geração M) no Estado de São Paulo, Município de São Paulo;

- Compreender os aspectos envolvidos nas diversas gerações (cluster) em relação à incidência de Aids;

- Identificar marcadores históricos que evidenciam aspectos relevantes na evolução dos índices de incidência da Aids. 


\section{MÉTODOS}

\subsection{Abrangência do estudo}

Os dados analisados são referentes à população do Estado de São Paulo e do Município de São Paulo, utilizando o Banco Relacionado da Vigilância Epidemiológica do Centro de Referência e Tratamento DTS/Aids (CRT)(33), que compreende o banco de dados do Sistema de Informações de Agravos de Notificação (SINAN) e o Sistema de Controle de Exames Laboratoriais (SISCEL)(53), compondo as informações de notificações para Aids em aferições estatísticas. Sendo que o estudo compreende todo o período de registros dos bancos citados até o ano de 2014.

Os dados fornecidos pela Vigilância Epidemiológica do Centro de Referência e Tratamento DST/Aids compreendem a população entre 15 a 25 anos do Estado de São Paulo com notificação de diagnóstico de Aids, o que corresponde o universo de 25.692 casos, sendo 16.567 do sexo Masculino e 9.125 do sexo Feminino que representam, respectivamente, $64,48 \%$ e $35,52 \%$.

\section{$5.2 \quad$ Tipo de estudo}

Trata-se de um estudo retrospectivo e descritivo de caráter epidemiológico, analisando os dados de notificação de Aids na População Paulista e Paulistana.

\subsection{Critérios de análise}

Foram analisados todos os dados disponibilizados pelos órgãos governamentais do Estado de São Paulo, separados em três grupos comparativos: o Estado como um todo e a Capital do Estado, Município de São Paulo, em relação à notificação de Aids e análises pontuais dentro do estudo, não havendo critério de exclusão. Os principais 
critérios para fundamentação das análises dos indivíduos são: Sexo; Data de diagnósticos; Raça/cor; Escolaridade; Município de residência; Bairro; Categoria de exposição hierarquizada com dois modelos de normatização e; data de nascimento.

Para as análises sócio históricas foram consideradas as ações do Ministério da Saúde e órgãos adjacentes em relação às ações e campanhas para prevenção e conscientização da população para promoção de atitudes conscientes em relação aos riscos de contaminação pelo HIV e evolução para Aids, além dos marcadores históricos também descritos pelo Órgão.

Decorrente das análises dos dados seguiram procedimentos e métodos estatísticos. Foram utilizadas representações de tabelas e gráficos, medidas descritivas e de dispersão, distribuição de frequência, séries temporais, medidas de tendências, entre outras, por meio do software Excel 2016, IBM SPSS Statistics 20 para Windows(54) e IBM Watson. As análises de causalidade foram consideradas a partir dos achados em relação aos fatos de cada período histórico avaliado no estudo, considerando as características compreendidas de cada Geração, com o objetivo de compreender as condições de infecção e características dos indivíduos no momento histórico.

\subsection{Procedimentos}

O projeto foi submetido ao Comitê de Ética em Pesquisa da Faculdade de Medicina da Universidade de São Paulo em 24/11/2015 obteve, em sessão de 09/12/2015, aprovação como Protocolo de Pesquisa sob o número 480/15 - apresentado pelo Departamento de Dermatologia. Em 21/10/2015 foram iniciados os contatos com a Vigilância Epidemiológica do Centro de Referência e Tratamento DTS/Aids (CRT), com reunião realizada em 04/02/2016 foram apresentados os objetivos do projeto e alinhamento das variáveis possível de liberação pelo setor de Vigilância Epidemiológica. Em 19/05/2016 ocorreram as assinaturas pela Diretoria da Vigilância Epidemiológica e o encaminhamento para submissão ao Comitê de Ética em Pesquisa do Centro de Referência e Treinamento DST/Aids via Emenda ao Projeto na Plataforma Brasil, observando os termos e procedimentos elencados pelo CEP-CRT, com base nos termos da Lei de Acesso à Informação (Lei Federal 12.527/2011), regulamentada pelo 
Decreto Estadual 58.052, de 16/05/2012 e demais órgãos que solicitarem tal aprovação. Com a aprovação nos órgãos específicos os dados solicitados foram liberados para a pesquisa. Após aquisição dos dados epidemiológicos, realizou-se a Pesquisa de Levantamento, para produção dos dados estatísticos analisados.

Os perfis sócio históricos e caracterização das Gerações que fundamentaram as análises de cada período identificado nos dados epidemiológicos foram fundamentados na introdução desta pesquisa.

\subsection{Análise descritiva}

A princípio, foi realizada uma análise descritiva dos resultados para a obtenção de tabelas de frequência, com o intuito de caracterizar os casos notificados de Aids, por geração. Para descrição dos resultados foram utilizadas a frequência absoluta e a porcentagem para as variáveis categóricas. A frequência absoluta $\left(n_{i}\right)$ é dada pelo número de vezes em que uma determinada variável assume um determinado valor/categoria em questão. A porcentagem $\left(p_{i}\right)$ é o resultado da razão entre a frequência absoluta e o número de casos da respectiva geração, multiplicado por 100, isto é, $100 \cdot \frac{n_{i}}{n} \%$.

\subsection{Teste de associação}

Para a verificação da associação entre as gerações dos indivíduos notificados com o sexo, categoria de exposição, cor, escolaridade e meio de contato foi utilizado o teste qui-quadrado. De acordo com Sheskin (55), a estatística teste, $\chi^{2}$, é dada por

$$
\chi^{2}=\sum_{i=1}^{r} \sum_{j=1}^{c} \frac{\left(O_{i j}-E_{i j}\right)^{2}}{E_{i j}},
$$

em que $r$ é o número de linhas, $c$ é o número de colunas, $O_{i j}$ as frequências observadas e $E_{i j}$ as frequências esperadas da tabela de contingência das variáveis em questão. 


\subsection{Regras de associação}

A fim de se verificar associações entre as variáveis sociodemográficas dos casos notificados de Aids em geral e por geração, usou-se a técnica de regra de associação, que calcula estimativas através de um evento antecedente e um consequente. Uma regra de associação é uma implicação da forma antecedente $\rightarrow$ consequente, possibilitando a verificação de possíveis tendências de interconexão entre as variáveis (itemsets) de um banco de dados. De acordo com Zhao (56), as medidas mais usadas para a seleção de regras são:

- Suporte: É o percentual de casos em que o antecedente e o consequente ocorrem simultaneamente.

- Confiança: Consiste no percentual de casos em que o consequente ocorre dado que o antecedente ocorreu.

As análises estatísticas foram realizadas no ambiente R ( R Development Core Team) (57), versão 3.4.1, utilizando o algoritmo Apriori implementado no pacote arules (58). O algoritmo Apriori, introduzido por Agrawal and Srikant (59), tem por objetivo selecionar os itemsets mais frequentes, com base em limites pré-estabelecidos de suporte e confiança.

Para tal, foram considerados os valores 0,1 como suporte mínimo e 0,7 como confiança mínima, para os dados em geral e 0,2 como suporte mínimo e 0,7 como confiança mínima, para os dados separados por geração. As regras redundantes foram desconsideradas.

\subsection{Análise da Incidência}

Para Análise da Incidência de casos com Aids no município de São Paulo, foi utilizado um gráfico temporal por sexo e faixa etária para melhor estudar o comportamento da série, seguido de gráficos boxplots e tabelas que mostram a incidência de pessoas com Aids por gênero e faixa etária. A modelagem estatística foi feita a partir de Modelos Aditivos Generalizados (metodologia mais detalhada será feita próxima dos resultados). O software utilizado para desenvolver a análise foi o $\mathrm{R}(\mathrm{R}$ CORE TEAM, 2017) (57). 


\subsection{Ajuste De Modelo de Regressão}

Com o objetivo de avaliar se a faixa etária, sexo, ano, início da popularização dos Antirretrovirais para o HIV (Antes/Depois de 1989 - período1) e início da distribuição dos Antirretrovirais de forma gratuita pelo governo (Antes/Depois de 1995 - período2) ajudam a explicar a variável resposta (número de casos novos de Aids) controlado pelo tamanho da população, foi ajustado um modelo aditivo generalizado (Generalized Aditive Model (GAM)) (60). Tal modelo permite ajustar uma curva suave para variáveis numéricas (que nesse caso é a variável ano) que é flexível a ponto de captar diferentes formas de curva para a variável resposta ao longo do tempo. A distribuição utilizada para modelar a contagem dos casos novos de Aids foi a Binomial Negativa por conta da super dispersão dos dados com a inclusão de um termo offset para o tamanho da população (o termo offset na modelagem tem o objetivo de controlar/"relativizar" a variável resposta em relação ao tamanho da população) com função de ligação logito.

O efeito de interação entre sexo e ano, efeito aditivo de sexo, faixa etária, período1 e período2 foram testados através do teste de Wald e mantidos aqueles com valor-p menor que 0,05 . Os resultados do modelo são mostrados através da razão de chances, intervalos de $95 \%$ de confiança e teste de Wald. Para as variáveis numéricas a interpretação do resultado é feita de forma gráfica. Para fins de validação do modelo, gráficos de resíduos foram utilizados (porém não mostrados):

- Gráficos de auto correlação e auto correlação parcial para cada uma das séries (Feminino e Masculino para cada faixa etária), e para todas as séries agrupadas;

- Gráficos de resíduo versus valores ajustados;

- Gráficos quantil-quantil em relação a distribuição Normal.

Nenhuma das análises de resíduo invalidaram o modelo ajustado.

Observações: Diferentes estratégias de modelagem foram consideradas, como por exemplo:

- Alterou-se a distribuição do modelo: Poisson, Quasipoisson;

- Diferentes estruturas para a fixa do modelo: sem considerar a interação entre ano e sexo; 
- Inclusão de um componente aleatório no modelo: inclusão de efeito aleatório para uma cada das séries, estrutura de correlação ARMA para os resíduos, e demais variações;

Essas ações não resultaram em bom ajuste. 


\section{ASPECTOS ÉTICOS}

Bancos de dados relacionados aos sistemas de notificações do Estado de São Paulo foram tratados com absoluto sigilo e todos os indivíduos tiveram suas identidades preservadas, visto que, dentre os dados solicitados aos órgãos responsáveis e disponibilizados pelos mesmos, não incluíram itens de identificação. Os dados foram apurados no contexto geral de cada item requerido, de forma estatística e analítica. 


\section{PANORAMA DA AIDS NO BRASIL}

O cenário brasileiro em relação manifestação da Aids ainda é um ponto de atenção para as autoridades pública e para a sociedade civil. Ao longo dos anos de existência da doença o Brasil já registrou, entre os anos de 1980 a 2015, 826.825 novos casos de Aids. Ao consideramos os dados até junho de 2016, foram 842.710 casos. A representatividade dos últimos cinco anos é em média 4,97\% do total de casos registrados na série histórica(31). O presente capítulo visa traçar um panorama da Aids no Brasil, buscando compreender e fundamentar as discussões previstas nesse estudo.

\subsection{O Brasil em números da Aids}

Em 2010 foram registrados 39.872 casos de Aids no país, no ano seguinte, 2011 foram registrados 41.429 casos, uma representatividade de $4,9 \%$ maior que o ano anterior. Para os anos posteriores registrou-se, em 2012, queda de 1,0\%, e em 2013 aumento de 2,0\%, totalizando 42.266 novos casos de Aids. Já para 2014 foram registrados um total de novos casos de 41.007 notificações, 3,0\% a menos do que no ano anterior(31). Esses dados demonstram que, apesar da atenção governamental sobre o enfrentamento da epidemia de Aids, políticas de distribuição, ampliação e modernização dos esquemas de tratamento (definição da terapia antirretroviral - TARV) e supressão do HIV, o cenário não tem apresentado queda substancial, em que, ainda com variações, observamos aumento no número de casos registrados. Apresenta-se a seguir a Tabela 5 que relaciona o número e taxa de detecção ao longo dos anos no Brasil, utilizando dados do Boletim Epidemiológico do Ministério da Saúde, edição de 2016. 
Tabela 5 - Número e taxa de detecção (por 100.000 hab.) de casos de Aids notificados no Sinan, declarados no SIM e registrados no Siscel/Siclom por sexo e razão de sexos, segundo ano de diagnóstico. Brasil, 1980-2016

\begin{tabular}{|c|c|c|c|c|c|c|c|}
\hline \multirow{2}{*}{$\begin{array}{c}\text { Ano de } \\
\text { Diagnóstico }\end{array}$} & \multicolumn{3}{|c|}{ Número de casos } & \multirow{2}{*}{$\begin{array}{c}\text { Razão } \\
\text { M:F }\end{array}$} & \multicolumn{3}{|c|}{ Taxa de detecção } \\
\hline & Masculino & Feminino & Total & & Masculino & Feminino & Total \\
\hline 1980 & 1 & 0 & 1 & - & 0 & 0 & 0 \\
\hline 1981 & 0 & 0 & 0 & - & 0 & 0 & 0 \\
\hline 1982 & 15 & 1 & 16 & 15 & 0 & 0 & 0 \\
\hline 1983 & 39 & 1 & 40 & 39 & 0,1 & 0 & 0 \\
\hline 1984 & 120 & 10 & 130 & 12 & 0,2 & 0 & 0,1 \\
\hline 1985 & 509 & 20 & 529 & 25,5 & 0,8 & 0 & 0,4 \\
\hline 1986 & 1045 & 71 & 1116 & 14,7 & 1,6 & 0,1 & 0,8 \\
\hline 1987 & 2412 & 273 & 2685 & 8,8 & 3,6 & 0,4 & 2 \\
\hline 1988 & 3747 & 592 & 4339 & 6,3 & 5,4 & 0,8 & 3,1 \\
\hline 1989 & 5128 & 858 & 5986 & 6 & 7,3 & 1,2 & 4,2 \\
\hline 1990 & 7273 & 1337 & 8610 & 5,4 & 10,2 & 1,8 & 6 \\
\hline 1991 & 9475 & 2001 & 11477 & 4,7 & 13,1 & 2,7 & 7,8 \\
\hline 1992 & 11346 & 2849 & 14195 & 4 & 15,5 & 3,8 & 9,5 \\
\hline 1993 & 12764 & 3616 & 16380 & 3,5 & 17,1 & 4,7 & 10,8 \\
\hline 1994 & 13729 & 4253 & 17982 & 3,2 & 18,1 & 5,5 & 11,7 \\
\hline 1995 & 15257 & 5484 & 20741 & 2,8 & 19,8 & 7 & 13,3 \\
\hline 1996 & 16643 & 6925 & 23570 & 2,4 & 21,5 & 8,7 & 15 \\
\hline 1997 & 17491 & 8357 & 25849 & 2,1 & 22,2 & 10,3 & 16,2 \\
\hline 1998 & 18956 & 9713 & 28669 & 2 & 23,8 & 11,8 & 17,7 \\
\hline 1999 & 17043 & 9300 & 26344 & 1,8 & 21,1 & 11,2 & 16,1 \\
\hline 2000 & 20011 & 11312 & 31324 & 1,8 & 23,9 & 13,1 & 18,4 \\
\hline 2001 & 20050 & 12048 & 32099 & 1,7 & 23,6 & 13,8 & 18,6 \\
\hline 2002 & 23878 & 15385 & 39268 & 1,6 & 27,8 & 17,4 & 22,5 \\
\hline 2003 & 23027 & 14891 & 37925 & 1,5 & 26,4 & 16,6 & 21,4 \\
\hline 2004 & 22930 & 15061 & 37998 & 1,5 & 26 & 16,6 & 21,2 \\
\hline 2005 & 22487 & 15357 & 37848 & 1,5 & 24,8 & 16,4 & 20,5 \\
\hline 2006 & 22127 & 15005 & 37133 & 1,5 & 24,1 & 15,8 & 19,9 \\
\hline 2007 & 22961 & 15193 & 38163 & 1,5 & 24,7 & 15,8 & 20,2 \\
\hline 2008 & 24376 & 16114 & 40508 & 1,5 & 26,2 & 16,7 & 21,4 \\
\hline 2009 & 24584 & 15771 & 40368 & 1,6 & 26,1 & 16,2 & 21,1 \\
\hline 2010 & 24880 & 14988 & 39872 & 1,7 & 26,6 & 15,4 & 20,9 \\
\hline 2011 & 26352 & 15479 & 41845 & 1,7 & 28 & 15,8 & 21,8 \\
\hline 2012 & 26357 & 15064 & 41429 & 1,7 & 27,7 & 15,2 & 21,4 \\
\hline 2013 & 27407 & 14847 & 42266 & 1,8 & 28,9 & 15 & 21,8 \\
\hline 2014 & 27062 & 13929 & 41007 & 1,9 & 28,5 & 14,1 & 21,1 \\
\hline 2015 & 26516 & 12579 & 39113 & 2,1 & 27,9 & 12,7 & 20,2 \\
\hline 2016 & 10852 & 5001 & 15885 & - & - & - & - \\
\hline Total & 548850 & 293685 & 842710 & - & - & - & - \\
\hline
\end{tabular}


Outro ponto relevante, ao analisarmos os últimos dados do Boletim Epidemiológico, é a Razão de Sexo, observamos estabilidade no índice a partir do ano de 1999 até 2014, com média de 1,64 e variância de 0,02 (Mínimo de 1,5 e Máximo de 1,9), e no último ano a taxa passou de 1,9, em 2014, para 2,1 em 2015, representando um aumento de $11 \%$ em relação ao índice anterior (52). Observa-se na Figura 3, a evolução deste índice na série histórica. A partir dos índices apresentados, pode-se inferir que as mulheres são um grupo com índices mais acentuados, visto que na Razão M:F (casos do sexo masculino por casos do sexo feminino), para um detalhamento mais aprofundado, é necessário considerar os casos de HSH (Homens que fazem sexo com Homens) e Homens Heterossexuais que se relacionam apenas com Mulheres. Sendo que este ponto será considerado nas análises do Estado de São Paulo e do Município de São Paulo.

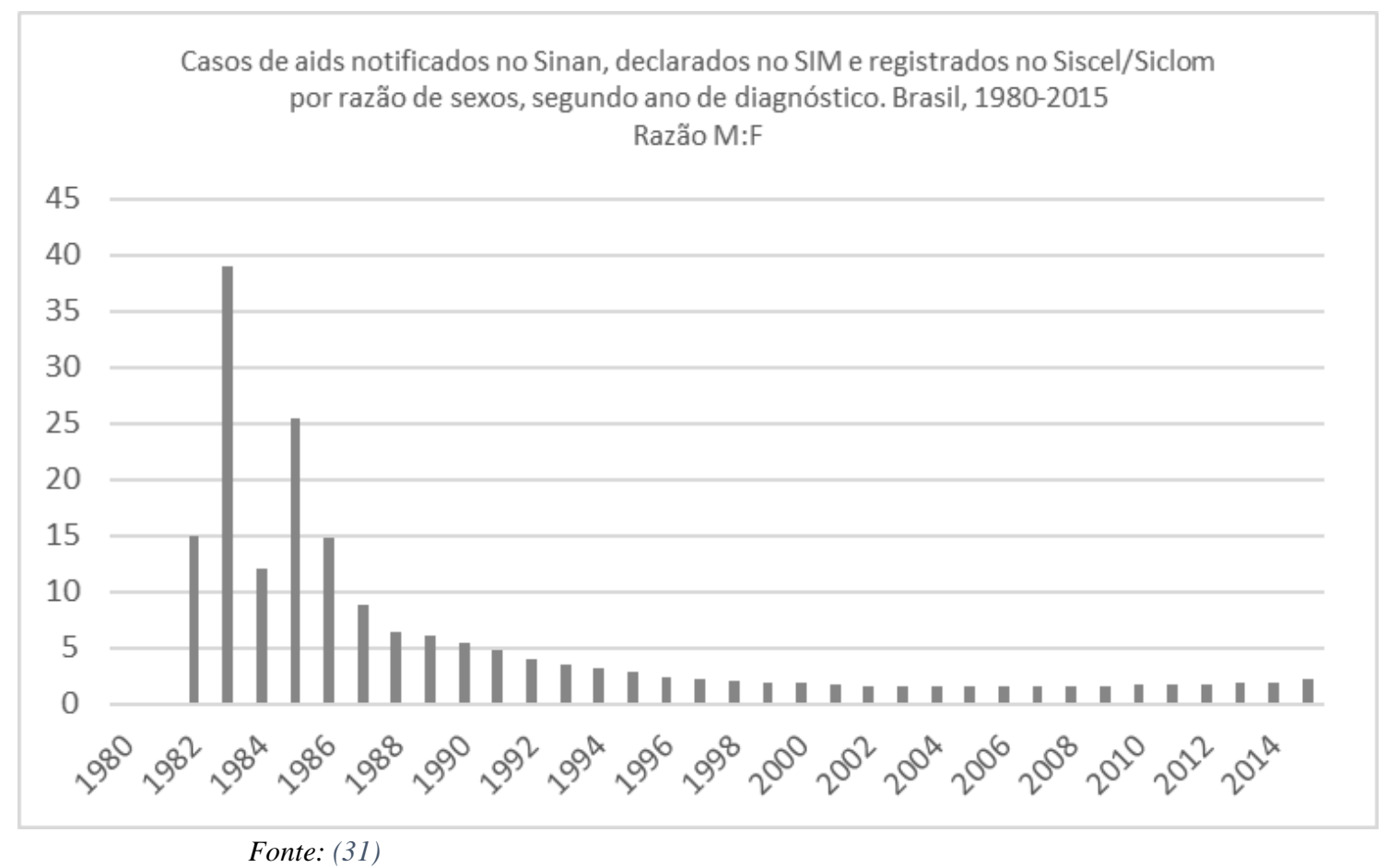

Figura 3 - Razão M:F - Casos de Aids notificados no Sinan, declarados no SIM e registrados no Siscel/Siclom por razão de sexos, segundo ano de diagnóstico. Brasil, 1980-2015

Ao longo dos anos o sexo masculino é um grupo consideravelmente mais presente nos dados de detecção da Aids. Os dados de Taxa de Detecção comprovam essa nota, como pode ser observado na Fonte: (31) Figura 4, e demonstrado na Tabela 6, que nos últimos cinco anos, de 2011 a 2015, apresenta-se da seguinte forma: 
Tabela 6 - Taxa de detecção de Aids por ano e sexo, Brasil 2011 a 2015

\begin{tabular}{c|c|c}
\hline Ano & Masculino & Feminino \\
\hline $\mathbf{2 0 1 1}$ & 28 & 15,8 \\
\hline $\mathbf{2 0 1 2}$ & 27,7 & 15,2 \\
\hline $\mathbf{2 0 1 3}$ & 28,9 & 15 \\
\hline $\mathbf{2 0 1 4}$ & 28,5 & 14,1 \\
\hline $\mathbf{2 0 1 5}$ & 37,9 & 12,7 \\
\hline
\end{tabular}

Fonte: (31)

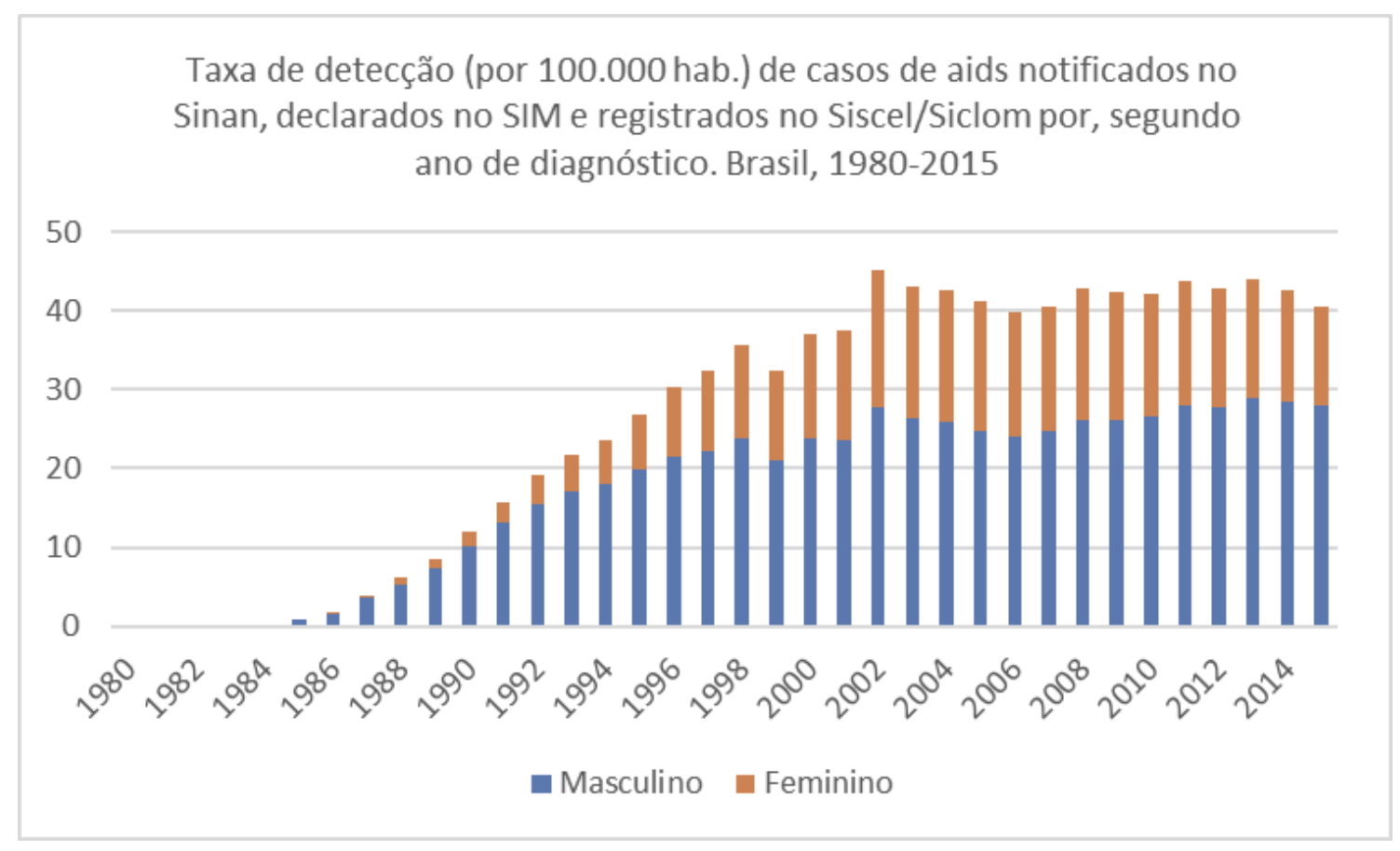

Fonte: (31)

Figura 4 - Taxa de detecção (por 100.000 hab.) de casos de Aids notificados no Sinan, declarados no SIM e registrados no Siscel/Siclom por sexo, segundo ano de diagnóstico. Brasil, 1980-2015

Ao consideramos a série histórica completa e segmentarmos em clusters com médias a cada 5 anos, a taxa de detecção do sexo masculino em relação ao sexo feminino (Tabela 7) também se apresenta da mesma forma que nos último 5 anos apresentados na Tabela 6 , sempre com resultados maiores. 
Tabela 7 - Taxa de detecção de Aids por ano e sexo, Brasil 1980 a 2015

\begin{tabular}{|c|c|c|}
\hline Anos agrupados & Masculino & Feminino \\
\hline $\mathbf{1 9 8 0}$ & 0,0 & 0,0 \\
\hline $\mathbf{1 9 8 1}$ a 1985 & 0,2 & 0,0 \\
\hline $\mathbf{1 9 8 6}$ a 1990 & 5,6 & 0,9 \\
\hline $\mathbf{1 9 9 6}$ a $\mathbf{2 0 0 0}$ & 16,7 & 4,7 \\
\hline $\mathbf{2 0 0 1}$ a 2005 & 22,5 & 11,0 \\
\hline 2006 a 2010 & 25,7 & 16,2 \\
\hline 2011 a 2015 & 25,5 & 16,0 \\
\hline Total Geral & 28,2 & 14,6 \\
\hline Fonte $:(31)$ & 17,3 & 8,8 \\
\hline
\end{tabular}

Destacando a Figura 5, com base no ano de 2015, depara-se com 26.516 casos de homens e 12.579 de mulheres notificadas com Aids, ano este de maior percentual de incidência de Aids em Homens da série histórica. $\mathrm{O}$ ano com maior percentual de Aids em Mulheres foi o de 2005, com 15.357 casos do sexo feminino e 22.487 para o sexo masculino(52). Observa-se, também, que 2013 tornou-se o ano com mais diagnósticos de Aids na série histórica, totalizando 42.226 casos, enquanto que nos anos 2000 ocorreu o menor número já registrado, num total de 3.324(52).

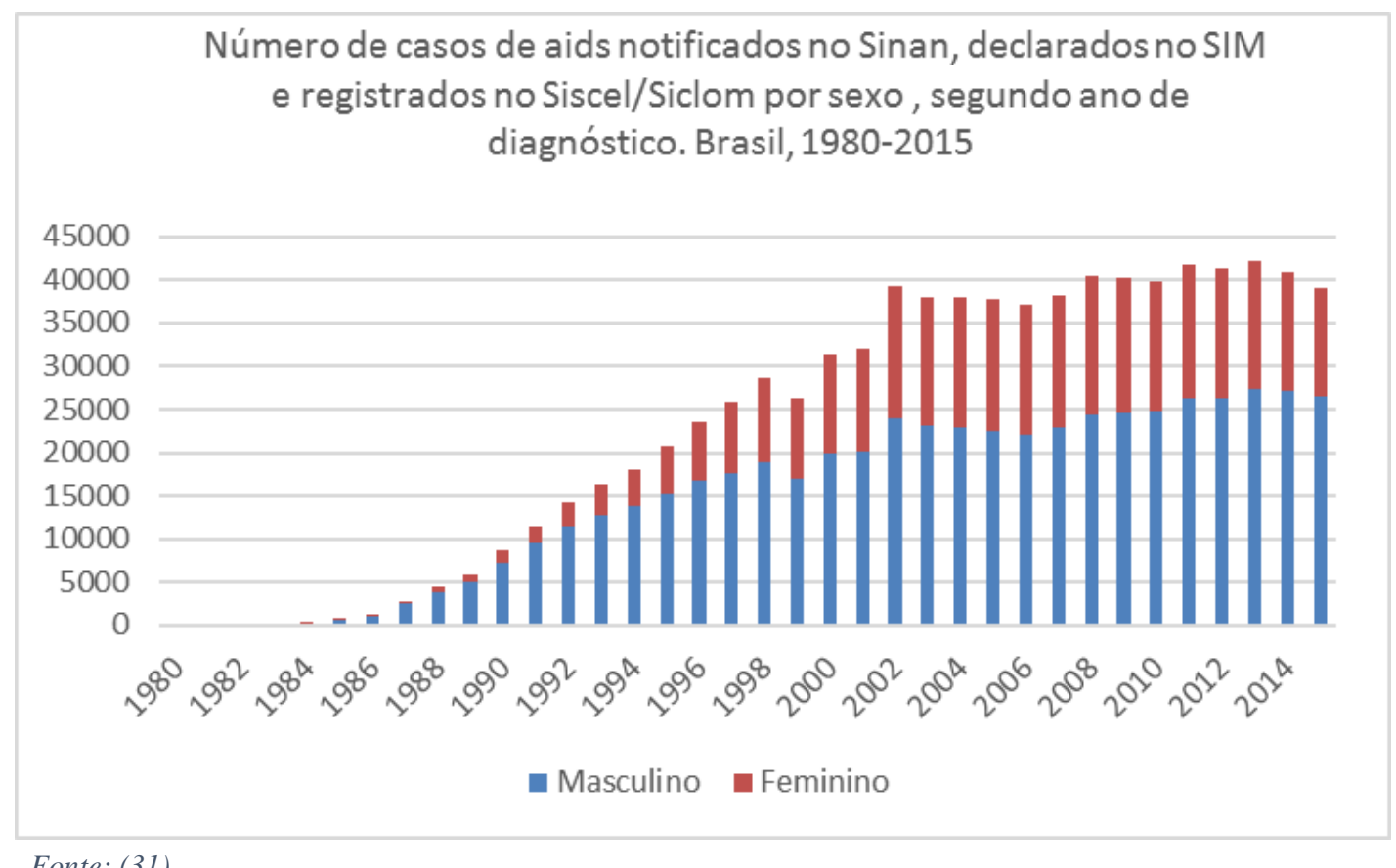

Fonte: (31)

Figura 5 - Número de casos de Aids notificados no Sinan, declarados no SIM e registrados no Siscel/Siclom por sexo, segundo ano de diagnóstico. Brasil, 1980-2015 
Ao focarmos na faixa etária deste estudo, indivíduos com idade de 15 a 24 anos, (Figura 6), os casos notificados de HIV no Brasil apresentados no Boletim Epidemiológico de 2016(31), identifica-se um aumento constante e significativo de casos. Considerando o ano de corte deste estudo, constatou-se que, de 2010 até 2014, são encontrados, sequencialmente, os seguintes índices de crescimento:

Tabela 8 - Comparativo percentual de casos de Aids ao longo dos anos de 2010 a 2015, faixa etária de 15 a 24 anos, Brasil.

\begin{tabular}{c|c|c}
\hline ANO & $\mathbf{1 5}$ a 19 anos & $\mathbf{2 0}$ a $\mathbf{2 4}$ anos \\
\hline $\mathbf{2 0 1 0}$ & $26 \%$ & $11 \%$ \\
\hline $\mathbf{2 0 1 1}$ & $24 \%$ & $25 \%$ \\
\hline $\mathbf{2 0 1 2}$ & $25 \%$ & $22 \%$ \\
\hline $\mathbf{2 0 1 3}$ & $45 \%$ & $46 \%$ \\
\hline $\mathbf{2 0 1 4}$ & $65 \%$ & $64 \%$ \\
\hline $\mathbf{2 0 1 5}$ & $26 \%$ & $32 \%$ \\
\hline Fonte: $(31)$
\end{tabular}

Em 2015, constatou-se diminuição dos casos notificados de Aids para as duas faixas etárias analisadas, sendo $26 \%$ para faixa etária de 15 a 19 anos e $32 \%$ de na faixa de 20 a 24 anos, sempre em relação ao ano anterior. Cabe ressaltar que os dados de 2016, observados na Figura 6, são parciais, referentes até o mês de junho de 2016 (31). Entretanto pode-se observar que os percentuais, em relação às demais faixas etárias, apresentaram a mesma tendência encontrada em anos anteriores.

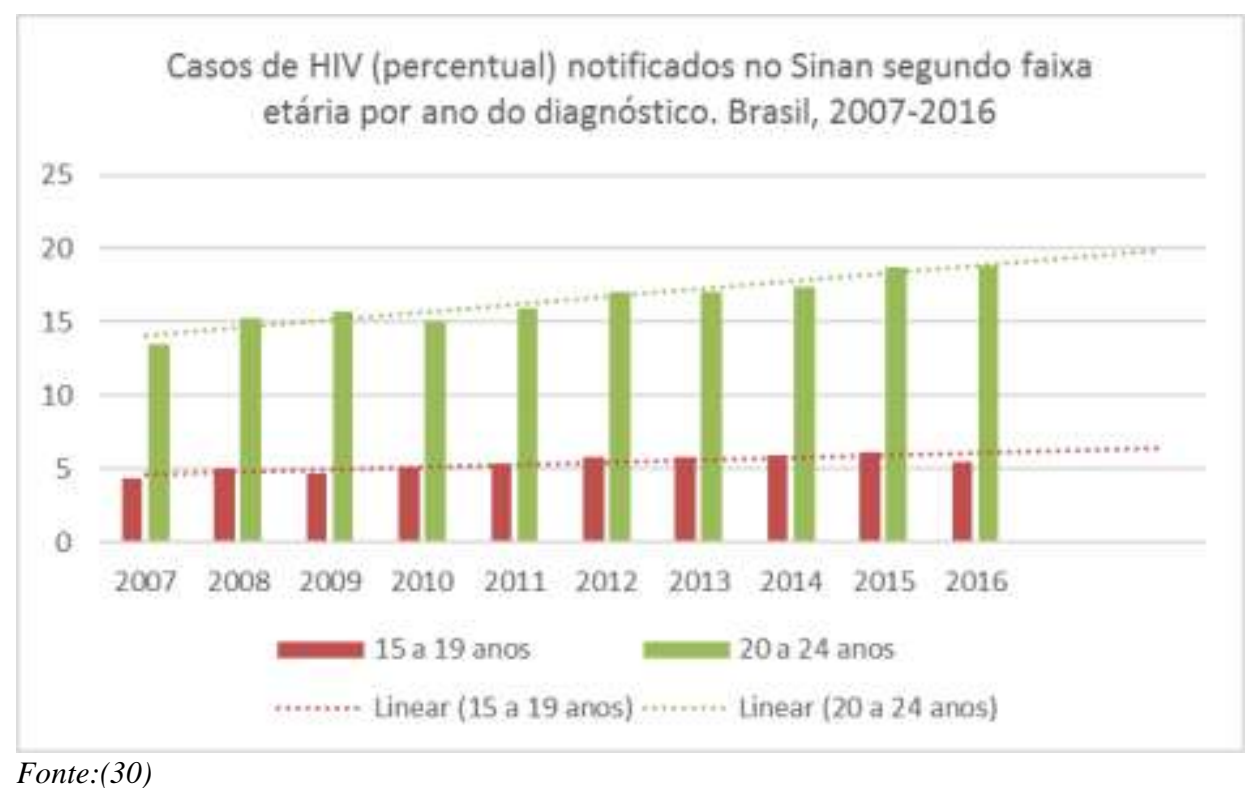

Figura 6 - Casos de HIV (percentual) notificados no Sinan segundo faixa etária por ano do diagnóstico. Brasil, 2007-2016 
Na Tabela 9 temos a distribuição percentual de casos de HIV utilizado no recorte de análise da Figura 6, evidenciando a evolução dos casos nas faixas etárias analisadas. Quanto às demais faixas etárias, pode necessitar um foco para esses indivíduos, para além do atual estudo. Isso corrobora com o pensamento de que a Aids é, e continuará sendo uma das principais preocupações nas políticas públicas do Brasil. Há de considerar, também, que o anor de 2016, na Tabela 9, contém os dados parciais, até junho deste mesmo ano.

Tabela 9 - Casos de HIV (percentual) notificados no Sinan segundo faixa etária por ano do diagnóstico. Brasil, 2007-2016

\begin{tabular}{|l|c|c|c|c|c|c|c|c|c|c|c|}
\hline \multicolumn{1}{|c|}{ Ano } & $\mathbf{2 0 0 7}$ & $\mathbf{2 0 0 8}$ & $\mathbf{2 0 0 9}$ & $\mathbf{2 0 1 0}$ & $\mathbf{2 0 1 1}$ & $\mathbf{2 0 1 2}$ & $\mathbf{2 0 1 3}$ & $\mathbf{2 0 1 4}$ & $\mathbf{2 0 1 5}$ & $\mathbf{2 0 1 6}$ & Total \\
\hline Faixa Etária & $\%$ & $\%$ & $\%$ & $\%$ & $\%$ & $\%$ & $\%$ & $\%$ & $\%$ & $\%$ & $\%$ \\
\hline < 5 anos & 0,5 & 0,5 & 0,5 & 0,5 & 0,4 & 0,4 & 0,3 & 0,3 & 0,2 & 0,2 & 0,3 \\
\hline $\mathbf{5}$ a 9 anos & 0,2 & 0,3 & 0,3 & 0,2 & 0,2 & 0,1 & 0,1 & 0,1 & 0,1 & 0 & 0,1 \\
\hline $\mathbf{1 0}$ a 14 anos & 0,3 & 0,3 & 0,4 & 0,4 & 0,3 & 0,3 & 0,2 & 0,2 & 0,2 & 0,2 & 0,3 \\
\hline $\mathbf{1 5}$ a 19 anos & $\mathbf{4 , 3}$ & $\mathbf{5}$ & $\mathbf{4 , 7}$ & $\mathbf{5 , 1}$ & $\mathbf{5 , 3}$ & $\mathbf{5 , 8}$ & $\mathbf{5 , 8}$ & $\mathbf{5 , 9}$ & $\mathbf{6 , 1}$ & $\mathbf{5 , 5}$ & $\mathbf{5 , 6}$ \\
\hline $\mathbf{2 0}$ a 24 anos & $\mathbf{1 3 , 5}$ & $\mathbf{1 5 , 3}$ & $\mathbf{1 5 , 7}$ & $\mathbf{1 5}$ & $\mathbf{1 5 , 9}$ & $\mathbf{1 7}$ & $\mathbf{1 7 , 1}$ & $\mathbf{1 7 , 4}$ & $\mathbf{1 8 , 7}$ & $\mathbf{1 8 , 8}$ & $\mathbf{1 7 , 1}$ \\
\hline $\mathbf{2 5}$ a 29 anos & 18,5 & 19,1 & 19,2 & 19,3 & 19,5 & 18,9 & 18,6 & 19 & 18,7 & 18,6 & 18,9 \\
\hline $\mathbf{3 0}$ a 34 anos & 18,2 & 16,5 & 16,8 & 17 & 16,5 & 16,8 & 16,4 & 16,3 & 15,7 & 15,1 & 16,3 \\
\hline $\mathbf{3 5}$ a 39 anos & 15,2 & 14,3 & 13,9 & 13 & 12,7 & 11,8 & 12,6 & 12,5 & 12,2 & 12,5 & 12,7 \\
\hline $\mathbf{4 0}$ a 44 anos & 11,3 & 10,7 & 10,2 & 10,5 & 10,3 & 10,1 & 9,4 & 9 & 8,9 & 9,3 & 9,6 \\
\hline $\mathbf{4 5}$ a 49 anos & 7,7 & 7,2 & 7,6 & 7,4 & 7,2 & 7,5 & 7,5 & 7 & 7,1 & 7 & 7,2 \\
\hline $\mathbf{5 0}$ a 54 anos & 4,4 & 4,6 & 4,3 & 4,8 & 5,1 & 4,8 & 4,6 & 5,1 & 4,9 & 5,2 & 4,9 \\
\hline $\mathbf{5 5}$ a 59 anos & 2,3 & 2,4 & 2,6 & 2,9 & 2,8 & 2,7 & 3,1 & 2,9 & 3 & 3,2 & 2,9 \\
\hline 60 e mais & 2,4 & 2,3 & 2,4 & 2,5 & 2,6 & 2,5 & 2,7 & 2,9 & 3,1 & 3,4 & 2,8 \\
\hline Ignorado & 1,3 & 1,5 & 1,3 & 1,4 & 1,3 & 1,2 & 1,5 & 1,3 & 1,1 & 0,9 & 1,2 \\
\hline Total & 100 & 100 & 100 & 100 & 100 & 100 & 100 & 100 & 100 & 100 & 100 \\
\hline Fonte: $(30)$ & & & & & & & & & & \\
\hline
\end{tabular}

Retomando o tema principal desta análise, mas não distante das discussões que cercam os fatores relacionados ao HIV, apresenta-se na Tabela 10 números absolutos de casos de Aids ao longo dos anos e na Tabela 11 pode-se observar os percentuais dos casos de Aids a cada ano(31). 
Tabela 10 - Casos de Aids notificados no Sinan, declarados no SIM e registrados no Siscel/Siclom(1) segundo faixa etária por ano de diagnóstico. Brasil, 1980-2015

\begin{tabular}{|c|c|c|c|c|c|c|c|c|c|c|c|c|c|c|}
\hline Ano & $\begin{array}{c}1980- \\
2002\end{array}$ & 2003 & 2004 & 2005 & 2006 & 2007 & 2008 & 2009 & 2010 & 2011 & 2012 & 2013 & 2014 & 2015 \\
\hline Faixa etária & $\mathrm{N}^{\circ}$ & $\mathrm{N}^{\circ}$ & $\mathrm{N}^{\circ}$ & $\mathrm{N}^{\circ}$ & $\mathrm{N}^{\circ}$ & $\mathrm{N}^{\circ}$ & $\mathrm{N}^{\circ}$ & $\mathrm{N}^{\circ}$ & $\mathrm{N}^{\circ}$ & $\mathrm{N}^{\circ}$ & $\mathrm{N}^{\circ}$ & $\mathrm{N}^{\circ}$ & $\mathrm{N}^{\circ}$ & $\mathrm{N}^{\circ}$ \\
\hline$<5$ anos & 8822 & 962 & 790 & 790 & 658 & 591 & 600 & 560 & 543 & 470 & 483 & 433 & 400 & 358 \\
\hline 5 a 9 anos & 1914 & 457 & 449 & 380 & 299 & 277 & 241 & 208 & 196 & 165 & 122 & 119 & 120 & 96 \\
\hline 10 a 14 anos & 941 & 156 & 194 & 201 & 190 & 221 & 236 & 202 & 172 & 178 & 157 & 133 & 117 & 88 \\
\hline 15 a 19 anos & 6852 & 648 & 622 & 547 & 593 & 584 & 688 & 674 & 670 & 763 & 850 & 952 & 1000 & 951 \\
\hline 20 a 24 anos & 31397 & 3049 & 2864 & 2776 & 2619 & 2697 & 2896 & 3043 & 3079 & 3455 & 3738 & 3854 & 3829 & 3879 \\
\hline 25 a 29 anos & 59701 & 5703 & 5800 & 5522 & 5437 & 5542 & 5960 & 5852 & 5841 & 5924 & 5804 & 6127 & 5978 & 5667 \\
\hline 30 a 34 anos & 67439 & 7198 & 6974 & 6868 & 6607 & 6713 & 6959 & 6993 & 6885 & 7200 & 7044 & 7066 & 6667 & 6190 \\
\hline 35 a 39 anos & 53321 & 7046 & 6880 & 6713 & 6548 & 6575 & 6612 & 6597 & 6133 & 6669 & 6373 & 6336 & 6200 & 5975 \\
\hline 40 a 44 anos & 35279 & 5289 & 5396 & 5660 & 5543 & 5645 & 5908 & 5773 & 5831 & 5801 & 5529 & 5475 & 5092 & 4762 \\
\hline 45 a 49 anos & 20904 & 3371 & 3582 & 3643 & 3819 & 3988 & 4359 & 4326 & 4200 & 4632 & 4542 & 4520 & 4376 & 4009 \\
\hline 50 a 54 anos & 11699 & 1935 & 2160 & 2338 & 2249 & 2497 & 2868 & 2816 & 2919 & 2942 & 3088 & 3175 & 3064 & 3082 \\
\hline 55 a 59 anos & 6455 & 1093 & 1135 & 1260 & 1286 & 1440 & 1604 & 1647 & 1758 & 1847 & 1811 & 1955 & 2045 & 1946 \\
\hline 60 e mais & 6579 & 1004 & 1128 & 1131 & 1261 & 1371 & 1556 & 1662 & 1624 & 1783 & 1883 & 2116 & 2109 & 2100 \\
\hline ignorado & 47 & 14 & 24 & 19 & 24 & 22 & 21 & 15 & 21 & 16 & 5 & 5 & 10 & 10 \\
\hline Total & 311350 & 37925 & 37998 & 37848 & 37133 & 38163 & 40508 & 40368 & 39872 & 41845 & 41429 & 42266 & 41007 & 39113 \\
\hline
\end{tabular}

Fonte:(30)

Tabela 11 - Percentual de Casos de Aids notificados no Sinan, declarados no SIM e registrados no Siscel/Siclom(1) segundo faixa etária por ano de diagnóstico. Brasil, 1980-2015

\begin{tabular}{|c|c|c|c|c|c|c|c|c|c|c|c|c|c|c|}
\hline Anos & $\begin{array}{c}1980- \\
2002\end{array}$ & 2003 & 2004 & 2005 & 2006 & 2007 & 2008 & 2009 & 2010 & 2011 & 2012 & 2013 & 2014 & 2015 \\
\hline Faixa Etária & $\%$ & $\%$ & $\%$ & $\%$ & $\%$ & $\%$ & $\%$ & $\%$ & $\%$ & $\%$ & $\%$ & $\%$ & $\%$ & $\%$ \\
\hline$<5$ anos & 2,83 & 2,54 & 2,08 & 2,09 & 1,77 & 1,55 & 1,48 & 1,39 & 1,36 & 1,12 & 1,17 & 1,02 & 0,98 & 0,92 \\
\hline 10 a 14 anos & 0,30 & 0,41 & 0,51 & 0,53 & 0,51 & 0,58 & 0,58 & 0,50 & 0,43 & 0,43 & 0,38 & 0,31 & 0,29 & 0,22 \\
\hline 15 a 19 anos & 2,20 & 1,71 & 1,64 & 1,45 & 1,60 & 1,53 & 1,70 & 1,67 & 1,68 & 1,82 & 2,05 & 2,25 & 2,44 & 2,43 \\
\hline 20 a 24 anos & 10,08 & 8,04 & 7,54 & 7,33 & 7,05 & 7,07 & 7,15 & 7,54 & 7,72 & 8,26 & 9,02 & 9,12 & 9,34 & 9,92 \\
\hline 25 a 29 anos & 19,17 & 15,04 & 15,26 & 14,59 & 14,64 & 14,52 & 14,71 & 14,50 & 14,65 & 14,16 & 14,01 & 14,50 & 14,58 & 14,49 \\
\hline 30 a 34 anos & 21,66 & 18,98 & 18,35 & 18,15 & 17,79 & 17,59 & 17,18 & 17,32 & 17,27 & 17,21 & 17,00 & 16,72 & 16,26 & 15,83 \\
\hline 35 a 39 anos & 17,13 & 18,58 & 18,11 & 17,74 & 17,63 & 17,23 & 16,32 & 16,34 & 15,38 & 15,94 & 15,38 & 14,99 & 15,12 & 15,28 \\
\hline 40 a 44 anos & 11,33 & 13,95 & 14,20 & 14,95 & 14,93 & 14,79 & 14,58 & 14,30 & 14,62 & 13,86 & 13,35 & 12,95 & 12,42 & 12,17 \\
\hline 45 a 49 anos & 6,71 & 8,89 & 9,43 & 9,63 & 10,28 & 10,45 & 10,76 & 10,72 & 10,53 & 11,07 & 10,96 & 10,69 & 10,67 & 10,25 \\
\hline 5 a 9 anos & 0,61 & 1,21 & 1,18 & 1,00 & 0,81 & 0,73 & 0,59 & 0,52 & 0,49 & 0,39 & 0,29 & 0,28 & 0,29 & 0,25 \\
\hline 50 a 54 anos & 3,76 & 5,10 & 5,68 & 6,18 & 6,06 & 6,54 & 7,08 & 6,98 & 7,32 & 7,03 & 7,45 & 7,51 & 7,47 & 7,88 \\
\hline 55 a 59 anos & 2,07 & 2,88 & 2,99 & 3,33 & 3,46 & 3,77 & 3,96 & 4,08 & 4,41 & 4,41 & 4,37 & 4,63 & 4,99 & 4,98 \\
\hline 60 e mais & 2,11 & 2,65 & 2,97 & 2,99 & 3,40 & 3,59 & 3,84 & 4,12 & 4,07 & 4,26 & 4,55 & 5,01 & 5,14 & 5,37 \\
\hline Ignorado & 0,02 & 0,04 & 0,06 & 0,05 & 0,06 & 0,06 & 0,05 & 0,04 & 0,05 & 0,04 & 0,01 & 0,01 & 0,02 & 0,03 \\
\hline
\end{tabular}

Quando nos deparamos com o espectro da evolução da epidemia no Brasil, ao longo dos anos, conforme apresentado no Boletim Epidemiológico (52), nota-se, em um primeiro momento, Figura 7, Figura 8 e Figura 9 que as regiões litorâneas foram mais afetadas. Mas de fato, ao observarmos, percebe-se que há uma densa concentração na região Sul e Sudeste. 


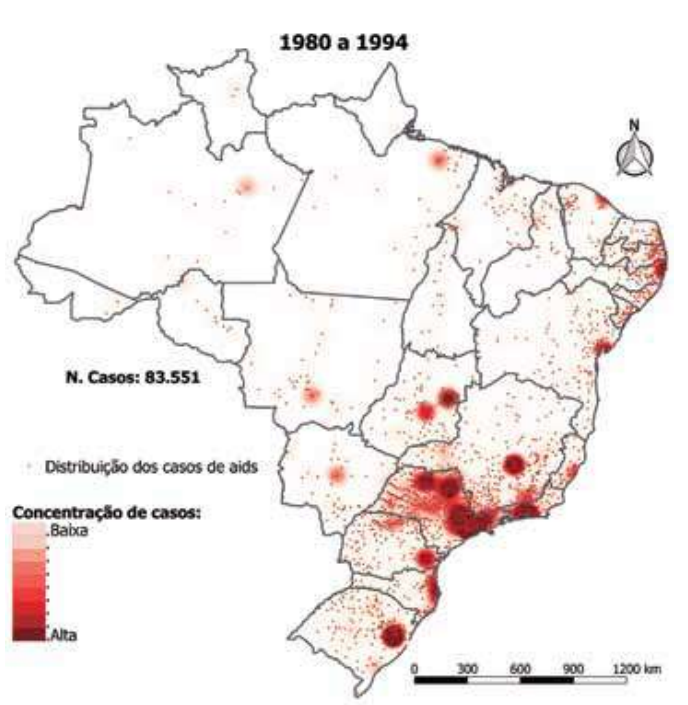

Fonte: (52)

Figura 7 - Georreferenciamento da Epidemia de Aids. Brasil, 1995 a 2004

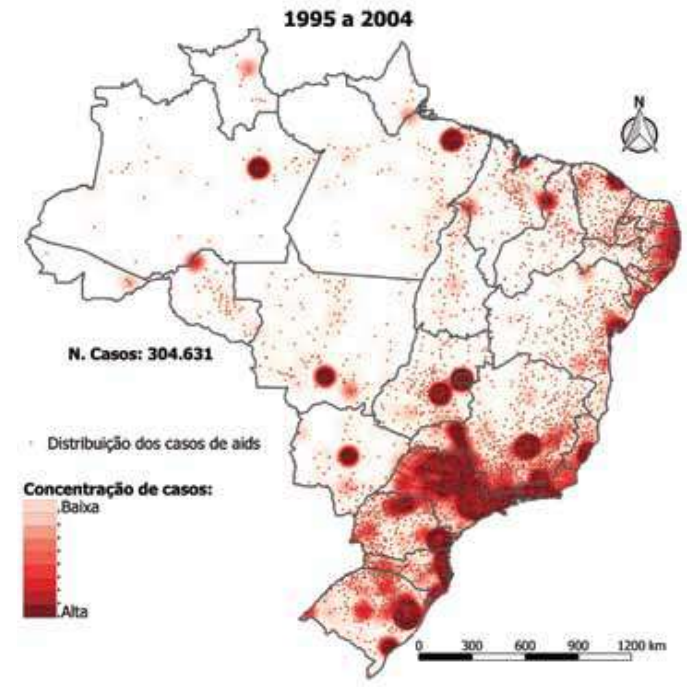

Fonte: (52))

Figura 8 - Georreferenciamento da Epidemia de Aids. Brasil, 1995 a 2004

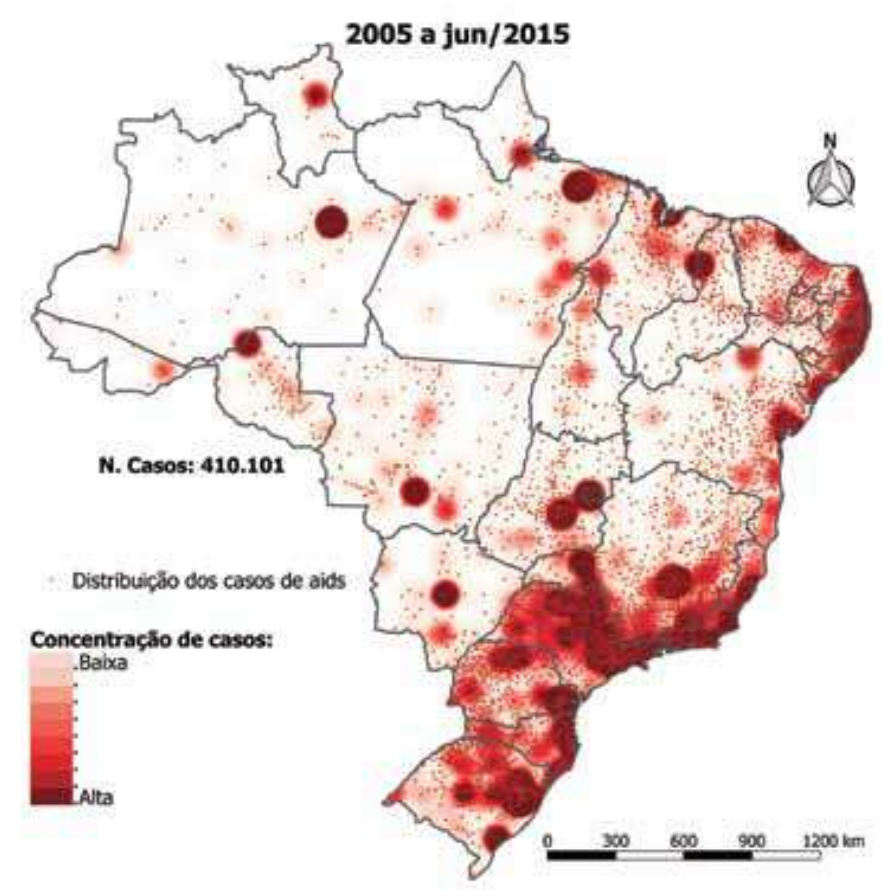

Fonte: (52)

Figura 9 - Georreferenciamento da Epidemia de Aids. Brasil, 2005 a jun/2015

Frente a esses dados, se faz necessário considerar as efetivas ações do Brasil rumo ao enfretamento da epidemia de Aids. As estratégias de políticas públicas podem refletir significativamente nos dados apresentados até o presente momento. 


\subsection{O Brasil no front contra a epidemia.}

Como explorado ao longo deste estudo, o Boletim Epidemiológico do Ministério da Saúde é o documento base para a compreensão da epidemia ao longo dos anos da Aids no Brasil, e foco de diversos estudos e reportagens sobre o tema. A Tabela 12 contém um resumo dos boletins abrangendo os anos de 2007 até 2016, último boletim disponível até a elaboração deste estudo. Nesta tabela foram reunidos os dados de totais dos casos de Aids por sexo, número de novos casos relatados a cada ano e óbitos apurados no período, de todas as faixas etárias. Esta análise é importante para estabelecer os caminhos escolhidos pelos editoriais, o que estabelece o ponto de atenção governamental em cada período de produção do documento.

Desses 10 boletins apresentados na Tabela 12, em quatro edições os temas norteadores foram jovens e crianças, em duas edições sobre a Cascata do Cuidado Contínuo, uma edição sobre idosos, uma edição sobre a notificação compulsória de casos de HIV e duas edições sem um texto base norteador. Este fato revela a constante atenção governamental sobre as questões que envolvem a juventude no cenário da Aids.

Essa atenção para a juventude desperta outros pontos de cuidado, ligados ao ciclo de vida e da história natural da doença, afetados pelo advento das terapias antirretrovirais. Citando um dos fatores que podem evidenciar essa dinâmica, em estudo realizado no final dos anos 1990, utilizando o método Kaplan-Meier (61), os autores estimaram sobrevivência de pelo menos 108 meses após o diagnóstico de Aids em $59,5 \%$ dos pacientes no Sudeste e 59,3\% no Sul do Brasil (62). Em estudo sobre expectativa de vida de pessoas vivendo com HIV dos Estados Unidos da América e Canadá, os resultados para indivíduos em tratamento e com perda de seguimento foram, respectivamente, 42,6 e 42,7 anos de vida (63). É aparente os motivos dos esforços estabelecidos para as ações de tratamento e prevenção que foram desenvolvidos no Brasil para o enfrentamento da epidemia, e esses estudos atualizam essa visão e reforçam a importância dessa questão nas Políticas Públicas. 
Tabela 12 - Resumo de dados de Boletins Epidemiológicos do Ministério da Saúde, Brasil.

\begin{tabular}{|c|c|c|c|c|c|c|c|c|c|}
\hline \multirow[b]{2}{*}{ Boletim } & \multirow[b]{2}{*}{$\begin{array}{c}\text { Texto } \\
\text { Destaque }\end{array}$} & \multicolumn{4}{|c|}{ Casos de Aids no Brasil } & \multicolumn{2}{|c|}{ Novos Casos de Aids } & \multicolumn{2}{|c|}{$\begin{array}{l}\text { Óbitos em decorrência } \\
\text { de Aids }\end{array}$} \\
\hline & & $\begin{array}{l}\text { Período de } \\
\text { Referência }\end{array}$ & $\begin{array}{c}\text { Total de } \\
\text { Casos de } \\
\text { Aids }\end{array}$ & $\begin{array}{c}\text { Aids } \\
\text { Sexo } \\
\text { Masculino } \\
\end{array}$ & $\begin{array}{c}\text { Aids } \\
\text { Sexo } \\
\text { Feminino } \\
\end{array}$ & $\begin{array}{c}\text { Ano } \\
\text { Referência }\end{array}$ & $\begin{array}{l}\text { Novos } \\
\text { Casos }\end{array}$ & $\begin{array}{l}\text { Período } \\
\text { referências }\end{array}$ & Óbitos \\
\hline 2007 & $\begin{array}{l}\text { Aids em } \\
\text { jovens } \\
\text { brasileiros }\end{array}$ & $\begin{array}{c}1980 \text { a } \\
\text { junho de } \\
2007\end{array}$ & 474.273 & 314.294 & 159.793 & 2005 & 35.965 & $\begin{array}{c}1980 \mathrm{a} \\
2006\end{array}$ & 192.709 \\
\hline 2008 & $\begin{array}{c}\text { Aids em } \\
\text { pessoas com } \\
50 \text { anos ou } \\
\text { mais de idade }\end{array}$ & $\begin{array}{c}1980 \text { a } \\
\text { junho de } \\
2008\end{array}$ & 506.499 & 333.485 & 172.995 & 2006 & 35.459 & $\begin{array}{c}1980 \mathrm{a} \\
2007\end{array}$ & 205.409 \\
\hline 2009 & $\begin{array}{c}\text { Aids em } \\
\text { menores de } \\
\text { cinco anos de } \\
\text { idade }\end{array}$ & $\begin{array}{c}1980 \text { a } \\
\text { junho de } \\
2009\end{array}$ & 462.237 & 356.427 & 188.396 & 2008 & 34.480 & $\begin{array}{c}1980 \mathrm{a} \\
2008\end{array}$ & 217.091 \\
\hline 2010 & $\begin{array}{c}\text { Aids em } \\
\text { jovens de } 13 \\
\text { a } 24 \text { anos de } \\
\text { idade }\end{array}$ & $\begin{array}{c}1980 \text { a } \\
\text { junho de } \\
2010\end{array}$ & 492.581 & 385.818 & 207.080 & 2009 & 38.538 & $\begin{array}{c}1980 \mathrm{a} \\
2009\end{array}$ & 229.222 \\
\hline 2011 & $\begin{array}{l}\text { Vulnerabi- } \\
\text { lidade dos } \\
\text { Jovens Gays }\end{array}$ & $\begin{array}{c}1980 \text { a } \\
\text { junho de } \\
2011\end{array}$ & 608.230 & 397.662 & 210.538 & 2010 & 34.218 & $\begin{array}{c}1980 \mathrm{a} \\
2010\end{array}$ & 241.469 \\
\hline 2012 & - & $\begin{array}{c}1980 \text { a } \\
\text { junho de } \\
2012\end{array}$ & 656.701 & 426.459 & 230.161 & 2011 & 38.776 & $\begin{array}{c}1980 \mathrm{a} \\
2011\end{array}$ & 253.706 \\
\hline 2013 & $\begin{array}{l}\text { Cascata do } \\
\text { Cuidado } \\
\text { Contínuo }\end{array}$ & $\begin{array}{c}1980 \text { a } \\
\text { junho de } \\
2013\end{array}$ & 686.478 & 445.197 & 241.223 & 2012 & 39.185 & $\begin{array}{c}1980 \mathrm{a} \\
2012\end{array}$ & 265.698 \\
\hline 2014 & $\begin{array}{l}\text { Notificação } \\
\text { do HIV }\end{array}$ & $\begin{array}{c}1980 \text { a } \\
\text { junho de } \\
2014\end{array}$ & 757.042 & 491.747 & 265.251 & 2013 & 39.501 & $\begin{array}{c}1980 \mathrm{a} \\
2013\end{array}$ & 278.306 \\
\hline 2015 & $\begin{array}{l}\text { Cascata do } \\
\text { cuidado } \\
\text { contínuo: } \\
\text { uma análise } \\
\text { de tendências }\end{array}$ & $\begin{array}{c}1980 \text { a } \\
\text { junho de } \\
2015\end{array}$ & 798.366 & 519.183 & 278.960 & 2014 & 39.951 & $\begin{array}{c}1980 \mathrm{a} \\
2014\end{array}$ & 290.929 \\
\hline 2016 & - & $\begin{array}{c}1980 \text { a } \\
\text { junho de } \\
2016 \\
\end{array}$ & 842.710 & 548.850 & 293.685 & 2015 & 39.113 & $\begin{array}{c}1980 \mathrm{a} \\
2015\end{array}$ & 303.353 \\
\hline
\end{tabular}

Fonte: O Autor

O acesso universal e gratuito às Terapias Antirretrovirais (TARV), estabelecido pela Lei 9.313 (3), em 1996, e proporcionou resultados significativos em relação à morbidade e mortalidade do indivíduo vivendo com HIV/Aids. Entre os países em desenvolvimento, o Brasil é o primeiro pais a adotar essa política de acesso às medicações referência contra o HIV (64). Recentemente, em 2013, estabeleceu-se o início imediato do tratamento contra o HIV (3). As autoridades brasileiras também promovem atualizações dos esquemas antirretrovirais indicados, o que ocorreu, por exemplo, em fevereiro de 2017 (65). Esses fatos não limitam as necessidades de atuação constante sobre como combater a disseminação do vírus. $\mathrm{O}$ fato é que:

Pensar uma epidemia como a da Aids é pisar em um terreno movediço e aberto a novas reflexões. Cerca de três décadas se passaram do início da epidemia e o debate permanece em voga. As inquietações são as mais diversas, mas [busca] se [concentrar] na relação da Aids no século XXI, as práticas de saúde e a sociedade (35). 
Essas revisão histórica da evolução da infecção HIV/Aids no Brasil reforça a importância do estabelecimento de políticas e programas de atenção ao cuidado, prevenção e redução de danos principalmente para os jovens (66), buscando formas de acessar esses indivíduos, com uma ação para cada forma de pensar das Gerações na atualidade. 


\section{PANORAMA DA AIDS NO ESTADO DE SÃO PAULO}

Segundo dados do IBGE (Instituto Brasileiro de Geografia e Estatística) a população estimada do Estado de São Paulo para o ano de 2016 é de 44.749.699 habitantes em 645 municípios (67). A divisão do Estado pela segmentação do instituto e para o Planejamento Regional se dá por subdivisões, compostas pela Região Metropolitana de São Paulo, a Região Metropolitana da Baixada Santista, de Campinas, do Vale do Paraíba e Litoral Norte, de Sorocaba, de Ribeirão Preto, a Aglomeração Urbana de Jundiaí, Aglomeração Urbana de Piracicaba e Macrometrópole Paulista (68).

Na estimativa do IBGE de população brasileira e paulista, em abril de 2017, o Estado representa $22 \%$ da população nacional (69). Com tal representatividade populacional, o Estado de São Paulo é uma federação chave para compreensão do fenômeno da Aids.

O presente capítulo estabelece os dados estatísticos do Estado da população entre 15 a 24 anos do período entre 1980 a 2014, notificados e constantes na Base Relacionada da Vigilância Epidemiológica do Centro de Referência e Tratamento DTS/Aids (CRT).

\subsection{Um retrato do Estado nos dados da Aids}

São Paulo é um dos estados mais acometidos pelos primeiros casos de Aids do país (70). O primeiro caso identificado no Banco Relacional do CRT (Centro de Referência e Tratamento) é do sexo masculino, em 1982, de um indivíduo nascido em 1958 categorizado como Homem que fazia sexo com Homem (HSH), da Geração Baby boomer. No ano seguinte foram relatados 5 casos, sendo dois casos de Usuários de Drogas Injetáveis (UDI), dois HSH e um bissexual. Em 1984 foram notificados 17 casos, 12 indivíduos da Geração Baby boomer e 5 da Geração X. No ano de 1985 ocorreu a primeira notificação do sexo feminino no Estado, 21 anos, heterossexual. Esse primeiro perfil da Aids no Estado acompanha o histórico da Aids em outros países, como, por exemplo, nos Estados Unidos da América (48). 
Assumindo a série histórica para a definição de nossa análise, na Figura 10, sempre considerando indivíduos diagnosticados com idade entre 15 a 24 anos, observase que indivíduos nascidos no ano 1954 foram os mais acometidos em comparação aos demais analisados nesse estudo. Foram 1.230 casos notificados, destes $41 \%$ do sexo feminino e $59 \%$ do sexo masculino. A categoria de exposição, em termos percentuais, se apresenta sendo 34\% heterossexual, 28\% de UDI e 15\% de HSH. Dos heterossexuais deste grupo, foram do sexo feminino 69\% e masculino 31\%, Figura 10.

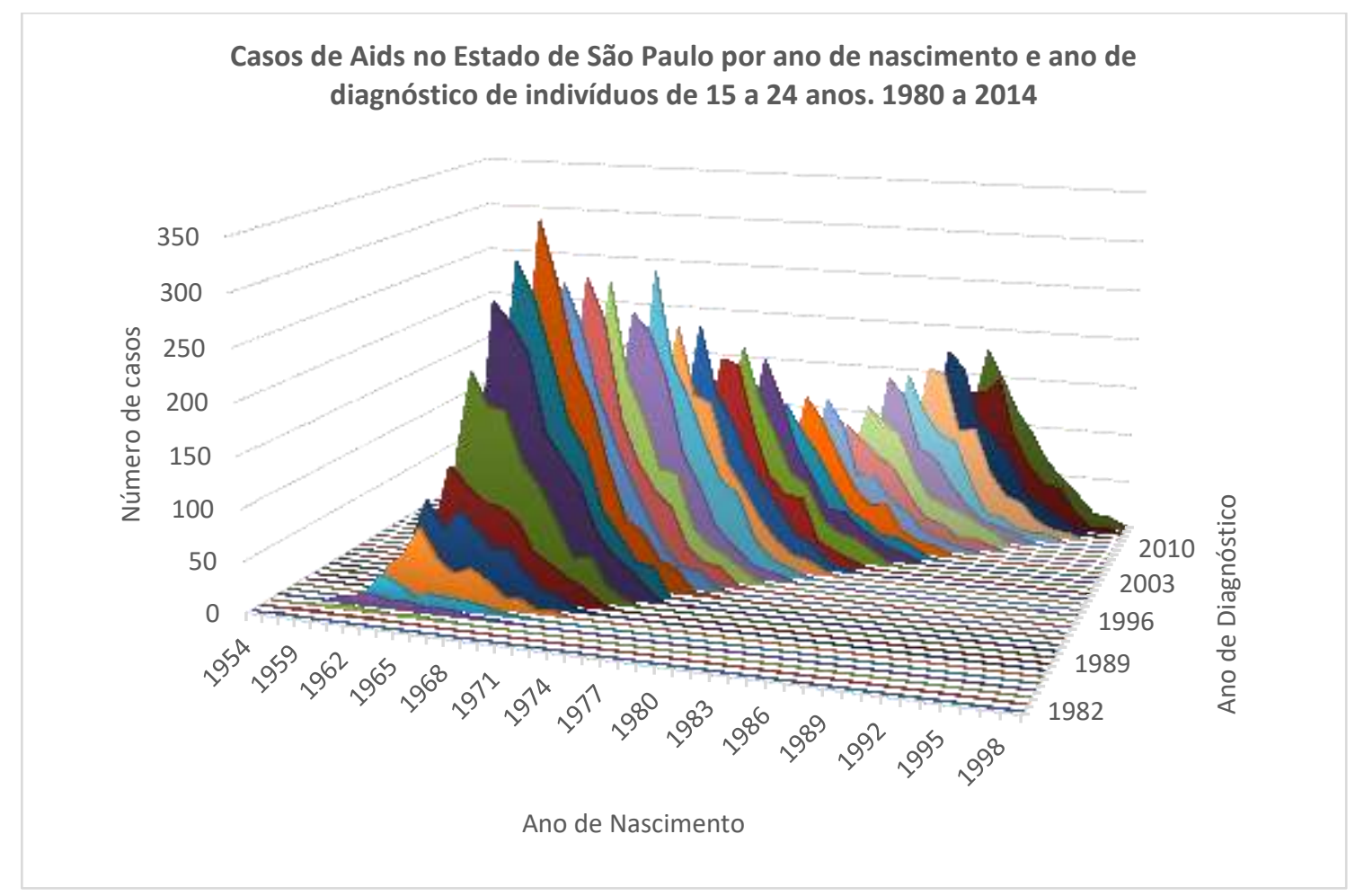

Fonte: O Autor

Figura 10 - Casos de Aids no Estado de São Paulo por ano de nascimento e ano de diagnóstico de indivíduos de 15 a 24 anos. Estado de São Paulo - 1980 a 2014

Quando calculamos a frequência relativa, para avaliar o crescimento de casos em relação ao ano anterior, verifica-se que, iniciando a partir de 1983 em relação à 1982, tem subsequentemente, os seguintes valores nos primeiros cinco anos da epidemia: 
Tabela 13 - Percentual de crescimento de casos de Aids em relação ao ano anterior, São Paulo, 1983 a 1987

\begin{tabular}{c|c|}
\hline ANO & Percentual \\
\hline $\mathbf{1 9 8 3}$ & $83 \%$ \\
\hline $\mathbf{1 9 8 4}$ & $74 \%$ \\
\hline $\mathbf{1 9 8 5}$ & $73 \%$ \\
\hline $\mathbf{1 9 8 6}$ & $56 \%$ \\
\hline $\mathbf{1 9 8 7}$ & $61 \%$ \\
\hline Fonte: O Autor & \\
\hline
\end{tabular}

Ao longo dos anos seguintes a taxa de frequência relativa apresentou queda, entretanto alcançou índice menor que $10 \%$ apenas em 1998, quando os casos de Aids neste ano chegaram a 1.157, com 12.108 casos acumulados até esse momento.

Ao observar a Figura 11, nota-se o avanço da epidemia no Estado, onde apenas em 1994 obteve-se registro menor do que o apresentado no ano anterior. Nos anos de 1996 e 1997 ocorreu certa estabilidade na notificação de novos casos e nota-se queda nos índices entre os anos de 1999 e 2007. O detalhamento da Figura 11 pode ser observado no Anexo 3, onde consta a distribuição de casos de Aids ao longo dos anos e a divisão por gerações.

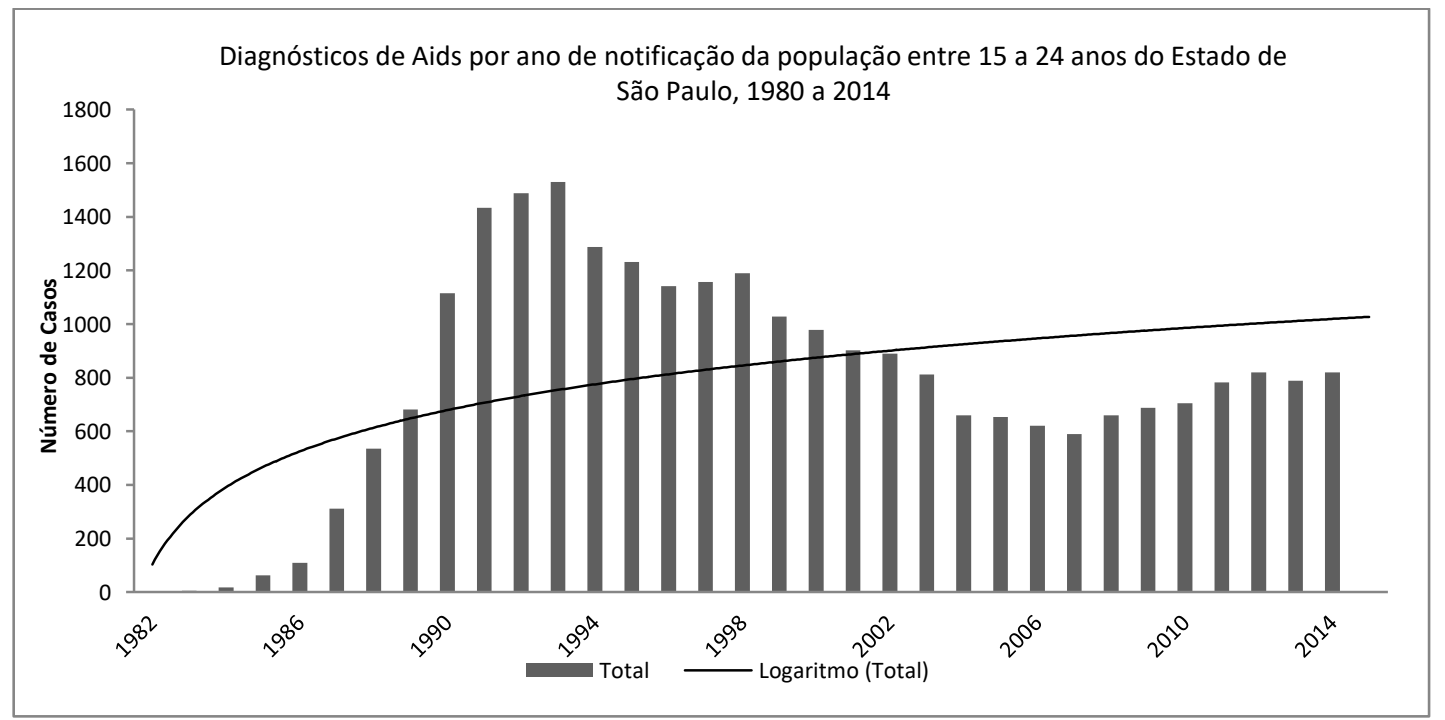

Fonte: Fonte: (32)

Figura 11 - Diagnósticos de Aids por ano de notificação da população entre 15 a 24 anos do Estado de São Paulo, 1980 a 2014

Em suma, percebe-se que nos últimos 30 anos, ocorreu o maior índice de diagnósticos de indivíduos de 15 a 24 anos, geração nascida entre o final dos anos 1960 e a metade dos 1970 . 
Ao colocar em foco a distribuição de casos de Aids por sexo na população estudada, observa-se a predominância de casos em indivíduos do sexo masculino, conforme demonstrado na Figura 13. Quando tabulamos a distribuição dos casos por sexo e categoria de exposição hierarquizada, considerando os dados com esse registro no banco relacionado, percebe-se que no início da epidemia, casos do sexo masculino e categoria de exposição HSH apresentava um índice maior de casos. Entretanto, ao longo do período, indivíduos caracterizados como exposição heterossexual cresceu em relação percentual (Fonte: (32) Figura 13).

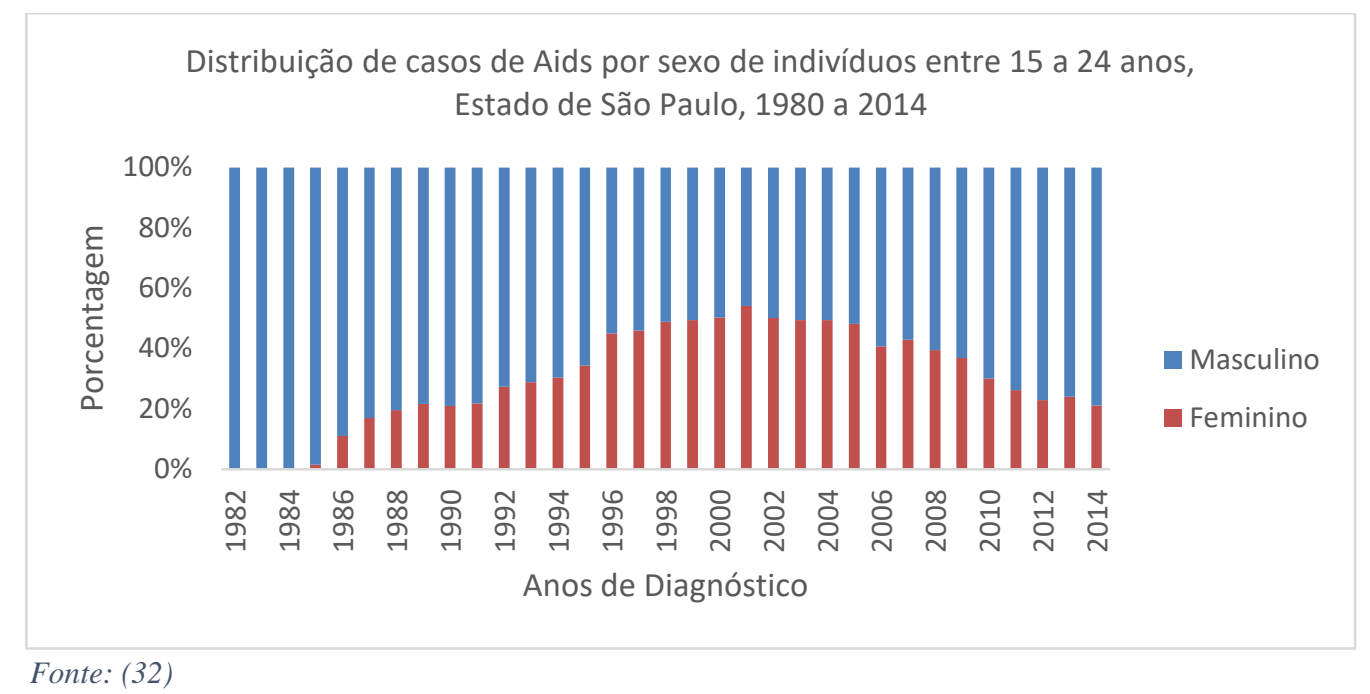

Figura 12 - Distribuição de casos de Aids por sexo de indivíduos entre 15 a 24 anos, Estado de São Paulo, 1980 a 2014

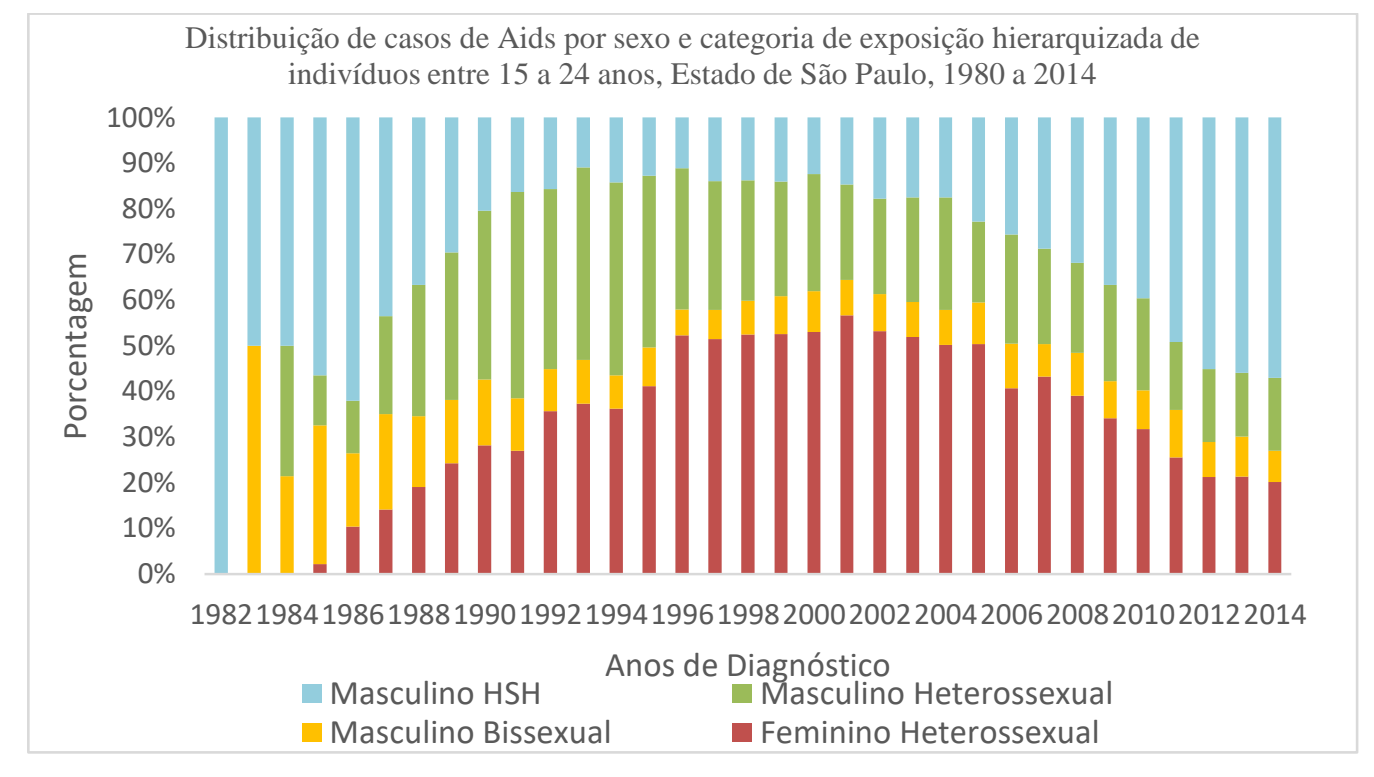

Fonte: (32)

Figura 13 - Distribuição de casos de Aids por sexo e categoria de exposição hierarquizada de indivíduos entre 15 a 24 anos, Estado de São Paulo, 1980 a 2014 
Para melhor compreensão da curva que cada categoria do sexo masculino percorreu, apresenta-se na Fonte: (33) Figura 14 essa evolução. Observando o ano de 1989, homens declarados heterossexuais tinham maior prevalência do que os homens que declaram fazer sexo com homens (HSH). Apenas em 2005 essa tendência se reverteu, tornando novamente $\mathrm{HSH}$ como o grupo mais acometido em relação aos demais.

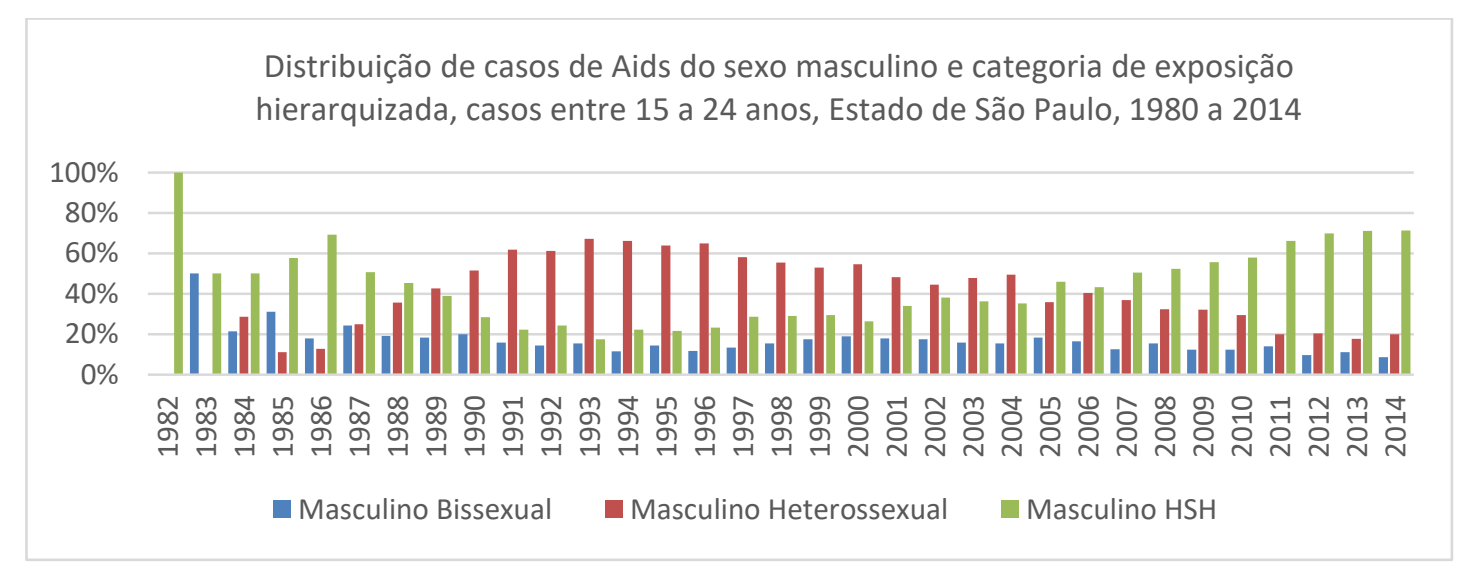

Fonte: (33)

Figura 14 - Distribuição de casos de Aids do sexo masculino e categoria de exposição hierarquizada de indivíduos entre 15 a 24 anos, Estado de São Paulo, 1980 a 2014

Em 1986, abordando essas três categorias, 69\% dos casos eram de HSH (Homens que fazem sexo com Homens) contra 13\% de Homens Heterossexuais (HSM - Homens que fazem sexo com Mulheres). No ano de 1989 observa-se que HSH representava 39\% de casos enquanto que HSM 43\%. Nos anos de 1993, 94 e 95 encontram-se, respectivamente, para HSH 17\%, 22\% e 22\% de casos e para HSM 67\%, 66\% e 64\%. Este cenário muda em 2007 quando se identifica indivíduos HSH com 51\% e HSM com 37\%, onde novamente HSM passa a ter mais casos do que outras categorias do sexo masculino ao longo dos anos subsequentes. Os dados de 2014 apontam para $71 \%$ de indivíduos HSH e $20 \%$ em HSM. Cabe aqui ressaltar que, para Homens Bissexuais, a média geral de todos os anos é de $15 \%$ dos casos.

Direcionando a atenção para a questão das Gerações, a Figura 15 e a Tabela 14 nos apresentam um cenário muito similar quando comparado às análises da população geral. Nos primeiros anos de manifestação da Aids, que acometeu a geração Baby boomer, os casos do sexo masculino prevaleciam, e o comportamento das demais gerações se mostra estável. 


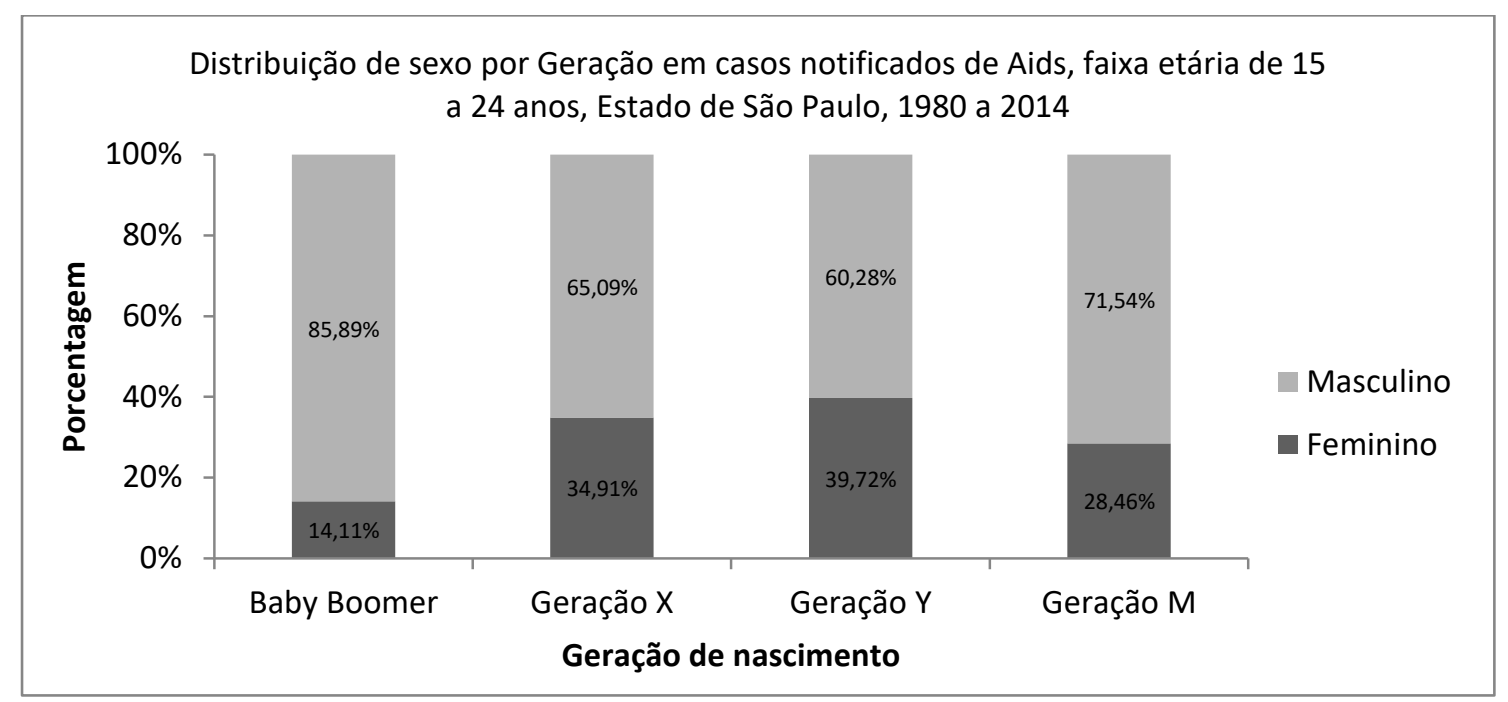

Fonte: (33)

Figura 15 - Distribuição de sexo por Geração em casos notificados de Aids, faixa etária de 15 a 24 anos, Estado de São Paulo, 1980 a 2014

Tabela 14 - Distribuição de sexo por Geração em casos notificados de Aids, faixa etária de 15 a 24 anos, Estado de São Paulo, 1980 a 2014

\begin{tabular}{c|c|c|c}
\hline \multirow{2}{*}{ Geração } & \multicolumn{2}{|c|}{ Sexo } & \multirow{2}{*}{ Total } \\
& Feminino & Masculino & \\
\hline Baby boomer & 34 & 207 & 241 \\
Geração X & 5626 & 10492 & 16118 \\
Geração Y & 2768 & 4201 & 6969 \\
Geração M & 641 & 1611 & 2252 \\
\hline Total & $\mathbf{9 0 6 9}$ & $\mathbf{1 6 5 1 1}$ & $\mathbf{2 5 5 8 0}$ \\
\hline
\end{tabular}

Fonte: O Autor

No aspecto de escolaridade, focando na Geração X e Geração Y, percebe-se que a quantidade de anos de estudo nessa população aumentou. Da Geração X 15\% tinham entre 8 a 11 anos de estudo, enquanto na Geração Y observa-se que 37\% dos casos relatados com essa informação, tinham essa mesma escolaridade (Fonte: (33) Figura 16). 


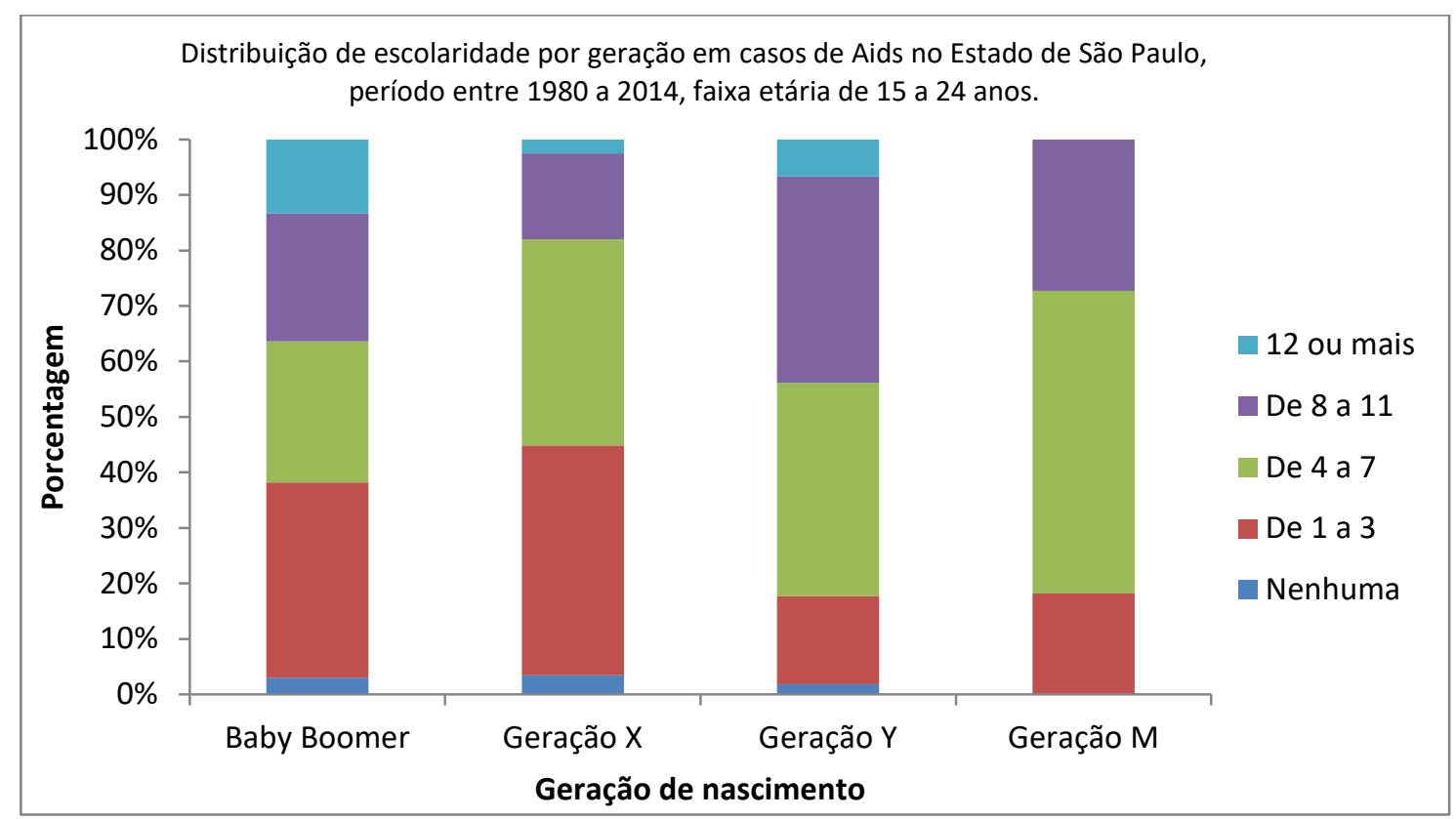

Fonte: (33)

Figura 16 - Distribuição de escolaridade por geração em casos de Aids no Estado de São Paulo, período entre 1980 a 2014, faixa etária de 15 a 24 anos

Tabela 15 - Distribuição de escolaridade por geração em casos de Aids no Estado de São Paulo, período entre 1980 a 2014, faixa etária de 15 a 24 anos.

\begin{tabular}{|l|c|c|c|c|c|}
\hline \multicolumn{1}{|c|}{$\begin{array}{c}\text { Geração / } \\
\text { Escolaridade }\end{array}$} & Nenhuma & De 1 a 3 & De 4 a 7 & De 8 a 11 & 12 ou mais \\
\hline Baby boomer & $3,03 \%$ & $35,15 \%$ & $25,45 \%$ & $23,03 \%$ & $13,33 \%$ \\
\hline Geração X & $3,48 \%$ & $41,37 \%$ & $37,15 \%$ & $15 \%$ & $2,51 \%$ \\
\hline Geração Y & $1,81 \%$ & $15,90 \%$ & $38,43 \%$ & $37 \%$ & $6,71 \%$ \\
\hline Geração M & $0,00 \%$ & $18,18 \%$ & $54,55 \%$ & $27,27 \%$ & $0,00 \%$ \\
\hline
\end{tabular}

Com relação à Categoria de Exposição Hierarquizada, para cada geração analisada, observa-se queda na categoria UDI (usuários de drogas injetáveis), apresentando-se com 34\% na Geração Baby boomer e $41 \%$ na Geração X, enquanto que nas Gerações subsequentes, Y e M, apresentam-se com $6 \%$ e 3\% respectivamente (Figura 17). Este dado pode estar associado às políticas de redução de danos que serão abordadas nos próximos capítulos. 


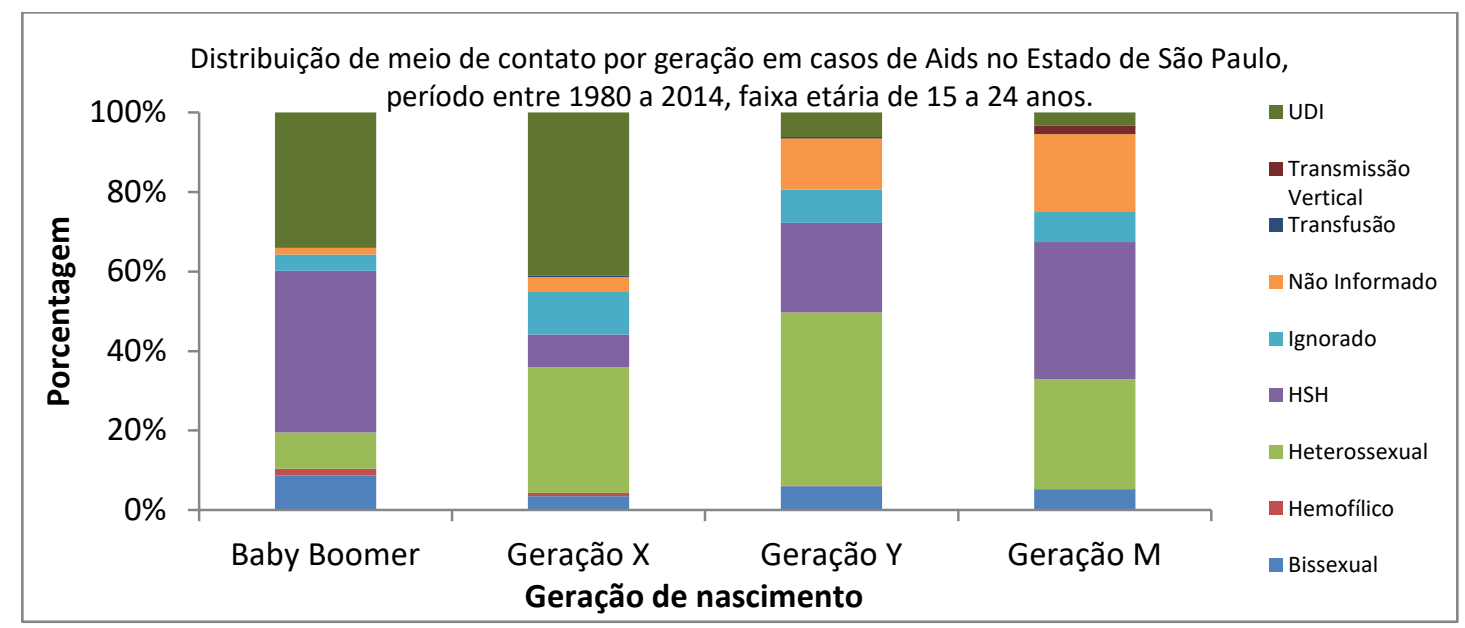

Fonte: $O$ Autor

Figura 17 - Distribuição de meio de contato por geração em casos de Aids no Estado de São Paulo, período entre 1980 a 2014, faixa etária de 15 a 24 anos

Tabela 16 - Distribuição de meio de contato por geração em casos de Aids no Estado de São Paulo, período entre 1980 a 2014, faixa etária de 15 a 24 anos.

\begin{tabular}{|l|c|c|c|c|c|c|c|c|c|}
\hline $\begin{array}{l}\text { Geração/ } \\
\text { Exposição }\end{array}$ & Bissexual & Hemofílico & Heterossexual & HSH & Ignorado & $\begin{array}{c}\text { Não } \\
\text { informado }\end{array}$ & Transfusão & $\begin{array}{c}\text { Transmissão } \\
\text { Vertical }\end{array}$ & UDI \\
\hline Baby boomer & $8,71 \%$ & $2 \%$ & $9 \%$ & $41 \%$ & $4 \%$ & $2 \%$ & $0 \%$ & $0 \%$ & $34 \%$ \\
\hline Geração X & $3,50 \%$ & $1 \%$ & $32 \%$ & $8 \%$ & $11 \%$ & $4 \%$ & $0 \%$ & $0 \%$ & $41 \%$ \\
\hline Geração Y & $5,98 \%$ & $0 \%$ & $44 \%$ & $23 \%$ & $8 \%$ & $13 \%$ & $0 \%$ & $0 \%$ & $6 \%$ \\
\hline Geração M & $5,28 \%$ & $0 \%$ & $28 \%$ & $35 \%$ & $8 \%$ & $20 \%$ & $0 \%$ & $2 \%$ & $3 \%$ \\
\hline
\end{tabular}

Fonte: $O$ Autor

\subsection{O Estado de São Paulo e a Aids em síntese}

Nas últimas três décadas, aproximadamente $65 \%$ dos diagnósticos de Aids na população jovem era do sexo masculino, sendo a população masculina maioria em quase todos os anos. As exceções são registradas nos anos de 2000, 2001 e 2002 em que, comparados aos registros de casos o sexo feminino apresentou-se com 5; 76 e 2 casos de Aids a mais do que os registros masculinos, respectivamente. Destaca-se, também, o período entre 1995 e 2005, no qual o número de diagnósticos em homens e mulheres era o similar.

Analisando a cor de pele, menos da metade dos 25 mil indivíduos presentes no banco de dados tem a cor registrada - apenas 11,5 mil. Destes, $60 \%$ se declararam como brancos, $24 \%$ como pardos, $8 \%$ como pretos, $7 \%$ não declararam e menos de $1 \%$ se declararam amarelo e/ou indígena. Ao longo dos anos, nota-se que a população parda 
cresceu a cada ano, enquanto a parcela de 'Ignorados' decrescia. Os percentuais de brancos e pretos se mantiveram perenes nestes 30 anos.

Quanto à escolaridade, nota-se que o perfil mudou completamente dos indivíduos diagnosticados nos anos 80 até 2014. A parcela da população com três ou menos anos de escolaridade chegou a ultrapassar 40\%, mas atualmente é inferior a 5\% e aproximadamente $70 \%$ dos indivíduos diagnosticados tem 8 ou mais anos de escolaridade. $50-55 \%$ tem entre 8-11 anos de escolaridade, $15-20 \%$ tem entre 12 ou mais de escolaridade), sendo que, até 1997 , menos de $15 \%$ da população tinha esse perfil.

Para a categoria de exposição hierarquizada, pouco mais da metade dos indivíduos se enquadra na categoria heterossexual $(51,1 \%)$, mas nota-se que, para as gerações Baby boomer e M, a maior parcela dos diagnósticos ocorreu em indivíduos Homens que fazem sexo com Homens (HSH). Também se destaca o fato de que a categoria de Usuários de Drogas Injetáveis (UDI), bastante presente para as gerações Baby boomer e X (quase 20\%), basicamente não aparece mais para as duas gerações mais recentes.

A Figura 18 apresenta um resumo dos dados cedidos pela Vigilância Epidemiológica CRT-SP, do período entre 1980 a 2014, com indivíduos jovens e jovens adultos entre 15 a 24 anos de idade com diagnóstico de Aids, notificados nos sistemas que compõem o Banco de Dados Relacionado.

\begin{tabular}{|c|c|c|c|c|c|c|}
\hline População & $\begin{array}{c}\text { Tamanho } \\
(\mathbf{n} .)\end{array}$ & Média & $\begin{array}{l}\text { Desvio } \\
\text { Padrão } \\
\end{array}$ & Mínimo & Mediana & Máximo \\
\hline Total & 25693 & & & & & \\
\hline Idade & & 21,66 & 2,18 & 15 & 22 & 24 \\
\hline Sexo & & & & & & \\
\hline Masculino & 16567 & & & & & \\
\hline Feminino & 9125 & & & & & \\
\hline Cor & & & & & & \\
\hline Branca & 7503 & & & & & \\
\hline Preta & 2994 & & & & & \\
\hline Parda & 1024 & & & & & \\
\hline Outros & 963 & & & & & \\
\hline Escolaridade & & & & & & \\
\hline Nenhuma & 504 & & & & & \\
\hline 1 a 3 & 5750 & & & & & \\
\hline 4 a 7 & 6761 & & & & & \\
\hline 8 a 11 & 6027 & & & & & \\
\hline 12 ou mais & 1339 & & & & & \\
\hline Ignorado & 4124 & & & & & \\
\hline
\end{tabular}

Figura 18 - Quadro resumo dos dados do Banco de Dados Relacionado da Vigilância Epidemiológica CRT-SP, 1980 a 2014, São Paulo 
Percebe-se que na distribuição pela idade, o indivíduo tinha no momento da notificação, pouca variação na média dentro das categorias de cada variável. Isso indica que, dentre os jovens de 15 a 24 anos, a idade não aparenta variar para diferentes cores de pele, níveis de escolaridade e gêneros.

Analisando a Figura 109 (complemento do Anexo 3), observa-se que no primeiro ano em que indivíduos da Geração X obtiveram notificação de Aids (mediana de idade para Geração X sendo 18 e para geração Baby boomer 22,5) obtendo como percentagem $71 \%$ para geração Baby boomer e $29 \%$ para geração X. No último ano de registro para indivíduos da geração Baby boomer (idade entre 19 e 24 anos nascidos no ano de 1963), observa-se que $10 \%$ dos casos são desta geração, enquanto que $90 \%$ dos casos são da geração X (indivíduos nascidos a partir de 1964 com idades entre 15 e 24 anos).

Avaliando esse mesmo elemento em comparação às gerações $\mathrm{X}$ e $\mathrm{Y}$, no primeiro ano em que as gerações coexistem, 1996, contam 99\% dos casos da geração X e 1\% da geração Y. E no último ano de análise com essas duas gerações coexistindo, em 2005, os percentuais estatísticos se invertem, tendo $1 \%$ da geração X e $99 \%$ da geração Y. No ano seguinte, temos a presença da geração $\mathrm{Y}$ e geração $\mathrm{M}$, com percentuais respectivos de $98 \%$ e $2 \%$. Em uma leitura sobre esses dados, observa-se que indivíduos mais jovens, entre 15 e 16 anos são menos acometidos pelo evento da Aids em comparação com as demais faixas etárias detalhadas analisadas.

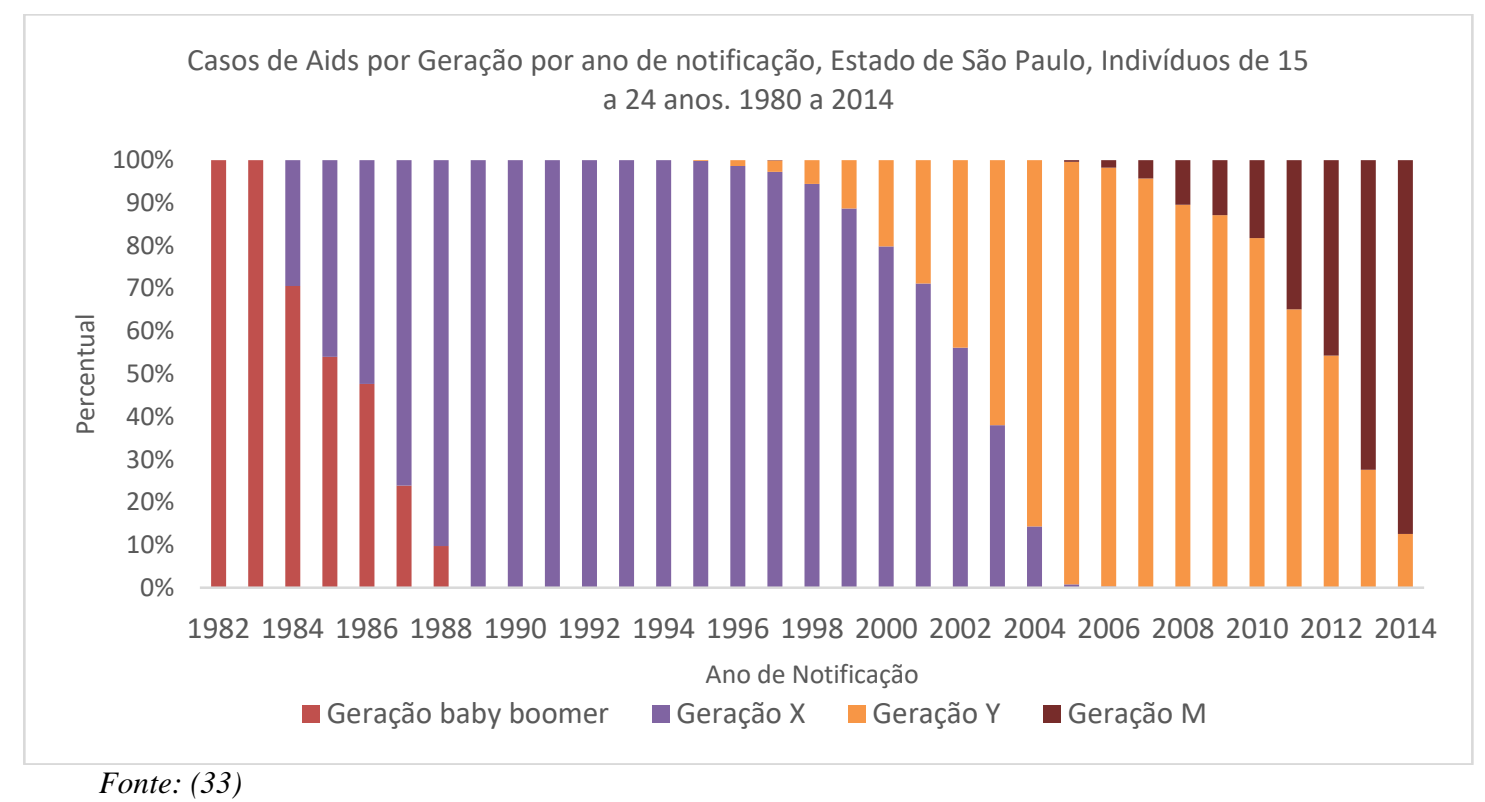

Figura 19 - Casos de Aids por Geração por ano de notificação, Estado de São Paulo, Indivíduos de 15 a 24 anos. 1980 a 2014 
A partir desse retrato do Estado de São Paulo, vamos considerar os dados da Região Metropolitana e, em seguida, do Município de São Paulo como base para as discussões e reflexões deste estudo.

\subsubsection{Teste de associação}

Considerando a análise dos dados agrupados por gerações, aplicando o teste de associação e segmentando algumas variáveis, compreende-se o comportamento dos dados em algumas caracterizações.

Tabela 17 - Distribuição de frequências e resultados do teste qui-quadrado das variáveis socioeconômicas e demográficas em relação as gerações dos casos notificados de Aids, faixa etária de 15 a 24 anos, Estado de São Paulo, 1980 a 2014.

\begin{tabular}{|c|c|c|c|c|c|c|}
\hline \multirow[b]{2}{*}{ Variável } & \multicolumn{4}{|c|}{ Geração } & \multicolumn{2}{|c|}{ Teste $\chi^{2}$} \\
\hline & Baby boomer & $\mathbf{X}$ & $\mathbf{Y}$ & $\mathbf{M}$ & $\chi^{2}$ & $\begin{array}{c}\text { Valor } \\
\mathbf{p}\end{array}$ \\
\hline Sexo & & & & & 153,59 & $<0,001$ \\
\hline Feminino & $34(14,1 \%)$ & $5626(34,9 \%)$ & $2768(39,7 \%)$ & $641(28,5 \%)$ & & \\
\hline Masculino & $207(85,9 \%)$ & $10492(65,1 \%)$ & $4201(60,3 \%)$ & $1611(71,5 \%)$ & & \\
\hline Cor & & & & & 185,09 & $<0,001$ \\
\hline Branca & $11(61,1 \%)$ & $2398(63,6 \%)$ & $3911(60,4 \%)$ & $1143(53,4 \%)$ & & \\
\hline Parda & $4(22,2 \%)$ & $702(18,6 \%)$ & $1580(24,4 \%)$ & $689(32,2 \%)$ & & \\
\hline Preta & $1(5,6 \%)$ & $293(7,8 \%)$ & $545(8,4 \%)$ & $180(8,4 \%)$ & & \\
\hline Amarela & $0(0 \%)$ & $21(0,6 \%)$ & $25(0,4 \%)$ & $17(0,8 \%)$ & & \\
\hline Indígena & $0(0 \%)$ & $5(0,1 \%)$ & $13(0,2 \%)$ & $4(0,2 \%)$ & & \\
\hline Não informado/Ignorado & $2(11,1 \%)$ & $353(9,4 \%)$ & $406(6,3 \%)$ & $107(5 \%)$ & & \\
\hline Idade & & & & & 1298,39 & $<0,001$ \\
\hline De 15 a 18 anos & $2(0,8 \%)$ & $1260(7,8 \%)$ & $780(11,2 \%)$ & $549(24,4 \%)$ & & \\
\hline De 19 a 21 anos & $12(5 \%)$ & $4358(27 \%)$ & $2023(29 \%)$ & $1029(45,7 \%)$ & & \\
\hline De 22 a 24 anos & $227(94,2 \%)$ & $10500(65,1 \%)$ & $4166(59,8 \%)$ & $674(29,9 \%)$ & & \\
\hline Escolaridade & & & & & 5062,58 & $<0,001$ \\
\hline De 1 a 3 anos & $58(24,5 \%)$ & $5165(33,4 \%)$ & $459(6,8 \%)$ & $57(2,7 \%)$ & & \\
\hline De 4 a 7 anos & $43(18,1 \%)$ & $4754(30,8 \%)$ & $1609(23,9 \%)$ & $341(16,4 \%)$ & & \\
\hline De 8 a 11 anos & $40(16,9 \%)$ & $2089(13,5 \%)$ & $2791(41,5 \%)$ & $1080(51,9 \%)$ & & \\
\hline 12 anos ou mais & $23(9,7 \%)$ & $350(2,3 \%)$ & $699(10,4 \%)$ & $265(12,7 \%)$ & & \\
\hline Não informado/Ignorado & $73(30,8 \%)$ & $3083(20 \%)$ & $1164(17,3 \%)$ & $336(16,2 \%)$ & & \\
\hline Categoria de exposição & & & & & 4960,71 & $<0,001$ \\
\hline Bissexual & $33(13,7 \%)$ & $996(6,2 \%)$ & $454(6,5 \%)$ & $122(5,4 \%)$ & & \\
\hline Hemofílico & $4(1,7 \%)$ & $125(0,8 \%)$ & $9(0,1 \%)$ & $0(0 \%)$ & & \\
\hline Heterossexual & $22(9,1 \%)$ & $5105(31,7 \%)$ & $3037(43,6 \%)$ & $622(27,6 \%)$ & & \\
\hline $\mathrm{HSH}$ & $98(40,7 \%)$ & $1324(8,2 \%)$ & $1572(22,6 \%)$ & $778(34,5 \%)$ & & \\
\hline Transfusão & $0(0 \%)$ & $36(0,2 \%)$ & $2(0 \%)$ & $0(0 \%)$ & & \\
\hline Transmissão Vertical & $0(0 \%)$ & $0(0 \%)$ & $18(0,3 \%)$ & $48(2,1 \%)$ & & \\
\hline UDI & $70(29 \%)$ & $6193(38,4 \%)$ & $393(5,6 \%)$ & $71(3,2 \%)$ & & \\
\hline Não informado/Ignorado & $14(5,8 \%)$ & $2339(14,5 \%)$ & $1484(21,3 \%)$ & $611(27,1 \%)$ & & \\
\hline Total & $241(100 \%)$ & $16118(100 \%)$ & $6969(100 \%)$ & $2252(100 \%)$ & - & - \\
\hline
\end{tabular}

Fonte: $O$ Autor 
Observa-se na Tabela 17 que, para todas as gerações, a maior parte dos casos notificados de Aids são referentes aos indivíduos do sexo masculino, sobretudo para a geração baby boomer, para qual mais de $85 \%$ dos indivíduos são homens. Em relação à cor, mais da metade dos casos de Aids foram notificados para pessoas da cor branca em todas as gerações. Entretanto, nota-se que tal porcentagem diminui ao longo das gerações, passando de $61,1 \%$ na geração baby boomer para 53,4\% na geração $\mathrm{M}$, sendo que as porcentagens de indivíduos das cores parda, preta, amarela e indígena aumentaram.

Considerando a geração baby boomer, quase metade dos casos foram notificados para indivíduos entre 22 e 24 anos de idade, sendo poucos os casos aqueles com idade inferior a 18 anos. Tal situação inverte-se ao longo das gerações, sendo observada uma porcentagem cada vez maior de casos em indivíduos entre 15 e 18 anos e entre 19 e 21 anos. Nota-se que nas duas primeiras gerações (baby boomer e X), a maior parte das pessoas notificadas tinham até sete anos de estudo ou sua escolaridade não notificada/ignorada. Por sua vez, nas gerações posteriores ( $\mathrm{Y}$ e M), mais da metade das notificações referem-se às pessoas com mais de 8 anos de estudo.

Quanto a categoria de exposição hierarquizada, a mais frequente na geração baby boomer é a categoria HSM (Homens que fazem sexo com Homens), seguida pela UDI (usuários de drogas injetáveis), correspondendo a 40,7\% e 29\% dos indivíduos notificados de tal geração, respectivamente. Por outro lado, na geração X, a UDI $(38,4 \%)$ e Heterossexual (31,7\%) são as categorias de exposição mais frequente, enquanto que na geração Y, há uma predominância da categoria Heterossexual $(43,6 \%)$. Por fim, considerando a geração $M$, vê-se uma alta frequência de notificações em que a categoria de exposição é HSH (34,5\%), Heterossexual $(27,6 \%)$ ou não informada/ignorada $(27,1 \%)$. Ainda, observa-se que todas as variáveis em questão estão significativamente associadas a geração dos indivíduos, ao nível de 5\% de significância (valores $\mathrm{p}<0,001$ ).

\subsubsection{Regras de associação}

A Tabela 18 apresenta as regras de associação mineradas do conjunto de dados referente aos casos de Aids notificados no estado de São Paulo. Nota-se que quase um quarto dos casos notificados de Aids no Estado de São Paulo são da categoria de exposição UDI e da geração X e mais de um quinto são da categoria de exposição UDI 
e do sexo masculino, sendo que dentre aqueles em que a exposição é UDI, 91,9\% são da geração X e 77,9\% são do sexo masculino, ao passo que entre as pessoas da categoria de exposição UDI e do sexo masculino, 93,2\% são da geração X.

Nota-se também que entre os indivíduos com escolaridade de 1 a 3 anos e de 4 a 7 anos, $89,8 \%$ e $70,3 \%$ são da geração X, respectivamente. $93,6 \%$ dos casos referentes aos indivíduos com idade entre 22 e 24 anos e categoria de exposição UDI, são da geração X e 78,7\% são do sexo masculino. Ainda, entre as notificações da geração X e categoria de exposição Heterossexual, $70,8 \%$ e 70,1\% são do sexo feminino e de idade entre 22 e 24 anos, respectivamente.

Também é possível notar que entre os homens com 1 a 3 anos de estudo, ou entre indivíduos com 22 a 24 anos de idade e 1 a 3 anos de estudo, a grande maioria é da geração X $(92,6 \%)$, da mesma forma que entre entre os homens com 4 a 7 anos de estudo e entre os indivíduos com 22 a 24 anos de idade e 4 a 7 anos de estudo, para os quais $74,5 \%$ e 76,5\% são da geração X, respectivamente. Por fim, vê-se que dos homens com 22 a 24 anos e categoria de exposição UDI, 94,3\% são da geração X, ao passo que dos indivíduos com 1 a 3 anos de estudo e exposição UDI, 96,1\% também são da geração X.

Tabela 18 - Regras de associação e suas respectivas medidas dos casos notificados de Aids, faixa etária de 15 a 24 anos, Estado de São Paulo, 1980 a 2014.

\begin{tabular}{|c|c|c|c|c|}
\hline \multicolumn{3}{|l|}{ Regras } & \multirow{2}{*}{$\frac{\text { Suporte }}{0,241}$} & \multirow{2}{*}{$\frac{\text { Confiança }}{0,919}$} \\
\hline Exposição = UDI & $\rightarrow$ & Geração $=$ X & & \\
\hline Exposição = UDI & $\rightarrow$ & Sexo $=M$ & 0,204 & 0,779 \\
\hline Escolaridade $=$ de 1 a 3 anos & $\rightarrow$ & Geração $=\mathrm{X}$ & 0,201 & 0,898 \\
\hline Sexo = M e Exposição = UDI & $\rightarrow$ & Geração = X & 0,190 & 0,932 \\
\hline Escolaridade $=$ de 4 a 7 anos & $\rightarrow$ & Geração = X & 0,185 & 0,703 \\
\hline Idade $=$ de 22 a 24 anos e Exposição = UDI & $\rightarrow$ & Geração $=X$ & 0,145 & 0,936 \\
\hline Geração = X e Exposição = Heterossexual & $\rightarrow$ & Sexo $=F$ & 0,141 & 0,708 \\
\hline Geração = X e Exposição = Heterossexual & $\rightarrow$ & Idade $=$ de 22 a 24 anos & 0,139 & 0,701 \\
\hline Sexo $=$ M e Escolaridade $=$ de 1 a 3 anos & $\rightarrow$ & Geração = X & 0,134 & 0,926 \\
\hline Idade $=$ de 22 a 24 anos e Escolaridade $=$ de 1 a 3 anos & $\rightarrow$ & Geração $=X$ & 0,125 & 0,926 \\
\hline Idade $=$ de 22 a 24 anos e Escolaridade $=$ de 4 a 7 anos & $\rightarrow$ & Geração $=X$ & 0,122 & 0,765 \\
\hline Idade $=$ de 22 a 24 anos e Exposição $=$ UDI & $\rightarrow$ & Sexo $=M$ & 0,122 & 0,787 \\
\hline Sexo $=$ M e Escolaridade $=$ de 4 a 7 anos & $\rightarrow$ & Geração = X & 0,116 & 0,745 \\
\hline Sexo $=$ M e Idade $=$ de 22 a 24 anos e Exposição $=$ UDI & $\rightarrow$ & Geração $=$ X & 0,115 & 0,943 \\
\hline Escolaridade $=$ de 1 a 3 anos e Exposição = UDI & $\rightarrow$ & Geração $=$ X & 0,100 & 0,961 \\
\hline
\end{tabular}

Fonte: $O$ Autor 
Especificamente para a geração baby boomer, vê-se que dentre os homens, $94,2 \%$ tem entre 22 e 24 anos, sendo que estas duas características são observadas em 80,9\% das notificações. Entre as notificações cuja categoria de exposição é HSM, UDI, que não houve informação de escolaridade ou é de 1 a 3 anos de estudo, 94,9\%, 92,9\%, $94,5 \%$ e 96,6\% possuem entre 22 e 24 anos, respectivamente. Por outro lado, os indivíduos com categoria de exposição UDI, escolaridade não informada ou de 1 a 3 anos de estudo, $82,2 \%, 72,9 \%$ e $84,5 \%$ são homens, respectivamente.

Considerando a geração $\mathrm{X}$, observa-se que entre os casos notificados com categoria de exposição UDI, 79\% são homens, ao passo que entre os casos com categoria de exposição Heterossexual 70,8\% são mulheres e 70,1\% tem entre 22 e 24 anos de idade. Entre as mulheres da geração Y notificadas, 74,7\% tem Heterossexual por categoria de exposição, sendo que esta combinação de fatores é observada em $29,7 \%$ dos casos desta geração. A geração $M$ revelou que referente à cor branca, escolaridade de 8 a 11 anos, idade entre 19 a 21 anos ou entre 22 a 24 anos, 73,7\%, $71,9 \%, 73,9 \%$ e $81,0 \%$ são do sexo masculino, respectivamente, com observado na Tabela 19.

Tabela 19 - Regras de associação por geração e suas respectivas medidas dos casos notificados de Aids, faixa etária de 15 a 24 anos, Estado de São Paulo, 1980 a 2014.

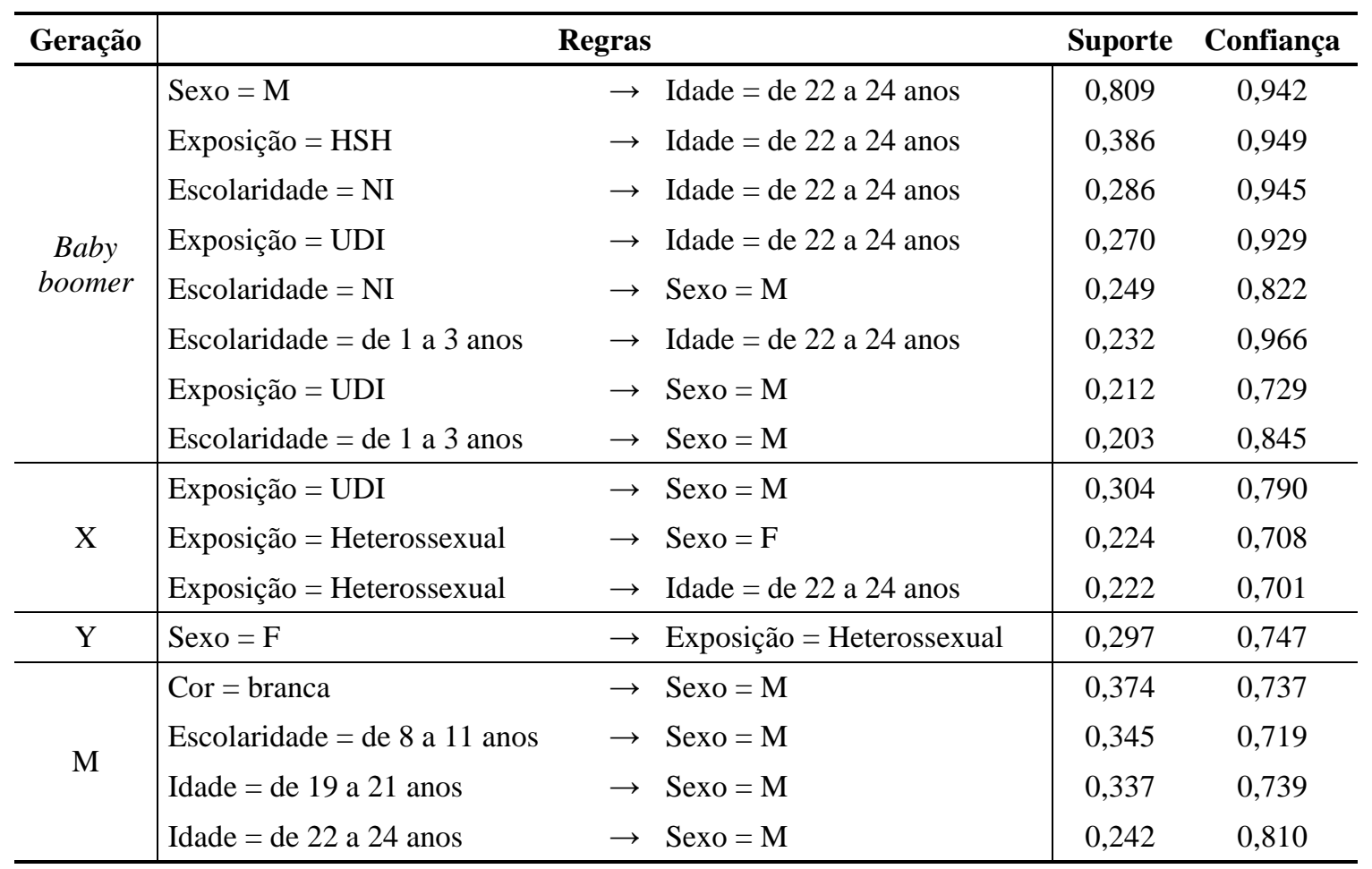

Fonte: O Autor 


\section{UM PANORAMA DA AIDS NA REGIÃO METROPOLITANA DE SÃO PAULO}

A Região Metropolitana de São Paulo é composta por 39 municípios e, atualmente, é dividida em sub-regiões baseadas nos pontos cardeais. A composição desta região segue(68):

- Central: São Paulo

- Leste: Arujá, Biritiba-Mirim, Ferraz de Vasconcelos, Guararema, Guarulhos, Itaquaquecetuba, Mogi das Cruzes, Poá, Salesópolis, Santa Isabel e Suzano.

- Norte: Caieiras, Cajamar, Francisco Morato, Franco da Rocha e Mairiporã.

- Oeste: Barueri, Carapicuíba, Itapevi, Jandira, Osasco, Pirapora do Bom Jesus e Santana de Parnaíba.

- Sudeste: Diadema, Mauá, Ribeirão Pires, Rio Grande da Serra, Santo André, São Bernardo do Campo e São Caetano do Sul.

- Sudoeste: Cotia, Embu, Embu-Guaçu, Itapecerica da Serra, Juquitiba, São Lourenço da Serra, Taboão da Serra e Vargem Grande Paulista.

Segundo dados do IBGE, nos dados de 2015, a Região Metropolitana contempla $50 \%$ da população do Estado de São Paulo(68), o que evidencia sua importância para as políticas públicas de saúde.

O principal objetivo do presente capítulo é traçar um perfil da Região Metropolitana de São Paulo para compreender a evolução da epidemia de Aids e identificar fatores que possam ter motivado políticas de enfrentamento à epidemia.

\subsection{Um recorte da Região Metropolitana Paulista.}

Como relatado no capítulo sobre o Estado de São Paulo, o primeiro diagnóstico de Aids ocorreu no ano de 1982. Este caso é oriundo do município de Osasco, região 
fronteiriça com o munícipio de São Paulo. Os 5 casos registrados no ano seguinte ocorreram 1 em São Bernardo do Campo e 4 no Município de São Paulo. Dos 17 casos do ano de 1984, 10 ocorreram na Região Metropolitana de São Paulo e os demais 7 no município do interior Paulista.

A Região Metropolitana é o retrato inicial do surgimento da Aids no Estado, e reflexo do histórico do país para a História do HIV/Aids. Ao observar a Figura 20 podemos notar a semelhança do comportamento dos dados com relação à Figura 11, que demostrava a evolução das notificações no Estado de São Paulo.

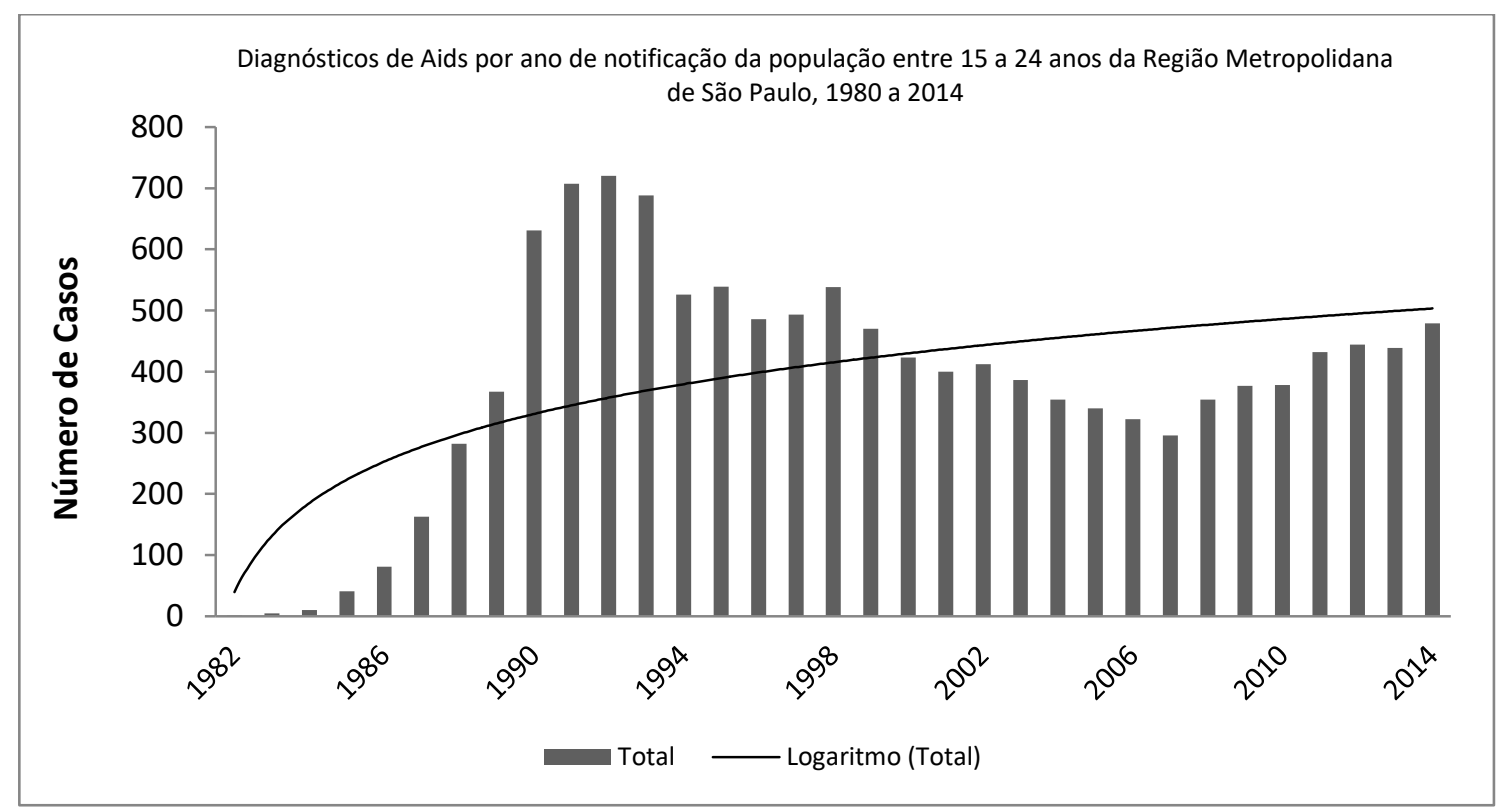

Fonte: (33)

Figura 20 - Diagnósticos de Aids por ano de notificação da população entre 15 a 24 anos da Região Metropolitana de São Paulo, 1980 a 2014

Entretanto, quando comparamos os números de casos, nota-se que a Região Metropolitana de São Paulo é responsável por um pouco mais de $50 \%$ dos casos registados no Estado, conforme observado na Tabela 20. 
Tabela 20 - Número de casos notificados de Aids no Estado e Porcentagem de casos da Região Metropolitana.

\begin{tabular}{|c|c|c|}
\hline Anos Diagnóstico & $\begin{array}{c}\text { Número de casos no } \\
\text { Estado }\end{array}$ & $\begin{array}{c}\text { Porcentagem de casos Região } \\
\text { Metropolitana. }\end{array}$ \\
\hline 1982 & 1 & $100 \%$ \\
\hline 1983 & 5 & $100 \%$ \\
\hline 1984 & 17 & $59 \%$ \\
\hline 1985 & 63 & $65 \%$ \\
\hline 1986 & 109 & $74 \%$ \\
\hline 1987 & 311 & $52 \%$ \\
\hline 1988 & 535 & $53 \%$ \\
\hline 1989 & 682 & $54 \%$ \\
\hline 1990 & 1115 & $57 \%$ \\
\hline 1991 & 1434 & $49 \%$ \\
\hline 1992 & 1488 & $48 \%$ \\
\hline 1993 & 1530 & $45 \%$ \\
\hline 1994 & 1288 & $41 \%$ \\
\hline 1995 & 1231 & $44 \%$ \\
\hline 1996 & 1142 & $43 \%$ \\
\hline 1997 & 1157 & $43 \%$ \\
\hline 1998 & 1189 & $45 \%$ \\
\hline 1999 & 1028 & $46 \%$ \\
\hline 2000 & 979 & $43 \%$ \\
\hline 2001 & 902 & $44 \%$ \\
\hline 2002 & 890 & $46 \%$ \\
\hline 2003 & 812 & $48 \%$ \\
\hline 2004 & 660 & $54 \%$ \\
\hline 2005 & 653 & $52 \%$ \\
\hline 2006 & 620 & $52 \%$ \\
\hline 2007 & 589 & $50 \%$ \\
\hline 2008 & 660 & $54 \%$ \\
\hline 2009 & 688 & $55 \%$ \\
\hline 2010 & 705 & $54 \%$ \\
\hline 2011 & 782 & $55 \%$ \\
\hline 2012 & 820 & $54 \%$ \\
\hline 2013 & 789 & $56 \%$ \\
\hline 2014 & 819 & $58 \%$ \\
\hline
\end{tabular}

Fonte: O Autor 
A distribuição de casos por sexo para esse recorte da pesquisa se apresenta da seguinte forma:

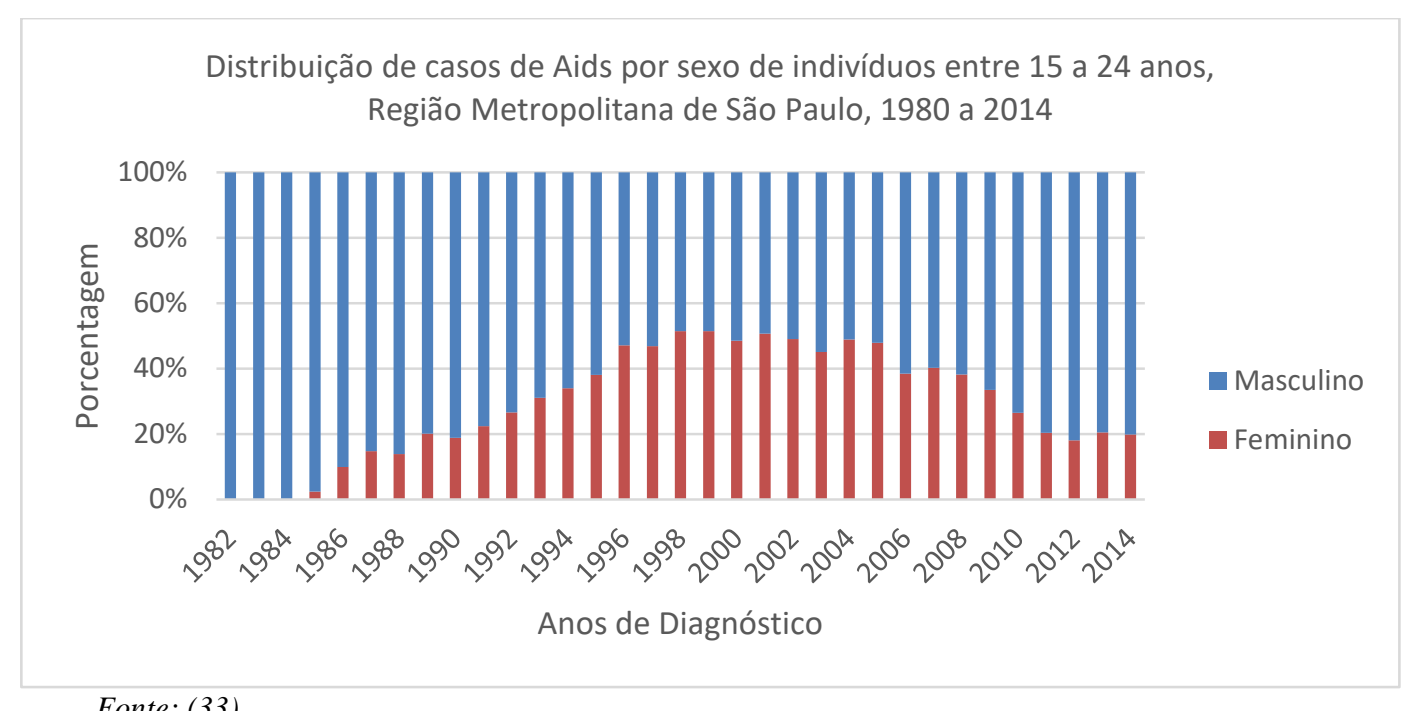

Figura 21 - Distribuição de casos de Aids por sexo de indivíduos entre 15 a 24 anos, Região Metropolitana de São Paulo, 1980 a 2014

Os casos notificados do sexo masculino permanecem maiores do que os casos do sexo feminino (Figura 21), como apresentado nos dados do Estado (Figura 11). Ao segmentarmos os casos do sexo masculino por meio de transmissão, nota-se o seguinte cenário apresentado na Figura 22:

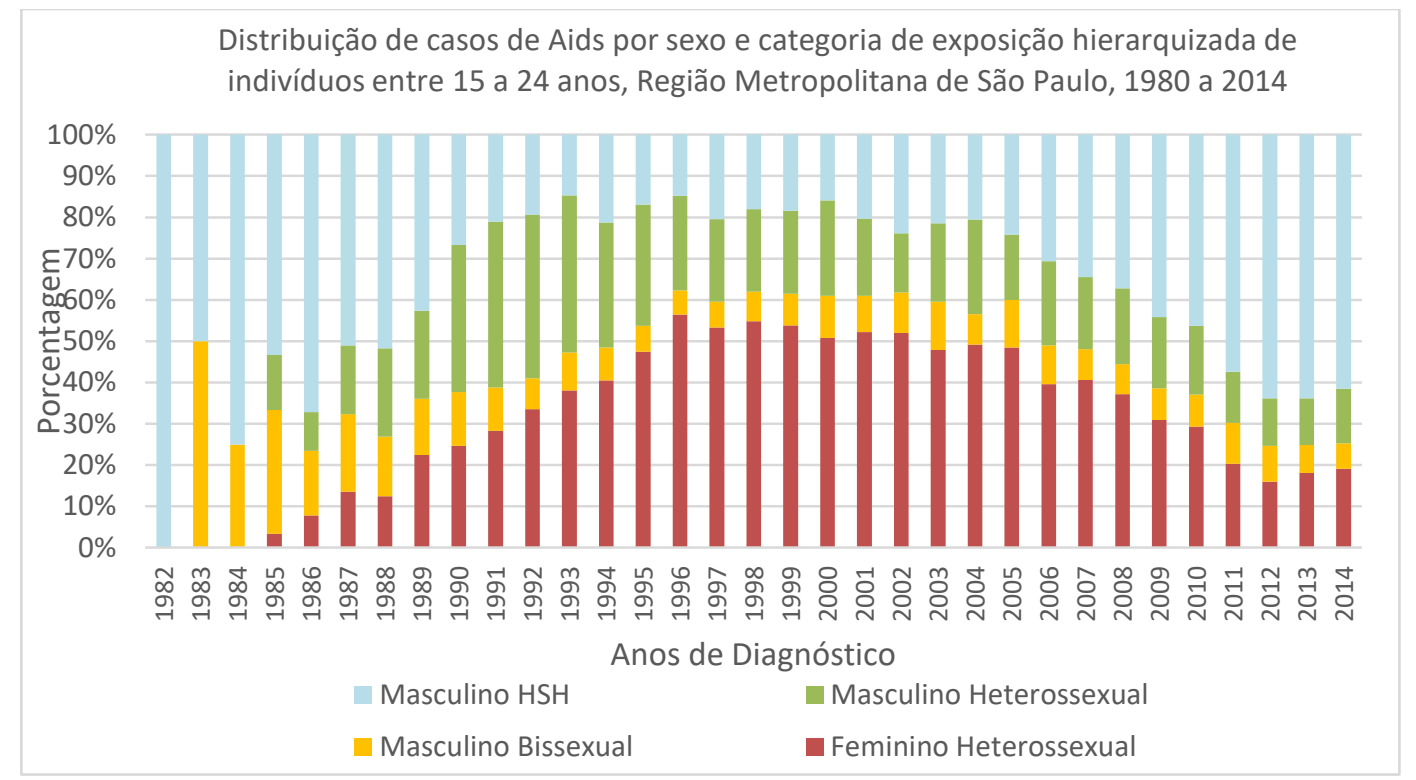

Fonte: (33)

Figura 22- Distribuição de casos de Aids por sexo e categoria de exposição hierarquizada de indivíduos entre 15 a 24 anos, Região Metropolitana de São Paulo, 1980 a 2014 
Novamente nota-se que no ano de 1996 os casos notificados em Razão Masculino: Feminino (Razão M:F) chegou a quase 1 para 1, mas ao longo dos anos a proporção de homens notificados cresceu com certa constância. Seguindo a análise proposta no capítulo anterior, segmentando os casos masculinos para esse recorte de dados (Figura 23), o mesmo fato é observado, em 1990 os casos masculinos com categoria de exposição Heterossexual passa a ser maior que outras categorias do sexo masculino. Em 1997 e 2001, 2002 e 2003 casos do sexo masculino e categoria de exposição HSH passam a ser maiores que a exposição Heterossexual. Já em 2005 a categoria HSH é maior que qualquer outra categoria para o sexo masculino e se mantem assim até 2014, ano do último dado para essa pesquisa.

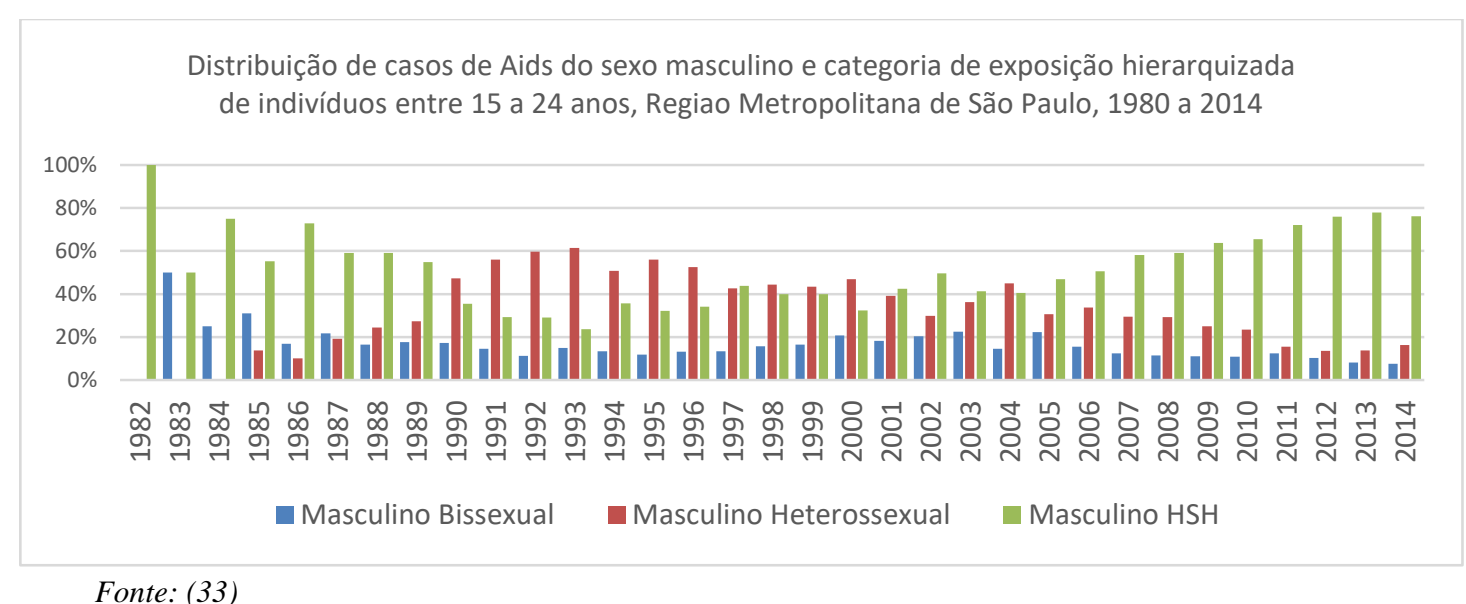

Figura 23 - Distribuição de casos de Aids do sexo masculino e categoria de exposição hierarquizada de indivíduos entre 15 a 24 anos, Região Metropolitana de São Paulo, 1980 a 2014

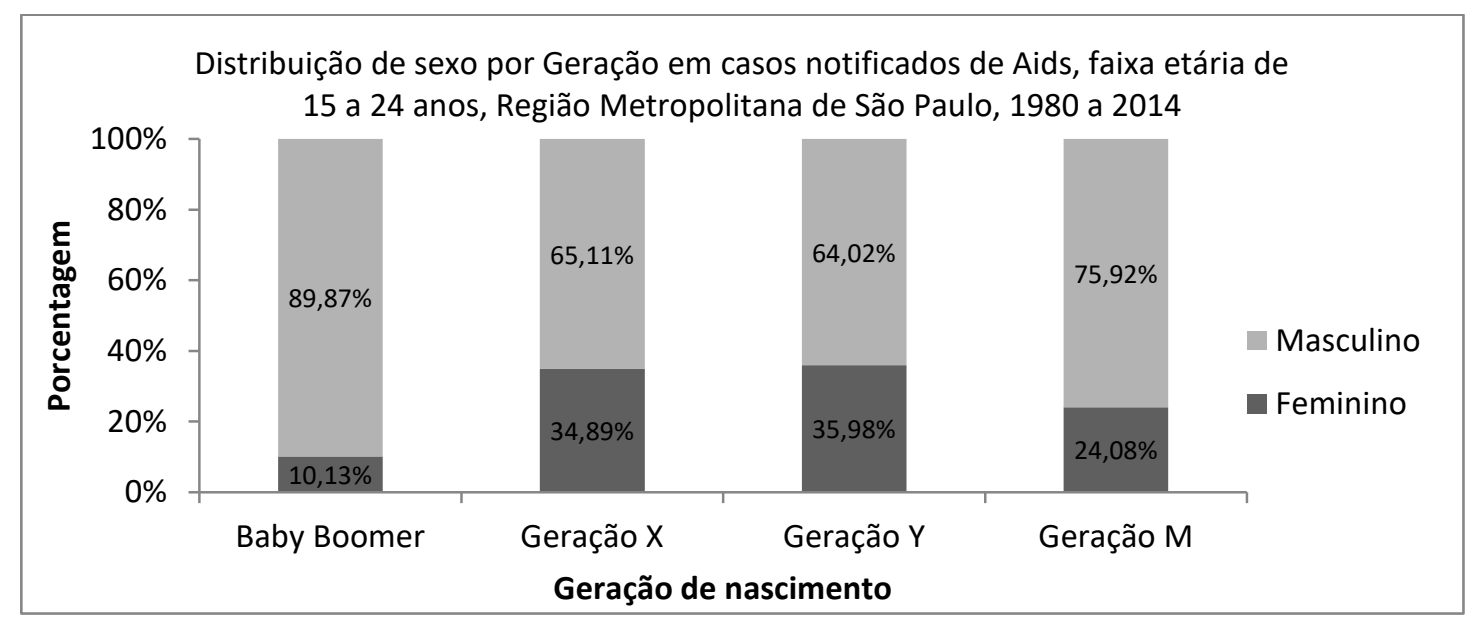

Fonte: $O$ Autor

Figura 24 - Distribuição de sexo por Geração em casos notificados de Aids, faixa etária de 15 a 24 anos, Região Metropolitana de São Paulo, 1980 a 2014 
Avaliando a questão das gerações em relação ao sexo, a tendência de detecção maior para o sexo masculino é presente em todas as gerações (Figura 24), e na soma geral dos casos para a faixa etária analisada, os casos do sexo masculino representam $66 \%$ dos casos notificados (Tabela 21).

Tabela 21 - Distribuição de sexo por Geração em casos notificados de Aids, faixa etária de 15 a 24 anos, Região Metropolitana de São Paulo, 1980 a 2014

\begin{tabular}{c|cc|c}
\hline \multirow{2}{*}{ Geração } & \multicolumn{2}{|c|}{ Sexo } & Total \\
\hline Baby Boomer & 16 & 142 & 158 \\
Geração X & 2625 & 4898 & 7523 \\
Geração Y & 1303 & 2318 & 3621 \\
Geração M & 294 & 927 & 1221 \\
\hline Total & $\mathbf{4 2 3 8}$ & $\mathbf{8 2 8 5}$ & $\mathbf{1 2 5 2 3}$ \\
\hline Fonte: $O$ Autor & $\mathbf{( 3 3 , 8 4 \% )}$ & $\mathbf{( 6 6 , 1 6 \% )}$ &
\end{tabular}

O cenário observado no Estado de São Paulo se reflete na análise da Região Metropolitana de São Paulo, demonstra um certo padrão da epidemia, mas quando vamos segmentando a região de análise dos dados.

\subsubsection{Teste de associação}

Vê-se na Tabela 22 que, os casos notificados de Aids na região metropolitana de São Paulo são predominantemente de homens, correspondendo a mais de três quartos dos casos da geração M e quase $90 \%$ dos casos da geração baby boomer. A exceção da geração M, mais da metade dos casos notificados de Aids em cada geração são referentes aos indivíduos da cor branca.

Enquanto que $94,3 \%$ dos casos da geração baby boomer foram notificados para indivíduos com 22 a 24 anos de idade, na geração M, 45,4\% referem-se a indivíduos entre 19 e 21 anos. Já quanto a escolaridade, nota-se que na geração X, 38,5\% dos indivíduos notificados possuíam entre 4 e 7 anos de escolaridade, ao passo que 46,5\% e $58 \%$ das notificações das gerações $\mathrm{Y}$ e $\mathrm{M}$, respectivamente, referem-se as pessoas que cursaram entre 8 e 11 anos de estudo. 
Para as gerações baby boomer e M, a categoria de exposição mais frequente é a HSH, equivalente a 47,5\% e 43,4\% dos casos, respectivamente. Já na geração X, UDI é a categoria mais frequente $(33,1 \%)$ e na geração Y é a Heterossexual $(39,1 \%)$.

Todas as variáveis apresentaram associação significativa com a geração dos indivíduos, de acordo com os resultados do teste qui-quadrado, fixado o nível de $5 \%$ de significância.

Tabela 22 - Distribuição de frequências e resultados do teste qui-quadrado das variáveis socioeconômicas e demográficas em relação as gerações dos casos notificados de Aids, faixa etária de 15 a 24 anos, Região metropolitana de São Paulo, 1980 a 2014

\begin{tabular}{|c|c|c|c|c|c|c|}
\hline \multirow{2}{*}{ Variável } & \multicolumn{4}{|c|}{ Geração } & \multicolumn{2}{|c|}{ Teste $\chi^{2}$} \\
\hline & Baby boomer & $\mathbf{X}$ & $\mathbf{Y}$ & M & $\chi^{2}$ & Valor $\mathbf{p}$ \\
\hline Sexo & & & & & 102,81 & $<0,001$ \\
\hline Feminino & $16(10,1 \%)$ & $2625(34,9 \%)$ & $1303(36 \%)$ & $294(24,1 \%)$ & & \\
\hline Masculino & $142(89,9 \%)$ & $4898(65,1 \%)$ & $2318(64 \%)$ & $927(75,9 \%)$ & & \\
\hline Cor & & & & & 154,41 & $<0,001$ \\
\hline Branca & $6(66,7 \%)$ & $895(57,6 \%)$ & $1916(56,4 \%)$ & $546(46,4 \%)$ & & \\
\hline Parda & $2(22,2 \%)$ & $343(22,1 \%)$ & $954(28,1 \%)$ & $464(39,5 \%)$ & & \\
\hline Preta & $0(0 \%)$ & $147(9,5 \%)$ & $319(9,4 \%)$ & $105(8,9 \%)$ & & \\
\hline Amarela & $0(0 \%)$ & $6(0,4 \%)$ & $16(0,5 \%)$ & $13(1,1 \%)$ & & \\
\hline Indígena & $0(0 \%)$ & $3(0,2 \%)$ & $7(0,2 \%)$ & $4(0,3 \%)$ & & \\
\hline Não informado/Ignorado & $1(11,1 \%)$ & $159(10,2 \%)$ & $185(5,4 \%)$ & $44(3,7 \%)$ & & \\
\hline Idade & & & & & 672,11 & $<0,001$ \\
\hline De 15 a 18 anos & $2(1,3 \%)$ & $563(7,5 \%)$ & $380(10,5 \%)$ & $279(22,9 \%)$ & & \\
\hline De 19 a 21 anos & $7(4,4 \%)$ & $1970(26,2 \%)$ & $954(26,3 \%)$ & $554(45,4 \%)$ & & \\
\hline De 22 a 24 anos & $149(94,3 \%)$ & $4990(66,3 \%)$ & $2287(63,2 \%)$ & $388(31,8 \%)$ & & \\
\hline Escolaridade & & & & & 2792,56 & $<0,001$ \\
\hline De 1 a 3 anos & $28(17,9 \%)$ & $1728(23,9 \%)$ & $171(4,9 \%)$ & $20(1,7 \%)$ & & \\
\hline De 4 a 7 anos & $32(20,5 \%)$ & $2778(38,5 \%)$ & $742(21,1 \%)$ & $160(13,9 \%)$ & & \\
\hline De 8 a 11 anos & $28(17,9 \%)$ & $1068(14,8 \%)$ & $1634(46,5 \%)$ & $668(58 \%)$ & & \\
\hline 12 anos ou mais & $18(11,5 \%)$ & $222(3,1 \%)$ & $445(12,7 \%)$ & $171(14,8 \%)$ & & \\
\hline Não informado/Ignorado & $50(32,1 \%)$ & $1427(19,8 \%)$ & $524(14,9 \%)$ & $133(11,5 \%)$ & & \\
\hline Categoria de exposição & & & & & 2417,96 & $<0,001$ \\
\hline Bissexual & $22(13,9 \%)$ & $431(5,7 \%)$ & $238(6,6 \%)$ & $69(5,7 \%)$ & & \\
\hline Hemofílico & $2(1,3 \%)$ & $57(0,8 \%)$ & $4(0,1 \%)$ & $0(0 \%)$ & & \\
\hline Heterossexual & $13(8,2 \%)$ & $2323(30,9 \%)$ & $1416(39,1 \%)$ & $307(25,1 \%)$ & & \\
\hline $\mathrm{HSH}$ & $75(47,5 \%)$ & $827(11 \%)$ & $993(27,4 \%)$ & $530(43,4 \%)$ & & \\
\hline Transfusão & $0(0 \%)$ & $24(0,3 \%)$ & $1(0 \%)$ & $0(0 \%)$ & & \\
\hline Transmissão Vertical & $0(0 \%)$ & $0(0 \%)$ & $9(0,2 \%)$ & $31(2,5 \%)$ & & \\
\hline UDI & $35(22,2 \%)$ & $2493(33,1 \%)$ & $146(4 \%)$ & $34(2,8 \%)$ & & \\
\hline Não informado/Ignorado & $11(7 \%)$ & $1368(18,2 \%)$ & $814(22,5 \%)$ & $250(20,5 \%)$ & & \\
\hline Total & $158(100 \%)$ & $7523(100 \%)$ & $3621(100 \%)$ & $1221(100 \%)$ & - & - \\
\hline
\end{tabular}

Fonte: $O$ Autor 


\subsubsection{Regras de associação}

Vê-se na Tabela 23 que entre os indivíduos com escolaridade de 4 a 7 anos de estudo ou de 1 a 3 anos de estudo, 74,7\% e 88,3\% são da geração X, respectivamente. Já entre os indivíduos com categoria de exposição UDI, 91,9\% são da geração X e 77,5\% são homens.

Entre os homens com categoria de exposição UDI, 92,7\% são da geração X, enquanto esta porcentagem é de 79,7\% dos casos entre aqueles com 22 a 24 anos de idade e 4 a 7 anos de estudo e de 78,2\% entre os homens com 4 a 7 anos de estudo. Considerando os casos notificados da geração $X$ e categoria de exposição Heterossexual, 71,8\% possuem entre 22 e 24 anos de idade e 71,4\% são mulheres.

Ainda, considerando as pessoas notificadas com 22 a 24 anos de idade e 8 a 11 anos de estudo, 70,3\% são do sexo masculino, ao passo que $93 \%$ dos indivíduos com 22 a 24 anos de idade e categoria de exposição UDI são da geração X.

Tabela 23 - Regras de associação e suas respectivas medidas dos casos notificados de Aids, faixa etária de 15 a 24 anos, Região metropolitana de São Paulo, 1980 a 2014.

\begin{tabular}{ll|cc}
\hline \multicolumn{1}{c}{ Regras } & & Suporte & Confiança \\
\hline Escolaridade = de 4 a 7 anos & $\rightarrow$ Geração = X & 0,221 & 0,747 \\
Exposição = UDI & $\rightarrow$ Geração $=$ X & 0,198 & 0,919 \\
Exposição = UDI & $\rightarrow$ Sexo = M & 0,167 & 0,775 \\
Sexo = M e Exposição = UDI & $\rightarrow$ Geração = X & 0,155 & 0,927 \\
Idade = de 22 a 24 anos e Escolaridade = de 4 a 7 anos & $\rightarrow$ Geração = X & 0,144 & 0,797 \\
Sexo = M e Escolaridade = de 4 a 7 anos & $\rightarrow$ Geração = X & 0,140 & 0,782 \\
Escolaridade = de 1 a 3 anos & $\rightarrow$ Geração = X & 0,137 & 0,883 \\
Geração = X e Exposição = Heterossexual & $\rightarrow$ Idade = de 22 a 24 anos & 0,133 & 0,718 \\
Geração = X e Exposição = Heterossexual & $\rightarrow$ Sexo = F & 0,132 & 0,714 \\
Idade = de 22 a 24 anos e Escolaridade = de 8 a 11 anos & $\rightarrow$ Sexo = M & 0,119 & 0,703 \\
Idade = de 22 a 24 anos e Exposição = UDI & $\rightarrow$ Geração = X & 0,118 & 0,930 \\
\hline
\end{tabular}

Fonte: $O$ Autor

Considerando os casos notificados de Aids da geração baby boomer, nota-se na Tabela 24 que entre os indivíduos do sexo masculino, com categoria de exposição HSH, escolaridade não informada ou categoria de exposição UDI, 94,4\%, 94,7\%, 98,0\% e $91,4 \%$ possuem entre 22 e 24 anos de idade, respectivamente, enquanto que entre as pessoas notificadas com escolaridade não informada, $86,0 \%$ são homens. 
Também se observa que, para os casos da geração $\mathrm{X}, 78,3 \%$ daqueles cuja categoria de exposição é UDI, são homens. Enquanto que entre aqueles cuja categoria de exposição é heterossexual, 71,8\% tem entre 22 e 24 anos e 71,4\% são mulheres.

Considerando os indivíduos do sexo feminino da geração $\mathrm{Y}, 74,8 \%$ tem Heterossexual por categoria de exposição, enquanto que dos indivíduos da cor branca e com 22 a 24 anos de idade, 74,8\% são homens. Ainda, dentre os homens com 8 a 11 anos de estudo ou categoria de exposição HSH, 72,1\% e 74,1\% possuem entre 21 e 24 anos, respectivamente.

Por fim, para as notificações referentes a geração $M$, vê-se que entre aqueles com escolaridade de 8 a 11 anos de estudo, idade de 19 a 21 anos, cor branca, cor parda ou idade de 22 a 24 anos, 76,5\%, 78,2\%, 78,9\%, 74,8\% e 84,8\% são homens, respectivamente.

Tabela 24 - Regras de associação por geração e suas respectivas medidas dos casos notificados de Aids, faixa etária de 15 a 24 anos, Região metropolitana de São Paulo, 1980 a 2014.

\begin{tabular}{|c|c|c|c|c|}
\hline Geração & Regras & & Suporte & Confiança \\
\hline \multirow{5}{*}{$\begin{array}{l}\text { Baby } \\
\text { boomer }\end{array}$} & Sexo $=M$ & $\rightarrow$ Idade $=$ de 22 a 24 anos & 0,848 & 0,944 \\
\hline & Exposição = HSH & $\rightarrow$ Idade $=$ de 22 a 24 anos & 0,449 & 0,947 \\
\hline & Escolaridade $=\mathrm{NI}$ & $\rightarrow$ Idade $=$ de 22 a 24 anos & 0,310 & 0,980 \\
\hline & Escolaridade $=\mathrm{NI}$ & $\rightarrow$ Sexo $=M$ & 0,272 & 0,860 \\
\hline & Exposição = UDI & $\rightarrow$ Idade $=$ de 22 a 24 anos & 0,203 & 0,914 \\
\hline \multirow{3}{*}{$\mathrm{X}$} & Exposição = UDI & $\rightarrow$ Sexo $=\mathrm{M}$ & 0,259 & 0,783 \\
\hline & Exposição = Heterossexual & $\rightarrow \quad$ Idade $=$ de 22 a 24 anos & 0,222 & 0,718 \\
\hline & Exposição $=$ Heterossexual & $\rightarrow$ Sexo $=\mathrm{F}$ & 0,220 & 0,714 \\
\hline \multirow{4}{*}{$\mathrm{Y}$} & Sexo $=F$ & $\rightarrow$ Exposição $=$ Heterossexual & 0,269 & 0,748 \\
\hline & Cor $=$ branca e Idade $=$ de 22 a 24 anos & $\rightarrow$ Sexo $=\mathrm{M}$ & 0,255 & 0,727 \\
\hline & Sexo $=\mathrm{M}$ e Escolaridade $=$ de 8 a 11 anos & $\rightarrow$ Idade $=$ de 22 a 24 anos & 0,214 & 0,721 \\
\hline & Exposição = HSH & $\rightarrow$ Idade $=$ de 22 a 24 anos & 0,203 & 0,741 \\
\hline \multirow{5}{*}{ M } & Escolaridade $=$ de 8 a 11 anos & $\rightarrow$ Sexo $=M$ & 0,419 & 0,765 \\
\hline & Idade $=$ de 19 a 21 anos & $\rightarrow$ Sexo $=M$ & 0,355 & 0,782 \\
\hline & Cor $=$ branca & $\rightarrow$ Sexo $=M$ & 0,353 & 0,789 \\
\hline & Cor $=$ parda & $\rightarrow$ Sexo $=M$ & 0,284 & 0,748 \\
\hline & Idade $=$ de 22 a 24 anos & $\rightarrow$ Sexo $=M$ & 0,269 & 0,848 \\
\hline
\end{tabular}

Fonte: $O$ Autor 


\section{PANORAMA DA AIDS NO MUNICÍPIO DE SÃO PAULO}

O município de São Paulo em 2017 registou 0,57\% da população do Brasil, sendo o dobro populacional registrado pela segunda cidade do ranking do IBGE (71). Com uma população estimada de 12.106.920, nesse mesmo ano (71), estudar a evolução do HIV/Aids no município de São Paulo é retratar um histórico relevante da epidemia não só no Estado de São Paulo, mas para o Brasil. A pirâmide de faixa etária do município (Figura 25) apresenta a importância do recorte de idade apresentado nesta pesquisa.

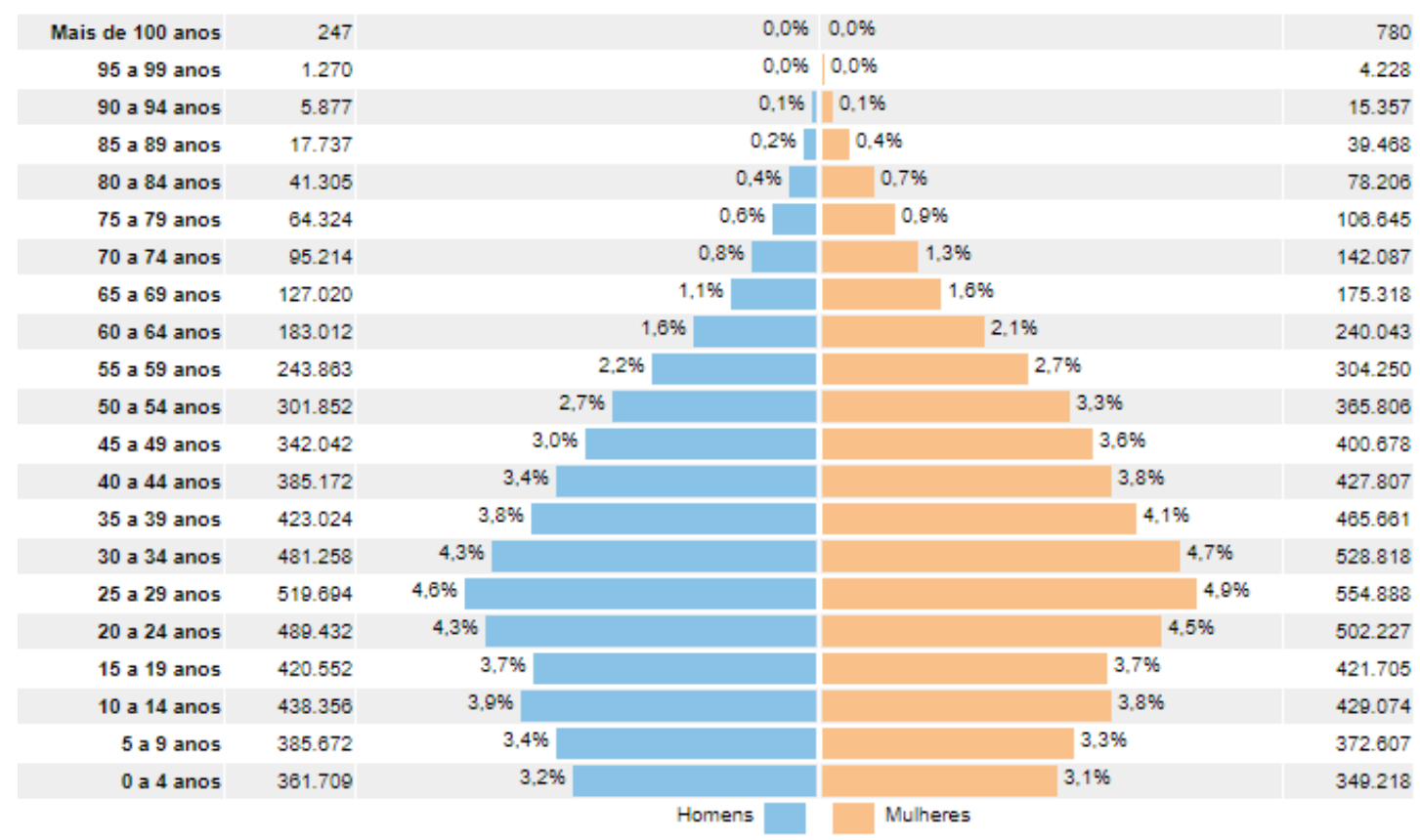

Fonte: (71)

Figura 25 - Distribuição da população por sexo, segundo os grupos de idade, Município de São Paulo, 2010

O Município tem como distribuição administrativa 32 subprefeituras, sendo elas Aricanduva, Butantã, Campo Limpo, Capela do Socorro, Casa Verde, Cidade Ademar, Cidade Tiradentes, Ermelino Matarazzo, Freguesia do Ó, Guaianases, Ipiranga, Itaim Paulista, Itaquera, Jabaquara, Jaçanã/Tremembé, Lapa, M’Boi Mirim, Mooca, Parelheiros, Penha, Perus, Pinheiros, Pirituba/Jaraguá, Santana/Tucuruvi, Santo Amaro, São Mateus, São Miguel, Sapopemba, Sé, Vila Maria/Vila Guilherme, Vila Mariana e Vila Prudente, em 9 divisões por zonas, Centro histórico; Centro Expandido; Noroeste; Norte; Leste ; Leste 2; Sudeste; Sul; Sudoeste; Oeste (72) 
O principal objetivo deste capítulo é traçar o panorama da epidemia no município de São Paulo e compará-lo com os dados já apresentados do Estado de São Paulo e da Região Metropolitana de São Paulo.

\subsection{O cenário da Aids na Capital Paulista.}

Com os dados apresentados até o capítulo anterior, pode-se observar a relevância do Estado de São Paulo frente aos números da epidemia de HIV/Aids no país. A importância do estado e as ações de atenção e prevenção são elementos chave para o combate da epidemia no Brasil, sendo o Estado de São Paulo assistido pelo Centro de Referência e Treinamento em DST/Aids (73) e pioneiro e estratégico em diversas ações relacionadas à epidemia.

Ao observar o histórico de notificações da Aids no Município de São Paulo e compararmos com o mesmo dado apresentado nos capítulos anteriores, sobre o Estado e a Região Metropolitana, constata-se semelhança entre a Figura 10, Figura 20 e Figura 26.

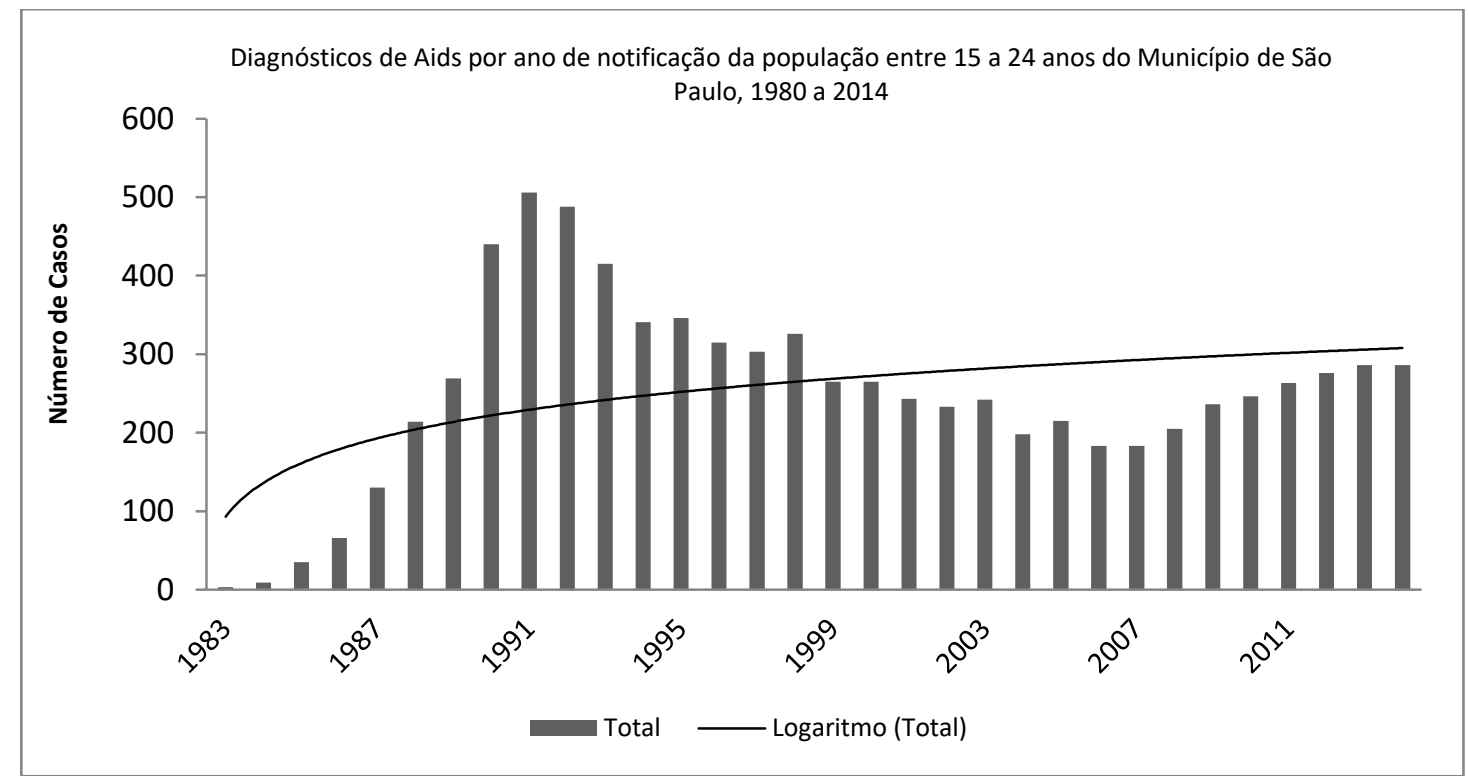

Fonte: (33)

Figura 26 - Diagnósticos de Aids por ano de notificação da população entre 15 a 24 anos do Município de São Paulo, 1980 a 2014 
Ao considerarmos as notificações a partir de 1990, em que o número de casos relativos ao Município e à Região Metropolitana se estabilizou percentualmente, o Município de São Paulo obteve média de $31 \%$ dos casos registrados no estado e a Região Metropolitana obteve média de 49\% (Tabela 25). Ponderando esses dados, cerca de 18\% dos casos foram da Região Metropolitana, enquanto que 31\% são do Município e, novamente, demonstra a importância de compreender a epidemia na Capital Paulista.

Tabela 25 - Número de casos notificados de Aids no Estado, Porcentagem de casos da Região Metropolitana e Município de São Paulo

\begin{tabular}{|c|c|c|c|}
\hline $\begin{array}{c}\text { Anos } \\
\text { Diagnóstico }\end{array}$ & $\begin{array}{c}\text { Número de casos no } \\
\text { Estado }\end{array}$ & $\begin{array}{l}\text { Porcentagem de } \\
\text { casos Região } \\
\text { Metropolitana. }\end{array}$ & $\begin{array}{c}\text { Porcentagem de } \\
\text { casos Município de } \\
\text { São Paulo. } \\
\end{array}$ \\
\hline 1982 & 1 & $100 \%$ & $0 \%$ \\
\hline 1983 & 5 & $100 \%$ & $60 \%$ \\
\hline 1984 & 17 & $59 \%$ & $53 \%$ \\
\hline 1985 & 63 & $65 \%$ & $56 \%$ \\
\hline 1986 & 109 & $74 \%$ & $61 \%$ \\
\hline 1987 & 311 & $52 \%$ & $42 \%$ \\
\hline 1988 & 535 & $53 \%$ & $40 \%$ \\
\hline 1989 & 682 & $54 \%$ & $39 \%$ \\
\hline 1990 & 1115 & $57 \%$ & $39 \%$ \\
\hline 1991 & 1434 & $49 \%$ & $35 \%$ \\
\hline 1992 & 1488 & $48 \%$ & $33 \%$ \\
\hline 1993 & 1530 & $45 \%$ & $27 \%$ \\
\hline 1994 & 1288 & $41 \%$ & $26 \%$ \\
\hline 1995 & 1231 & $44 \%$ & $28 \%$ \\
\hline 1996 & 1142 & $43 \%$ & $28 \%$ \\
\hline 1997 & 1157 & $43 \%$ & $26 \%$ \\
\hline 1998 & 1189 & $45 \%$ & $27 \%$ \\
\hline 1999 & 1028 & $46 \%$ & $26 \%$ \\
\hline 2000 & 979 & $43 \%$ & $27 \%$ \\
\hline 2001 & 902 & $44 \%$ & $27 \%$ \\
\hline 2002 & 890 & $46 \%$ & $26 \%$ \\
\hline 2003 & 812 & $48 \%$ & $30 \%$ \\
\hline 2004 & 660 & $54 \%$ & $30 \%$ \\
\hline 2005 & 653 & $52 \%$ & $33 \%$ \\
\hline 2006 & 620 & $52 \%$ & $30 \%$ \\
\hline 2007 & 589 & $50 \%$ & $31 \%$ \\
\hline 2008 & 660 & $54 \%$ & $31 \%$ \\
\hline 2009 & 688 & $55 \%$ & $34 \%$ \\
\hline 2010 & 705 & $54 \%$ & $35 \%$ \\
\hline 2011 & 782 & $55 \%$ & $34 \%$ \\
\hline 2012 & 820 & $54 \%$ & $34 \%$ \\
\hline 2013 & 789 & $56 \%$ & $36 \%$ \\
\hline 2014 & 819 & $58 \%$ & $35 \%$ \\
\hline
\end{tabular}

Fonte: $O$ Autor 
$\mathrm{Na}$ distribuição de casos por sexo, segue permanecendo na tendência das análises do estado e da região metropolitana, o sexo masculino também apresenta números maiores de detecção comparado com o sexo feminino. Observando a Figura 27, em 1998, a Razão de Sexo ficou em 0,9 casos masculinos por casos femininos. Ou seja, foram mais casos femininos notificados do que casos do sexo masculino.

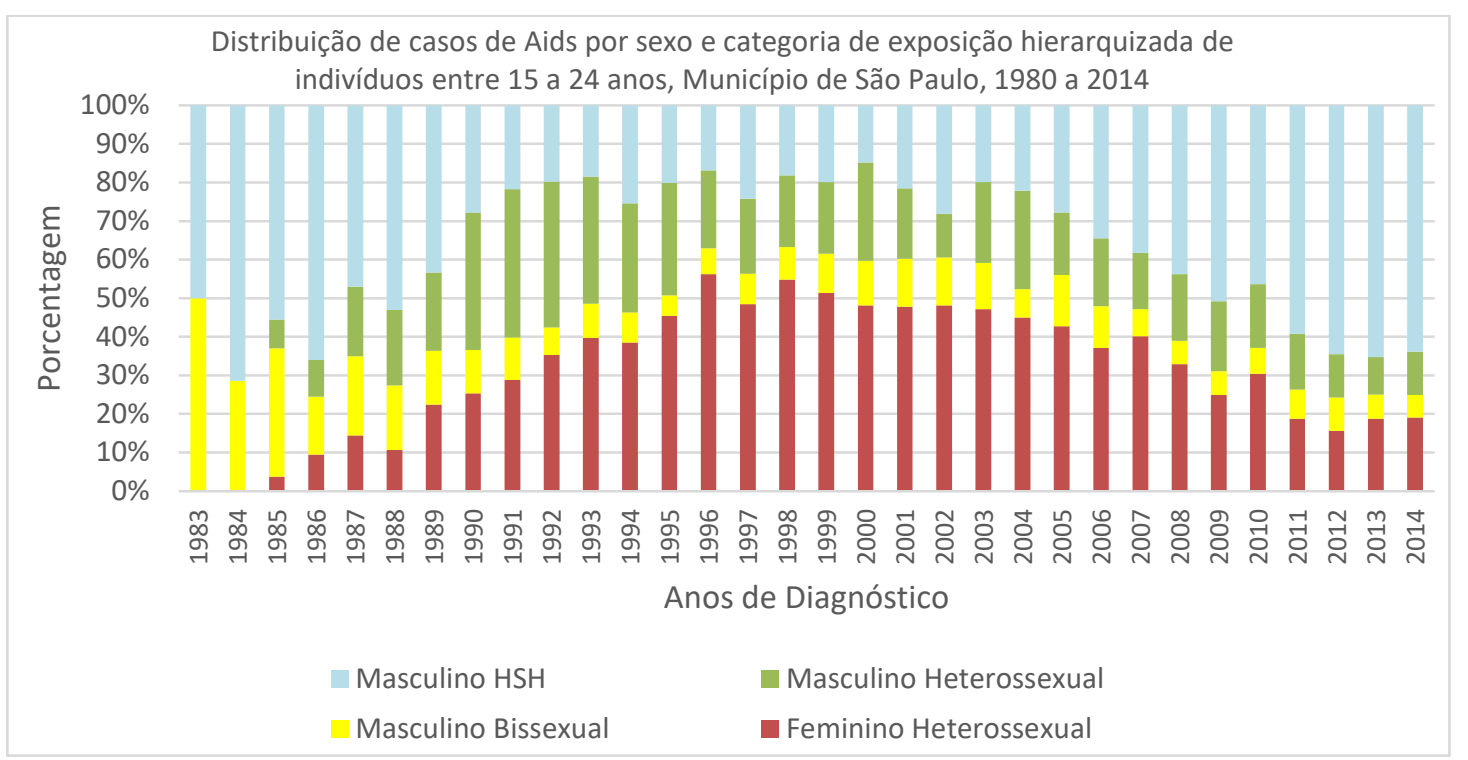

Fonte: (33)

Figura 27 - Distribuição de casos de Aids por sexo e categoria de exposição hierarquizada de indivíduos entre 15 a 24 anos, Município de São Paulo, 1980 a 2014

O ponto de atenção na atualidade é justamente o impacto do índice Razão Masculino: Feminino. Observa-se entre 2011 a 2014 a sequência dos seguintes resultados, respectivamente: 4,4; 4,8; 4,1 e 4,0, com maior notificação para casos de $\mathrm{HSH}$.

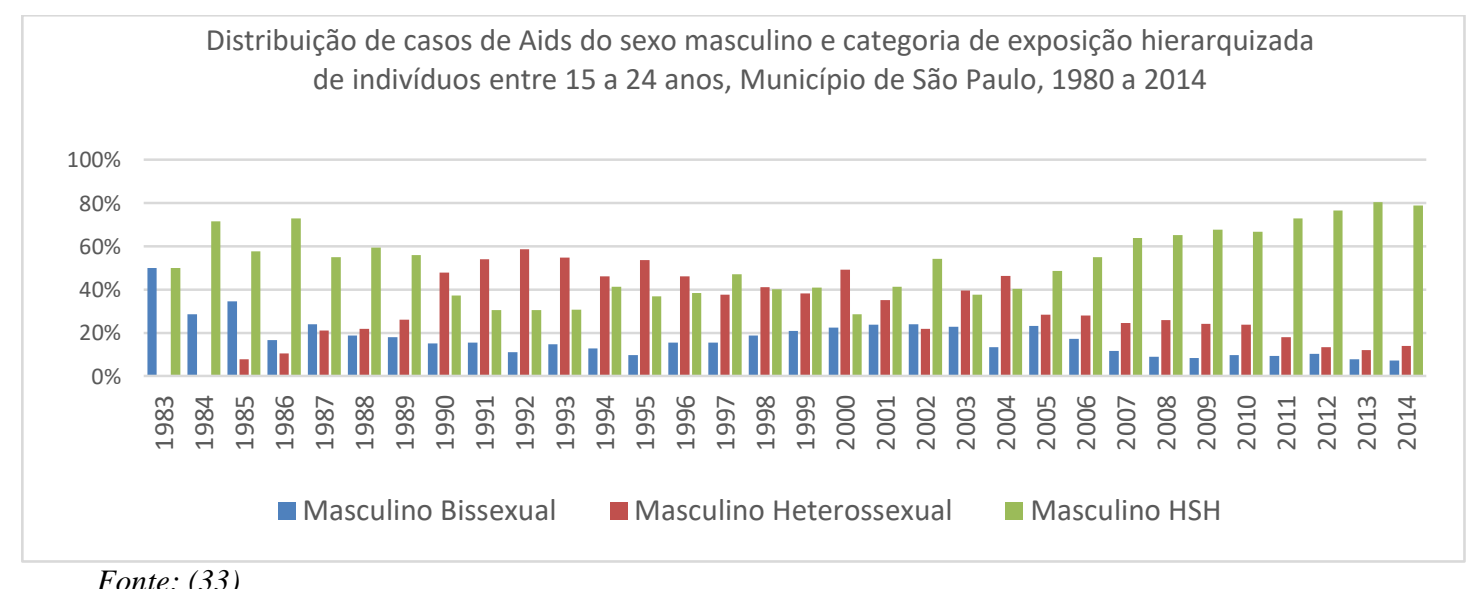

Figura 28 - Distribuição de casos de Aids do sexo masculino e categoria de exposição hierarquizada de indivíduos entre 15 a 24 anos, Município de São Paulo, 1980 a 2014 
Considerando somente os casos do sexo masculino para a análise (Figura 28), a evidência dos casos de HSH ao longo dos últimos anos está aparente na figura. Ao calcularmos casos do sexo Masculino que se declararam Heterossexuais com os casos Masculinos que declararam algum contato com parceiro do mesmo sexo (HSH) o cálculo de Razão para esses casos aparece maior para Heterossexuais apenas nos anos de 1991, 1992, 1993 e 1995 (Tabela 26). No ano de 2000 a Razão era de um caso declarado como Heterossexual para um caso de HSH. Em 27 anos dos 32 analisados, casos HSH estiveram com número de notificação maiores dos casos em que o sexo masculino se declarava heterossexual (HSM - Homens que fazem sexo com Mulheres).

Tabela 26 - Notificações para o sexo Masculino, Razão Heterossexual: HSH, Município de São Paulo, 1983 a 2014

\begin{tabular}{|c|c|c|c|}
\hline Ano & Razão HSM: HSH & Ano & Razão HSM: HSH \\
\hline $\mathbf{1 9 8 3}$ & 0,0 & $\mathbf{1 9 9 9}$ & 0,6 \\
\hline $\mathbf{1 9 8 4}$ & 0,0 & $\mathbf{2 0 0 0}$ & 1,0 \\
\hline $\mathbf{1 9 8 5}$ & 0,1 & $\mathbf{2 0 0 1}$ & 0,5 \\
\hline 1986 & 0,1 & $\mathbf{2 0 0 2}$ & 0,3 \\
\hline 1987 & 0,3 & $\mathbf{2 0 0 3}$ & 0,7 \\
\hline 1988 & 0,3 & $\mathbf{2 0 0 4}$ & 0,9 \\
\hline $\mathbf{1 9 8 9}$ & 0,4 & $\mathbf{2 0 0 5}$ & 0,4 \\
\hline $\mathbf{1 9 9 0}$ & 0,9 & $\mathbf{2 0 0 6}$ & 0,4 \\
\hline 1991 & 1,2 & $\mathbf{2 0 0 7}$ & 0,3 \\
\hline $\mathbf{1 9 9 2}$ & 1,4 & $\mathbf{2 0 0 8}$ & 0,3 \\
\hline $\mathbf{1 9 9 3}$ & 1,2 & $\mathbf{2 0 0 9}$ & 0,3 \\
\hline $\mathbf{1 9 9 4}$ & 0,9 & $\mathbf{2 0 1 0}$ & 0,3 \\
\hline 1995 & 1,2 & $\mathbf{2 0 1 1}$ & 0,2 \\
\hline 1996 & 0,9 & $\mathbf{2 0 1 2}$ & 0,2 \\
\hline 1997 & 0,6 & $\mathbf{2 0 1 3}$ & 0,1 \\
\hline 1998 & 0,7 & $\mathbf{2 0 1 4}$ & 0,2 \\
\hline
\end{tabular}

Fonte: $O$ Autor

O Gráfico apresentado na Figura 29 demonstra a evolução da Razão entre casos notificados com relato de contato apenas heterossexual (HT) e casos relatados como HSH. Observa-se o pico no ano de 1992, precedido pelos anos de 1990 e 1991. Em 1980 a Razão HT: HSH foi de 0,4, enquanto que em 1990 passou para 0,9 e 1991 para 1,2, mesmo índice do ano de 1995. Os anos 2000 e 2004 foram, também, marcados pelo aumento do índice, sendo observado, respectivamente, 1,0 e 0,9 de Razão HT: HSH. 


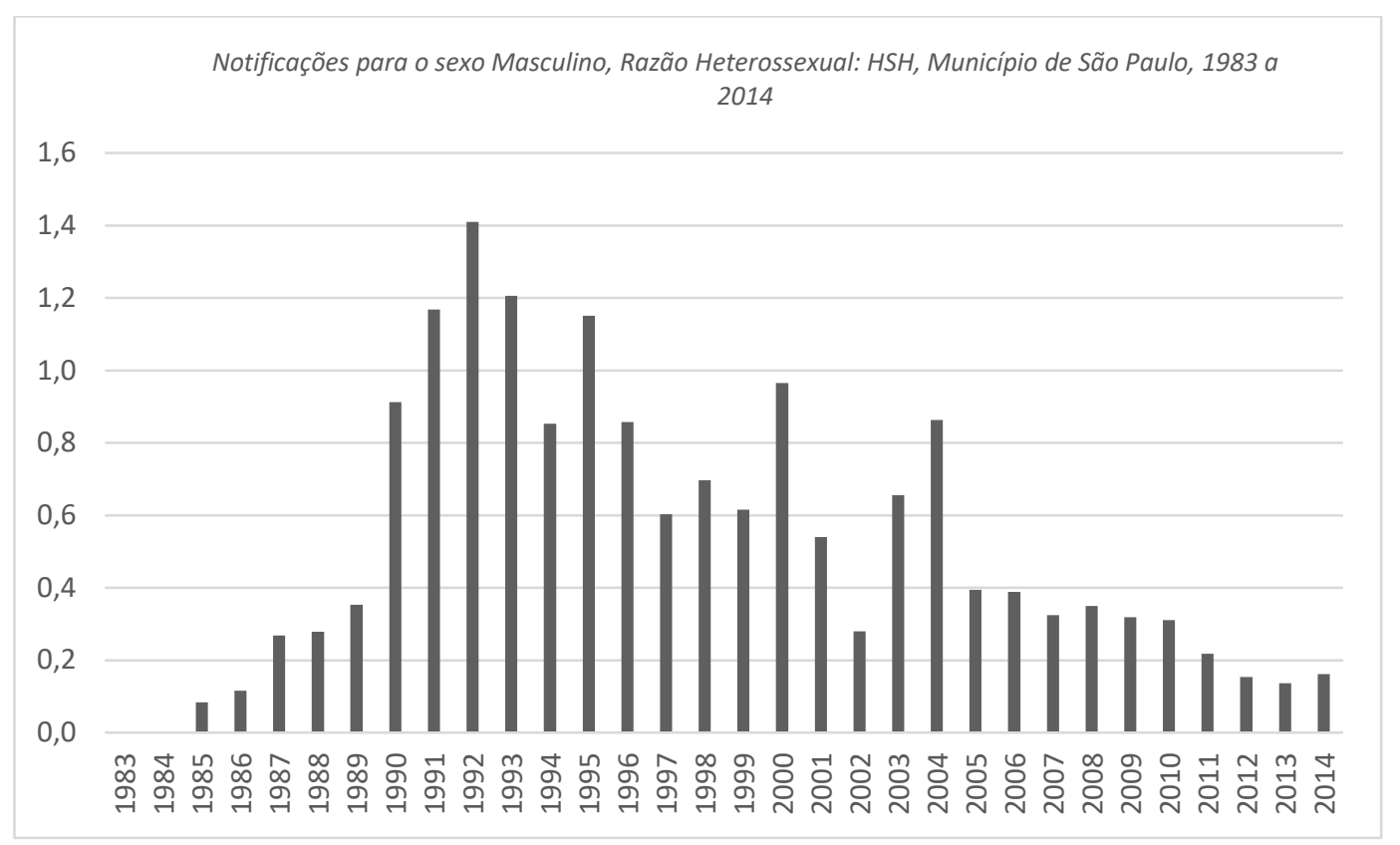

Fonte: (33)

Figura 29 - Notificações para o sexo Masculino, Razão Heterossexual: HSH, Município de São Paulo, 1983 a 2014

Com a segmentação por gerações, a distribuição de casos por sexo masculino e feminino observa-se que para a Geração X e Geração Y são porcentagens aproximadas e para a Geração M o índice cai da faixa dos $34 \%$ e $33 \%$ para $24 \%$.

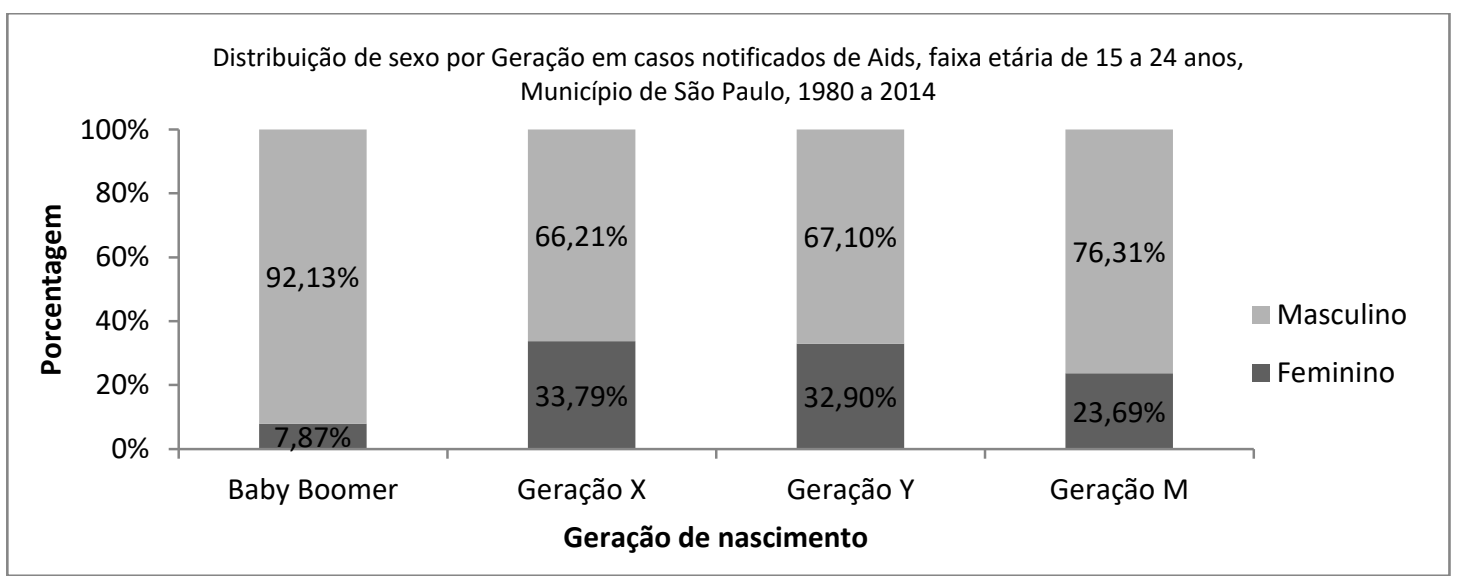

Fonte: $O$ Autor

Figura 30 - Distribuição de sexo por Geração em casos notificados de Aids, faixa etária de 15 a 24 anos, Município de São Paulo, 1980 a 2014 
Verifica-se na Tabela 27 a proporção geral de casos femininos e masculinos, sendo, respectivamente, $32 \%$ e $67 \%$.

Tabela 27 - Distribuição de sexo por Geração em casos notificados de Aids, faixa etária de 15 a 24 anos, Município de São Paulo, 1980 a 2014

\begin{tabular}{c|cc|c}
\hline \multirow{2}{*}{ Geração } & \multicolumn{2}{|c|}{ Sexo } & \multirow{2}{*}{ Total } \\
\cline { 2 - 3 } & Feminino & Masculino & \\
\hline Baby boomer & 10 & 117 & 127 \\
\hline Geração X & 1663 & 3259 & 4922 \\
\hline Geração Y & 729 & 1487 & 2216 \\
\hline Geração M & 177 & 570 & 747 \\
\hline Total & $\begin{array}{c}\mathbf{2 5 7 9} \\
(\mathbf{3 2 , 1 9 \%})\end{array}$ & $\begin{array}{c}\mathbf{5 4 3 3} \\
(\mathbf{6 7 , 8 1 \% )}\end{array}$ & $\mathbf{8 0 1 2}$ \\
\hline
\end{tabular}

Fonte: $O$ Autor

Com a base de dados apresentada, apresenta-se nos próximos subcapítulos testes estatísticos para averiguar o comportamento das variáveis estudadas com relação a cada uma das Gerações estudadas nesta pesquisa.

\subsubsection{Teste de associação}

Nota-se na Tabela 28 que, para as gerações X e Y, cerca de dois terços dos casos de Aids notificados no município de São Paulo referem-se a indivíduos do sexo masculino de todas as gerações, sendo esta proporção ainda maior para os casos da geração M (77,0\%) e da geração baby boomer $(91,0 \%)$. Em relação à cor, vê-se que a grande maioria dos casos notificados para a geração baby boomer referem-se aos indivíduos da cor branca $(83,3 \%)$, sendo que tal porcentagem diminui ao longo das gerações, correspondendo a apenas $45,7 \%$ das notificações na geração $\mathrm{M}$.

Considerando a geração baby boomer, 93,3\% dos casos foram notificados para indivíduos entre 22 e 24 anos de idade, sendo poucos os casos aqueles com idade inferior a 21 anos. Tal situação inverte-se ao longo das gerações, sendo observada uma porcentagem cada vez maior de casos em indivíduos entre 15 e 18 anos e entre 19 e 21 anos. Na geração baby boomer, cerca de um terço das notificações tinha a escolaridade não informada ou ignorada, enquanto que na geração $X, 40 \%$ possuíam de 4 a 7 anos de estudo e nas gerações Y e M, 47,6\% e 58,8\% dos indivíduos possuíam de 8 a 11 anos de estudo, respectivamente. 
Observa-se que quase metade dos casos notificados da geração baby boomer e geração M têm HSH por categoria de exposição, enquanto a categoria mais frequente para os indivíduos notificados da geração X é UDI (Usuários de Drogas Injetáveis) $(34,9 \%)$ e da geração Y é Heterossexual $(38,1 \%)$.

Tabela 28 - Distribuição de frequências e resultados do teste qui-quadrado das variáveis socioeconômicas e demográficas em relação as gerações dos casos notificados de Aids, faixa etária de 15 a 24 anos, Município de São Paulo, 1980 a 2014.

\begin{tabular}{|c|c|c|c|c|c|c|}
\hline \multirow{2}{*}{ Variável } & \multicolumn{4}{|c|}{ Geração } & \multicolumn{2}{|c|}{ Teste $\chi^{2}$} \\
\hline & Baby boomer & $\mathbf{X}$ & $\mathbf{Y}$ & $\mathbf{M}$ & $\chi^{2}$ & Valor $\mathbf{p}$ \\
\hline Sexo & & & & & 72,05 & $<0,001$ \\
\hline Feminino & $12(9 \%)$ & $1844(33,8 \%)$ & $816(33,1 \%)$ & $189(23 \%)$ & & \\
\hline Masculino & $122(91 \%)$ & $3619(66,2 \%)$ & $1649(66,9 \%)$ & $633(77 \%)$ & & \\
\hline Cor & & & & & 130,64 & $<0,001$ \\
\hline Branca & $5(83,3 \%)$ & $630(58,4 \%)$ & $1305(56,5 \%)$ & $364(45,7 \%)$ & & \\
\hline Parda & $1(16,7 \%)$ & $225(20,9 \%)$ & $634(27,4 \%)$ & $328(41,2 \%)$ & & \\
\hline Preta & $0(0 \%)$ & $106(9,8 \%)$ & $227(9,8 \%)$ & $61(7,7 \%)$ & & \\
\hline Amarela & $0(0 \%)$ & $5(0,5 \%)$ & $14(0,6 \%)$ & $10(1,3 \%)$ & & \\
\hline Indígena & $0(0 \%)$ & $3(0,3 \%)$ & $5(0,2 \%)$ & $3(0,4 \%)$ & & \\
\hline Não informado/Ignorado & $0(0 \%)$ & $110(10,2 \%)$ & $125(5,4 \%)$ & $31(3,9 \%)$ & & \\
\hline Idade & & & & & 419,91 & $<0,001$ \\
\hline De 15 a 18 anos & $2(1,5 \%)$ & $428(7,8 \%)$ & $258(10,5 \%)$ & $175(21,3 \%)$ & & \\
\hline De 19 a 21 anos & $7(5,2 \%)$ & $1410(25,8 \%)$ & $621(25,2 \%)$ & $373(45,4 \%)$ & & \\
\hline De 22 a 24 anos & $125(93,3 \%)$ & $3625(66,4 \%)$ & $1586(64,3 \%)$ & $274(33,3 \%)$ & & \\
\hline Escolaridade & & & & & 2013,13 & $<0,001$ \\
\hline De 1 a 3 anos & $22(16,5 \%)$ & $1085(20,3 \%)$ & $105(4,4 \%)$ & $13(1,6 \%)$ & & \\
\hline De 4 a 7 anos & $32(24,1 \%)$ & $2137(40 \%)$ & $468(19,4 \%)$ & $116(14,7 \%)$ & & \\
\hline De 8 a 11 anos & $20(15 \%)$ & $793(14,9 \%)$ & $1146(47,6 \%)$ & $465(58,8 \%)$ & & \\
\hline 12 anos ou mais & $14(10,5 \%)$ & $170(3,2 \%)$ & $328(13,6 \%)$ & $103(13 \%)$ & & \\
\hline Não informado/Ignorado & $45(33,8 \%)$ & $1153(21,6 \%)$ & $363(15,1 \%)$ & $94(11,9 \%)$ & & \\
\hline Categoria de exposição & & & & & 1789,26 & $<0,001$ \\
\hline Bissexual & $21(15,7 \%)$ & $330(6 \%)$ & $176(7,1 \%)$ & $45(5,5 \%)$ & & \\
\hline Hemofílico & $1(0,7 \%)$ & $33(0,6 \%)$ & $3(0,1 \%)$ & $0(0 \%)$ & & \\
\hline Heterossexual & $11(8,2 \%)$ & $1575(28,8 \%)$ & $939(38,1 \%)$ & $207(25,2 \%)$ & & \\
\hline $\mathrm{HSH}$ & $63(47 \%)$ & $644(11,8 \%)$ & $752(30,5 \%)$ & $386(47 \%)$ & & \\
\hline Transfusão & $0(0 \%)$ & $15(0,3 \%)$ & $0(0 \%)$ & $0(0 \%)$ & & \\
\hline Transmissão Vertical & $0(0 \%)$ & $0(0 \%)$ & $6(0,2 \%)$ & $20(2,4 \%)$ & & \\
\hline UDI & $31(23,1 \%)$ & $1906(34,9 \%)$ & $95(3,9 \%)$ & $28(3,4 \%)$ & & \\
\hline Não informado/Ignorado & $7(5,2 \%)$ & $960(17,6 \%)$ & $494(20 \%)$ & $136(16,5 \%)$ & & \\
\hline Total & $134(100 \%)$ & $5463(100 \%)$ & $2465(100 \%)$ & $822(100 \%)$ & - & - \\
\hline
\end{tabular}

Fonte: O Autor 


\subsubsection{Regras de associação}

De acordo com a Tabela 29, vê-se que entre os indivíduos com 4 a 7 anos de estudo ou categoria de exposição UDI, $77,5 \%$ e $92,3 \%$ são da geração $X$, respectivamente. Também se nota que dos indivíduos que possuem de 8 a 11 anos de estudo ou categoria de exposição UDI, 70,4\% e 77,2\% são homens, respectivamente.

Entre os homens com categoria de exposição UDI e homens com 4 a 7 anos de estudo, 93,3\% e 80,7\% são da geração X, respectivamente. Do mesmo modo, entre os indivíduos de 22 a 24 anos de idade com 4 a 7 anos de estudo, 81,4\% são da geração $X$ e entre mulheres de 22 a 24 anos, 71,0\% também são desta geração. Considerando os casos notificados que se referem às pessoas da geração Y entre 22 e 24 anos de idade, vê-se que 71,7\% são homens, ao passo que entre as pessoas notificadas com 22 a 24 anos com categoria de exposição UDI, 93,3\% são da geração X.

Tabela 29 - Regras de associação e suas respectivas medidas dos casos notificados de Aids, faixa etária de 15 a 24 anos, Município de São Paulo, 1980 a 2014.

\begin{tabular}{|c|c|c|c|}
\hline Regras & & Suporte & Confiança \\
\hline Escolaridade $=$ de 4 a 7 anos & $\rightarrow$ Geração $=$ X & 0,240 & 0,775 \\
\hline Exposição = UDI & $\rightarrow$ Geração $=X$ & 0,214 & 0,923 \\
\hline Escolaridade $=$ de 8 a 11 anos & $\rightarrow$ Sexo $=M$ & 0,192 & 0,704 \\
\hline Exposição = UDI & $\rightarrow$ Sexo $=\mathrm{M}$ & 0,179 & 0,772 \\
\hline Sexo $=$ M e Exposição = UDI & $\rightarrow$ Geração $=$ X & 0,167 & 0,933 \\
\hline Sexo $=\mathrm{M}$ e Escolaridade $=$ de 4 a 7 anos & $\rightarrow$ Geração $=\mathrm{X}$ & 0,157 & 0,807 \\
\hline Idade $=$ de 22 a 24 anos e Escolaridade $=$ de 4 a 7 anos & $\rightarrow$ Geração $=X$ & 0,155 & 0,814 \\
\hline Sexo $=$ F e Idade $=$ de 22 a 24 anos & $\rightarrow$ Geração $=X$ & 0,141 & 0,710 \\
\hline Geração $=$ Y e Idade $=$ de 22 a 24 anos & $\rightarrow \operatorname{Sexo}=\mathrm{M}$ & 0,127 & 0,717 \\
\hline Idade $=$ de 22 a 24 anos e Exposição $=$ UDI & $\rightarrow$ Geração $=$ X & 0,127 & 0,933 \\
\hline Geração = X e Exposição = Heterossexual & $\rightarrow$ Idade $=$ de 22 a 24 anos & 0,127 & 0,717 \\
\hline Geração $=$ X e Exposição = Heterossexual & $\rightarrow$ Sexo $=F$ & 0,125 & 0,710 \\
\hline Idade $=$ de 22 a 24 anos e Escolaridade $=$ de 8 a 11 anos & $\rightarrow \mathrm{Sexo}=\mathrm{M}$ & 0,125 & 0,728 \\
\hline Escolaridade $=$ de 1 a 3 anos & $\rightarrow$ Geração $=X$ & 0,122 & 0,880 \\
\hline Geração $=$ Y e Cor $=$ branca & $\rightarrow \operatorname{Sexo}=\mathrm{M}$ & 0,103 & 0,702 \\
\hline Escolaridade $=$ de 4 a 7 anos e Exposição $=$ UDI & $\rightarrow$ Geração $=$ X & 0,101 & 0,956 \\
\hline
\end{tabular}

Fonte: $O$ Autor 
Também se observa que, em restringindo-se aos casos notificados de indivíduos da geração X e categoria de exposição Heterossexual, 71,7\% possuem entre 22 e 24 anos e 71,0\% são mulheres. Ainda, considerando as pessoas notificadas com 22 a 24 anos de idade e 8 a 11 anos de estudo, $72,8 \%$ são do sexo masculino, ao passo que $88 \%$ dos indivíduos com 1 a 3 anos de estudo são da geração X. As duas últimas regras mineradas apontam que entre os indivíduos da geração $X$ e cor branca, 70,2\% são homens e que entre os indivíduos com 4 a 7 anos de estudo e categoria de exposição UDI, 95,6\% são da geração X.

$\mathrm{Na}$ Tabela 30, nota-se que, para a geração baby boomer, entre os casos notificados de Aids cujos indivíduos são do sexo masculino, tem categoria de exposição HSH, escolaridade não informada, com 4 a 7 anos de estudo ou categoria de exposição UDI, 93,4\%, 93,7\%, 97,8\%, 96,9\% e 90,3\% possuem idade entre 22 e 24 anos, respectivamente. Ainda, vê-se que todos os homens com 4 a 5 anos de estudo também possuem de 22 a 24 anos de idade. Por outro lado, entre os indivíduos com escolaridade não informada ou entre 4 e 7 anos de estudo, $84,4 \%$ e 90,6\% são homens, respectivamente. Considerando a geração X, observa-se que entre os casos notificados com categoria de exposição UDI, 78,0\% são homens, ao passo que entre os casos com categoria de exposição Heterossexual 71,7\% tem entre 22 e 24 anos de idade e 71,0\% são mulheres.

Referente à geração Y, observa-se que indivíduos com 22 a 24 anos de idade e cor branca, são em sua maioria homens (74,5\%), assim como os indivíduos com 22 a 24 anos de idade e 8 a 11 anos de estudo (73,3\%). Entre as mulheres da geração Y notificadas, $77 \%$ tem Heterossexual por categoria de exposição, enquanto que entre os indivíduos com categoria de exposição HSH, 75,3\% tem de 22 a 24 anos de idade.

Em relação à geração $\mathrm{M}$, observa-se que entre os casos notificados referentes à escolaridade de 8 a 11 anos, cor branca, idade entre 19 a 21 anos, cor parda ou idade entre 22 a 24 anos, 78,1\%, 80,2\%,78,3\%,73,8\% e 86,1\% são do sexo masculino, respectivamente. Do mesmo modo, entre as pessoas de cor branca e com 8 a 11 anos de estudo, 80,7\% são homens e entre as pessoas com 19 a 21 anos de idade e 8 a 11 anos de estudo, 79,0\% também são homens. Por fim, vê-se que entre os homens com 8 a 11 anos de estudo, 72,2\% tem HSH por categoria de exposição. 
Tabela 30 - Regras de associação por geração e suas respectivas medidas dos casos notificados de Aids, faixa etária de 15 a 24 anos, Município de São Paulo, 1980 a 2014.

\begin{tabular}{|c|c|c|c|c|}
\hline \multirow[t]{2}{*}{ Geração } & \multicolumn{2}{|l|}{ Regras } & \multicolumn{2}{|c|}{ Suporte Confiança } \\
\hline & Sexo $=M$ & $\rightarrow$ Idade $=$ de 22 a 24 anos & 0,851 & 0,934 \\
\hline \multirow{7}{*}{$\begin{array}{c}\text { Baby } \\
\text { boomer }\end{array}$} & Exposição = HSH & $\rightarrow$ Idade $=$ de 22 a 24 anos & 0,440 & 0,937 \\
\hline & Escolaridade $=$ NI & $\rightarrow$ Idade $=$ de 22 a 24 anos & 0,328 & 0,978 \\
\hline & Escolaridade $=$ NI & $\rightarrow$ Sexo $=\mathrm{M}$ & 0,284 & 0,844 \\
\hline & Escolaridade $=$ de 4 a 7 anos & $\rightarrow$ Idade $=$ de 22 a 24 anos & 0,231 & 0,969 \\
\hline & Escolaridade $=$ de 4 a 7 anos & $\rightarrow \mathrm{Sexo}=\mathrm{M}$ & 0,216 & 0,906 \\
\hline & Sexo $=\mathrm{M}$ e Escolaridade $=$ de 4 a 7 anos & $\rightarrow$ Idade $=$ de 22 a 24 anos & 0,216 & 1,000 \\
\hline & Exposição = UDI & $\rightarrow$ Idade $=$ de 22 a 24 anos & 0,209 & 0,903 \\
\hline \multirow{3}{*}{$\mathrm{X}$} & Exposição = UDI & $\rightarrow \mathrm{Sexo}=\mathrm{M}$ & 0,272 & 0,780 \\
\hline & Exposição = Heterossexual & $\rightarrow$ Idade $=$ de 22 a 24 anos & 0,207 & 0,717 \\
\hline & Exposição = Heterossexual & $\rightarrow$ Sexo $=\mathrm{F}$ & 0,205 & 0,710 \\
\hline \multirow{6}{*}{ Y } & Idade $=$ de 22 a 24 anos & $\rightarrow$ Sexo $=M$ & 0,461 & 0,717 \\
\hline & Cor $=$ branca & $\rightarrow$ Sexo $=M$ & 0,372 & 0,702 \\
\hline & Cor $=$ branca e Idade $=$ de 22 a 24 anos & $\rightarrow$ Sexo $=\mathrm{M}$ & 0,269 & 0,745 \\
\hline & $\operatorname{Sexo}=F$ & $\rightarrow \begin{array}{l}\text { Exposição = } \\
\text { Heterossexual }\end{array}$ & 0,255 & 0,770 \\
\hline & Idade $=$ de 22 a 24 anos e Escolaridade $=$ de 8 a 11 anos & $\rightarrow$ Sexo $=\mathrm{M}$ & 0,231 & 0,733 \\
\hline & Exposição = HSH & $\rightarrow$ Idade $=$ de 22 a 24 anos & 0,230 & 0,753 \\
\hline \multirow{8}{*}{ M } & Escolaridade $=$ de 8 a 11 anos & $\rightarrow \mathrm{Sexo}=\mathrm{M}$ & 0,442 & 0,781 \\
\hline & Cor $=$ branca & $\rightarrow$ Sexo $=M$ & 0,355 & 0,802 \\
\hline & Idade $=$ de 19 a 21 anos & $\rightarrow$ Sexo $=\mathrm{M}$ & 0,355 & 0,783 \\
\hline & Sexo $=\mathrm{M}$ e Escolaridade $=$ de 8 a 11 anos & $\rightarrow$ Exposição $=$ HSH & 0,321 & 0,727 \\
\hline & Cor $=$ parda & $\rightarrow \mathrm{Sexo}=\mathrm{M}$ & 0,294 & 0,738 \\
\hline & Idade $=$ de 22 a 24 anos & $\rightarrow$ Sexo $=\mathrm{M}$ & 0,287 & 0,861 \\
\hline & Cor $=$ branca e Escolaridade $=$ de 8 a 11 anos & $\rightarrow$ Sexo $=\mathrm{M}$ & 0,208 & 0,807 \\
\hline & Idade $=$ de 19 a 21 anos e Escolaridade $=$ de 8 a 11 anos & $\rightarrow$ Sexo $=\mathrm{M}$ & 0,206 & 0,790 \\
\hline
\end{tabular}

Fonte: $O$ Autor

\subsection{Análise da Incidência de Aids no município de São Paulo}

A despeito dos avanços do Brasil relacionados ao combate à epidemia de Aids (74), a prevalência deste agravo a saúde ainda é motivo de preocupação para a sustentabilidade da Saúde Pública (75), principalmente com o acometimento de comorbidades (76). O HIV/Aids ainda é um agravo com nuances de desconhecimento, na ignorância da população geral, e alvo de preconceito com os grupos fortemente afetados pelo vírus (77). Analisar a prevalência auxilia na compreensão da magnitude que a epidemia de HIV/Aids tomou, enquanto que, avaliar a incidência pode ajudar no entendimento da evolução da epidemia. 


\subsubsection{Análise Descritiva}

Conforme observado nas análises que precedem o capítulo atual, o primeiro caso de Aids na Cidade de São Paulo é relatado em 1983. Observa-se nos dados a seguir a evolução da epidemia, diante de suas premissas, trançando o perfil de cada período dos casos notificados de Aids na Cidade.

A Figura 31 apresenta a incidência de Aids por ano, gênero e faixa etária para o município de São Paulo. As linhas verticais representam os anos em que as medicações começaram a se popularizar (1889) (44) e que começaram a ser distribuídas gratuitamente pelo governo (1996) (43-45). A partir do gráfico, observa-se que, a despeito popularização dos remédios, a incidência de Aids permaneceu em crescimento, principalmente para indivíduos do sexo masculino e faixa etária de 20 a 24 anos. Já a partir de 1996, nota-se que a incidência se manteve em um patamar menor que antes de 1996 e constante. A série dos indivíduos do sexo masculino e de 20 a 24 anos teve um decréscimo na incidência a partir do ano de 1991. As mulheres de 15 a 19 foram as que apresentaram menor incidência entre todos os grupos, enquanto que os indivíduos do sexo masculino e 20 a 24 apresentaram maior incidência de casos de Aids para toda a série observada.

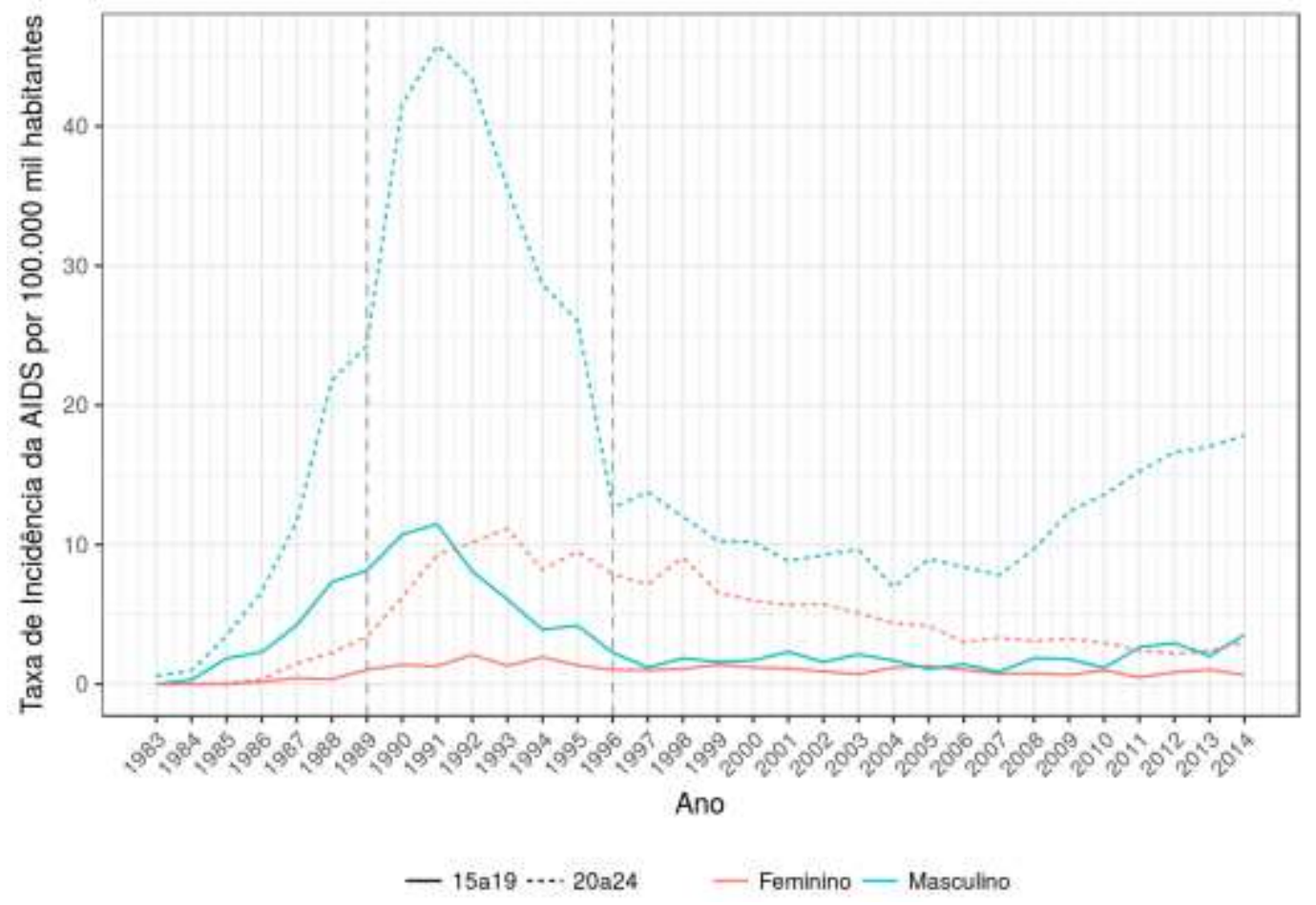

Fonte: $O$ Autor

Figura 31 - Taxa de Incidência de Aids por 100.000 mil habitantes 
A Figura 32 busca visualizar a distribuição da incidência de casos de Aids entre sexo e faixa etária:

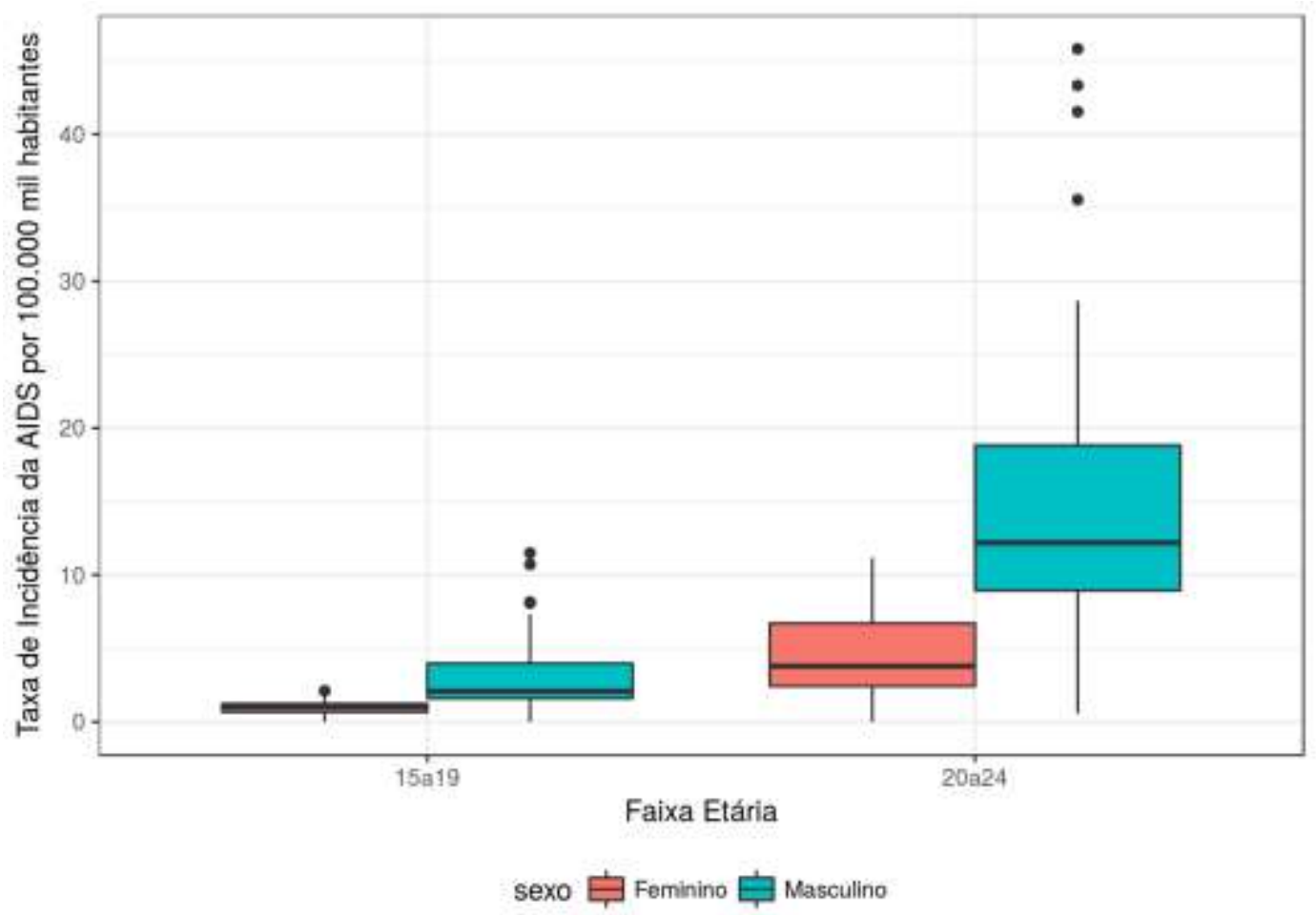

Fonte: O Autor

Figura 32 - Taxa de Incidência da Aids por 100.000 mil habitantes

Nota-se que as "caixas" da faixa etária dos indivíduos de 20 a 24 anos apresentam maior incidência do que a dos indivíduos de 15 a 19 anos; ainda, dentro de cada faixa etária, o sexo masculino apresentou maior incidência de Aids que os indivíduos do sexo feminino. Embora esse gráfico não leva em consideração os anos, é possível ver de forma mais clara a distribuição e comportamento "médio" / "mediano" das covariáveis sexo e faixa etária.

\subsection{Tabelas de análise para incidência de Aids na Cidade de São Paulo}

Além dos dados obtidos de notificações de Aids do município de São Paulo (33), as análises e tabelas apresentadas a seguir contaram com dado do IBGE (71) de cada um dos períodos apresentados. Para compreendermos a trajetória da epidemia na Cidade, a Tabela 31 apresenta a taxa de incidência de Aids para 100.000 habitantes por ano. 
Tabela 31 - Incidência de Aids por ano

\begin{tabular}{c|c|c|c|c|c|c|c}
\hline Ano & Aids & Pop & Taxa $^{\mathbf{a}}$ & Ano & Aids & Pop & Taxa $^{\mathbf{a}}$ \\
\hline $\mathbf{1 9 8 3}$ & 4 & 3652975 & 0.10950 & 1999 & 310 & 6448197 & 4.80755 \\
\hline $\mathbf{1 9 8 4}$ & 9 & 3673207 & 0.24502 & 2000 & 301 & 6559958 & 4.58844 \\
\hline $\mathbf{1 9 8 5}$ & 38 & 3692736 & 1.02905 & 2001 & 283 & 6530921 & 4.33323 \\
\hline $\mathbf{1 9 8 6}$ & 69 & 3711546 & 1.85906 & 2002 & 276 & 6492786 & 4.25087 \\
\hline $\mathbf{1 9 8 7}$ & 136 & 3729681 & 3.64642 & 2003 & 272 & 6450035 & 4.21703 \\
\hline $\mathbf{1 9 8 8}$ & 239 & 3747175 & 6.37814 & 2004 & 223 & 6404485 & 3.48193 \\
\hline $\mathbf{1 9 8 9}$ & 286 & 3764022 & 7.59826 & 2005 & 241 & 6356521 & 3.79138 \\
\hline $\mathbf{1 9 9 0}$ & 470 & 3780253 & 12.43303 & 2006 & 209 & 6304350 & 3.31517 \\
\hline $\mathbf{1 9 9 1}$ & 545 & 3795912 & 14.35755 & 2007 & 195 & 6247408 & 3.12129 \\
\hline $\mathbf{1 9 9 2}$ & 533 & 3873987 & 13.75844 & 2008 & 227 & 6188247 & 3.66824 \\
\hline $\mathbf{1 9 9 3}$ & 472 & 3953674 & 11.93826 & 2009 & 264 & 6127089 & 4.30873 \\
\hline $\mathbf{1 9 9 4}$ & 381 & 4036035 & 9.43996 & 2010 & 271 & 6066295 & 4.46731 \\
\hline $\mathbf{1 9 9 5}$ & 379 & 4118029 & 9.20343 & 2011 & 289 & 6020485 & 4.80028 \\
\hline $\mathbf{1 9 9 6}$ & 352 & 6105461 & 5.76533 & 2012 & 307 & 5974052 & 5.13889 \\
\hline $\mathbf{1 9 9 7}$ & 345 & 6216670 & 5.54959 & 2013 & 303 & 5927030 & 5.11217 \\
\hline $\mathbf{1 9 9 8}$ & 374 & 6332058 & 5.90645 & 2014 & 331 & 5879471 & 5.62976 \\
\hline
\end{tabular}

Fonte: $O$ Autor

No ano de 1987, observa-se que a taxa de incidência é de 3.64642 casos por 100.000 habitantes. Todo o enfoque da visualização dessas taxas e quais são os comportamentos do número ao longo dos anos por sexo e faixa etária, são notados ao visualizarmos a Figura 33. Nos dados apresentados na Tabela 31 e visualizados na Figura 33 observa-se a evolução da Taxa de Incidência para o município. A tendência observada ao longo deste estudo permanece presente, em 1991 encontra-se o pico da Taxa de Incidência, observa-se queda nos anos seguintes, mas a taxa tem se elevado novamente, como é notado a partir do ano de 2008.

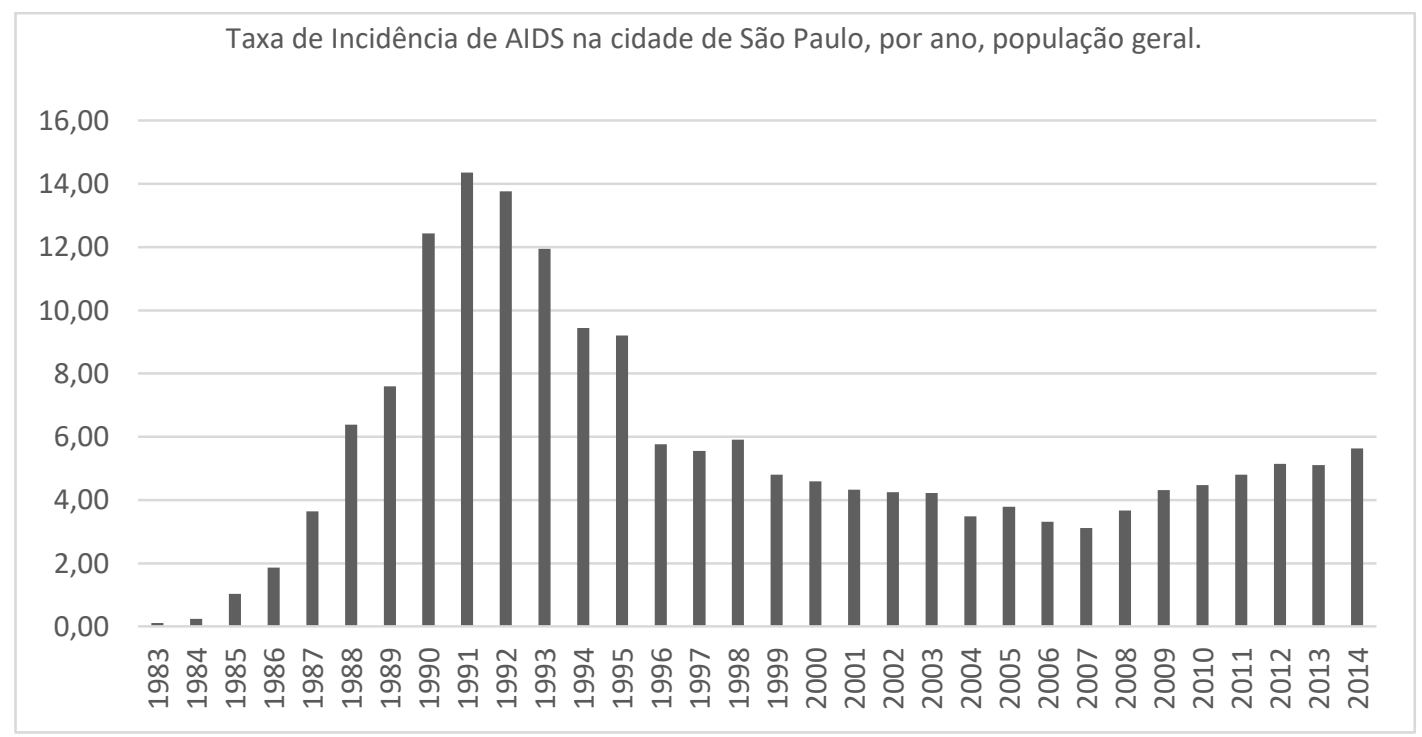

Fonte: (33)

Figura 33 - Taxa de Incidência de Aids na cidade de São Paulo, por ano, população geral 
A Tabela 32 apresenta a taxa de incidência de Aids para 100.000 habitantes por ano e sexo. Esta segmentação apresenta os anos com maior taxa de incidência por 100.000 habitantes, sendo, em ordem decresceste da taxa, 1993, 1992, 1995, 1991 e 1998 para o sexo feminino, com as respectivas taxas de 6,33, 6,21, 5,50, 5,36 e 5,16. Para o sexo masculino, temos os anos de 1991, 1990, 1992, 1993 e 1994, com taxas de incidência, respectivamente, de 29,28, 26,73, 26,27, 21,22 e 16,57.

Tabela 32 - Incidência de Aids por sexo e ano

\begin{tabular}{|c|c|c|c|c|c|c|}
\hline \multirow[b]{2}{*}{ Ano } & \multicolumn{3}{|c|}{ Feminino } & \multicolumn{3}{|c|}{ Masculino } \\
\hline & Aids & Pop & $\operatorname{Taxa}^{a}$ & Aids & Pop & $\operatorname{Taxa}^{\mathbf{b}}$ \\
\hline 1983 & 0 & 2305015 & 0.00000 & 4 & 1347960 & 0.29674 \\
\hline 1984 & 0 & 2314970 & 0.00000 & 9 & 1358237 & 0.66262 \\
\hline 1985 & 1 & 2324334 & 0.04302 & 37 & 1368402 & 2.70388 \\
\hline 1986 & 6 & 2333074 & 0.25717 & 63 & 1378472 & 4.57028 \\
\hline 1987 & 23 & 2341226 & 0.98239 & 113 & 1388455 & 8.13854 \\
\hline 1988 & 31 & 2348804 & 1.31982 & 208 & 1398371 & 14.87445 \\
\hline 1989 & 53 & 2355808 & 2.24976 & 233 & 1408214 & 16.54578 \\
\hline 1990 & 91 & 2362247 & 3.85226 & 379 & 1418006 & 26.72767 \\
\hline 1991 & 127 & 2368136 & 5.36287 & 418 & 1427776 & 29.27630 \\
\hline 1992 & 150 & 2415812 & 6.20909 & 383 & 1458175 & 26.26571 \\
\hline 1993 & 156 & 2464469 & 6.32996 & 316 & 1489205 & 21.21938 \\
\hline 1994 & 129 & 2514756 & 5.12972 & 252 & 1521279 & 16.56501 \\
\hline 1995 & 141 & 2564722 & 5.49767 & 238 & 1553307 & 15.32215 \\
\hline 1996 & 162 & 3589135 & 4.51362 & 190 & 2516326 & 7.55069 \\
\hline 1997 & 151 & 3654987 & 4.13134 & 194 & 2561683 & 7.57315 \\
\hline 1998 & 192 & 3723152 & 5.15692 & 182 & 2608906 & 6.97610 \\
\hline 1999 & 152 & 3791620 & 4.00884 & 158 & 2656577 & 5.94750 \\
\hline 2000 & 140 & 3857457 & 3.62933 & 161 & 2702501 & 5.95744 \\
\hline 2001 & 132 & 3833828 & 3.44303 & 151 & 2697093 & 5.59862 \\
\hline 2002 & 129 & 3804896 & 3.39037 & 147 & 2687890 & 5.46897 \\
\hline 2003 & 112 & 3773333 & 2.96820 & 160 & 2676702 & 5.97751 \\
\hline 2004 & 106 & 3740197 & 2.83408 & 117 & 2664288 & 4.39142 \\
\hline 2005 & 104 & 3705723 & 2.80647 & 137 & 2650798 & 5.16825 \\
\hline 2006 & 76 & 3668878 & 2.07148 & 133 & 2635472 & 5.04653 \\
\hline 2007 & 77 & 3629357 & 2.12159 & 118 & 2618051 & 4.50717 \\
\hline 2008 & 72 & 3588651 & 2.00632 & 155 & 2599596 & 5.96246 \\
\hline 2009 & 73 & 3546921 & 2.05812 & 191 & 2580168 & 7.40262 \\
\hline 2010 & 72 & 3505513 & 2.05391 & 199 & 2560782 & 7.77106 \\
\hline 2011 & 53 & 3472405 & 1.52632 & 236 & 2548080 & 9.26188 \\
\hline 2012 & 53 & 3438976 & 1.54116 & 254 & 2535076 & 10.01942 \\
\hline 2013 & 59 & 3405270 & 1.73261 & 244 & 2521760 & 9.67578 \\
\hline 2014 & 62 & 3371280 & 1.83906 & 269 & 2508191 & 10.72486 \\
\hline
\end{tabular}

\footnotetext{
${ }^{\text {a }}$ Taxa por 100.000 habitantes

${ }^{\mathrm{b}}$ Taxa por 100.000 habitantes

Fonte: $O$ Autor
} 
Dos anos destacados com maiores taxas de incidência entre o sexo feminino e masculino, observa-se na Tabela 33, apenas o ano de 1998 apresentou percentual próximo para os dois sexos, entretanto, quando avaliamos a taxa deste ano para os sexos em separados obtemos taxa de 5,16 para o sexo feminino e taxa de 6,98 para o sexo masculino. Desta forma, esse comportamento dos números se dá mais pela baixa taxa de incidência do sexo masculino do que por um aumento significativo da taxa para o sexo feminino.

Tabela 33 - Distribuição percentual da Taxa de Incidência de Casos de Aids no Município de São Paulo

\begin{tabular}{c|c|c}
\hline Ano & Feminino & Masculino \\
\hline $\mathbf{1 9 9 0}$ & $13 \%$ & $87 \%$ \\
\hline $\mathbf{1 9 9 1}$ & $15 \%$ & $85 \%$ \\
\hline $\mathbf{1 9 9 2}$ & $19 \%$ & $81 \%$ \\
\hline $\mathbf{1 9 9 3}$ & $23 \%$ & $77 \%$ \\
\hline $\mathbf{1 9 9 4}$ & $24 \%$ & $76 \%$ \\
\hline $\mathbf{1 9 9 5}$ & $26 \%$ & $74 \%$ \\
\hline $\mathbf{1 9 9 8}$ & $43 \%$ & $57 \%$ \\
\hline
\end{tabular}

Fonte: $O$ Autor

Ao analisamos a Figura 34, observa-se que o pico da taxa de incidência para o sexo feminino ocorreu no ano de 1993 (6,33 casos por 100.000 habitantes), com o segundo ano com maior taxa o de 1992 (6,21 casos por 100.000 habitantes). Para o sexo masculino o pico ocorre no ano de 1991 (29,28 casos por 100.000 habitantes), seguido pelo ano de 1990 e 1992 (26,73 e 26,27 casos por 100.000 habitantes, respectivamente).

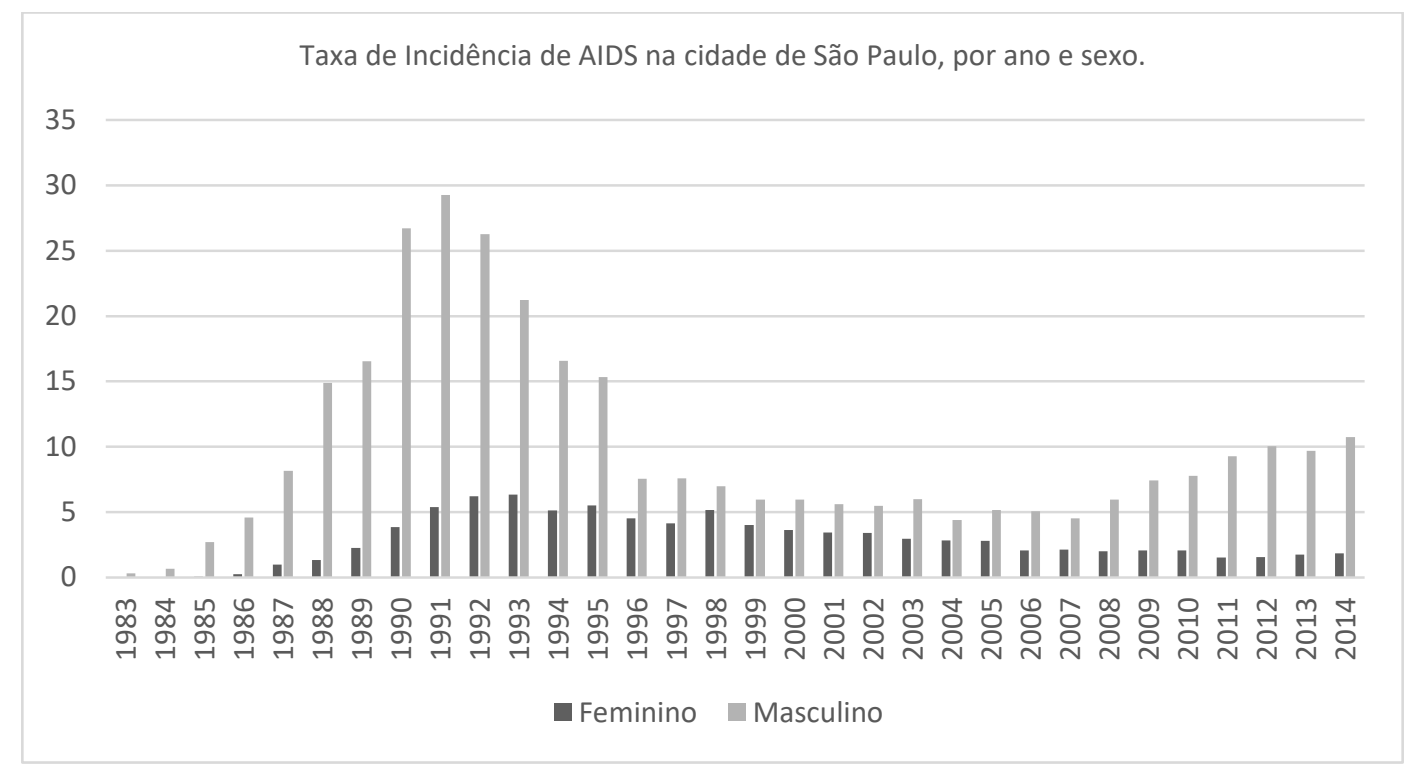

Fonte: (33)

Figura 34 - Taxa de Incidência de Aids na cidade de São Paulo, por ano e sexo 
Como consequência da apresentação dos dados do IBGE, por faixa etária, as análises por geração para essa segmentação de dados não pode ocorrer, dessa forma, apresenta-se na Tabela 34, a taxa de incidência de Aids para 100.000 habitantes por ano e faixa etária.

Tabela 34 - Incidência de Aids por faixa etária e ano

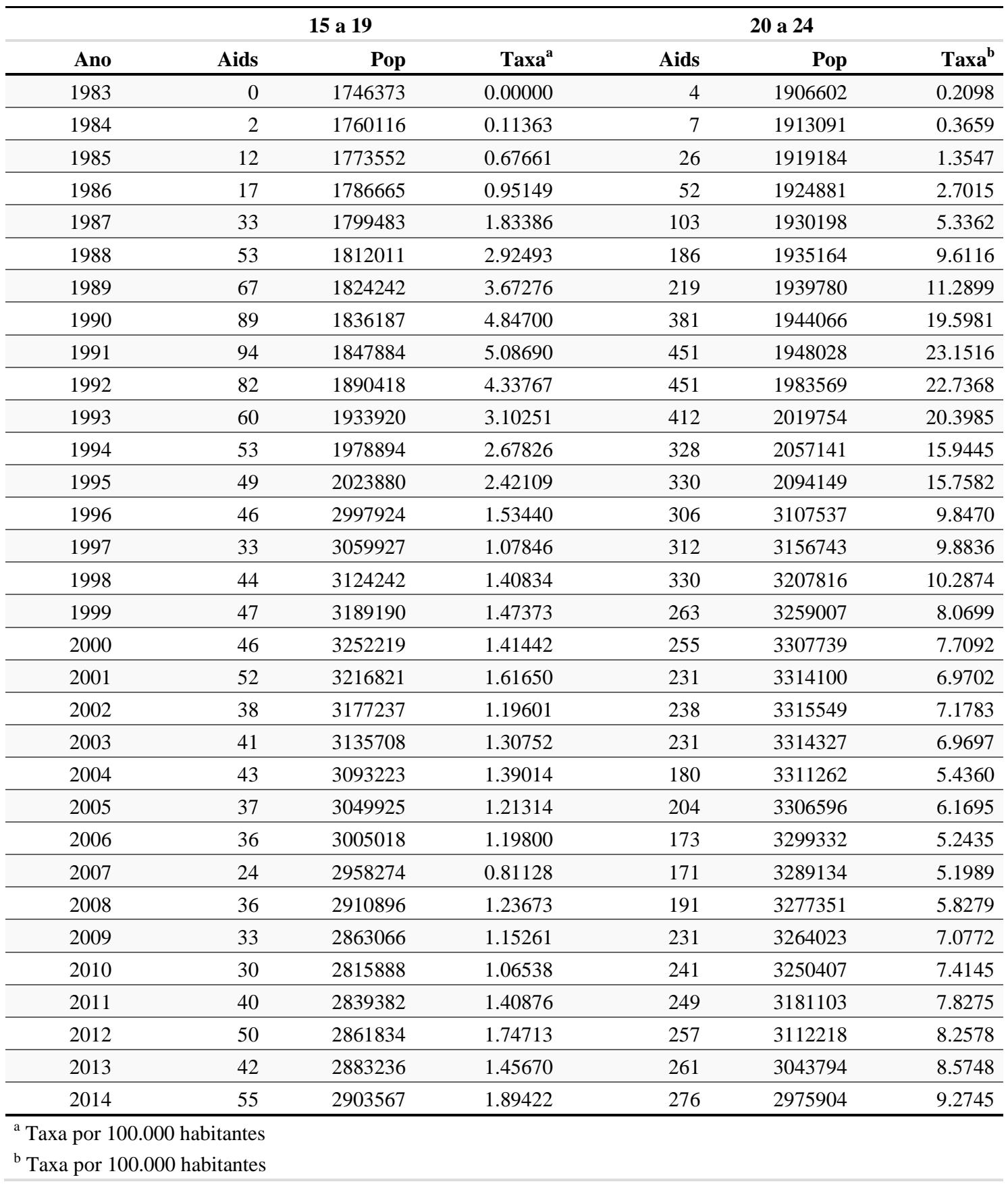

Fonte: $O$ Autor 
Complementando a apresentação desses dados, a Tabela 35 apresenta a taxa de incidência de Aids para 100.000 habitantes por ano, sexo e faixa etária da Cidade de São Paulo.

Tabela 35 - Incidência de Aids por faixa etária, sexo e ano da Cidade de São Paulo.

\begin{tabular}{|c|c|c|c|c|c|c|c|c|c|c|c|c|}
\hline \multirow[b]{2}{*}{ Ano } & \multicolumn{3}{|c|}{ Fem.15a19 } & \multicolumn{3}{|c|}{ Fem.20a24 } & \multicolumn{3}{|c|}{ Masc.15a19 } & \multicolumn{3}{|c|}{ Masc.20a24 } \\
\hline & Aids & Pop & Taxa $^{\mathbf{a}}$ & Aids & Pop & Taxa $^{b}$ & Aids & Pop & $\operatorname{Taxa}^{\mathrm{c}}$ & Aids & Pop & Taxa $^{\text {d }}$ \\
\hline 1983 & 0 & 1111335 & 0.00000 & 0 & 1193680 & 0.00000 & 0 & 635038 & 0.00000 & 4 & 712922 & 0.56107 \\
\hline 1984 & 0 & 1118383 & 0.00000 & 0 & 1196587 & 0.00000 & 2 & 641733 & 0.31166 & 7 & 716504 & 0.97697 \\
\hline 1985 & 0 & 1125163 & 0.00000 & 1 & 1199171 & 0.08339 & 12 & 648389 & 1.85074 & 25 & 720013 & 3.47216 \\
\hline 1986 & 2 & 1131652 & 0.17673 & 4 & 1201422 & 0.33294 & 15 & 655013 & 2.29003 & 48 & 723459 & 6.63479 \\
\hline 1987 & 5 & 1137872 & 0.43942 & 18 & 1203354 & 1.49582 & 28 & 661611 & 4.23209 & 85 & 726844 & 11.69439 \\
\hline 1988 & 4 & 1143823 & 0.34970 & 27 & 1204981 & 2.24070 & 49 & 668188 & 7.33327 & 159 & 730183 & 21.77536 \\
\hline 1989 & 12 & 1149503 & 1.04393 & 41 & 1206305 & 3.39881 & 55 & 674739 & 8.15130 & 178 & 733475 & 24.26804 \\
\hline 1990 & 16 & 1154914 & 1.38538 & 75 & 1207333 & 6.21204 & 73 & 681273 & 10.71523 & 306 & 736733 & 41.53472 \\
\hline 1991 & 15 & 1160075 & 1.29302 & 112 & 1208061 & 9.27106 & 79 & 687809 & 11.48575 & 339 & 739967 & 45.81285 \\
\hline 1992 & 25 & 1184675 & 2.11028 & 125 & 1231137 & 10.15322 & 57 & 705743 & 8.07659 & 326 & 752432 & 43.32617 \\
\hline 1993 & 16 & 1209815 & 1.32252 & 140 & 1254654 & 11.15845 & 44 & 724105 & 6.07647 & 272 & 765100 & 35.55091 \\
\hline 1994 & 24 & 1235801 & 1.94206 & 105 & 1278955 & 8.20983 & 29 & 743093 & 3.90261 & 223 & 778186 & 28.65639 \\
\hline 1995 & 17 & 1261695 & 1.34739 & 124 & 1303027 & 9.51630 & 32 & 762185 & 4.19846 & 206 & 791122 & 26.03897 \\
\hline 1996 & 18 & 1763347 & 1.02079 & 144 & 1825788 & 7.88701 & 28 & 1234577 & 2.26798 & 162 & 1281749 & 12.63898 \\
\hline 1997 & 18 & 1797451 & 1.00142 & 133 & 1857536 & 7.16002 & 15 & 1262476 & 1.18814 & 179 & 1299207 & 13.77764 \\
\hline 1998 & 20 & 1832761 & 1.09125 & 172 & 1890391 & 9.09865 & 24 & 1291481 & 1.85833 & 158 & 1317425 & 11.99309 \\
\hline 1999 & 26 & 1868291 & 1.39165 & 126 & 1923329 & 6.55114 & 21 & 1320899 & 1.58983 & 137 & 1335678 & 10.25696 \\
\hline 2000 & 23 & 1902585 & 1.20888 & 117 & 1954872 & 5.98505 & 23 & 1349634 & 1.70417 & 138 & 1352867 & 10.20056 \\
\hline 2001 & 21 & 1878521 & 1.11790 & 111 & 1955307 & 5.67686 & 31 & 1338300 & 2.31637 & 120 & 1358793 & 8.83137 \\
\hline 2002 & 17 & 1852078 & 0.91789 & 112 & 1952818 & 5.73530 & 21 & 1325159 & 1.58472 & 126 & 1362731 & 9.24614 \\
\hline 2003 & 13 & 1824593 & 0.71249 & 99 & 1948740 & 5.08021 & 28 & 1311115 & 2.13559 & 132 & 1365587 & 9.66617 \\
\hline 2004 & 21 & 1796641 & 1.16885 & 85 & 1943556 & 4.37343 & 22 & 1296582 & 1.69677 & 95 & 1367706 & 6.94594 \\
\hline 2005 & 23 & 1768289 & 1.30069 & 81 & 1937434 & 4.18079 & 14 & 1281636 & 1.09235 & 123 & 1369162 & 8.98360 \\
\hline 2006 & 18 & 1739109 & 1.03501 & 58 & 1929769 & 3.00554 & 18 & 1265909 & 1.42190 & 115 & 1369563 & 8.39684 \\
\hline 2007 & 13 & 1708960 & 0.76070 & 64 & 1920397 & 3.33264 & 11 & 1249314 & 0.88048 & 107 & 1368737 & 7.81743 \\
\hline 2008 & 13 & 1678538 & 0.77448 & 59 & 1910113 & 3.08882 & 23 & 1232358 & 1.86634 & 132 & 1367238 & 9.65450 \\
\hline 2009 & 11 & 1647973 & 0.66749 & 62 & 1898948 & 3.26497 & 22 & 1215093 & 1.81056 & 169 & 1365075 & 12.38027 \\
\hline 2010 & 16 & 1617882 & 0.98895 & 56 & 1887631 & 2.96668 & 14 & 1198006 & 1.16861 & 185 & 1362776 & 13.57523 \\
\hline 2011 & 8 & 1628537 & 0.49124 & 45 & 1843868 & 2.44052 & 32 & 1210845 & 2.64278 & 204 & 1337235 & 15.25536 \\
\hline 2012 & 14 & 1638528 & 0.85443 & 39 & 1800448 & 2.16613 & 36 & 1223306 & 2.94285 & 218 & 1311770 & 16.61877 \\
\hline 2013 & 17 & 1647856 & 1.03164 & 42 & 1757414 & 2.38988 & 25 & 1235380 & 2.02367 & 219 & 1286380 & 17.02452 \\
\hline 2014 & 11 & 1656490 & 0.66405 & 51 & 1714790 & 2.97413 & 44 & 1247077 & 3.52825 & 225 & 1261114 & 17.84137 \\
\hline 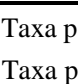 & 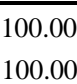 & nabilan & & & & & & & & & & \\
\hline
\end{tabular}

Fonte: $O$ Autor

Esse conjunto de dados será base para as análises e reflexões do capítulo 12, além de propor reflexões sobre as ações para a promoção da prevenção do agravo. 


\section{RESULTADOS DO MODELO DE REGRESSÃO}

De forma sucinta, os termos significativos do modelo foram:

- Uma curva suave dos anos para cada um dos sexos;

- Efeito aditivo de sexo;

- Efeito aditivo de faixa etária;

- Efeito aditivo de período (1996-2014);

A Tabela 36 apresenta as estimativas dos parâmetros do modelo para as variáveis sexo, faixa etária e período:

Tabela 36 - Resumo dos coeficientes paramétricos do modelo

\begin{tabular}{l|c|c|c|c|c|c}
\hline & Estimativa & Erro Padrão & $\begin{array}{c}\text { Razão } \\
\text { De Chances }\end{array}$ & IC(95\%) & Estatística-Z & Valor-p \\
\hline (Intercept) & -11.8768 & 0.10624 & 0.00001 & $0 ; 0$ & -111.7970 & 0.00000 \\
\hline sexoMasculino & 1.3958 & 0.06032 & 4.03824 & $3.5879 ; 4.5451$ & 23.1383 & 0.00000 \\
\hline faixa20a24 & 1.6281 & 0.03863 & 5.09423 & $4.7228 ; 5.4949$ & 42.1511 & 0.00000 \\
\hline periodo1996-2014 & -0.3068 & 0.14588 & 0.73580 & $0.5528 ; 0.9793$ & -2.1031 & 0.03546 \\
\hline
\end{tabular}

Fonte: $O$ Autor

Interpretação do modelo considerando constante o valor das demais covariáveis:

- A chance de ter um novo caso de Aids para os indivíduos do sexo masculino foi 4.03 vezes que a do sexo feminino (IC 95\%: 3.59 ; 4.55);

- A chance de ter um novo caso de Aids para os indivíduos da faixa etária de 20 a 24 anos foi 5.09 vezes que entre os indivíduos de 15 a 19 anos (IC 95\%: $4.72 ; 5.49)$;

- A chance de ter um novo caso de Aids entre 1983 e 1995 foi 1.3591 (1/0.73580) vezes a chance de ter um caso novo de Aids entre 1996 e 2014. 
A Figura 35 apresenta as estimativas do modelo na escala da variável resposta:
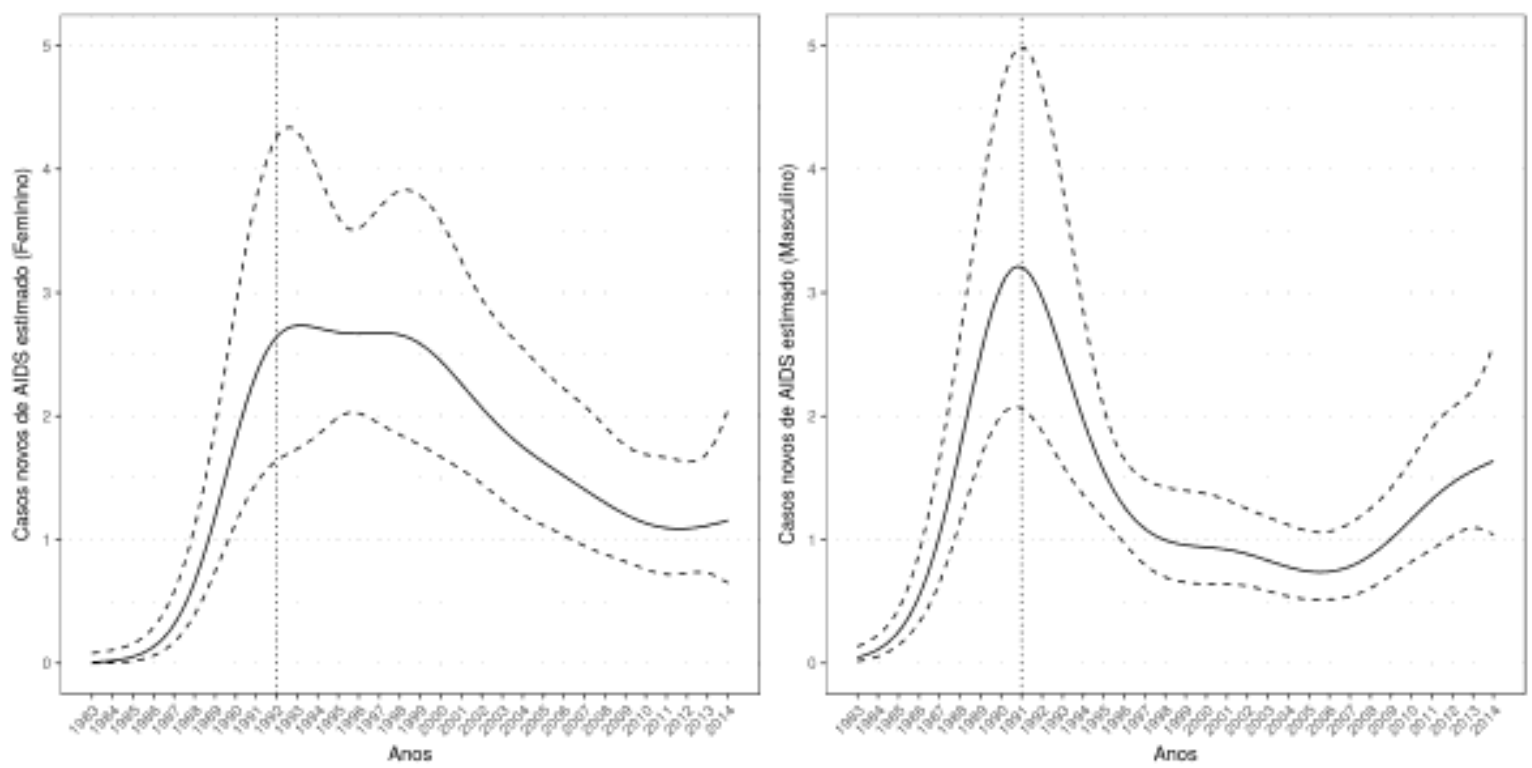

Fonte: $O$ Autor

Figura 35 - Casos novos de Aids estimado

O gráfico da esquerda apresenta a curva dos casos novos estimados de Aids entre os indivíduos do sexo feminino e o da direita para os indivíduos do sexo masculino. A linha contínua representa a curva estimada, e as linhas pontilhadas representam o intervalo de confiança correspondente.

Para os indivíduos do sexo feminino, o número de casos novos chegou ao pico no ano de 1992, e manteve-se constante praticamente até o ano de 1999 e o número de casos decaiu até o ano 2012, com um leve aumento no ano de 2013 e 2014.

Para os indivíduos do sexo masculino, a partir de 1983, o número de casos novos chegou ao pico no ano de 1991 e então a incidência para essa parcela da população diminui até 2006, e após esse ano, a incidência dos casos de Aids aumentou. 


\section{REFLEXÕES E PRINCIPAIS DESAFIOS PARA O ENFRETAMENTO DA EPIDEMIA DE AIDS}

A epidemia de Aids no Brasil tem um considerável crescimento ao longo dos últimos anos, o que fundamenta diversas necessidades de análise. O propósito desta pesquisa foi oferecer uma reflexão sobre os dados da epidemia no Estado de São Paulo. Com base nessa análise, observa-se que, para o Estado, ocorreu um pico de casos notificados em 2002, e a partir de então a epidemia se mantém constante tanto no cenário brasileiro como também no cenário do Estado de São Paulo, apesar de pequena diferença em relação ao crescimento. Observando o ano de 1993, houve considerável aumento no número de casos notificados, até 1998. Houve, no entanto, nos anos subsequentes, redução no número de casos notificados, principalmente com idade entre 15 a 24 anos, até 2007.

Quando comparamos os dados do Estado de São Paulo, da Região Metropolitana de São Paulo e do Município de São Paulo, nota-se que, na evolução, são muito próximos no comportamento a quantidade de casos ao longo de cada ano. Já para a faixa etária estudada nesta pesquisa, para essas mesmas regiões, observa-se o primeiro pico nos casos notificados em 1991. Seguindo o mesmo raciocínio ao analisarmos as notificações no Brasil, a partir de1991 os casos notificados de Aids dessa população estudada, encontramos um pico no ano de 1998 para a cidade de São Paulo e para Região Metropolitana, enquanto que no Estado esse comportamento também se apresenta, mas comparado aos outros dois cenários, temos um menor impacto nos anos subsequentes, as taxas de notificação tem pequenos decréscimos e, no ano de 2008 , ocorre novamente um aumento no número de casos notificados.

Quando observamos as políticas públicas voltadas para o HIV/Aids do Governo Federal e do Governo estadual de São Paulo, observamos algumas iniciativas que, tecnicamente, poderiam auxiliar na diminuição da incidência de casos de Aids na população, entretanto isso não se reflete nos números observados até então nesse estudo. Tivemos, nesse período o convênio do Governo Brasileiro com Banco Mundial e o acesso universal e gratuito às medicações antirretrovirais. Ao passo que os registros das campanhas de conscientização ao HIV/Aids e outras infecções sexualmente 
transmissíveis (IST) começaram a partir de 1998. Mesmo com o gap de informações, pode-se inferir que as temáticas observadas nos anos subsequentes seguiram os padrões que se observa ênfase nos jovens adultos, usuários de drogas e campanha sazonais para o carnaval. Já em 1999 são registradas campanhas focadas no uso da camisinha e para orientação aos indivíduos para buscarem auxílio médico sobre diagnóstico e tratamento. O ciclo de campanhas, então, se repete, sendo sazonais durante o carnaval e no dia mundial de luta contra a Aids.

Ao analisarmos os dados de cada uma das segmentações de categoria de exposição hierarquizada realizadas nessa pesquisa, nota-se, para o sexo masculino, comportamentos distintos no número de casos notificados. Para todas as segmentações, a partir de 1989 para o Estado de São Paulo e 1990 para o Município de São Paulo e Cidade de São Paulo, os casos do sexo masculino declarados como heterossexuais passam a ser maiores que os casos do sexo masculino declarados com HSH (Homens que fazem sexo com Homens). Até o ano de 2005 observamos esse comportamento dos casos masculino heterossexuais, as exceções ficam para os anos de 1997, 2001, 2002 e 2003 para a Região Metropolitana e os anos de 1997, 1999, 2001 e 2002 para a cidade de São Paulo.

Observando as campanhas vinculadas pelo Ministério da Saúde, nota-se que o enfoque generalista predominou durante esses anos, nessas veiculações. As Populações Chave não eram tema foco nas peças de informe público, e os alertas sobre os principais meios de contato não eram nas campanhas. Essas temáticas permaneceram ao longo dos anos, com campanhas generalistas e sazonais, no Carnaval e o Dia Mundial de Combate à Aids. Há de se considerar, dessa forma, o quanto às populações em geral enxerga-se incluída no risco possível de infecção e nas ações efetivas para testagem. O indivíduo deve se perceber como alguém passível de risco, sendo este um ponto chave para a tomada de decisão, o primeiro passo para o cuidado. Sem essa noção de pertencimento à população de "risco", suscetível à doença não há mudança de comportamento ou iniciativa para testagem. Buscando o histórico de programas de testagem do CRT, o início dos testes rápidos se iniciou em 2005 (78), este fato agiliza o processo de diagnóstico,

Um dos focos deste trabalho era identificar marcadores históricos que pudessem auxiliar na compreensão do comportamento de cada Geração. Temos dois pontos importantes a serem considerados para o objetivo deste trabalho: o primeiro é a limitação da faixa etária, 15 a 24 anos, reflexo da autorização feita pelo Centro de Vigilância Epidemiológica. Fato é que a delimitação de idade era prevista para a produção dessas 
análises, mas a compreensão completa das Gerações ficou inviabilizada por essa delimitação de idade, temos os dados desta faixa etária e não de outras.

Com isso essa delimitação exposta, temos duas gerações com todos os dados da janela de tempo definida, gerações X e Y, e duas gerações com limitação de tempo que seguimento parte do período possível de análise, geração Baby Bommers e M. O comportamento dessas gerações em relação ao sexo segue a tendência das delimitações só de idade, temos mais casos do sexo masculinos do que casos do sexo feminino

Quanto à categoria de exposição hierarquizada, ao levantarmos o tipo de exposição, nota-se que, durante o período de 1990 a 2005, temos aspectos muito parecidos com os encontrados nos recortes de delimitação geográfica (Estado, Região Metropolitana e Município de São Paulo).

No período de 1980 a 1998 as gerações que tiveram como categoria de exposição predominante os casos declarados como HSH. O acontecimento observado de aumento de casos para o sexo masculino heterossexual, como declaração de contato, passa o número de casos de HSH. Os casos de HSH voltam a ser maiores do que HSM. A representatividade nas campanhas novamente pode ser um fator de impacto.

Outra tendência verificada nas análises é de que, quanto maior a idade dos indivíduos, maiores os casos para a categoria de exposição HSM. Apesar de, nos comparativos com o número de casos do sexo masculino, o sexo feminino relativamente baixo, não há como desconsiderar e realizar uma leitura sobre esses dados. Nota-se, nesses casos, também, baixa representatividade nas ações realizadas pelo Ministério da Saúde. O foco observado nas campanhas é para caso de prevenção da transmissão vertical. Há a necessidade de um enfoque de prevenção para as mulheres.

As respostas governamentais, como a instituição do Sistema Único de Saúde, que tem como uma de suas diretrizes a manutenção de "um conjunto articulado e contínuo das ações e serviços preventivos e curativos, individuais e coletivos, exigidos para cada caso em todos os níveis de complexidade do sistema”, em algum sentido, não supriu as necessidades necessárias para o enfrentamento da Aids, como a produção de campanhas mais próximas aos públicos alvo, sem a segmentação de Populações Chave. Observa-se mais a possibilidade de gerar preconceito e os indivíduos poderiam não se sentir alvo das campanhas, assim como registrado nos dados dos anos 1990, registro de casos masculino heterossexuais maiores que o registro de casos masculinos $\mathrm{HSH}$. 
Há, nesse sentido, a possibilidade de criação de estratégias voltadas efetivamente para as Populações Chave, esclarecendo que todos que são sexualmente ativos correm algum tipo de risco associados às Infecções Sexualmente Transmissíveis.

Em suma, observa-se que as ações do Ministério da Saúde, frente à política de orientação da população, conforme Tabela 37, estão voltadas para a população base desta pesquisa, com textos guias das últimas 10 edições do Boletim Epidemiológico. Ainda, note-se que a preocupação com a Cascata do Cuidado Contínuo, sendo foco em 2 edições do Boletim nesse período de análise.

Tabela 37 - Resumo das Últimas 10 Edições do Boletim Epidemiológico de São Paulo.

\begin{tabular}{c|l}
\hline \multicolumn{1}{c|}{ Edições } & \multicolumn{1}{c}{ Tema } \\
\hline 4 & Jovens e Crianças \\
\hline 2 & Cascata do Cuidado Contínuo \\
\hline 1 & Idosos \\
\hline 1 & Notificação compulsória de casos de HIV \\
\hline 2 & Sem tema específico \\
\hline
\end{tabular}

Fonte: $O$ Autor

O universo de Casos de Aids ao longo dos anos é uma questão importantes para analisarmos. No Brasil, foram notificados 787.712 mil casos, de todas as faixas etárias, Figura 36. Destes casos, 32\% ocorreram no Estado de São Paulo, e da faixa etária analisada, de 15 a 24 anos, 3\% do total no Brasil e 10\% do total do estado. Esses dados podem ser observados nas Figuras Figura 36, Figura 37 e Figura 38.

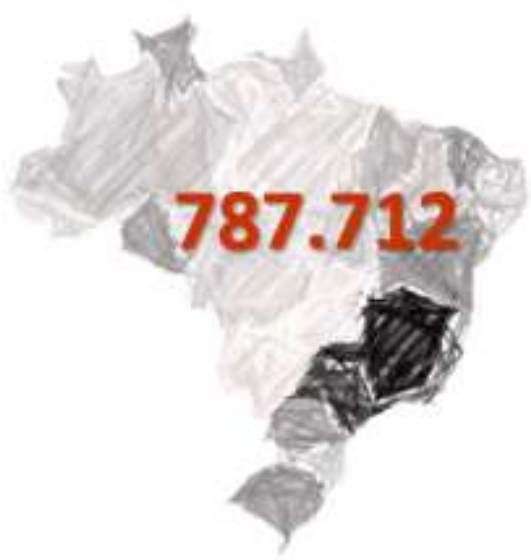

Figura 36 - Total de diagnósticos de Aids de 1980 a 2014 brasil 


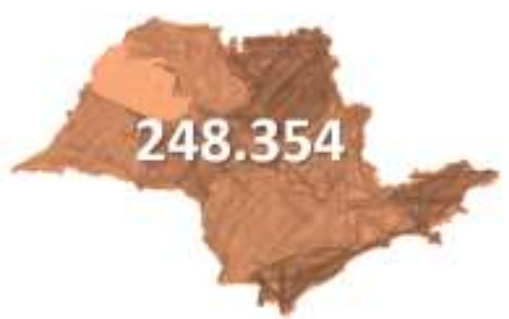

Figura 37 - Total de diagnósticos de Aids de 1980 a 2014 São Paulo

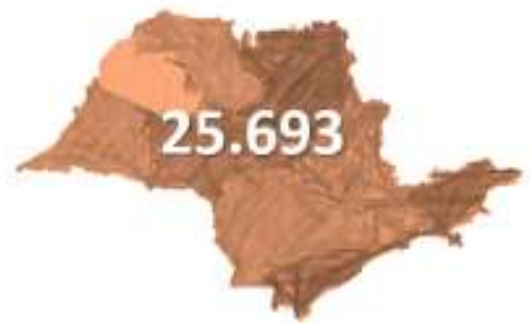

Figura 38 - Total de diagnósticos de Aids de 1980 a 2014 São Paulo - Faixa etária de 15 a 24 anos

No levantamento histórico, composto pela análise das vinculações de Informes Públicos de atenção ao combate ao HIV, Tabela 38, as campanhas são voltadas para Populações Chave vulneráveis, deixando de lado populações do grupo de heterossexuais. Das 3 campanhas voltadas para o público heterossexual, um tenha como tema Caminhoneiros, um para Profissionais do sexo e um para prevenção da Transmissão Vertical do vírus.

Tabela 38 - Resumo das Campanhas de Prevenção do Ministério da Saúde - 1998 a 2004

\begin{tabular}{c|l}
\hline Edições & \multicolumn{1}{c}{ Tema } \\
\hline 7 & Dia Mundial de Luta contra a Aids \\
\hline 6 & Carnaval \\
\hline 6 & Adesão ao Tratamento \\
\hline 2 & LGBTQ+ \\
\hline 1 & Usuário de Drogas \\
\hline 3 & Campanhas voltadas apenas ao Público Heterossexual \\
\hline
\end{tabular}

Fonte: $O$ autor

As campanhas identificadas refletem, em partes, a evolução histórica da infecção. Ao analisar as Gerações e a Categoria de Exposição Hierarquizada, observa-se que, para as Gerações $\mathrm{X}, \mathrm{Y}$ e $\mathrm{M}$, contato heterossexual são mais evidentes, conforme consta na Tabela 39.

Tabela 39 - Distribuição de meio de contato por geração em casos de Aids no Estado de São Paulo,

\begin{tabular}{|c|c|c|c|c|c|c|c|c|c|}
\hline $\begin{array}{c}\text { Geração/ } \\
\text { Exposição }\end{array}$ & Bissexual & Hemofílico & Heterossexual & HSH & Ignorado & $\begin{array}{c}\text { Não } \\
\text { informado }\end{array}$ & Transfusão & $\begin{array}{c}\text { Transmissão } \\
\text { Vertical }\end{array}$ & UDI \\
\hline Baby boomer & $9 \%$ & $2 \%$ & $9 \%$ & $41 \%$ & $4 \%$ & $2 \%$ & $0 \%$ & $0 \%$ & $34 \%$ \\
\hline Geraçãa X & $4 \%$ & $1 \%$ & $32 \%$ & $8 \%$ & $11 \%$ & $4 \%$ & $0 \%$ & $0 \%$ & $41 \%$ \\
\hline Geração Y & $6 \%$ & $0 \%$ & $44 \%$ & $23 \%$ & $8 \%$ & $13 \%$ & $0 \%$ & $0 \%$ & $6 \%$ \\
\hline Geração M & $6 \%$ & $0 \%$ & $28 \%$ & $35 \%$ & $8 \%$ & $20 \%$ & $0 \%$ & $2 \%$ & $3 \%$ \\
\hline
\end{tabular}

Fonte: O Autor 
A questão de gênero também é um ponto importante para a análise desse contexto, visto que um dos achados deste trabalho versou sobre a Categoria de Exposição heterossexual, observa-se tal fato realizando o cálculo da Razão HSM versus $\mathrm{HSH}$, em que, em 9 anos dos 32 analisados, nota-se que o resultado é quase 1 caso de HSM para 1 caso de HSH.

Tabela 40 - Notificações para o sexo Masculino, Razão Heterossexual: HSH, Município de São Paulo, 1983 a 2014

\begin{tabular}{|c|c|c|c}
\hline Ano & Razão HSM: HSH & Ano & Razão HSM: HSH \\
\hline $\mathbf{1 9 8 3}$ & 0,0 & $\mathbf{1 9 9 9}$ & 0,6 \\
\hline $\mathbf{1 9 8 4}$ & 0,0 & $\mathbf{2 0 0 0}$ & 1,0 \\
\hline $\mathbf{1 9 8 5}$ & 0,1 & $\mathbf{2 0 0 1}$ & 0,5 \\
\hline $\mathbf{1 9 8 6}$ & 0,1 & $\mathbf{2 0 0 2}$ & 0,3 \\
\hline $\mathbf{1 9 8 7}$ & 0,3 & $\mathbf{2 0 0 3}$ & 0,7 \\
\hline $\mathbf{1 9 8 8}$ & 0,3 & $\mathbf{2 0 0 4}$ & 0,9 \\
\hline $\mathbf{1 9 8 9}$ & 0,4 & $\mathbf{2 0 0 5}$ & 0,4 \\
\hline $\mathbf{1 9 9 0}$ & 0,9 & $\mathbf{2 0 0 6}$ & 0,4 \\
\hline $\mathbf{1 9 9 1}$ & 1,2 & $\mathbf{2 0 0 7}$ & 0,3 \\
\hline $\mathbf{1 9 9 2}$ & 1,4 & $\mathbf{2 0 0 8}$ & 0,3 \\
\hline $\mathbf{1 9 9 3}$ & 1,2 & $\mathbf{2 0 0 9}$ & 0,3 \\
\hline $\mathbf{1 9 9 4}$ & 0,9 & $\mathbf{2 0 1 0}$ & 0,3 \\
\hline $\mathbf{1 9 9 5}$ & 1,2 & $\mathbf{2 0 1 1}$ & 0,2 \\
\hline $\mathbf{1 9 9 6}$ & 0,9 & $\mathbf{2 0 1 2}$ & 0,2 \\
\hline $\mathbf{1 9 9 7}$ & 0,6 & $\mathbf{2 0 1 3}$ & 0,1 \\
\hline $\mathbf{1 9 9 8}$ & 0,7 & $\mathbf{2 0 1 4}$ & 0,2 \\
\hline & & & \\
\hline
\end{tabular}

Fonte: $O$ Autor

A compreensão sobre esses fatores pode facilitar o diálogo com essa população, sendo necessário a segmentação das ações do Ministério da Saúde e demais órgão que buscam diminuir os índices de infecção por HIV e, consequentemente, com ações voltadas para a Adesão ao tratamento, a diminuição das notificações de Aids. 


\section{CONCLUSÃO}

A epidemia de Aids no Brasil, assim como no mundo, acompanhou a evolução dos diversos tipos de tratamentos empregados. Apesar dos números se manterem estáveis e, em alguns períodos, se apresentarem com crescimento, a as ações e políticas públicas foram desenvolvidas visando a diminuição de casos.

Frente aos objetivos desta pesquisa, compreender as possíveis melhorias com o que diz respeito à comunicação e orientação da população, observa-se possibilidade de melhoria nas ações governamentais. O foco das campanhas em datas festivas e sazonais, fragiliza as ações de contenção do vírus, e no caso de indivíduos HIV+, a falta de conscientização sobre a Adesão ao Tratamento são fatores que ainda são desafios para as Políticas Públicas.

Esta pesquisa, ao se propor à avaliar os índices de notificação da Aids e as divisões geracionais, promoveu um entendimento sobre as condições de infecção, principalmente a observada nos períodos entre 1989 e 2004, em que a notificação para homens heterossexuais superou os números de notificação para homens HSH, demonstrando um cenário pouco comentado nos artigos que surgiram até a presente data. Nota-se, também, que, quando comparadas as Gerações, observa-se que indivíduos do sexo masculino são mais acometidos do que os indivíduos do sexo feminino, entretanto, os números acionam um alerta para a atenção para esse público.

Há de se considerar que, a despeito de o acesso ao tratamento antirretroviral ser gratuito no Brasil, outros aspectos relevantes estão envolvidos na evolução dos índices de incidência da Aids. Cabe, nesse sentido, novos estudos relacionados, principalmente, à adesão ao tratamento e ao incentivo para que os indivíduos conheçam sua sorologia, realizando a testagem para o HIV sempre que ocorrer contato sexual sem proteção.

Entre os principais achados dessa pesquisa, destaca-se que as chances, atuais de ter um novo caso de Aids são menores do que na década passada, e que homens tem mais de 4 vezes mais chances do que as mulheres. Ponto importante a se destacar é que o item Escolaridade não interferiu em qualquer resultado, supondo-se, assim, que independente do grau de instrução do indivíduo, as chances de um indivíduo com HIV evoluir para a Aids são as mesmas. 
Demais análises foram sugeridas ao longo da pesquisa e, apesar da quantidade de dados fornecida pelos órgãos responsáveis, não houve como aplicar o Escore de Propensão, o que auxiliaria na identificação de marcadores passíveis de análise para prever a probabilidade de um indivíduo, primeiro, contrair HIV, e depois, evoluir para a Aids. Além desse fato, a escassez em alguns registros de campanhas do Ministério da Saúde, inviabilizou uma análise mais profunda sobre as condições das produções vinculadas.

Como evolução para essa pesquisa, existe a possibilidade de análise quanto ao diagnóstico comparado ao IDH (índice de desenvolvimento humano) de cada Cidade do Estado, e até mesmo, de cada Bairro da Cidade de São Paulo. Ações pontuais e a criação de postos de atendimento em cada época e região são outros fatores importantes de análise. A aplicação deste modelo metodológico para outros Estados ou Regiões é um diferencial possível, utilizando os recortes históricos aqui dispostos e compreendendo a regionalidade, também, da epidemia.

Em suma, esta pesquisa contribui para a sociedade e políticas públicas, visto que promove uma reflexão sobre as ações públicas e o alcance dessas políticas para a população como um todo. Demonstra que Populações Chaves não foram devidamente orientadas pelas inserções de propaganda do governo. Promove uma análise sobre a necessidade conscientização da população geral frente aos perigos da Aids e outras ISTs. Neste caso, se faz necessário a abrangência das ações públicas voltadas para a População em Geral e em diferentes segmentações sociais. Espera-se que esta pesquisa possa possibilitar Insumo para Publicitários desenvolverem campanhas voltadas para a Prevenção e à Adesão ao Tratamento de HIV e outras ISTs.

Falar sobre o HIV/Aids possibilita ter um diálogo sobre assuntos tabus na sociedade, como o sexo e a saúde como um todo. Ter um diálogo aberto ajuda a esclarecer dúvidas e a desenvolver estratégias de proteção. Ao passo que o indivíduo se percebe como um grupo de risco, independente de seus comportamentos sexuais, a probabilidade de se expor aos vírus diminui.

O fato é que, as oportunidades que esta pesquisa proporcionou pode verter tanto para a produção de marcadores que auxiliem ações de prevenção, como a criação de conceitos chaves que auxiliam prever características geracionais que estabeleçam parâmetros para identificar alto índice de probabilidade de contrair HIV. 


\section{ANEXOS}

Anexo 1 - Distribuição de casos de Aids do Estado de São Paulo segundo Geração

\begin{tabular}{|c|c|c|c|c|c|}
\hline $\begin{array}{c}\text { Ano de } \\
\text { nascimento }\end{array}$ & Baby boomer & Geração X & Geraçãa Y & Geração M & Total \\
\hline 1982 & 1 & & & & 1 \\
\hline 1983 & 5 & & & & 5 \\
\hline 1984 & 12 & 5 & & & 17 \\
\hline 1985 & 34 & 29 & & & 63 \\
\hline 1986 & 52 & 57 & & & 109 \\
\hline 1987 & 74 & 236 & & & 310 \\
\hline 1988 & 52 & 480 & & & 532 \\
\hline 1989 & & 681 & & & 681 \\
\hline 1990 & 1 & 1110 & & & 1111 \\
\hline 1991 & & 1427 & & & 1427 \\
\hline 1992 & 2 & 1480 & & & 1482 \\
\hline 1993 & 1 & 1522 & & & 1523 \\
\hline 1994 & 2 & 1280 & & & 1282 \\
\hline 1995 & 1 & 1225 & 3 & & 1229 \\
\hline 1996 & & 1125 & 16 & & 1141 \\
\hline 1997 & & 1123 & 31 & 1 & 1155 \\
\hline 1998 & 2 & 1108 & 66 & & 1176 \\
\hline 1999 & & 904 & 115 & & 1019 \\
\hline 2000 & & 777 & 196 & & 973 \\
\hline 2001 & & 642 & 260 & & 902 \\
\hline 2002 & & 498 & 389 & & 887 \\
\hline 2003 & & 307 & 501 & & 808 \\
\hline 2004 & & 94 & 562 & & 656 \\
\hline 2005 & & 5 & 644 & 3 & 652 \\
\hline 2006 & & 2 & 603 & 11 & 616 \\
\hline 2007 & & & 560 & 25 & 585 \\
\hline 2008 & 1 & & 588 & 69 & 658 \\
\hline 2009 & & 1 & 592 & 88 & 681 \\
\hline 2010 & & & 574 & 128 & 702 \\
\hline 2011 & 1 & & 507 & 272 & 780 \\
\hline 2012 & & & 442 & 372 & 814 \\
\hline 2013 & & & 217 & 568 & 785 \\
\hline 2014 & & & 103 & 715 & 818 \\
\hline Total & 241 & 16118 & 6969 & 2252 & 25580 \\
\hline
\end{tabular}

Fonte: O Autor 
Anexo 2 - Distribuição percentual de casos de Aids no Estado de São Paulo segundo Geração.

\begin{tabular}{|c|c|c|c|c|}
\hline $\begin{array}{c}\text { Ano de } \\
\text { nascimento }\end{array}$ & Baby boomer & Geração X & Geraçãa Y & Geração M \\
\hline 1982 & $100 \%$ & & & \\
\hline 1983 & $100 \%$ & & & \\
\hline 1984 & $71 \%$ & $29 \%$ & & \\
\hline 1985 & $54 \%$ & $46 \%$ & & \\
\hline 1986 & $48 \%$ & $52 \%$ & & \\
\hline 1987 & $24 \%$ & $76 \%$ & & \\
\hline 1988 & $10 \%$ & $90 \%$ & & \\
\hline 1989 & & $100 \%$ & & \\
\hline 1990 & & $100 \%$ & & \\
\hline 1991 & & $100 \%$ & & \\
\hline 1992 & & $100 \%$ & & \\
\hline 1993 & & $100 \%$ & & \\
\hline 1994 & & $100 \%$ & & \\
\hline 1995 & & $100 \%$ & & \\
\hline 1996 & & $99 \%$ & $1 \%$ & \\
\hline 1997 & & $97 \%$ & $3 \%$ & \\
\hline 1998 & & $94 \%$ & $6 \%$ & \\
\hline 1999 & & $89 \%$ & $11 \%$ & \\
\hline 2000 & & $80 \%$ & $20 \%$ & \\
\hline 2001 & & $71 \%$ & $29 \%$ & \\
\hline 2002 & & $56 \%$ & $44 \%$ & \\
\hline 2003 & & $38 \%$ & $62 \%$ & \\
\hline 2004 & & $14 \%$ & $86 \%$ & \\
\hline 2005 & & $1 \%$ & $99 \%$ & \\
\hline 2006 & & & $98 \%$ & $2 \%$ \\
\hline 2007 & & & $96 \%$ & $4 \%$ \\
\hline 2008 & & & $89 \%$ & $10 \%$ \\
\hline 2009 & & & $87 \%$ & $13 \%$ \\
\hline 2010 & & & $82 \%$ & $18 \%$ \\
\hline 2011 & & & $65 \%$ & $35 \%$ \\
\hline 2012 & & & $54 \%$ & $46 \%$ \\
\hline 2013 & & & $28 \%$ & $72 \%$ \\
\hline 2014 & & & $13 \%$ & $87 \%$ \\
\hline Total & $1 \%$ & $63 \%$ & $27 \%$ & $9 \%$ \\
\hline
\end{tabular}

Fonte: O Autor 
Anexo 3 - Casos de Aids no Estado de São Paulo por ano de nascimento e ano de diagnóstico de indivíduos de 15 a 24 anos. 1980 a 2014

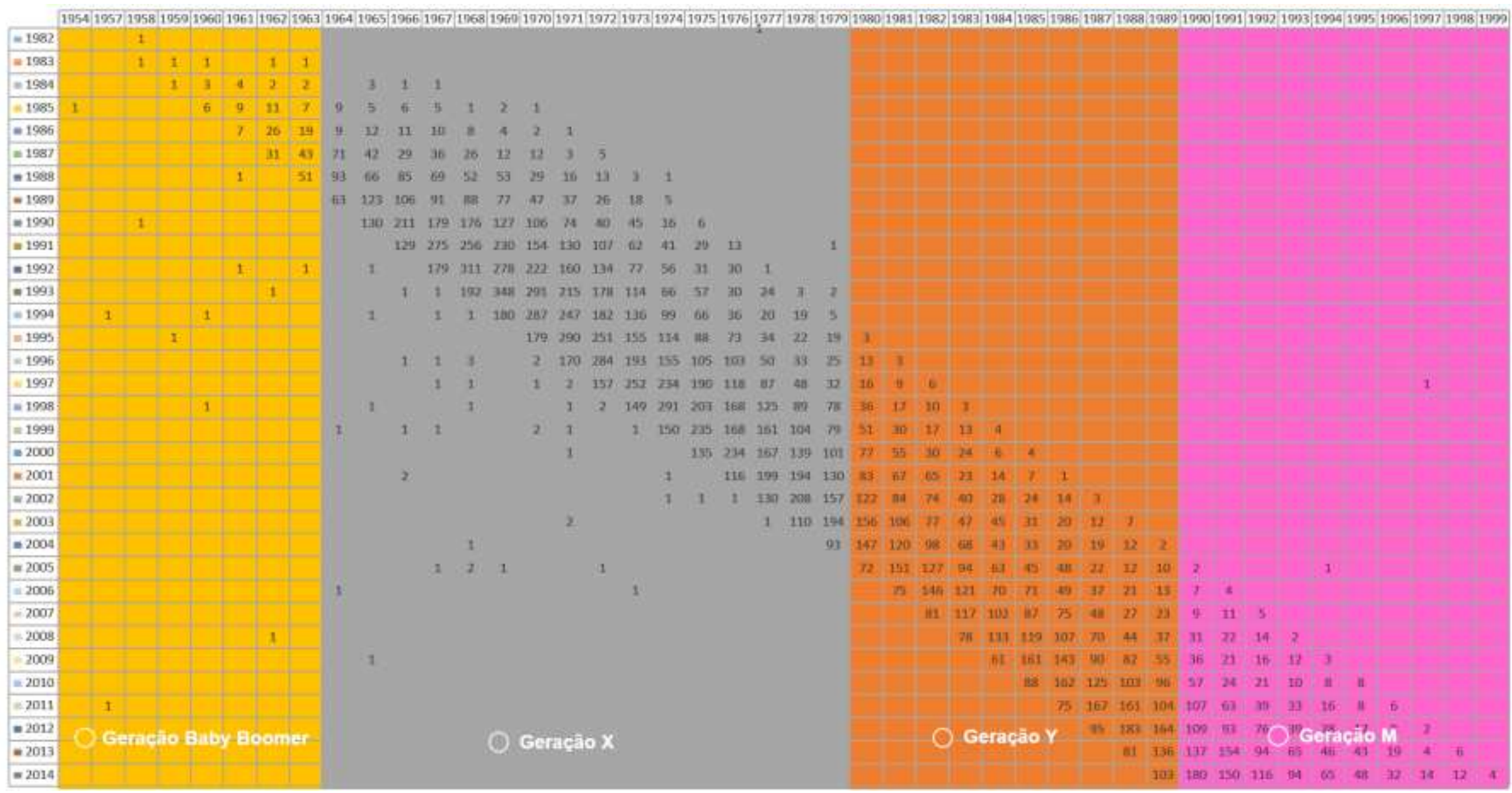

Fonte: O Autor 
Anexo 4 - Descrição das Campanhas do Ministério da Saúde para IST e DTS

\begin{tabular}{l|l}
\hline Título da Campanha & Descrição da Campanha \\
\hline & $\begin{array}{l}\text { Campanha realizada para mobilizar a população jovem para a prevenção à Aids e para a melhoria da } \\
\text { qualidade de vida de jovens com HIV/Aids. }\end{array}$ \\
$\begin{array}{l}\text { Buscando oferecer respostas à situação especial de vulnerabilidade dos jovens à infecção pelo HIV, } \\
\text { evidenciada pela prevalência de mais de } 30 \% \text { dos casos conhecidos entre pessoas com idade entre } \\
10 \text { e } 24 \text { anos que vivem em países em desenvolvimento, o UNAIDS recomendou, como tema de } \\
1998, \text { "Jovens: a força da mudança". }\end{array}$ \\
$\begin{array}{l}\text { A partir daí, realizou-se campanha nacional a fim de mobilizar a população jovem para a prevenção } \\
\text { da Aids e para a melhoria da qualidade de vida de jovens afetados pelo HIV/Aids. A mensagem } \\
\text { escolhida procurava despertar o jovem para a seriedade e responsabilidade diante do problema, ao } \\
\text { mesmo tempo em que convidava a sociedade a refletir sobre o seu enfrentamento. } \\
\text { Mundial de Luta contra }\end{array}$
\end{tabular}

a Aids - A força da mudança: com os jovens em campanha contra a Aids - 1998

População-alvo: Jovens em idade sexualmente ativa.

Período: 01 a 15 de dezembro.

Meios: TV; rádio; cinema.

TV: Programação nas principais redes nacionais abertas e TV a cabo, por um período de quinze dias. Veiculação de comerciais de 60 e 30 segundos, com volume médio de 270 TRP semanal.

Rádio: Veiculação em cidades com taxas de prevalência de (no mínimo) 100 casos por 100 mil habitantes, incluindo depoimento de 30 segundos com os principais comunicadores das emissoras indicadas, além de declarações dirigidas à população adolescente e adulta jovem, programados para redes FM especializadas nesse segmento. O investimento de $\mathrm{R} \$ 3.934 .888,25$ em mídia ficou assim distribuído: TV, R\$ 3.093.926,97; rádio, R\$ 787.461,28; cinema, R\$ 53.500,00.

Para prevenir o compartilhamento de agulhas e seringas e, consequentemente, reduzir a infecção pelo HIV entre usuários de drogas injetáveis, o Programa Nacional de Aids lançou, em 1998, a campanha: Se fosse seringa, você usava?

Campanha para Usuários de Drogas Injetáveis (UDI): Se fosse seringa, você usava? 1998
As imagens utilizadas na mensagem de prevenção causaram grande impacto, criando uma certa polêmica e estimulando o envolvimento de usuários de drogas injetáveis (soropositivos ou não) no debate sobre uma abordagem de saúde mais digna para essa parcela da população, que possibilite um resgate de sua cidadania e uma inclusão mais justa no contexto social.

Estratégia: produção de cartazes com veiculação estritamente dirigida aos UDI.

Abrangência: concentração nas regiões Sul e Sudeste e em zonas de fronteira.

Período: dezembro de 1998.

O tema trabalhado na campanha de Carnaval deste ano relacionava a responsabilidade individual sobre a manutenção da saúde e a prevenção da infecção pelo HIV.

Após a campanha, o Instituto Brasileiro de Opinião Pública e Estatística (Ibope) entrevistou 2.000 pessoas em todo o país, verificando os seguintes dados: índice de recall (lembrança retida pelo público) de $72 \%$; e recall espontâneo (lembrança espontânea, sem estímulo de qualquer ordem) de $10 \%$. Esses percentuais são equivalentes aos alcançados pela cerveja Brahma e superiores, por exemplo, ao das marcas Coca-Cola e Skol (de 4\%).

Público-alvo: mulheres das classes sociais C, D, E, entre 15 e 39 anos (2.752.923 mulheres ou $17,5 \%$ da população geral).

Período: 07 a 16 de fevereiro de 1999

Total de domicílios: 3.979 .000

Distribuição de preservativos: 5.400 .000

Meios: TV, rádio, revista, outdoor, cinema, cartazes (200.000), folders (3.450.000), adesivos (1.000.000), fitas de cabeça (200.000), camisetas (10.000), banners (500).

$\mathrm{Na}$ TV, a mensagem foi veiculada durante dez dias, em todas as redes nacionais abertas. Apesar de o público-alvo principal ser aquele composto pelas mulheres, foram feitas também inclusões em programas de audiência ampla, sempre divulgando informações sobre práticas de sexo mais seguro. Seu custo de veiculação, o mais significativo entre as campanhas de massa, foi de R\$2.009.544,07. 


\begin{tabular}{l|l}
\hline Título da Campanha & Descrição da Campanha \\
\hline & $\begin{array}{l}\text { Em 1999, o Brasil foi escolhido como país sede para o lançamento da Campanha Mundial. Em uma } \\
\text { cerimônia que contou com a presença do Presidente da República, do Ministro da Saúde e do } \\
\text { Diretor Executivo do UNAIDS, Peter Piot, foi definido que, em todo mundo, as crianças e os jovens } \\
\text { deveriam ser considerados populações prioritárias para a prevenção à Aids, e que o diálogo é o } \\
\text { melhor instrumento na defesa dos jovens contra a epidemia. "Escute, Aprenda e Viva": este foi o } \\
\text { lema escolhido pelo UNAIDS. }\end{array}$ \\
$\begin{array}{l}\text { Mampanha do Dia } \\
\text { a Aids: Pais e Filhos - }\end{array}$ & $\begin{array}{l}\text { A campanha "Escute, Aprenda e Viva sem Aids" contou com diversas ações de intervenção } \\
\text { possibilitadas pela mobilização nacional em torno da data. Entre as principais, destacou-se } \\
\text { mensagem veiculada em TV, spot de rádio, cartaz e dois grandes shows. }\end{array}$ \\
& $\begin{array}{l}\text { O primeiro, realizado no Sul - região onde a epidemia mais cresce no país -, na cidade de Curitiba, } \\
\text { PR, contou com a participação solidária de diversos artistas de renome nacional, público } \\
\text { aproximado de 15.000 pessoas e duas retransmissões nacionais pela Rede Nacional da TV } \\
\text { Educativa. O segundo espetáculo aconteceu na Rocinha, maior favela do Rio de Janeiro, marcando } \\
\text { o início de um projeto que realiza, mensalmente, shows de promoção da saúde e divulgação de } \\
\text { ações preventivas em diferentes favelas da cidade, com distribuição de preservativos e fôlderes } \\
\text { informativos. Em ambos os eventos, foi dado especial destaque às mensagens de prevenção em } \\
\text { DST/Aids. }\end{array}$
\end{tabular}

Para ampliar o número de pacientes com Aids que fazem uso correto dos medicamentos antirretrovirais, o Ministério da Saúde realizou uma campanha em parceria com os laboratórios Merck Sharp \& Dhome e Abbot.

A estratégia da ação incluía a distribuição de estojos de medicamentos, a confecção de cartelas de programação de medicamentos, a produção de materiais gráficos educativos, com ênfase na responsabilidade individual do paciente, e a realização de 40 treinamentos para 48 facilitadores de

Campanha de Adesão de Pessoas Vivendo com HIV/Aids - 1999
Campanha - Camisinha: eu vivo com ela - 1999 adesão ao tratamento.

População-alvo: Pacientes com HIV/Aids que fazem uso de medicamentos.

Meios: revistas (100.000); cartazes (15.000); displays (10.000); estojos (100.000), além de 100.000 medicamentos (investimento de $\mathrm{R} \$ 340.000,00$, assumido pelas empresas).

Treinamentos: Grupo Adesão Autoajuda: 40 treinamentos para 48 facilitadores (investimento de $\mathrm{R} \$$ 250.000,00, assumido pelas empresas).

Campanha nacional realizada em parceria com a Ação da Cidadania Contra a Fome, a Miséria e Pela Vida, veiculada gratuitamente pela Rede Globo de Televisão, pelo Sistema Brasileiro de Televisão - SBT e pela Rede Nacional de Televisão Educativa - TVE. Personalidades de destaque na área artística participaram de forma voluntária nessa campanha, baseada na importância do uso do preservativo e na prevenção da Aids e direcionada à população geral de baixa renda. A iniciativa foi apresentada como uma mobilização da sociedade brasileira, sem assinaturas de instituições. O investimento do Ministério da Saúde limitou-se à produção de um filme de 30", ao custo aproximado de $\mathrm{R} \$ 25.000,00$.

Veiculada em 1999, a campanha objetivou alertar a população para a necessidade de procurar assistência médica, diagnóstico e tratamento adequado das DST, além de recomendar o uso do preservativo como prevenção das DST/HIV/Aids. A estratégia envolveu profissionais da saúde como multiplicadores das informações repassadas ao público geral.

Ao perceber sintomas ou sinais, a pessoa deve:

Mudar o comportamento de risco que a levou a adquirir a DST;

Perceber que pode ter se exposto ao HIV;

Fazer o tratamento de forma correta;

Avisar seus parceiros/parceiras sexuais, que também precisam receber tratamento e orientação; do contrário, a cadeia de transmissão não se interromperá.

Público-alvo: população sexualmente ativa, ampliando a faixa de 15 a 49 anos, especialmente no sentido de incorporar os mais jovens, para uma faixa de 12 a 60 anos, atingindo meninas mais jovens e homens mais velhos e profissionais de saúde.

Meios: TV, rádio, panfletos, cartazes e cartilhas para profissionais de saúde.

O investimento na campanha considerou os seguintes valores por veículo/mídia: TV - R\$ 2.024.283,23; rádio - R \$ 910.899,20; cartazes - R \$ 91.000,00; cartilhas - R \$ 12.300,00. 


\begin{tabular}{|c|c|}
\hline Título da Campanha & Descrição da Campanha \\
\hline $\begin{array}{l}\text { Campanha de Carnaval: } \\
\text { Prevenir é tão fácil } \\
\text { quanto pegar - } 2000\end{array}$ & $\begin{array}{l}\text { A campanha, com grande veiculação na mídia impressa e eletrônica, simulava um depoimento, com } \\
\text { alerta para as consequências do não uso do preservativo. } \\
\text { Público-alvo: homens, mulheres e jovens adultos das classes C, D e E, entre } 15 \text { e } 39 \text { anos. } \\
\text { Período: } 25 \text { de fevereiro a } 07 \text { de março. } \\
\text { Meios: TV, rádio, revista, outdoor, cinema. } \\
\text { Televisão: Para todas as redes nacionais abertas (principalmente em programas preferencialmente } \\
\text { dirigidos ao público-alvo), foi produzida e transmitida uma programação com volume de } 801 \text { GRP } \\
\text { domiciliar, sendo } 338 \text { GRP no público-alvo, atingindo um total estimado de } 50.987 .300 \text { pessoas. A } \\
\text { distribuição dos investimentos foi baseada na audiência, conforme relatório de novembro/99, } \\
\text { emitido pelo Ibope. } \\
\text { Rádio: Participaram as emissoras líderes e mais populares (FM e AM) das principais cidades em } \\
\text { que a festa de Carnaval possui maior público. } \\
\text { Revista: Visando atingir formadores de opinião e também públicos mais segmentados, publicou-se } \\
\text { anúncio no formato de página dupla impressa em } 4 \text { cores, nas principais revistas semanais do país. } \\
\text { Outdoor: Foram exibidos cartazes em } 26 \text { cidades, privilegiando todo o litoral do país, em um total } \\
\text { de } 638 \text { outdoors. } \\
\text { Cinema: Visando atingir o público jovem das classes A e B, foram exibidos filmes nas salas de } \\
\text { cinemas dos maiores centros brasileiros: São Paulo, Rio de Janeiro, Belo Horizonte, Brasília e Porto } \\
\text { Alegre. } \\
\text { Anexo }\end{array}$ \\
\hline $\begin{array}{l}\text { Campanha para } \\
\text { caminhoneiros - } 2000\end{array}$ & 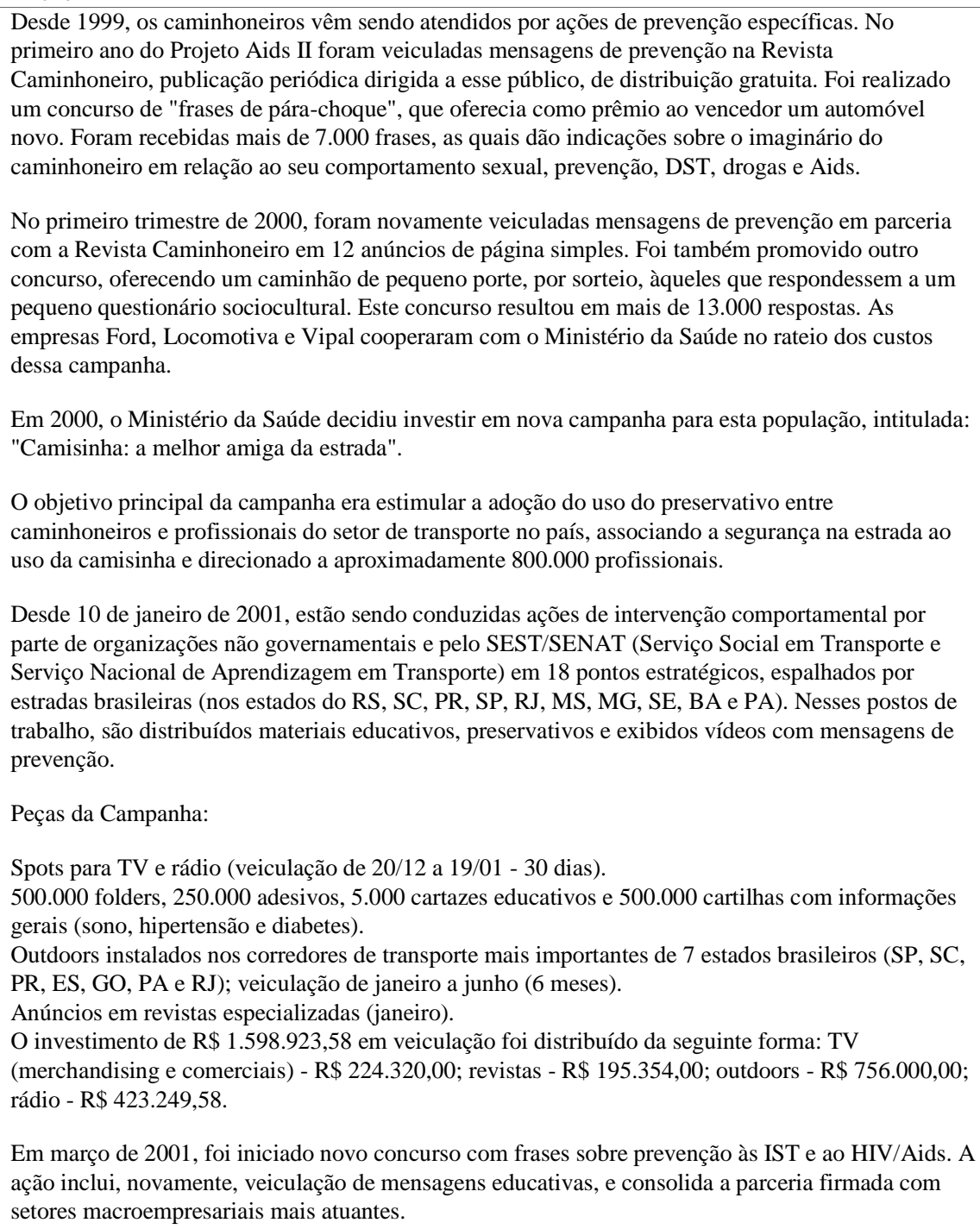 \\
\hline
\end{tabular}




\begin{tabular}{l}
\hline Título da Campanha \\
\hline \\
Campanha do Dia \\
Mundial de Luta contra \\
a Aids: Não leve Aids \\
para casa - 2000
\end{tabular}

Campanha de Carnaval: Não importa de que lado você está, use camisinha - 2001

\section{Descrição da Campanha}

Durante a 21 a Sessão Especial da Assembleia Geral das Nações Unidas, em 1999, atentou-se para a especial vulnerabilidade a que estão expostas as pessoas do sexo masculino à infecção pelo HIV/Aids. Constatou-se que:

A saúde masculina recebe pouca atenção, apesar da sua importância;

O comportamento do homem o expõe ao HIV;

O comportamento do homem expõe a mulher ao HIV;

O sexo entre homens sem proteção ameaça tanto homens como mulheres; e

O homem deve considerar que a Aids pode atingir a sua família.

Partindo desse paradigma, o UNAIDS recomendou a abordagem de gênero durante as ações que tradicionalmente se realizam por ocasião do Dia Mundial de Luta contra a Aids.

Obedecendo a essas diretrizes, o Ministério da Saúde desenvolveu campanha nacional conforme segue:

Objetivo: atentar para a responsabilidade do homem sobre a sua própria saúde e a de seus parceiros e, principalmente, sobre o seu papel na prevenção e controle da epidemia da Aids no Brasil.

Veículos: TV, rádio, peças gráficas (banners, cartazes e folders), outdoors e evento (festival de cinema).

Veiculação: dezembro de 2000.

A campanha de Carnaval deste ano procurou focalizar a percepção individual sobre situações de risco e vulnerabilidade, buscando motivar o uso do preservativo.

População: homens e mulheres das classes C, D e E, heterossexuais, entre 20 e 45 anos. Período: 14 a 27 de fevereiro de 2001. Meios: TV, rádio, outdoors (609), cartazes (1.500.000), ventarolas (10.000.000)

Televisão: Exibição de filme de 30" nos programas com maior audiência entre o público-alvo em redes nacionais abertas, alcançando nível de GRP domiciliar de 1071.

Rádio: Veiculação de spot de 30" em emissoras FM e AM das cidades em que a festa de Carnaval possui maior público, além de Santos e Itajaí, centros urbanos importantes que apresentam grande incidência de casos de Aids.

Outdoor: Exibição de cartazes nas principais capitais e cidades da região litorânea.

Os investimentos da campanha foram distribuídos entre as seguintes mídias: R\$ 3.357,525,80 em $\mathrm{TV} ; \mathrm{R} \$ 325.361,15$ em rádio; $\mathrm{R} \$ 468.697,60$ em outdoor; $\mathrm{R} \$ 250.194,50$ em cartazes; $\mathrm{R} \$$ $1.584 .882,50$ em ventarolas.

No ano de 2001 foi lançada uma campanha que visava alertar a população sobre os riscos das DST (Doenças Sexualmente Transmissíveis) e estimular a população a buscar os serviços de saúde quando perceber sintomas como corrimento, verrugas, feridas nos órgãos genitais.

Acredita-se que 12 milhões de novos casos de DST ao ano ocorram no país, sendo que apenas 30\% dos doentes procuram os serviços de saúde. Em alguns casos, as DST podem aumentar em 18 vezes o risco de infecção pelo vírus da Aids. Portanto, a campanha pretendia ajudar o Governo a reduzir ainda mais a incidência de Aids no país.

Campanha de prevenção às DST - 2001

A campanha foi direcionada também aos profissionais de saúde - médicos, agentes de saúde e farmacêuticos - com informativos próprios para cada segmento, em forma de cartas, folhetos, livretos, bottons e cartazes. Quase dois milhões de adesivos para banheiros, com informações para o público masculino e feminino, foram afixados em 400 mil bares, restaurantes e hotéis do país, numa parceria inédita com a Coca-Cola.

Os spots têm a participação de Maria Paula e Bussunda, do programa "Casseta e Planeta", que conversaram seriamente com a população sobre os sintomas das doenças e o uso do preservativo como forma de evitá-las. Essa foi a campanha sobre DST mais abrangente já feita pelo Ministério da Saúde.

Em 2001, o Ministério da Saúde permanece atento para a vulnerabilidade à infecção pelo HIV/Aids a que se expõem os homens brasileiros. De fato, os homens com prática homo, bi ou heterossexual são, na sua maioria, educados segundo os aspectos de masculinidade de nossa cultura, em que o ato e a prática sexual são muito valorizados. Isso tem estimulado/incentivado/permitido a busca do prazer sem medir as consequências: o homem que não usa camisinha continua mantendo a cadeia de transmissão do vírus da Aids.

Por esse motivo, a mensagem da campanha de $1^{\circ}$ de dezembro de 2001 recomendará aos homens brasileiros algo como: não importa com quem você transa, não importa como. Use camisinha. Não transmita, nem se infecte com o HIV. A respeito do público da campanha, não priorizaremos os homens que fundamentam suas relações com base na parceria única. A campanha deverá considerar a diversidade sexual masculina, evitando qualquer abordagem que valorize apenas o universo heterossexual.

Objetivos: levar o homem a usar o preservativo, se reconhecer em risco, reconhecer que coloca outras pessoas em risco e perceber sua responsabilidade na dinâmica da epidemia. Veículos: TV, rádio, cartazes, jornais populares e outdoors.

Veiculação: dezembro de 2001 


\begin{tabular}{l}
\hline Título da Campanha \\
\hline \\
\\
Campanha de Carnaval: \\
Sem Camisinha nem
\end{tabular}

Sem Camisinha nem Pensar - 2002

\section{Campanha Travestis -} 2002

Campanha: Homens que fazem Sexo com Homens (HSH) - 2002

\section{Descrição da Campanha}

Campanha bem humorada alerta foliões sobre o uso de preservativo - 29/01/2002

O Ministério da Saúde está usando o talento e a credibilidade da atriz Cláudia Jimenez para alertar os foliões sobre a necessidade do uso de preservativo em todas as relações sexuais. Cláudia faz o papel da consciência pesada de um indivíduo que, sob os efeitos do álcool, esquece de usar preservativo nos dias de festa.

A campanha de Aids do ano de 2002 foi veiculada em rádio e televisão entre os dias 30 de janeiro e 11 de fevereiro e conta ainda com 1,5 milhão de cartazes, 6 milhões de abanadores e 7 milhões de cartões postais a serem distribuídos durante o Carnaval. O custo da campanha foi de R $\$ 5$ milhões, e a distribuição do material impresso foi feita em parceria com a Coca-Cola, Texaco, Intervias (concessionária de rodovias federais) e ABRATI (Associação Brasileira de Transportes Rodoviários Intermunicipais, Interestaduais e Internacionais).

A estratégia do Ministério da Saúde é sensibilizar o público a usar o preservativo como a forma mais segura de evitar a infecção pelo HIV, reduzindo assim a incidência de Aids principalmente entre as mulheres. Na década de 80, para cada mulher infectada pelo HIV havia 25 casos de Aids registrados entre os homens. Hoje essa relação é de apenas $2 / 1$.

Desde o início da epidemia de Aids, 215.805 casos da doença já foram notificados, sendo 159.226 em homens e 56.584 em mulheres. Em 2001, a maior parte das infecções pelo HIV ocorreu nas relações heterossexuais (52\%) seguida das relações homo/bissexuais $(19,8 \%)$ e do uso de drogas injetáveis, e pelo compartilhamento de seringas e agulhas $(9,1 \%)$. Já os casos de transmissão materno-infantil representaram 1,4\% dos casos de Aids registrados em 2001

Além da campanha de prevenção, o Ministério da Saúde distribuiu 21 milhões de preservativos no mês de fevereiro. Oito milhões são para ações educativas e de prevenção nos quatro dias de folia, que serão conduzidas por Organizações da Sociedade Civil que já trabalham em DST/Aids. O restante faz parte das ações continuadas do Ministério da Saúde em prevenção à Aids. "Travesti e respeito: já está na hora de os dois serem vistos juntos. Em casa. Na boate. Na escola. No trabalho. Na vida". A Campanha Travestis foi lançada no Congresso Nacional, em agosto de 2001, e é centrada no reforço a atitudes de respeito e de inclusão social desse segmento da população, que se torna muito vulnerável ao vírus da Aids pelo preconceito e violência. A campanha foi realizada por lideranças do movimento organizado de travestis e transgêneros, em parceria com o Programa Nacional de DST/Aids, e tem quatro alvos a atingir: escolas, serviços de saúde, comunidade e clientes das travestis profissionais do sexo. O slogan é reproduzido em cartazes e folders com fotos das 27 travestis que participaram da elaboração da campanha. O ministro da Saúde, Barjas Negri, e o coordenador nacional do Programa de DST e Aids, Paulo Teixeira, lançam a campanha de prevenção à Aids voltada para os homossexuais. O objetivo é estimular o uso frequente da camisinha nas relações sexuais entre homens e reduzir o preconceito da sociedade, em particular entre profissionais de saúde e da educação e familiares, em relação às diferenças sexuais.

Os grupos de homossexuais que trabalham em parceria com o Ministério da Saúde e pesquisadores nacionais e internacionais concordam em dizer que a discriminação e o preconceito levam o homossexual, principalmente os mais jovens, a se distanciar das fontes de informação. Isso dificulta a adoção de uma postura mais proativa na prevenção, colocando-os, dessa forma, em risco de infecção pelo HIV.

Estudo do Ministério da Saúde mostra que homens que fazem sexo com homens têm 11 vezes mais risco de contrair o vírus da Aids, se comparados com homens que mantêm relações sexuais apenas com mulheres. Atualmente, $0,4 \%$ da população heterossexual masculina está infectada pelo HIV, contra $4,5 \%$ dos que mantêm relações homossexuais.

Apesar de ser um grupo com elevado grau de conhecimento sobre formas de contágio e prevenção pesquisa da ABIA (Associação Brasileira Interdisciplinar de Aids) revela que $90 \%$ dos homossexuais conhecem as formas de contágio e prevenção -, após um período de redução de casos de Aids entre homens que fazem sexo com homens, o número voltou a crescer. A partir de 1996 aumenta $4 \%$ ao ano (em 1996 foram 4.147 casos e, em 2001, 5.400 casos), notando-se essa elevação com mais intensidade entre os mais jovens (taxa de crescimento de $8,7 \%$ entre 15 a 24 anos; $3,4 \%$ entre 25 a 34 anos; $3,1 \%$ entre 35 e 44 anos).

Dados do Boletim Epidemiológico de Aids indicam que, dos 222.356 casos de Aids registrados pelo Ministério da Saúde desde o início da epidemia, 52.120 se referem à transmissão homossexual e à bissexual. E, desde 1996, quase a metade (49\%) dos casos de infecção pela via sexual em homens com mais de 13 anos foi observada no grupo de homo/bissexuais masculinos.

Com base nessas informações, o Ministério da Saúde desenvolveu uma campanha em três linhas estratégicas consideradas essenciais para a redução do preconceito e para o aumento do uso do preservativo:

A Campanha de Massa dirigida à população geral contará com uma peça para TV ("Respeitar as diferenças é tão importante quanto usar camisinha"), uma peça para Cinema ("Fantasias", produzida pela CE-DST/AIDS de SP) e anúncio em revistas de grande circulação ("Use camisinha com seu namorado" também é uma conversa de pai para filho).

A intervenção direta com apoio da Sociedade Civil, na qual 80 grupos de homossexuais distribuirão material de prevenção (filme para salas de cinema frequentadas por homossexuais - "Exibicionista"; cartazes; filipetas; adesivos; chaveiro para sauna; baleiros com preservativo para bares e boates e, ainda, anúncios em formato de classificados em revistas segmentadas).

Além disso, o Ministério da Saúde quer sensibilizar os profissionais de saúde e de educação para torná-los peças importantes na aceitação das diferenças de orientação sexual, atuando contra o preconceito e pela prevenção às DSTs e à Aids. Serão distribuídos materiais para escolas (cartazes; fôlderes para professores e filme educativo para alunos) e para os serviços de saúde (cartazes e fôlderes para profissionais de saúde).

Resultados da Pesquisa de Retorno (Recall) da Campanha Nacional sobre Homossexuais veiculada nos meios de comunicação (TV e Revista) promovida pela Coordenação Nacional de DST/Aids do Ministério da Saúde e realizada pelo NEPAIDS (em formato powerpoint) 


\begin{tabular}{l}
\hline Título da Campanha \\
\hline \\
Campanha Profissionais \\
do Sexo: Sem vergonha, \\
garota. Você tem \\
profissão - 2002
\end{tabular}

\section{Campanha do Dia Mundial: Aids. O preconceito tem cura - 2002}

\section{Descrição da Campanha}

A Coordenação Nacional de DST e Aids, do Ministério da Saúde, lançou, durante o Seminário Aids e Prostituição, no dia 6 de março, em Brasília, uma campanha nacional de prevenção direcionada às profissionais do sexo feminino, com ênfase no desenvolvimento da autoestima e da cidadania, como forma de mobilizar as profissionais para a promoção à saúde.

A consciência de seus direitos, como a negociação com clientes pelo uso da camisinha, o esclarecimento sobre o uso correto do preservativo e a promoção do preservativo feminino também são focos da campanha.

A campanha, que tem como título "Sem vergonha, garota. Você tem profissão", é veiculada no rádio e nos locais de prática do sexo pago. Além do spot para rádio, contém material impresso (folder, cartilha) com informações sobre práticas seguras de sexo; principais doenças que podem ser transmitidas nas relações sem o uso do preservativo; direitos humanos; dependência química e redução de danos entre usuários de drogas injetáveis. Também conta com adesivos para banheiros, manual do multiplicador (profissionais do sexo que ensinam os companheiros a se prevenir das doenças) e bottons.

Mais informações: Assessoria de imprensa da Coordenação Nacional de DST/Aids Este ano, foram produzidos cartazes e fôlderes, além da veiculação de filme relativo ao tema. Abaixo, fazemos uma descrição das ações:

Filme para televisão:

Cena desfocada mostra uma mulher deitada com uma mancha vermelha como sangue em sua barriga. Agora, com a cena em foco, nota-se que é apenas uma mulher sorrindo, deitada no sofá, lendo um cartãozinho do namorado e com flores vermelhas sobre seu corpo. Locução: "Com preconceito é assim. Você não enxerga as coisas como realmente são". Assinatura: "Aids. O preconceito tem cura".

Cartaz

É assim que muita gente encara a Aids. Encare a Aids com informação sobre a prevenção e respeito aos portadores. $1^{\circ}$ de dezembro. Dia Mundial de Luta contra a Aids.

Folder para profissionais de saúde

Saiba aqui o fundamental para tratar um pessoa com Aids. O mais importante é saber que uma pessoa com Aids deve ser tratada com o mesmo respeito e dedicação que uma pessoa que não tem Aids.

A campanha de Carnaval que o Ministério da Saúde começa a veicular, a partir deste domingo, nas principais emissoras de TV e rádios comerciais de todo o país, é voltada para a população jovem, principalmente adolescentes do sexo feminino, nas quais os novos casos de Aids vêm superando as ocorrências entre os meninos de 13 a 19 anos de idade. Protagonizada pela cantora Kelly Key, a mensagem procura estimular as jovens que iniciam a vida sexual a tomarem para si a responsabilidade da prevenção à Aids, exigindo que o parceiro use o preservativo e não tendo vergonha de comprá-lo ou carregá-lo na bolsa.

O filme mostra a cantora entrando numa farmácia e perguntando pelos preservativos aos vendedores, seguido do slogan: "Mostre que você cresceu e sabe o que quer. Neste Carnaval, use camisinha". Além do filme, a cantora gravou um jingle para rádios com uma versão de sua mais conhecida música, "Baba Baby", cujo sentido é: "Sem camisinha, apenas olha e baba, baby". Cartazes e outdoors são as outras peças da campanha. As coordenações estaduais de DST/Aids receberão o material a partir de hoje e ficarão responsáveis pela sua distribuição. Além das peças publicitárias, mais 9 milhões de preservativos, fora o quantitativo de 19 milhões distribuídos para as 27 unidades da federação a cada mês, já estão a caminho. Esses preservativos serão usados em ações específicas entre os foliões, a critério local e das Organizações não Governamentais que trabalham na prevenção às DST/Aids.

Por que uma campanha para jovens

Os últimos dados sobre a Aids revelam que, desde 2000, está ocorrendo uma inversão na relação da doença entre homens e mulheres na faixa etária de 13 a 19 anos de idade, com um número maior de casos em adolescentes do sexo feminino. Em 2000, foram 191 casos em meninas de 13 a 19 anos contra 151 casos em rapazes da mesma idade. Em 2001, foram notificados 152 casos de Aids em adolescentes do sexo feminino, contra $91 \mathrm{em}$ adolescentes homens. Entre os jovens de até 24 anos, essa relação homem/mulher já está igual, tendendo para as mulheres superarem os homens também.

Dessa forma, os novos números da Aids confirmam uma maior "feminização" da epidemia ano a ano, apontando as mulheres como a população na qual a epidemia de Aids mais cresce no país. Enquanto no período de 1980-1990 havia uma média de 6,5 casos de Aids em homens para cada caso observado em mulheres, no período entre 1991-2001 a relação média é de 2,4 casos em homens para cada caso na população feminina. A tendência é um avanço da epidemia para as classes menos favorecidas; daí a escolha da cantora Kelly Key para protagonizar a campanha, uma vez que ela atinge segmentos mais populares da juventude brasileira. 


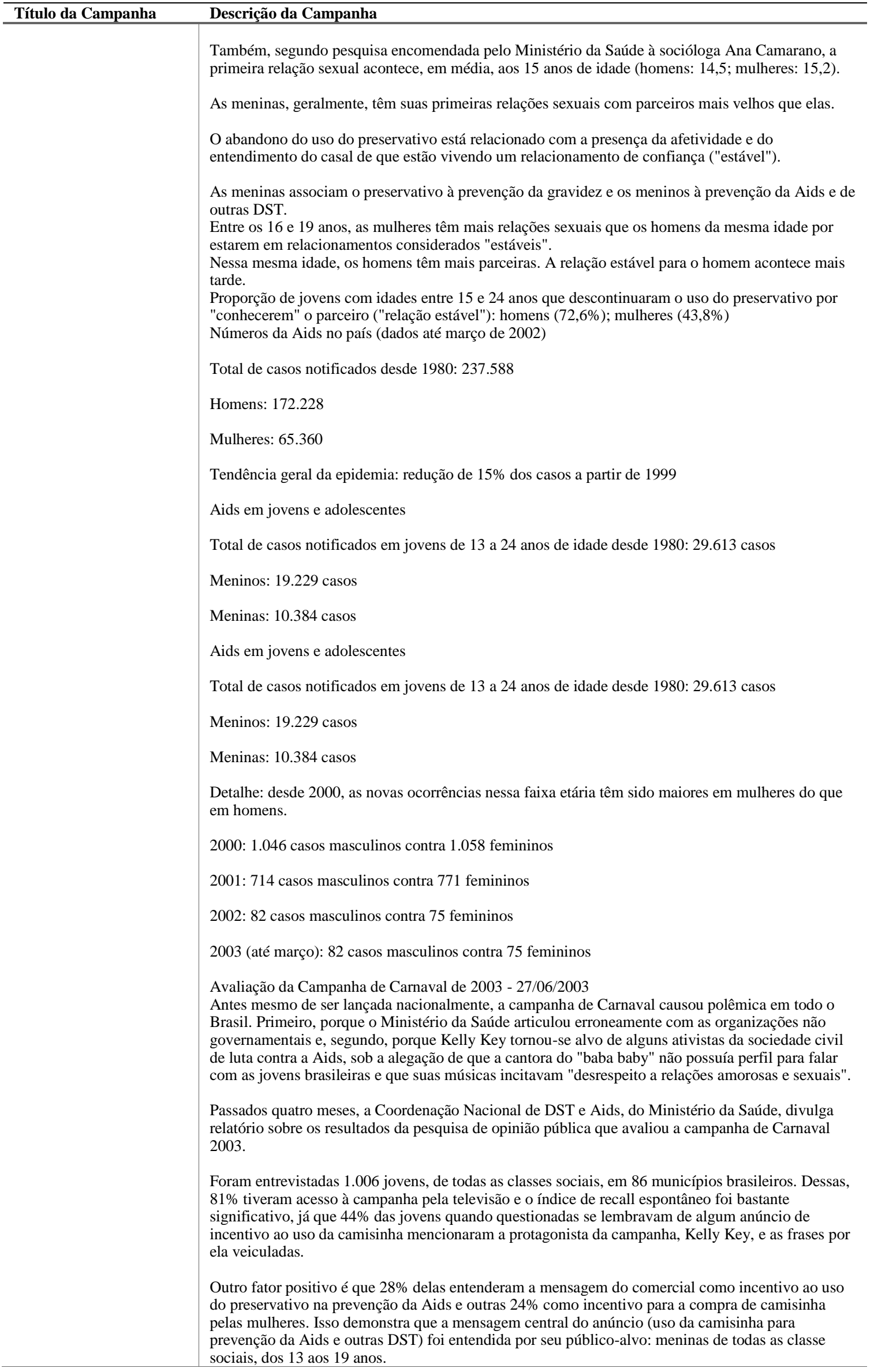




\begin{tabular}{|c|c|}
\hline Título da Campanha & Descrição da Campanha \\
\hline & $\begin{array}{l}\text { A pesquisa demonstrou ainda que metade das jovens gostou muito da campanha passada na } \\
\text { televisão, classificando-a como excelente ou muito boa. E apenas } 15 \% \text {, que pertenciam às classes de } \\
\text { maior renda, A e B, criticaram o anúncio, considerando-o razoável, ruim ou péssimo. } \\
\text { Entre as diversas questões, perguntou-se a elas o motivo que as levaram a classificar a campanha de } \\
\text { Carnaval como excelente, muito boa, péssima ou ruim. Para a maioria, um dos principais } \\
\text { argumentos é que ela conscientiza, previne, alerta e lembra que a camisinha deve ser usada para a } \\
\text { prevenção contra doenças sexualmente transmissíveis. Para outra parte das entrevistadas, serviu } \\
\text { para conscientizar a população a usar o preservativo e, por fim, outras disseram que serviu para } \\
\text { incentivar a prevenção contra a Aids, valorizando, nessa hora, a presença da cantora Kelly Key, } \\
\text { principalmente em relação ao anúncio da televisão. } \\
\text { Relevante também é seu papel como estímulo às discussões sobre o uso da camisinha. Das } \\
\text { entrevistadas, } 25 \% \text { disseram ter ouvido discussões sobre o anúncio da TV e } 27 \% \text { relataram tê-lo } \\
\text { discutido com alguém. Mais ainda, as pessoas com quem mais comentaram o anúncio foram amigos } \\
\text { (45\%), colegas da escola (40\%) e parentes (24\%). } \\
\text { Ao final da pesquisa, } 84 \% \text { das entrevistadas acharam que a campanha reforçou a ideia de } \\
\text { responsabilidade pelas mulheres na compra de preservativos e de seu poder diante da decisão de } \\
\text { usar a camisinha com seus parceiros, assimilando, dessa forma, uma das mensagens mais } \\
\text { importantes da campanha. } \\
\text { Mesmo com tanta discussão acerca da figura de Kelly Key e da campanha, os resultados da } \\
\text { avaliação mostram que ela atingiu seu objetivo, que a mensagem foi apreendida por seu público- } \\
\text { alvo e, sobretudo, que prevenção não segue padrões sociais. }\end{array}$ \\
\hline $\begin{array}{l}\text { Campanha de } \\
\text { diagnóstico - } 2003\end{array}$ & $\begin{array}{l}\text { A campanha de diagnóstico lançada pelo Ministro da Saúde, Humberto Costa, visa sensibilizar a } \\
\text { população para a importância do teste de diagnóstico do HIV, o vírus causador da Aids. A } \\
\text { campanha utilizou dois filmetes, cada um com } 30 \text { segundos de duração. Um deles mostra algumas } \\
\text { pessoas carregando pianos no meio da multidão. O instrumento musical significa o peso da dúvida } \\
\text { de quem tem comportamento de risco e ainda não fez o teste de Aids. }\end{array}$ \\
\hline $\begin{array}{l}\text { Campanha Fique } \\
\text { Sabendo - } 2003\end{array}$ & $\begin{array}{l}\text { O Fique Sabendo é uma mobilização de incentivo ao teste de Aids e tem como objetivo } \\
\text { conscientizar a população sobre a importância da realização do exame. Artistas e formadores de } \\
\text { opinião já estão se envolvendo para incentivar a população a fazer o teste e diminuir cada vez mais } \\
\text { o preconceito em relação ao HIV/Aids. Fazer o teste de Aids é uma atitude que mostra como você } \\
\text { se preocupa com a sua saúde. }\end{array}$ \\
\hline
\end{tabular}

Acesse o site da campanha de sensibilização da população sobre a importância do teste de diagnóstico do HIV.

O tema deste ano para o Dia Mundial de Luta contra a Aids é "Discriminação e Preconceito". A campanha do Ministério da Saúde é pautada pela mobilização social, envolvendo todo o país no combate à epidemia.

Ao completar 20 anos de resposta à Aids, o Brasil chega a 2003 com a data de $1^{\circ}$ de Dezembro consolidada, sendo a principal pauta de todos os veículos de comunicação. Com esse espírito, todos os esforços foram empreendidos para apoiar e convocar para a mobilização os estados, municípios e a sociedade civil, em ações que vão de dezembro a março de 2004, mostrando o engajamento de todos para vencer o preconceito.

Entre as diversas ações programadas para o Dia Mundial de Luta contra a Aids, estas são as principais:

COLCHA DA SOLIDARIEDADE: crianças e adolescentes de vários estados do Brasil participaram da construção de uma colcha de 6.000 metros quadrados, que será estendida na Praça dos Três Poderes no dia $1^{\circ}$ de Dezembro, em solenidade que contará com a presença do Ministro da Saúde, Humberto Costa, representantes da sociedade civil e trezentos estudantes representando todos os que contribuíram para a confecção da colcha.

Mundial de Luta contra a Aids: Discriminação e Preconceito - 2003

LANÇAMENTO DA MÚSICA AMOR CUIDADO: considerado o Hino de Solidariedade para este $1^{\circ}$ de Dezembro, composto Wagner Tiso e Caique Botkai, com letra de Elisa Lucinda e interpretado por Chico Buarque, Lenine, Fernanda Abreu e vários outros importantes artistas brasileiros e de outros países de língua portuguesa. A música já está sendo executada em centenas de rádios em todo o país e o jornal O Globo irá disponibilizar o $\mathrm{CD}$ em suas próximas edições. O lucro da venda dos CDs será doado a instituições que trabalham com Aids.

SAMBA-ENREDO DA GRANDE RIO: "Camisinha: pecado é não usar". Esse tema marca os vinte anos de combate à epidemia em uma das manifestações mais populares do país - o Carnaval. Você já pode saber mais sobre o samba-enredo visitando a página da Grande Rio.

LANÇAMENTO DO SELO LUTA CONTRA O HIV/AIDS: também no dia $1^{\circ}$, passa a estar disponível nas agências dos correios de todo o país o selo LUTA CONTRA O HIV/AIDS, com tiragem de 4.000.000 de exemplares e arte de Darlan Rosa.

SEMINÁRIO 20 ANOS DE AIDS - DESAFIOS E PROPOSTAS: São Paulo, berço do primeiro Programa Estadual de Aids - e um dos marcos do início da luta contra a epidemia -, será palco de uma discussão aprofundada sobre os principais obstáculos e possíveis soluções em relação à epidemia. No evento, também será lançado o VÍDEO 20 ANOS DE AIDS, que conta um pouco a história da resposta brasileira e que será distribuído em todo o país. 
Historicamente, o Ministério da Saúde promove o preservativo durante o período de Carnaval por meio de campanha de comunicação de massa e da distribuição extra de preservativos para o período de festas. Já existe até uma expectativa por parte da própria população em relação a essa ação. Das três campanhas de massa promovidas pelo Ministério da Saúde durante o ano, a campanha de preservativos para o Carnaval é definitivamente a mais lembrada pela população.

Esta não é uma tentativa de rebater as declarações da Igreja Católica de que o preservativo não é seguro contra o vírus da Aids?

Não. A campanha foi elaborada após análise da pesquisa comportamental encomendada ao IBOPE em 2003 que sinalizou que aproximadamente $15 \%$ da população sexualmente ativa (cerca de 14 milhões de pessoas) não acreditam totalmente na eficácia do preservativo. Ainda prevalece a crença de que o preservativo pode deixar passar o vírus da Aids ou rasgar durante a relação sexual. Nesse sentido, informação e orientação direta à respeito da segurança do preservativo, quando usado de maneira correta e consistente, aumentará a confiança no produto, ampliando o uso e a proteção à população.

Então os índices de uso do preservativos são considerados baixos?

Não. Os índices de uso do preservativo no Brasil estão na média de países considerados desenvolvidos. Entretanto, apesar das insistentes campanhas de promoção ao preservativo, a sua utilização depende de diversos fatores, inclusive do conhecimento sobre as formas de uso e sobre a segurança do preservativo.

O preservativo possui poros?

Não. Sempre houve um grande questionamento em torno da existência de poros nos preservativos em decorrência da própria matéria-prima utilizada na sua fabricação, o látex. Entretanto, esta hipótese não se confirmou nas duas mais importantes pesquisas que buscavam detectar poros naturais nos preservativos. Na mais recente delas, datada de 1993, do National Institute of Health (NIH) / Estados Unidos, utilizou-se um microscópio eletrônico para ampliar os preservativos duas mil vezes e nenhum poro foi encontrado, mesmo quando os preservativos foram esticados. Outro estudo, datado de 1989 pelo The Consumers Union, demonstrou que nenhuma das marcas de preservativos mais utilizadas no mundo apresentavam poros (mais de 40 foram testadas). Nesse estudo, a microscopia eletrônica também foi utilizada nos preservativos esticados, mas com a magnificação de X 30.000, na qual é possível observar partículas do tamanho do HIV, e novamente

Campanha de Carnaval: Pela camisinha não passa nada. Use e confie - 2004 não houve confirmação de poros.

Mas mesmo não tendo poros, existe a possibilidade do preservativo estourar.

A grande maioria das pesquisas sobre o rompimento do preservativo durante a relação sexual indica que a possibilidade de ocorrer um rompimento não chega a $5 \%$ dos preservativos utilizados. A pesquisa realizada pelo The Consumer Union detectou índices de rompimento do preservativo inferiores a $1 \%$. Os problemas de rompimento são atribuídos muito mais ao uso incorreto, à inexperiência, do que à qualidade do preservativo em si. Outros fatores também interferem no rompimento do preservativo como uso de lubrificantes contraindicados para uso junto com o látex, o armazenamento incorreto e a reutilização da camisinha.

Então a campanha também pretende ensinar a usar o preservativo?

Sim. Esta é uma das mensagens contidas na campanha. O filme e as peças que serão distribuídas durante o Carnaval, trarão informações sobre como colocar o preservativo corretamente. Este ano a parceria com estados, organizações não governamentais e universidades, que já fazem um trabalho reconhecido de oficinas de sexo seguro durante o Carnaval nos locais de maior concentração de foliões, foi intensificada, possibilitando maior atenção ao aspecto educativo.

O preservativo gratuito, distribuído pelo Ministério da Sáude, é tão confiável quanto os preservativos de marcas que estão à venda no Brasil?

A confiança no preservativo que é distribuído e comercializado no Brasil deve partir de um único referencial, o selo do Inmetro. Se a embalagem contiver este selo, existe a garantia de que o preservativo está certificado no âmbito do Sistema Brasileiro de Certificação em conformidade com as prescrições da resolução RDC $n^{\circ} 3$ da Anvisa e a portaria do Inmetro $n^{\circ} 50$, de 28/03/2002, que estabelecem requisitos para esse produto, seja ele distribuído gratuitamente ou comercializado. Os preservativos brasileiros, tanto os fabricados no Brasil quanto os importados, são considerados produtos de certificação compulsória pelo Inmetro e pela Anvisa.

Por que a campanha pretende atingir somente os homens, se muito se fala atualmente sobre a vulnerabilidade das mulheres frente ao HIV/Aids?

Porque os homens são os maiores consumidores do preservativo. A mesma pesquisa do IBOPE indica que $65 \%$ dos preservativos vendidos no Brasil são adquiridos por homens, contra $35 \%$ das mulheres. Queremos reforçar a responsabilidade deles no controle da epidemia, já que são os maiores compradores. Mas, apesar da campanha ter como público-alvo os homens, ela foi prétestada por públicos femininos e teve grande aceitação. Acreditamos, assim, que ela será entendida e assimilada também pelas mulheres, que cada vez mais assumem um papel ativo na adoção do preservativo como prática sexual segura. 


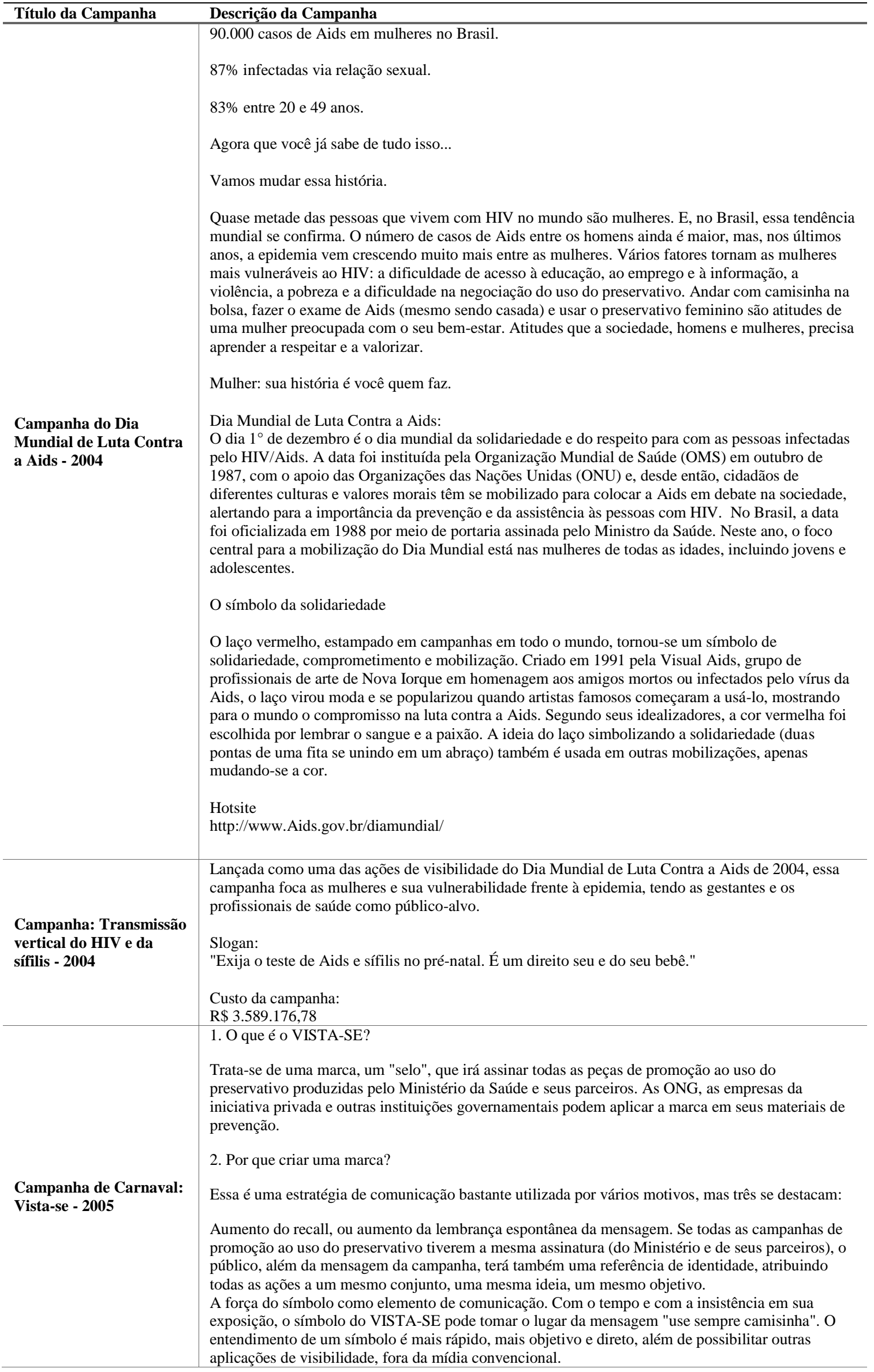




\begin{tabular}{|c|c|}
\hline Título da Campanha & Descrição da Campanha \\
\hline & 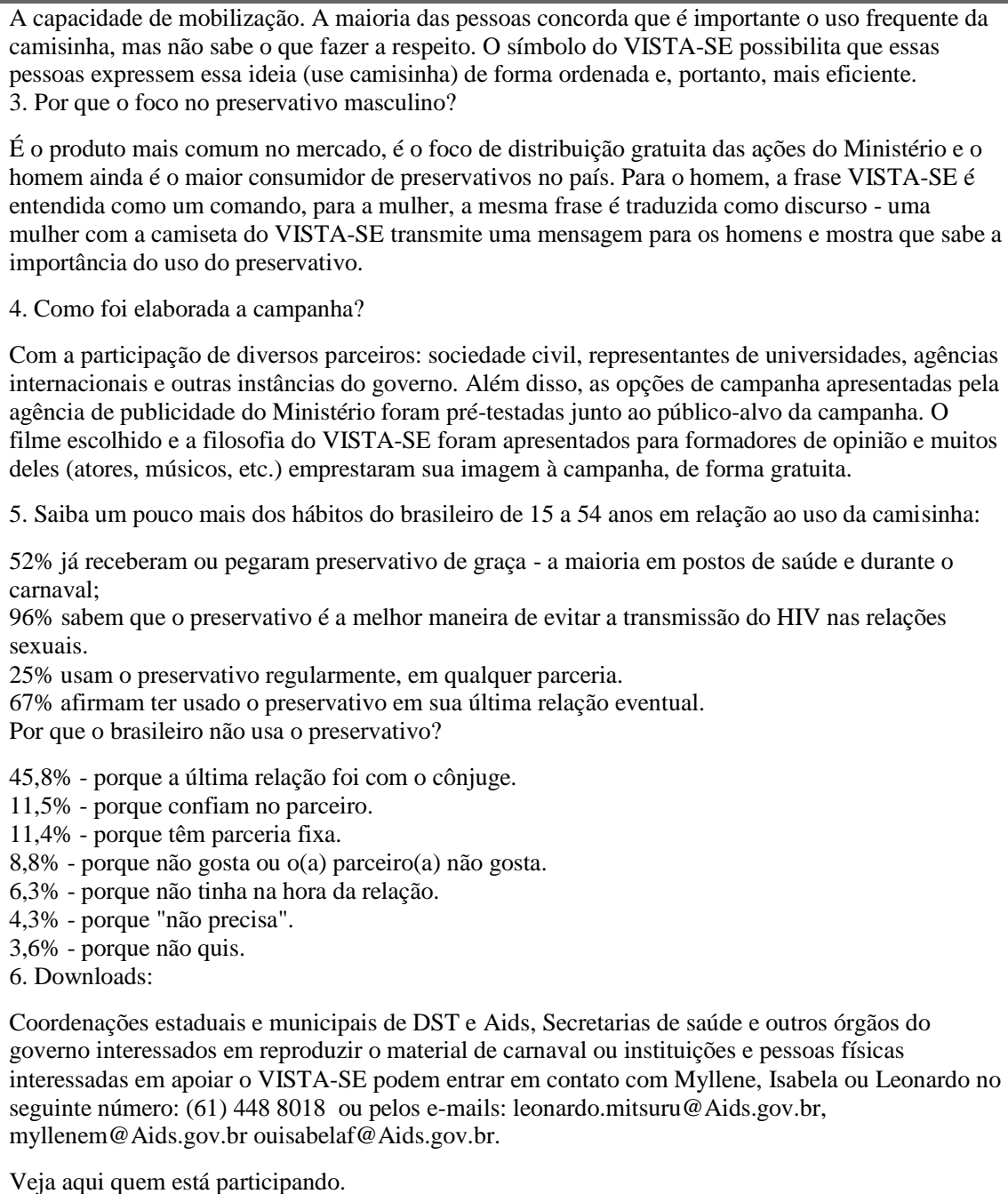 \\
\hline $\begin{array}{l}\text { Campanha do Dia } \\
\text { Mundial: Aids e } \\
\text { Racismo. O Brasil tem } \\
\text { que viver sem } \\
\text { preconceito - } 2005\end{array}$ & $\begin{array}{l}\text { O Dia Mundial de Luta contra a Aids deste ano tem como tema no Brasil a Aids e o racismo. Este } \\
\text { tema foi escolhido a partir da perspectiva de que a população negra nunca foi alvo de campanhas de } \\
\text { prevenção, sendo que representa } 47,3 \% \text { da população brasileira, segundo o IBGE. Essa } \\
\text { representatividade aumenta quando verificamos que englobaa aproximadamente } 65 \% \text { da população } \\
\text { de baixa renda. } \\
\text { No Brasil, apesar da tendência de estabilização da epidemia, os casos de Aids vêm aumentando } \\
\text { entre a população mais pobre, em que a população negra encontra-se em maior proporção. Daí a } \\
\text { importância dessa população como protagonista do Dia Mundial de Luta contra a Aids de } 2005 . \\
\text { O } 1^{\circ} \text { de dezembro, Dia Mundial de Luta contra a Aids, é o momento político que irá colocar o tema } \\
\text { racismo, e suas consequências para os portadores de HIV e para a população negra, na agenda da } \\
\text { sociedade. Seguem abaixo mais informações sobre a ação do dia } 1^{\circ} \text { de dezembro: } \\
\text { Tema: } \\
\text { Aids e o racismo } \\
\text { Slogan: } \\
\text { "Aids e Racismo. O Brasil tem que viver sem preconceito." } \\
\text { Materiais: } \\
\text { Cartaz e folderes para distribuição em estados e mMunicípios } \\
\text { Ações: } \\
\text { Laço da solidariedade no prédio da Secretaria Especial de Políticas de Promoção da Igualdade } \\
\text { Racial (SEPPIR) e nos postes dos Eixos Rodoviário e Monumental. } \\
\text { Campanha do Laço Vermelho da Solidariedade do UNAIDS. Instalação do laço vermelho nos } \\
\text { principais marcos de todos os municípios do Brasil. Convite feito para todas as prefeituras. } \\
\text { Pronunciamento do Ministro da Saúde e da Ministra da Secretaria Especial de Políticas de } \\
\text { Promoção da Igualdade Racial em cadeia de rádio e TV no dia } 30 \text { de novembro. } \\
\text { Lançamento do Boletim Epidemiológico DST/AIids de } 2005 \text { (dia } 30 \text { de novembro). } \\
\text { Solenidade "Pela Inclusão Social da População Negra": homenagem para ONG, Universidades e } \\
\text { personalidades que se destacaram no trabalho com esta população, no auditório Emílio Ribas do } \\
\text { Ministério da Saúde. }\end{array}$ \\
\hline
\end{tabular}




\begin{tabular}{l|l}
\hline Título da Campanha & Descrição da Campanha \\
\hline \multirow{4}{*}{$\begin{array}{l}\text { Campanha de Carnaval - }- \\
\text { 2006 }\end{array}$} & $\begin{array}{l}\text { "Campanha de Carnaval de 2006 do Ministério da Saúde terá como tema a promoção do uso do } \\
\text { audiência prioritária para essa campanha é de foliões, independente do sexo e gênero, faixa etária e } \\
\text { da classe social. }\end{array}$ \\
& $\begin{array}{l}\text { A escolha desse tema foi motivada pelos resultados de uma pesquisa de comportamento da } \\
\text { população brasileira realizada pelo PN-DST/AIDS em 2005. De acordo com o estudo, 47,5\% dos } \\
\text { homens entre 16 e 19 anos não usaram o preservativo porque não o tinham na hora e 36,4\% das } \\
\text { mulheres, na mesma faixa etária, não se lembraram da camisinha na hora H. Esses dados } \\
\text { sinalizaram a importância de conscientizar a população sobre a necessidade de ter o preservativo } \\
\text { sempre à mão para quando precisar, principalmente durante o Carnaval. }\end{array}$ \\
$\begin{array}{l}\text { Como o público-alvo da campanha deste ano serão os foliões, os materiais foram pensados de modo } \\
\text { a atender a essa população. Serão produzidas bandanas, folhetos de apoio para distribuição de } \\
\text { preservativos e cartazes para bares. Estes materiais serão enviados para os Estados em que haverá a } \\
\text { maior concentração de foliões durante o Carnaval. São eles: Salvador, Rio de Janeiro, Pernambuco e } \\
\text { Minas Gerais, além dos estados do Amazonas e Pará, áreas de maior concentração de foliões na } \\
\text { região Norte. Os cartazes para bares serão distribuídos pela Coca-Cola. }\end{array}$
\end{tabular}

Para os demais estados haverá a distribuição de folhetos de apoio para distribuição de preservativos, que não serão de uso exclusivo no carnaval, podendo ser utilizados ao longo do ano. Estes folhetos serão distribuídos diretamente para as coordenações estaduais e estarão chegando até dia 17 de fevereiro.

Além das peças de intervenção, fazem parte da campanha o comercial de 30 " de veiculação nacional, spot de rádio, mobiliário urbano (banner para ponto de ônibus) e outdoor.

A campanha do Dia Mundial de Luta contra a Aids deste ano terá como foco as pessoas que vivem com HIV/Aids, com base no conceito de Prevenção Posithiva.

A Prevenção Posithiva é a prevenção voltada para as pessoas que vivem com HIV/Aids. A partir do tratamento, elas têm uma maior qualidade de vida, novas perspectivas, o desejo de relacionar-se afetivamente, trabalhar, estudar, ter filhos, enfim, ter projetos de vida. Isso se tornou uma questão importante, não só para essas pessoas, mas para toda a sociedade.

Daí a importância de combater a discriminação, o preconceito e o estigma que envolve a doença por meio do protagonismo das pessoas que vivem com HIV. Essa é a proposta para o Dia Mundial de Luta Contra a Aids. Devemos destacar que é a primeira vez que adotamos tal estratégia.

O $1^{\circ}$ de dezembro é o momento político que irá colocar o tema viver com HIV e Aids, e suas conseqüências, na agenda da sociedade. Mas será apenas o começo de uma série de ações de comunicação que, pretendemos, dará continuidade ao tema ao longo de todo o próximo ano.

Campanha do Dia Mundial de Luta Contra a Aids - 2006
Seguem abaixo mais informações sobre a ação do dia $1^{\circ}$ de dezembro:

Tema:

Viver com HIV/Aids

Slogan:

"A vida é mais forte que a Aids."

Materiais:

Filme de 30" - Com o objetivo de reforçar o protagonismo e diminuir o estigma, uma pessoa que realmente tem o vírus irá dar o seu depoimento ao público. Veiculação prevista para a semana do dia $1^{\circ}$ de dezembro.

Cartaz e folder para distribuição por meio dos estados - Será um material com uma pessoa que vive com HIV como protagonista. A distribuição destes materiais estão previstas para a semana do dia $1^{\circ}$ de dezembro. O material gráfico não será datado para que possa ser usado de forma contínua A campanha de carnaval deste ano terá como tema o preservativo com o slogan "Com camisinha, a alegria continua durante e depois da festa". A idéia é fazer com que os foliões descubram a tranqüilidade que eles podem ter depois da "festa" quando usam camisinha, prolongando assim a sua alegria e o seu prazer, sendo mais um argumento para a prevenção. A campanha será composta de filme de 30", spot de rádio, cartaz e folheto. Este ano a campanha terá em sua assinatura um diferencial importante das anteriores. Será incluída nas peças a seguinte mensagem: "Vivendo com Aids ou não, use camisinha e fique tranqüilo", com a idéia de incluir as pessoas que vivem com HIV nas campanhas oficiais de massa. 


\begin{tabular}{|c|c|}
\hline Título da Campanha & Descrição da Campanha \\
\hline $\begin{array}{l}\text { Campanha do Dia } \\
\text { Mundial de Luta contra } \\
\text { a Aids - } 2007\end{array}$ & 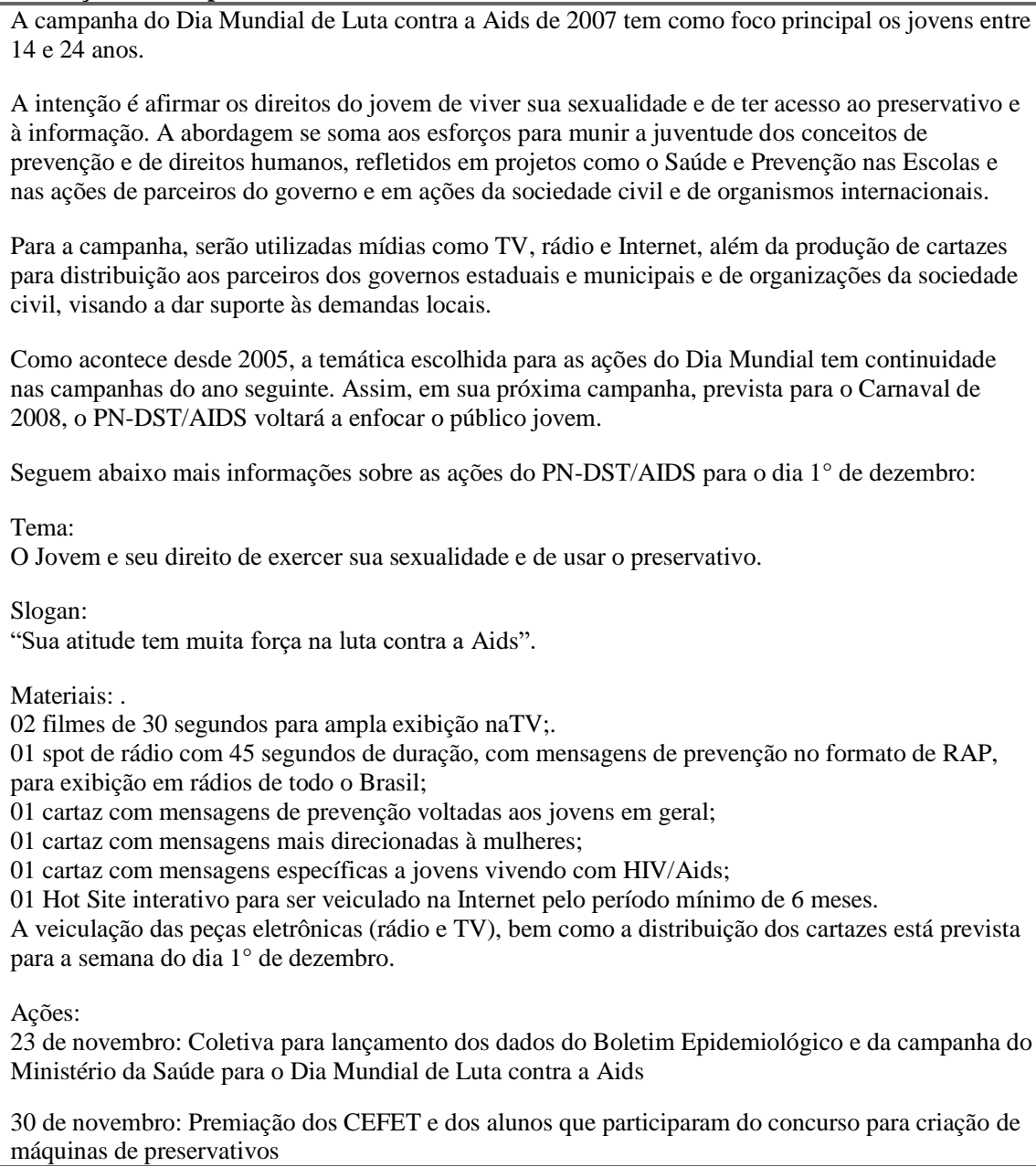 \\
\hline $\begin{array}{l}\text { Campanha de Carnaval - } \\
2008\end{array}$ & $\begin{array}{l}\text { Este ano, a Campanha de Carnaval dá continuidade ao tema do Dia Mundial de Luta contra a Aids } \\
\text { de } 2007 . \text { O foco continua sendo o jovem, e a chamada principal "Qual a sua atitude na Luta Contra } \\
\text { a Aids?", também permanece. } \\
\text { O filme e as peças gráficas voltam a contar com a participação de Negra Li, e as duas mídias vão } \\
\text { atuar de forma diversificada. O filme está mais centrado nas mulheres jovens, lembrando que é } \\
\text { importante ter a camisinha sempre à mão. Já os cartazes, que serão distribuídos prioritariamente em } \\
\text { banheiros de bares e restaurantes, utilizam o título "Bom de cama é quem usa camisinha", para falar } \\
\text { com jovens de ambos os sexos. } \\
\text { Outra mídia que contribui com a continuidade da campanha é o site www.qualsuaatitude.com.br, } \\
\text { que contou com posts diários falando sobre sexualidade, preconceito e, claro, atitude. } \\
\text { Tema: } \\
\text { "O papel do jovem na prevenção à Aids." } \\
\text { Slogan } \\
\text { "Qual a sua Atitude na Luta Contra a Aids?" } \\
\text { Materiais: } \\
\text { Filme ( } 30 ") ; \\
\text { Jingle ( } 30 ") ; \\
\text { Bandana (com distribuição dirigida); } \\
\text { Tatuagem (com distribuição dirigida); } \\
\text { Folder; } \\
\text { Cartaz para banheiros (um modelo para homens e outro para mulheres); } \\
\text { Hotsite; } \\
\text { Mobiliário urbano. } \\
\text { Período de veiculação: } \\
27 / 01 \text { a 05/02/2008 } \\
\text { Outras ações: } \\
\text { Lançamento da campanha: dia 27/01/2008, no Centro Cultural Cartola, Rio de Janeiro. }\end{array}$ \\
\hline
\end{tabular}




\begin{tabular}{l}
\hline Título da Campanha \\
\hline \\
Campanha do Dia \\
Internacional da Mulher \\
- 2008
\end{tabular}

\section{Descrição da Campanha}

Aqui você encontra depoimentos de algumas personalidades que podem ser veiculados em qualquer emissora de rádio ou distribuídos pela internet, em duas versões: 1) spot de 30", com referência ao Dia Internacional da Mulher; 2) apenas o depoimento, para ser montado e mixado pela emissora (obs: os depoimentos não podem ser editados novamente. Eles devem ser exibidos como se encontram aqui, para evitar que sejam utilizados fora de contexto). SPOTS DE RÁDIO - 08 DE MARÇO, DIA INTERNACIONAL DA MULHER

Plano Nacional de

Enfrentamento da

Epidemia de Aids e das

DST entre Gays, HSH e Travestis - 2008

Como parte das ações do Plano Nacional de Enfrentamento da Epidemia de Aids e das DST entre gays, homens que fazem sexo com homens (HSH) e travestis, o Ministério da Saúde, por intermédio do Programa Nacional de DST e Aids, lança cartaz e folder de conscientização para a população gay. As duas peças têm como foco o estímulo ao uso do preservativo, e sua veiculação é dirigida. A distribuição contará com o apoio de ONG especializadas em ações de prevenção para HSH.

Tiragem: Cartaz - 100.000 Folder - 500.000 Confira a publicação.

A Campanha do Dia Mundial de Luta contra a Aids em 2008 tem como público-alvo a população heterossexual com mais de 50 anos de idade. $\mathrm{O}$ foco são homens maduros das classes $\mathrm{C}$ e D. A escolha desse público se deu, principalmente, porque a incidência de Aids praticamente dobrou nessa população nos últimos dez anos (de 7,5\% em 96 para 15,7\% em 2006). Ao contrário do que muitos pensam, as pessoas acima de 50 anos de idade têm uma vida sexualmente ativa, 73,1\% fizeram sexo no último ano e apenas $22,3 \%$ usaram preservativo na última relação, ao contrário da população de 15 a 24 anos, na qual 57,3\% usaram o insumo na última relação. Esse público nunca foi alvo de nossas campanhas e os números mostram o quanto é importante conscientizar essa faixa etária sobre o uso da camisinha.

A Campanha Clube dos Enta, que tem como slogan "Sexo não tem idade. Proteção também não", trata de assuntos ligados à relação sexual, como o uso do preservativo, além de oferecer dicas para melhorar o sexo depois dos 50 .

Para a campanha, serão utilizadas mídias como TV, rádio, mobiliários urbanos e Internet, além da produção de cartazes e fôlderes para distribuição aos parceiros. Este ano o material gráfico foi disponibilizado no site no Programa desde 15 de outubro para que os governos estaduais e

Campanha do Dia Mundial de Luta contra a Aids: Sexo não tem idade. Proteção também não - 2008 municipais e organizações da sociedade civil pudessem reproduzi-lo.

Como acontece desde 2005, o tema da Campanha do Dia Mundial tem continuidade no ano seguinte. Assim, no Carnaval 2009 teremos como público-alvo também as pessoas com mais de 50 anos de idade.

Campanha do Dia Mundial de Luta Contra a Aids 2008:

Tema: Pessoas com mais de 50 anos, homens maduros.

Slogan: "Sexo não tem idade. Proteção também não."

Materiais:

- 1 Filme para TV $(30 \mathrm{sec})$

- 2 Spots de rádio $(30$ e $60 \mathrm{sec})$

- 3 modelos de Cartazes e Mobiliários Urbanos

- 1 Folder

-1 Hot Site

Ações relacionadas ao Dia Mundial: 25 de Novembro: - Lançamento da Campanha e Boletim Epidemiológico sobre Aids e DST - 2008.

$1^{\circ}$ de Dezembro:

O público prioritário da Campanha de Carnaval 2009 é a população feminina com mais de 50 anos.

A campanha é uma resposta à tendência de crescimento da epidemia entre a população nessa faixa etária. Dados epidemiológicos apontam que a incidência de Aids praticamente dobrou nessa população nos últimos dez anos (de 7,3 em 96 para 14,5 em 2006).

No dia $1^{\circ}$ de dezembro do ano passado, Dia Mundial de Luta contra a Aids, a campanha priorizou a mesma faixa etária, mas voltada para os homens. Agora, no Carnaval, ela retorna com foco nas mulheres.

Campanha de Carnaval Sexo não tem idade para acabar. Proteção também não - 2009

Incentivar a mulher a negociar com o parceiro o uso do preservativo é um dos objetivos da campanha, já que a maioria das mulheres nessa faixa etária tem pouco poder de decisão em relação à camisinha.

A campanha procura fortalecer a imagem da mulher, para que ela se sinta mais segura e possa exercer sua sexualidade de forma protegida. Buscar o prazer seguro na relação não deve ser motivo de vergonha e sim de atitude.

Além disso, o folder alerta para o uso da camisinha feminina e do gel lubrificante. Com a camisinha feminina, a mulher tem o poder de decisão. Já o gel aumenta a lubrificação da vagina, diminuindo a sensação de desconforto causada pela menopausa e pelo uso do preservativo. 


\begin{tabular}{|c|c|}
\hline Título da Campanha & Descrição da Campanha \\
\hline & $\begin{array}{l}\text { As peças principais da campanha são o VT e o jingle, ambos com veiculação nacional. O vídeo do Clube } \\
\text { da Mulher Madura mostra amigas reunidas se preparando para o Carnaval, entre rimas elas falam frases } \\
\text { como "Homem sem camisinha a gente não atura" e "Use camisinha. É coisa de mulher segura". } \\
\text { As artes dos materiais gráficos, como cartaz, folder etc., foram enviadas para que os estados e } \\
\text { municípios as reproduzam localmente. A solicitação de artes gráficas deve ser feita por meio do } \\
\text { endereço eletrônico: publicidade @ Aids.gov.br. } \\
\text { Carnaval } 2009 \\
\text { Bloco da Mulher Madura } \\
\text { Slogan: Sexo não tem idade para acabar. Proteção também não. } \\
\text { Lançamento: } \\
\text { A Roda de Samba na Luta Contra a Aids contará com apresentação de famosos como Alcione e } \\
\text { Leci Brandão. Os ministros José Gomes Temporão e Nilcéa Freire, da Secretaria Especial de } \\
\text { Políticas para as Mulheres, apresentarão os dados e a campanha. } \\
\text { Data: } 13 / 02 / 2009 \\
\text { Hora: } 10 \text { h30 } \\
\text { Local: Cidade do Samba no Rio de Janeiro } \\
\text { Materiais: } \\
\text { VT } 30 " \\
\text { Jingle } \\
\text { Cartaz } \\
\text { Folder } \\
\text { Bobiliário Urbano } \\
\text { Camiseta }\end{array}$ \\
\hline $\begin{array}{l}\text { Campanha de DST: } \\
\text { Muito Prazer. Sexo sem } \\
\text { DST - } 2009\end{array}$ & 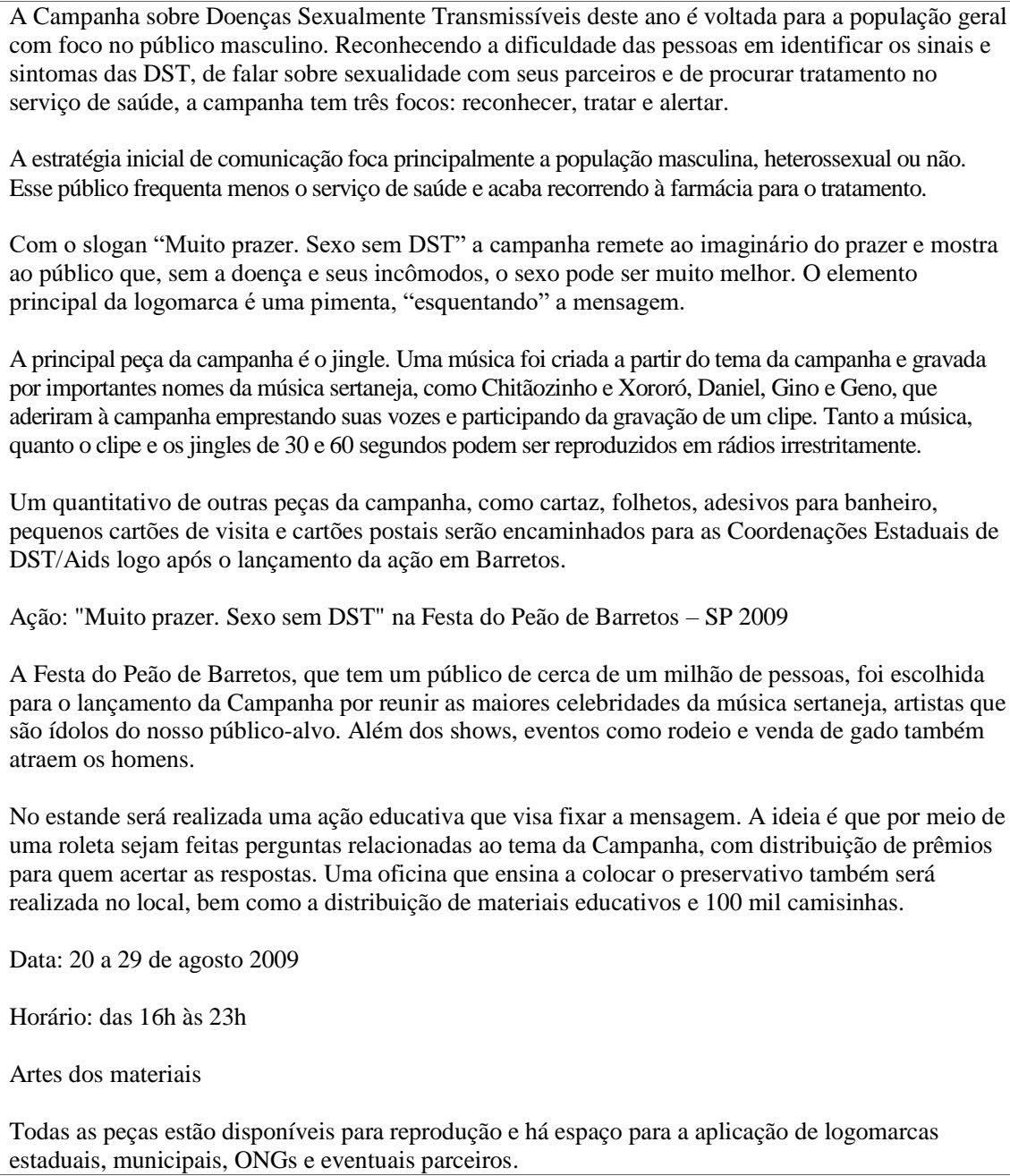 \\
\hline
\end{tabular}




\begin{tabular}{l|l}
\hline Título da Campanha & Descrição da Campanha \\
\hline Campanha CNBB - 2009 & $\begin{array}{l}\text { O Departamento de DST, Aids e Hepatites Virais do Ministério da Saúde e a Conferência Nacional } \\
\text { dos Bispos do Brasil (CNBB) se unem em uma ação inédita e histórica. A Igreja Católica vai } \\
\text { mobilizar suas pastorais e movimentos religiosos, além da rede de saúde e meios de comunicação, } \\
\text { para sensibilizar os fiéis sobre a importância da testagem para Aids na população geral e para sífilis } \\
\text { entre as gestantes. Com o slogan: "Declare seu amor por você", a campanha será veiculada em } \\
\text { vários meios de comunicação. }\end{array}$ \\
\hline $\begin{array}{l}\text { Pesquisas sobre o comportamento da população brasileira alertam para o fato de que, apesar de as } \\
\text { pessoas possuírem informações sobre as formas corretas de prevenção ao HIV/Aids, o preconceito e } \\
\text { a discriminação às pessoas vivendo com o HIV/Aids ainda é muito forte na nossa sociedade. Por } \\
\text { esse motivo, a campanha do Ministério da Saúde para o Dia Mundial de Luta contra a Aids deste } \\
\text { ano tratará o preconceito como tema. }\end{array}$
\end{tabular}

As peças da campanha usarão imagens de beijos, um forte símbolo de amor e amizade que, no campo da Aids, assume outras conotações: o beijo mostra que não se transmite o HIV dessa forma, que as pessoas que vivem com o HIV/Aids podem e devem se relacionar com as demais, que a

Campanha do Dia Mundial de Luta contra a Aids: Viver com Aids é possível. Com o preconceito não - 2009

Campanha: Meu nome não é Aids - 2009 solidariedade precisa ser praticada.

O slogan "Viver com Aids é possível. Com o preconceito não" é uma resposta às pesquisas. Quem vive com o HIV/Aids pode trabalhar, estudar, praticar esportes, namorar e fazer sexo com camisinha, como todo mundo. É verdade que quem vive com o HIV/Aids precisa se adaptar às rotinas de consultas e medicamentos. Mas o mais difícil de viver com o HIV/Aids é ter que conviver com o preconceito.

Para a campanha, serão utilizadas mídias como TV, rádio, mobiliários urbanos e internet, além de cartazes e fôlderes. As artes dos materiais gráficos, como cartaz, fôlder etc., foram enviadas aos estados e municípios para reprodução local, o que, conforme pactuação, vem sendo realizado desde 2007. Ao Departamento de DST, Aids e Hepatites Virais cabe a produção do quantitativo mínimo para abastecer aqueles locais em que não houve possibilidade de garantir tal reprodução.

Quem vive com HIV e Aids pode trabalhar, estudar, namorar, constituir família e fazer exercícios físicos, como todo mundo. Quem vive com HIV e Aids só não pode conviver com o preconceito. O material "Meu nome não é Aids" conta histórias reais de pessoas vivendo com HIV e Aids, retratadas por belas fotografias. São 12 modelos de postais e 1 modelo de calendário. As fotos foram produzidas durante as filmagens do documentário Histórias Posithivas, com locações em Belo Horizonte, Recife e Fortaleza. O documentário é dividido em 13 vídeos que oferecem informações úteis para a melhoria da qualidade de vida das pessoas vivendo com HIV e Aids. Veja os vídeos no link www.Aids.gov.br/historiasposithivas. A arte dos materiais está disponível para download abaixo. Dúvidas e informações? Entre em contato pelo e-mail publicidade@ Aids.gov.br.

A campanha de Carnaval de 2010 é uma resposta à tendência de crescimento da epidemia entre as meninas na faixa etária de 13 a 19 anos. O número de casos de Aids é maior entre as mulheres jovens: são oito casos em meninos para cada dez casos em meninas. Essa inversão apresenta-se desde 2008. No sexo masculino, há maior transmissão entre homossexuais $(39,2 \%)$. A proporção em heterossexuais era de 22,2\%, de acordo com dados de 2007.

Este ano, a campanha tem uma estratégia diferente da dos anos anteriores: foram criadas duas mensagens que serão veiculadas em dois momentos: antes do Carnaval e depois do carnaval.

Antes do Carnaval

A mensagem para quem vai curtir o Carnaval é de prevenção. O slogan "Camisinha. Com amor, paixão ou só sexo mesmo. Use sempre" busca atingir tanto os apaixonados quanto quem quer apenas curtir. São dois vídeos, um direcionado às meninas e o outro aos jovens gays. Em ambos, o protagonista é uma camisinha falante que alerta os jovens para o uso do preservativo.

Depois do Carnaval

A mensagem para depois do Carnaval é sobre o teste de Aids. Quem fez sexo sem camisinha, no Carnaval ou não, deve fazer o teste. No vídeo, um jovem se revira na cama, sem conseguir dormir, como se estivesse incomodado. A camisinha também é protagonista e fala sobre as vantagens em se realizar o exame. As principais peças da campanha são os VTs e jingles, além de mobiliários urbanos, cartazes e folderes. Todos os materiais têm veiculação e distribuição nacional. As artes dos materiais gráficos (cartaz, fôlder etc) foram enviadas para que os estados e municípios as reproduzam localmente, conforme pactuado desde 2007. Ao Departamento de DST, Aids e Hepatites Virais cabe a produção de um quantitativo mínimo para abastecer aqueles locais em que não houve possibilidade de garantir essa reprodução. A grade de produção e distribuição dessa reserva está disponível abaixo. 


\begin{tabular}{l|l} 
Título da Campanha & Descrição da Campanha \\
\hline & $\begin{array}{l}\text { Diante do crescimento da incidência de Aids entre as mulheres nos últimos anos, o governo federal, } \\
\text { em uma ação interministerial inédita, decidiu incorporar a luta contra a doença às ações do principal } \\
\text { programa social brasileiro. A partir de agora, serão realizadas ações de prevenção às DST/HIV/Aids } \\
\text { nos centros de assistência do Ministério do Desenvolvimento Social e do Combate à Fome (MDS) } \\
\text { que atendem aos beneficiários do Bolsa Família. Esses serviços também poderão disponibilizar } \\
\text { preservativos. }\end{array}$
\end{tabular}

Para levar a iniciativa ao conhecimento das mulheres e dos gestores do programa, foi concebida a campanha "Camisinha, um direito seu", que tem duas beneficiárias do Bolsa Família como garotaspropaganda dos materiais impressos. Constam da campanha folders, cartazes, faixas, portapreservativos, manuais explicativos para as mulheres sobre a importância do uso da camisinha e materiais que ensinam aos gestores por que realizar essas ações em conjunto com a saúde. Além disso, serão veiculados spots nas rádios do país, com mensagem às mulheres gravada pela atriz e cantora Zezé Motta.

O Ministério da Saúde, a Secretaria Especial de Políticas para as Mulheres e o MDS são parceiros na campanha, que prevê a distribuição de 1 milhão de camisinhas em Centros de Referência em Assistência Social, localizados nas capitais brasileiras. Nesses locais são atendidas 1,2 milhão de mulheres em situação de pobreza ou extrema pobreza. $\mathrm{O}$ objetivo é facilitar o acesso ao preservativo às mulheres de baixa renda, orientá-las sobre como discutir com o parceiro a questão do uso da camisinha e incentivá-las a fazer o teste de HIV. A campanha "Camisinha, um direito seu" é uma mobilização para a ação continuada de prevenção do HIV/Aids voltada às beneficiárias do Bolsa Família.

Camisinha, um direito seu: Campanha direcionada às mulheres beneficiárias do Programa Bolsa Família $-2010$

Campanha: Sou travesti. Tenho direito de ser quem eu sou - 2010

Campanha de combate às Hepatites Virais 2010

\section{Feminização}

A ação é parte do Plano Nacional de Enfrentamento de Feminização da Epidemia de Aids e outras Doenças Sexualmente Transmissíveis, criado em razão do aumento da epidemia entre as mulheres.

Segundo o Boletim Epidemiológico de 2009, em 1986 a razão entre os sexos era de 15 casos de Aids em homens para cada caso em mulheres; a partir de 2002, essa razão estabilizou-se em 15 casos em homens para cada 10 em mulheres. Na faixa etária de 13 a 19 anos, o número de casos de Aids é maior entre as moças do que entre os rapazes. A inversão apresenta-se desde 1998, com oito casos em meninos para cada dez casos em meninas.

Entre 2000 e junho de 2009, foram registrados no Brasil 3.713 casos de Aids em meninas de 13 a 19 anos (60\% do total), contra 2.448 meninos. Na faixa etária seguinte (20 a 24 anos), há 13.083 (50\%) casos entre elas e 13.252 entre eles. No grupo com 25 anos e mais, há uma clara inversão - 174.070 $(60 \%)$ do total (280.557) de casos ocorrem entre os homens.

A Pesquisa de Conhecimentos, Atitudes e Práticas da População Brasileira, lançada pelo Ministério da Saúde em 2009, também ajuda a explicar a vulnerabilidade das jovens à infecção pelo HIV. De acordo com o estudo, $64,8 \%$ das entrevistadas entre 15 e 24 anos eram sexualmente ativas (haviam tido relações sexuais nos 12 meses anteriores à pesquisa). Dessas, apenas 33,6\% usaram preservativos em todas as relações casuais.

Entre os homens, $69,7 \%$ dos entrevistados eram sexualmente ativos. Porém, eles usam mais a camisinha: $57,4 \%$ afirmaram ter usado o insumo em todas as relações com parceiros ou parceiras casuais.

Principais alvos da violência discriminatória, travestis de todo o país criaram material para sensibilizar a população contra o preconceito. A campanha de promoção de direitos humanos e prevenção à Aids contém toques de celular, telas de descanso e vídeos de celular, cartazes e fôlderes. É a primeira vez que as travestis produzem e criam o conceito de um material destinado a elas mesmas. Com o slogan "Sou travesti. Tenho direito de ser quem eu sou", a proposta é promover a inserção social e a imagem positiva das travestis, além de disseminar o conhecimento sobre as formas de prevenção à Aids e outras doenças sexualmente transmissíveis, além do combate à violência e à discriminação. "Como são vítimas de violência e têm dificuldade de acesso a serviços públicos, como saúde e educação, as travestis tornam-se mais vulneráveis à infecção pelo HIV", explica a diretora do Departamento de DST, Aids e Hepatites Virais, Mariângela Simão. Produzir o seu próprio material, diz, as torna protagonistas de suas próprias histórias. Na vida real, elas não são ouvidas, nem vistas. Sem serem acolhidas de forma adequada nos serviços de saúde, elas também têm mais dificuldades para recorrer aos instrumentos necessários à prevenção às DST e outros problemas de saúde.

As hepatites virais são doenças graves. Muitas pessoas desconhecem a doença e suas formas de transmissão mesmo quando estão vivendo em um ambiente propício à contaminação. Com isso, muitas vezes essas doenças são diagnosticadas tardiamente, dificultando o tratamento. Para aumentar o acesso da sociedade às formas de prevenção dessas doenças, o Departamento de DST, Aids e Hepatites Virais lança uma campanha voltada para a população geral. Com o tema: "Você não sabe, mas pode ter pego hepatite assim", essa campanha foi criada para orientar a população sobre as formas de contágio e como se prevenir dessas doenças. 


\begin{tabular}{l|l}
\hline Título da Campanha & Descrição da Campanha \\
\hline & No dia $1^{\circ}$ de dezembro, vários países comemoram o Dia Mundial de Luta contra a Aids. Essa data \\
& foi instituída como forma de despertar a necessidade da prevenção, promover o entendimento sobre \\
& a pandemia e incentivar a análise sobre a Aids pela sociedade e órgãos públicos. No Brasil, a data \\
começou a ser comemorada no final dos anos 1980, envolvendo os governos federal, estaduais, \\
distrital e municipais e organizações sociais.
\end{tabular}

Campanha do Dia Mundial de Luta Contra a Aids - 2010

Campanha de Carnaval 2011
Este ano, a campanha do Dia Mundial tem como público primordial os jovens de 15 a 24 anos. Essa escolha foi feita ao se levarem em consideração dados comportamentais como o maior número de parceiros casuais dos jovens em relação aos não jovens e o elevado índice de jovens (40\%) que declaram não usar preservativo em todas as relações sexuais.

Os objetivos da campanha são a desconstrução do preconceito sobre as pessoas vivendo com HIV/Aids e a conscientização dos jovens sobre comportamentos seguros de prevenção. Para isso, o tema da campanha será: "O preconceito como aspecto de vulnerabilidade ao HIV/Aids". Confira notícias e eventos sobre o Dia Mundial de Luta Contra a Aids 2010, o vídeo da campanha e o making of das fotos da exposição "Somos iguais. Preconceito não".

Para comemorar o Dia Mundial de Luta contra as Hepatites Virais, o Minitério da Saúde criou a campanha "Hepatite é coisa séria", com o objetivo de alertar a população sobre os riscos dessas doenças. São filmes, spots, anúncios, cartazes, fôlderes, faixas, hotsite e banners de internet destinados a vários públicos diferentes. Uma das intenções é estimular a vacinação de jovens até 24 anos e grupos vulneráveis. Quem já esteve em situações de exposição ao vírus das hepatites B e C será incentivado a realizar o teste gratuito. Já o público geral será alertado sobre as principais formas de prevenção e contágio da doença. Além das peças listadas abaixo, há algumas publicações relacionadas:

Boletim Epidemiológico

Hepatites Virais 2011 Hepatites Virais no Brasil: Situação, Ações e Agenda

Estudo de Prevalência de Base Populacional das Infecções pelos vírus das Hepatites A, B e C nas Capitais do Brasil

Protocolo Clínico e Diretrizes Terapêuticas para Hepatite Viral C e Coinfecções

Veja, ainda, a lista dos primeiros Centros de Testagem e Aconselhamento (CTA) a realizarem testes rápidos para hepatites $\mathrm{B}$ e $\mathrm{C}$.

Assista aos vídeos:

Dia Mundial de Luta Contra as Hepatites Virais 2011 - Prevenção e Testagem

Dia Mundial de Luta Contra as Hepatites Virais - Vacinação

Dia Mundial de Luta Contra as Hepatites Virais - Testagem

Para comemorar o Dia Mundial de Luta contra as Hepatites Virais, o Minitério da Saúde criou a campanha "Hepatite é coisa séria", com o objetivo de alertar a população sobre os riscos dessas doenças. São filmes, spots, anúncios, cartazes, fôlderes, faixas, hotsite e banners de internet destinados a vários públicos diferentes. Uma das intenções é estimular a vacinação de jovens até 24 anos e grupos vulneráveis. Quem já esteve em situações de exposição ao vírus das hepatites B e C será incentivado a realizar o teste gratuito. Já o público geral será alertado sobre as principais formas de prevenção e contágio da doença. Além das peças listadas abaixo, há algumas publicações relacionadas:

Boletim Epidemiológico

Hepatites Virais 2011 Hepatites Virais no Brasil: Situação, Ações e Agenda

Estudo de Prevalência de Base Populacional das Infecções pelos vírus das Hepatites A, B e C nas

Capitais do Brasil

Protocolo Clínico e Diretrizes Terapêuticas para Hepatite Viral C e Coinfecções

Veja, ainda, a lista dos primeiros Centros de Testagem e Aconselhamento (CTA) a realizarem testes rápidos para hepatites $\mathrm{B}$ e $\mathrm{C}$.

Assista aos vídeos:

Dia Mundial de Luta Contra as Hepatites Virais 2011 - Prevenção e Testagem

Dia Mundial de Luta Contra as Hepatites Virais - Vacinação

Dia Mundial de Luta Contra as Hepatites Virais - Testagem

Em $1^{\circ}$ de dezembro, comemora-se o Dia Mundial de Luta contra a Aids. A campanha deste ano dará enfoque aos jovens gays de 15 a 24 anos das classes C, D e E. A ação busca discutir as questões relacionadas à vulnerabilidade ao HIV/Aids, na população prioritária, sob o ponto de vista do estigma e do preconceito. Por isso, o slogan "A Aids não tem preconceito. Previna-se". Além disso, a ideia é estimular a reflexão sobre a falsa impressão de que a Aids afeta apenas o outro, distante da percepção de que todos estamos vulneráveis.

Públicos secundários: profissionais de saúde, gestores, profissionais da área de educação e comunidade escolar.

Mídias sugeridas: TV, rádio, internet, cartazes, fôlderes e mobiliários urbanos 


\begin{tabular}{l}
\hline Título da Campanha \\
\hline \\
Campanha: Sou travesti. \\
Tenho direito de ser
\end{tabular}

Tenho direito de ser quem eu sou - 2012

Campanha de Carnaval 2012

Campanha do Dia das

Mães - UnAids:

\&quot;Acredite. Faça a sua parte\&quot; - 2012

\section{Descrição da Campanha}

Para comemorar o Dia Nacional da Visibilidade Travesti, 29 de janeiro, o Departamento de DST,

Aids e Hepatites Virais produziu uma série de materiais que seguem a mesma identidade visual da campanha lançada em 2010, fruto de uma oficina de criação de que travestis de todo o país participaram. O foco do material é sensibilizar a população contra o preconceito.

Com o slogan "Sou travesti. Tenho direito de ser quem eu sou", a proposta é promover a inserção social e a imagem positiva das travestis, além de disseminar o conhecimento sobre as formas de prevenção a Aids e outras doenças sexualmente transmissíveis, além do combate à violência e à discriminação.

Este ano, pela primeira vez, uma travesti será protagonista de uma campanha de prevenção durante o Carnaval. Em um dos cartazes que serão veiculados, um rapaz e uma travesti aparecem juntos como um casal. A ideia é mostrar que esse tipo de situação é normal e que o único problema em qualquer relação dé se esquecer da camisinha. O objetivo é conscientizar todos os brasileiros, independente da opção sexual, da importância do uso do preservativo. Confira o making of da produção aqui.

Os jovens gays de 15 a 24 anos são o principal foco da campanha do Ministério da Saúde para o Carnaval deste ano, porque, de 1998 a 2010, o percentual de casos na população homossexual de 15 a 24 anos subiu 10,1\%, conforme o Boletim Epidemiológico de 2011. O conceito da campanha é: "Na empolgação pode rolar de tudo. Só não rola sem camisinha. Tenha sempre a sua".

Ela será veiculada em dois momentos: a partir do dia 13, antecipando o Carnaval, com alertas para o uso regular do preservativo, e no período pós-festa, a partir do final de fevereiro, com a promoção do diagnóstico e a conscientização da necessidade da realização do teste.

A grande novidade do Carnaval deste ano é um pôster dirigido às travestis. É primeira vez que o Ministério da Saúde apresenta um material específico para esse público na campanha de Carnaval. Outros dois pôsteres direcionam-se aos jovens gays e à população heterossexual.

A história desta campanha começa com você. O mundo vive uma oportunidade extraordinária de mudar o rumo da história. É possível eliminar as novas infecções pelo HIV em crianças até 2015 e assegurar que mulheres vivendo com o HIV permaneçam saudáveis durante a gravidez, parto e amamentação. Imagine bebês nascendo sem o HIV e sorrindo saudáveis nos braços de suas mães. Transformar esse sonho em realidade em todos os lugares do mundo é mais fácil do que se imagina.

O Departamento de DST, Aids e Hepatites Virais apoia a campanha lançada pelo Programa Conjunto das Nações Unidas sobre HIV/Aids (UnAids) para erradicar a transmissão vertical do HIV (infecção de mãe para filho). A ação busca disseminar informações sobre as formas de evitar a infecção de mãe para filho durante a gravidez, o parto e a amamentação, em comemoração ao Dia das Mães, dia 13 de maio.

Em 2009, uma chamada à ação promovida pelo Diretor-executivo do UNAIDS, Michel Sidibé, obteve muito resultado. A UNAIDS tem um Plano Global (arquivo em pdf). Temos o comprometimento dos líderes mundiais. Mas o relógio não para: sem a sua ajuda não conseguiremos ir de 390.000, em todo o mundo, para zero. Quanto mais pessoas conhecerem essa importante meta e conversarem sobre ela em suas redes sociais ou adotarem a simples ação de enviar um cartão virtual ou de apoiar uma mãe, mais perto chegaremos de acabar com a infecção da mãe para o bebê.

Fácil como $2+2=4$

Participe da campanha “Acredite. Faça sua parte”. Há quatro coisas muito fáceis que você pode fazer para ajudar a eliminar as novas infecções pelo HIV em crianças e apoiar as mães no mundo todo.

\section{Conheça os fatos}

A cada ano, cerca de 390.000 crianças são infectadas pelo HIV em países de baixa e média renda. Todos os anos, chega a 42.000 o número de mulheres vivendo com o HIV que morrem de complicações decorrentes da infecção e da gravidez. Em contraste, o número de novas infecções pelo HIV em crianças e a taxa de mortalidade materna relacionada ao HIV em países de alta renda são praticamente zero. Qual a razão da diferença? Em países de baixa e média renda, um número muito pequeno de mulheres recebe os serviços de prevenção e tratamento para o HIV que as protegeriam e aos seus filhos. Em 2011, os líderes mundiais se comprometeram nas Nações Unidas, a eliminar até 2015 as novas infecções pelo HIV em crianças e preservar as vidas das mães. Um novo e ousado plano global foi adotado e várias ações visando a aumentar o acesso e a igualdade estão sendo desenvolvidas mundialmente.

\section{Envie um cartão}

Escreva para o mundo. Quanto mais pessoas souberem de nossa meta, maiores as chances de que consigamos atingi-la. Considere a possibilidade de enviar um cartão personalizado para familiares, amigos, redes sociais e representantes governamentais. A UnAids fez uma parceria com Sujean Rim, uma artista super descolada, que criou uma linda série de ilustrações e cartões. É fácil 


\begin{tabular}{|c|c|}
\hline \multirow[t]{5}{*}{ Título da Campanha } & Descrição da Campanha \\
\hline & $\begin{array}{l}\text { selecionar uma de suas criações ou criar seu próprio cartão. Às vezes, bastam algumas poucas } \\
\text { palavras para fazer uma grande diferença. }\end{array}$ \\
\hline & Envie um cartão virtual agora. \\
\hline & $\begin{array}{l}\text { 3. Seja nosso Parceiro Teremos o maior prazer em conectarmos com você. Você é um ativista em } \\
\text { sua comunidade? Tem um blog? Pertence à Associação de Pais e Mestres? Tem conta no Facebook? } \\
\text { Faz parte de algum comitê? Realiza campanhas para levantar recursos para crianças? Repasse essas } \\
\text { informações entre seus amigos e nas redes sociais para aumentar o conhecimento sobre a } \\
\text { transmissão vertical e ajudar a eliminar as novas infecções pelo HIV em crianças. }\end{array}$ \\
\hline & $\begin{array}{l}\text { 4. Apoie uma mãe Transforme todos os dias em Dia das Mães. No mundo todo, organizações } \\
\text { parceiras fantásticas estão trabalhando diretamente com mulheres grávidas vivendo com o HIV para } \\
\text { mantê-las saudáveis durante a gravidez, parto e amamentação, assegurando que seus bebês nasçam } \\
\text { livres do HIV. Há maneiras fáceis de doar seu tempo, conhecimento e recursos. Alguns dos nossos } \\
\text { parceiros à frente dessa tarefa incluem: CARITAS Internacional, Fundação Elizabeth Glaser } \\
\text { Pediatric AIDS, Comunidade Internacional de Mulheres Vivendo com o HIV/Aids, } \\
\text { Mothers2Mothers, UNAIDS, UNFPA, UNICEF e OMS. Visite o site da UnAids e saiba mais sobre } \\
\text { a campanha (site em inglês) }\end{array}$ \\
\hline & $\begin{array}{l}\text { Com o slogan "Não fique na dúvida, fique sabendo", a campanha do Dia Mundial de Luta contra a } \\
\text { Aids } 2012 \text { enfatiza e incentiva o diagnóstico precoce do HIV, o sigilo e confidencialidade do teste, } \\
\text { além do respeito aos direitos humanos. Ela está aliada à estratégia de mobilização nacional de } \\
\text { testagem Fique Sabendo, que ocorrerá de } 20 \text { de novembro à } 1^{\circ} \text { de dezembro. O público a ser } \\
\text { alcançado em mídias de massa é população geral das classes sociais C, D e E, e as populações } \\
\text { segmentadas são profissionais e gestores de saúde, homens que fazem sexo com outros homens } \\
\text { (HSH), travestis, mulheres profissionais do sexo. }\end{array}$ \\
\hline
\end{tabular}

Dia Mundial de Luta contra a Aids - 2012
A estretégia prevê a veiculação das mensagens em internet, TV, rádio e salas de cinema, com mensagens de promoção ao diagnóstico de HIV com base nos direitos humanos e combate ao estigma e ao preconceito.

Veja, abaixo, as artes produzidas e assista aos vídeos.

Vídeo de veiculação na internet

Depoimento de Silvia Almeida

Depoimento de João Geraldo Netto

Em alusão ao Dia da Visibilidade Trans, o Departamento de DST, Aids e Hepatites Virais, do Ministério da Saúde, lança campanha de combate à violência contra travestis e transexuais. O cartaz, estrelado pela travesti Ivana Spears, traz a frase: "Travesti que se cuida, denuncia", incentivando o uso do "Disque 100" - serviço de proteção da Secretaria de Direitos Humanos com foco em violência. A ideia é promover o direito das travestis de serem respeitadas e terem acesso digno nos serviços de saúde. A ação traz, ainda, material informativo sobre a data, um marco na luta pelos direitos humanos, cidadania e respeito à identidade de gênero do segmento. Veja, abaixo, depoimento da travesti Ivana Spears sobre a importância de se denunciar a violência contra esse público.

"A vida é melhor sem Aids. Proteja-se, use sempre camisinha". Este é o conceito da campanha de prevenção à Aids para o Carnaval 2013, que tem o objetivo de conscientizar a população para a prevenção da doença, incentivando o uso da camisinha em todas as relações sexuais. A ideia é fazer uma comparação mostrando que o uso do preservativo pode ser tão simples quanto outros hábitos comuns do dia a dia. Após o período de festas, diversas peças publicitárias serão adaptadas, mantendo a mensagem de prevenção. Confira as peças e divulgue também para os seus amigos e família. Com mais pessoas conscientes dos riscos, haverá mais proteção contra o HIV e será mais fácil combater a doença.

A campanha comemorativa ao Dia Internacional da Mulher 2013 traz depoimentos de mulheres soropositivas e portadoras de hepatites virais, ou que convivem com a doença. As mensagens são de incentivo ao diagnóstico e à prevenção. Com os slogans "A vida pode ser positiva", para a Aids, e "Quebre o silêncio das hepatites com atitude", para as hepatites, a ação contém vídeos, cartazes e banners. Voltada para as redes sociais, a ideia é compartilhar as dificuldades das mulheres em relação ao viver com Aids e a ser portadoras de hepatites virais, por meio das suas histórias de vida. A população geral pode ajudar a divulgar a campanha por meio do site do Departamento de DST, Aids e Hepatites Virais: www.Aids.gov.br/mulheres, um espaço criado especialmente para a data, no qual é possível encontrar:

Campanha do Dia Internacional da Mulher $-2013$
Publicações para gestores e para a sociedade geral relacionadas à política de combate à Aids, às hepatites virais e a outras DST;

Informações sobre a campanha do Dia Internacional da Mulher;

Fotos e perfis das protagonistas da campanha;

Vídeos com os depoimentos das mulheres que vivem e convivem com Aids e hepatites virais; Vídeos com depoimentos de homens e mulheres sobre a camisinha feminina;

Notícias sobre ações, políticas e histórias de vida de quem vive e convive com Aids e hepatites virais; entre outras informações. 


\begin{tabular}{|c|c|}
\hline Título da Campanha & Descrição da Campanha \\
\hline $\begin{array}{l}\text { Prevenção para } \\
\text { Profissionais do Sexo - } \\
\text { Campanha nas redes } \\
\text { sociais - } 2013\end{array}$ & $\begin{array}{l}\text { O Ministério da Saúde relança a campanha de redes sociais "Prostituta que se cuida usa sempre } \\
\text { camisinha", elaborada a partir de oficinas de comunicação comunitária realizadas com representantes } \\
\text { desse público-alvo. As peças orientam as profissionais do sexo sobre a importância do uso do } \\
\text { preservativo e as incentivam a buscar as unidades públicas de saúde em busca do item, gratuitamente. } \\
\text { A ação circulará nas redes sociais até } 2 \text { de julho, quando acontecerá um seminário sobre prostituição e } \\
\text { prevenção às DST, promovido pelo Departamento de DST, Aids e Hepatites Virais do Ministério da } \\
\text { Saúde. Além disso, serão impressos cartazes e flyers para distribuição em entidades parceiras e envio às } \\
\text { coordenações estaduais de DST/Aids. Os banners da ação foram produzidos a partir de uma Oficina de } \\
\text { Comunicação em Saúde para Profissionais do Sexo, realizada entre os dias } 11 \text { e } 14 \text { de março de 2013, } \\
\text { em João Pessoa (PB). Participaram da Oficina representantes de organizações não-governamentais, } \\
\text { associações e movimentos sociais que atuam junto a profissionais do sexo de todas as regiões do país, } \\
\text { apoiando o enfrentamento às DST, Aids e hepatites virais. }\end{array}$ \\
\hline $\begin{array}{l}\text { Campanha do Dia } \\
\text { Mundial das Hepatites } \\
\text { Virais - } 2013\end{array}$ & $\begin{array}{l}\text { O Departamento de DST, Aids e Hepatites Virais do Ministério da Saúde lança uma campanha } \\
\text { nacional de comunicação para o Dia Mundial de Hepatites Virais com o tema "Hepatites Virais: } \\
\text { sem perceber, você pode ter". Estados e Municípios também se organizaram para uma mobilização } \\
\text { de testagem contra as hepatites B e C. A mobilização nacional começou no dia } 22 \text { de julho e vai até } \\
\text { dia } 02 \text { de agosto. Composta por um filme de veiculação nacional e três cartazes para públicos } \\
\text { específicos, a campanha será veiculada no período de } 28 \text { de julho a } 31 \text { de agosto. É a primeira vez } \\
\text { que as hepatites virais ganham uma campanha de televisão e mais três peças para públicos } \\
\text { específicos, além de peças para as redes sociais. Um dos cartazes será destinado às gestantes e alerta } \\
\text { sobre a importância do teste no pré-natal e da vacina para elas e o bebê. O outro é direcionado aos } \\
\text { jovens lembrando a importância do teste e da vacina para a hepatite B. O terceiro cartaz aborda a } \\
\text { população acima de } 45 \text { anos, com mensagem sobre a testagem para a hepatite C. Fazem parte da } \\
\text { campanha, ainda, dois spots de rádio, intervenção nas mídias sociais e um anúncio para } \\
\text { profissionais de saúde sobre a universalização da vacina para hepatite B e sobre a recomendação dos } \\
\text { testes para hepatites B e C. }\end{array}$ \\
\hline $\begin{array}{l}\text { Campanha de Sífilis - } \\
2013\end{array}$ & $\begin{array}{l}\text { A campanha de Sífilis } 2013 \text { é voltada para o incentivo do diagnóstico da sífilis ainda na gestação. } \\
\text { As mensagens são de incentivo ao diagnóstico durante o pré-natal e são destinadas não apenas às } \\
\text { gestantes, mas também a profissionais de saúde e gestores. Motivada pelo ainda alto índice de casos } \\
\text { de crianças com sífilis gestacional, a campanha propõe o engajamento de todos para a reversão } \\
\text { desse quadro. Um dos slogans da campanha é "Faça o teste de sífilis no pré-natal", indicando que o } \\
\text { papel das mães é fundamental para o sucesso da iniciativa, mas não exime aos demais profissionais } \\
\text { da responsabilidade do diagnóstico precoce. As peças também estarão presentes nas redes sociais, o } \\
\text { que facilita a divulgação por todos da sociedade. }\end{array}$ \\
\hline & \\
\hline
\end{tabular}

Filme oficial da Campanha para o Dia Mundial de Luta contra contra a Aids.

Para viver melhor, é preciso saber. Faça o teste de Aids.

Mensagem do Dr. Gottfried Hirnschall, Diretor do Departamento de HIV/Aids da Organização Mundial de Saúde, para o Brasil, em comemoração ao Dia Mundial de Luta contra a Aids 2013. Mensagem de Michel Sidibé, Diretor Executivo do Programa Conjunto das Nações Unidas sobre

Veja o que os grandes líderes na Luta contra a Aids pensam sobre o Brasil - 2013
HIV/Aids (UNAIDS), para o Brasil, em comemoração ao Dia Mundial de Luta contra a Aids 2013. Mensagem do Dr. Julio Montaner, Diretor do Centro de Excelência em HIV/Aids da British Columbia, para o Brasil, em comemoração ao Dia Mundial de Luta contra a Aids 2013. Mensagem da Dra. Rosana Del Bianco, médica infectologista do Hospital Emílio Ribas, em comemoração ao Dia Mundial de Luta contra a Aids 2013.

Mensagem do Dr. Érico Arruda - Presidente da Sociedade Brasileira de Infectologia, em comemoração ao Dia Mundial de Luta contra a Aids 2013.

Mensagem do Dr. Celso Ramos - Médico Infectologista (UFRJ), em comemoração ao Dia Mundial de Luta contra a Aids 2013.

Em 2013, o Ministério da Saúde foi além dos festejos de Carnaval e promoveu uma campanha de prevenção à Aids que foi adaptada a diversas épocas do ano. Por isso, em 2014, a estratégia teve sequência com um esforço de comunicação capaz de se adequar aos diversos períodos de festas que encontramos pelo Brasil.

O carro-chefe da campanha são dois filmes para televisão que, embora explorem o conceito de maneira universal, se complementam na amplitude: um possui uma visão macro das diferentes festas de todos os tamanhos pelo Brasil, das mais íntimas às gigantescas, como a Copa do Mundo; o outro explora o lado pessoal, a atitude de estar sempre preparado, com camisinha, seja qual for a festa. Como o clima dos eventos é de festa, os filmes, e a campanha como um todo, precisam estar no mesmo "clima" para criar a maior identificação possível com os telespectadores. Logo, são leves, simpáticos e alegres.

Além dos filmes, a campanha ainda conta com jingles regionalizados para rádio, anúncios para jornais e revistas, peças e mídia exterior e merchandisings. Nas ativações de rua, contamos com entregas de folders para conscientização e entrega gratuita de preservativos. Na internet, a ampla estratégia conta com banners e ativações em redes sociais.

Campanha realizada pelo Ministério da Saúde para divulgar a vacinação contra o HPV. As peças da campanha encontram-se no Portal da Saúde. As peças mostram que toda menina e toda mulher precisam de proteção contra o vírus HPV. Por isso, se você tiver entre 25 e 64 anos, faça os exames preventivos. E, se sua filha tiver entre 11 e 13 anos, ela deve ser vacinada contra o HPV. Fique atenta ao período de vacinação na escola ou vá a uma unidade de saúde. É importante prevenir o câncer de colo de útero. 


\begin{tabular}{l}
\hline Título da Campanha \\
Campanha Proteja o Gol \\
UnAids - 2014
\end{tabular}

UnAids - 2014

\section{Campanha do Dia}

Mundial de Luta contra

a Aids - CNBB e Pastoral

da Aids - 2014

\section{Descrição da Campanha}

A iniciativa Proteja o Gol é nova campanha do UNAIDS para a conscientização sobre HIV em nível

mundial. A partir de uma ideia simples que ilustra o poder da proteção, faz-se uma analogia entre goleiros protegendo o gol e cada pessoa protegendo a si própria. O objetivo da campanha é usar a popularidade e o poder de união do esporte para promover a prevenção do HIV, principalmente entre os jovens.

Cuide bem de você e de todos os que você ama - este é o slogan da campanha que visa a disseminar informações no maior número de canais de informação disponíveis em todo o Brasil. O Departamento de DST, Aids e Hepatites virais apoiou tecnicamente a proposta da CNBB Conferência Nacional dos Bispos do Brasil, por meio da Pastoral da Aids, para a realização de uma campanha de incentivo à testagem em todas as paróquias e dioceses brasileiras. Essa ação pretende alcançar cerca de mais de onze mil paróquias em todo o Brasil, representando 250 comunidades.

A Pastoral da Aids, com seus agentes e o trabalho junto à comunidade e unidades de saúde, realizará atividades de conscientização para a necessidade da testagem de HIV em seus espaços de atuação.

O objetivo é incentivar o diagnóstico precoce do HIV e colaborar para o cumprimento da meta 9090-90 (90\% de pessoas testadas, 90\% tratadas e 90\% com carga viral indetectável até 2020), estabelecida pelo UNAIDS - Programa Conjunto das Nações Unidas sobre HIV/Aids.

A campanha teve seu lançamento oficial em 27 de novembro, na sede da CNBB em Brasília e, concomitantemente, nas dioceses e arquidioceses, será veiculada em emissoras de TV e rádio, mídias sociais, jornais, folders e outros meios de comunicação da Igreja Católica, no Brasil inteiro, inclusive em celebrações. O protagonista da campanha será o Padre Fábio de Melo.

O Departamento de DST, Aids e Hepatites Virais apoiou a construção da campanha por meio da criação dos materiais gráficos, vídeo para televisão e materiais de internet. A proposta é que a campanha da Pastoral de Aids tenha uma identidade própria e afirmativa.

Veja mais vídeos da campanha em http://lnk.nu/youtube.com/1cv03

A campanha de $1^{\circ}$ de Dezembro terá como objetivos principais: dar maior visibilidade às questões do viver com HIV/Aids e à importância do teste e do tratamento como prevenção.

Sobre os temas, públicos e mídias das campanhas

Considerando que o incentivo à testagem e tratamento (prevenção combinada) é uma nova abordagem de política pública que vem permeando todas as recentes ações de comunicação do Ministério da Saúde e que estará amplamente presente durante o ano de 2015 , a campanha do $1^{\circ}$ de Dezembro de 2014 incentiva "Testar e tratar", com enfoque na adesão ao tratamento precoce.

Campanha do Dia Mundial de Luta contra a Aids - 2014
Campanha de Carnaval 2015
O objetivo é o aumento do foco estratégico em ambientes e populações prioritárias para acelerar a expansão do tratamento. A campanha vai ao encontro das metas do UNAIDS/OMS. São elas: aumentar para $90 \%$ a proporção de pessoas que vivem com o HIV a conhecerem seu diagnóstico; desse total, ter $90 \%$ recebendo tratamento antirretroviral; e desse número, em tratamento como prevenção, ter 90\% com carga viral indetectável.

As artes dos materiais serão disponibilizadas abaixo. Lembramos que a proposta é de que as artes possam ser utilizadas em vários momentos do ano. Entretanto, caso haja interesse em produzir seus próprios materiais, sugerimos que estes sejam voltados para o mesmo público selecionado pelo Ministério da Saúde e pelo grupo de trabalho.

Para solicitar a arte para impressão dos materiais, entre em contato com publicidade@ Aids.gov.br A campanha de Carnaval 2015 é uma continuidade da campanha lançada no $1^{\circ}$ de Dezembro, Dia Mundial de Luta contra a Aids, que tem como principais objetivos dar maior visibilidade às questões do viver com HIV/Aids, à importância do teste e ao tratamento como prevenção, principalmente aos jovens.

Sobre os temas, públicos e mídias das campanhas

Considerando que o incentivo à testagem e tratamento (prevenção combinada) é uma nova abordagem de política pública que vem permeando todas as recentes ações de comunicação do Ministério da Saúde e que estará amplamente presente durante o ano de 2015, a campanha de Carnaval 2015 incentiva o "Testar e tratar", com enfoque na adesão ao tratamento precoce.

O objetivo é o aumento do foco estratégico em ambientes e populações prioritárias para acelerar a expansão do tratamento. A campanha vai ao encontro das metas do UNAIDS/OMS. São elas: aumentar para $90 \%$ a proporção de pessoas que vivem com o HIV a conhecerem seu diagnóstico; desse total, ter $90 \%$ recebendo tratamento antirretroviral; e desse número, em tratamento como prevenção, ter $90 \%$ com carga viral indetectável.

As artes dos materiais serão disponibilizadas abaixo. Lembramos que a proposta é de que as artes possam ser utilizadas em vários momentos do ano. Entretanto, caso haja interesse em produzir os próprios materiais, sugerimos que estes sejam voltados para o mesmo público selecionado pelo Ministério da Saúde e pelo grupo de trabalho.

Para solicitar a arte para impressão dos materiais, entre em contato com informacoes@ Aids.gov.br. 


\begin{tabular}{l|l}
\hline Título da Campanha & Descrição da Campanha \\
\hline $\begin{array}{l}\text { Campanha do Dia das } \\
\text { Mães - Testes de HIV, } \\
\text { sífilis e hepatites B e C - } \\
\text { 2015 }\end{array}$ & $\begin{array}{l}\text { Campanha direcionada às futuras mamães, para que exijam a realização de testes de HIV, sífilis e } \\
\text { hepatites virais B e C para evitar a transmissão vertical desses agravos. As peças da campanha são } \\
\text { cartaz, vídeo e peças gráficas para uso eletrônico. }\end{array}$ \\
\hline $\begin{array}{l}\text { Campanha Festas } \\
\text { Populares - Partiu Teste } \\
\text { - 2015 }\end{array}$ & $\begin{array}{l}\text { Para dar continuidade à estratégia de comunicação no combate ao HIV, o vírus da Aids, o } \\
\text { Ministério da Saúde ingressa em uma nova fase: as grandes festas brasileiras. Uma estratégia para } \\
\text { dar maior força à campanha \#PartiuTeste com uma nova roupagem, mas com a mesma linguagem e } \\
\text { conteúdo, mantendo a coesão. As festas escolhidas foram uma combinação de tradição, } \\
\text { popularidade e apelo jovem, principal público-alvo. Esses desdobramentos foram veiculados nos } \\
\text { principais meios como TV, rádio, mobiliário urbano e internet. }\end{array}$ \\
\hline $\begin{array}{l}\text { Campanha do Dia } \\
\text { Mundial de Luta contra as } \\
\text { Hepatites Virais - 2015 }\end{array}$ & Dia Mundial de Luta contra as Hepatites Virais - 2015. Slogan: "O teste é o primeiro passo para a cura" \\
\hline $\begin{array}{l}\text { Campanha do Dia } \\
\text { Mundial de Luta contra } \\
\text { a Aids - 2015 }\end{array}$ & $\begin{array}{l}\text { Campanha que tem como foco o incentivo ao tratamento precoce da infecção. Slogan: "Com o } \\
\text { tratamento, você é mais forte que a Aids". }\end{array}$ \\
\hline $\begin{array}{l}\text { Campanha de Carnaval - } \\
\text { 2016 }\end{array}$ & $\begin{array}{l}\text { A Campanha de Prevenção à Aids no Carnaval 2016 tem como slogan: "Deixe a camisinha entrar na } \\
\text { festa". Ela reforça o preservativo como a mais importante arma de combate ao HIV/Aids, } \\
\text { trabalhando a mensagem de prevenção nas açães pré-Carnaval e durante as festas. Entre as peças } \\
\text { estão filme, jingle para veiculação em rádios e versão estendida da música para trios elétricos e } \\
\text { carros de som. }\end{array}$ \\
\hline $\begin{array}{l}\text { Campanha de IST - } \\
\text { Encontrou um sinal } \\
\text { diferente em você? 2016 }\end{array}$ & $\begin{array}{l}\text { Campanha e materiais informativos sobre Infecções Sexualmente Transmissíveis (IST) com o } \\
\text { slogan: "Encontrou um sinal diferente em você? Pode ser uma IST". }\end{array}$ \\
\hline
\end{tabular}

Campanha do Dia

Mundial de Luta contra

as Hepatites Virais - 2016

Campanha do Dia

Nacional de Combate à

Sífilis Congênita - 2016

Campanha voltada para a população geral, alerta para a importância do teste para a hepatite $\mathrm{C}$ e traz como slogan: "Hepatite C tem tratamento e cura".

A campanha de combate à sífilis de 2016 tem como foco a importância do pré-natal e da participação do parceiro no processo de gestação. Com o slogan: "Casal que combina em tudo não pode deixar de proteger seu bebê", a campanha é destinada às redes sociais e apresenta materiais como posts eletrônicos, vídeo e cartazes.

O ministério da saúde também disponibiliza a landing page da campanha: http://portalarquivos.saude.gov.br/campanhas/sifilis/

Muitas pessoas desconhecem as hepatites virais e suas formas de transmissão mesmo quando estão vivendo em um ambiente propício à contaminação. Com isso, muitas vezes essas doenças são diagnosticadas tardiamente, dificultando o tratamento.

Para aumentar o acesso da sociedade às formas de prevenção, o Departamento de DST, Aids e Hepatites Virais lança uma campanha com dois grandes públicos: profissionais de salões de beleza e de estúdios de tatuagem. às hepatites virais em salões de beleza e estúdios de tatuagem 2010

Profissionais de salões de beleza

Com o tema "Meu salão livre das hepatites", essa campanha foi criada para orientar manicures e pedicures sobre práticas seguras no ambiente de trabalho, buscando prevenir tanto o profissional quanto seus clientes.

Profissionais de estúdios de tatuagem

Com o tema "Este estúdio de tatuagem se preocupa com você, previna-se da hepatites", esse selo foi criado para mobilizar estúdios de tatuagem sobre práticas seguras no ambiente de trabalho, buscando prevenir tanto o profissional quanto seus clientes.

Campanha Dia Mundial de Luta contra a Aids CNBB e Pastoral da Aids $-2016$

Campanha do Ministério da Saúde sobre Prevenção Combinada 2016

à Aids no Carnaval 2017

Campanha Tem Camisinha na Festa - 2017
Materiais informativos sobre o Dia Mundial de Luta contra a Aids 2016 - CNBB e Pastoral da Aids. Slogan da campanha: "Nós podemos construir um futuro sem Aids"

Campanha do Ministério da Saúde com foco na Prevenção Combinada, com o slogan: "Aids. Escolha sua forma de prevenção".

As peças da campanha são constituídas por dois filmes, um de 90 segundos para as redes sociais e um de 30 segundos para as TV abertas; spot de rádio; cartazes voltados para gestantes, casal homoafetivo, heterossexuais e mulheres trans.

O público-alvo prioritário da campanha são os jovens - atualmente, uma das populações-chave para a infecção pelo HIV. Por isso, a linguagem simples e leve, de fácil entendimento.

Campanha de prevenção à Aids no Carnaval - 2017

Campanha que visa dar continuidade às ações de prevenção ao HIV/Aids e às hepatites virais ao longo do ano durante as festas populares. Os materiais são destinados às festas juninas, paradas gays, festa do boi de Parintins e Oktoberfest. 


\begin{tabular}{|c|c|}
\hline Título da Campanha & Descrição da Campanha \\
\hline $\begin{array}{l}\text { Campanha do Dia } \\
\text { Mundial de Luta contra às } \\
\text { Hepatites Virais - 2017 }\end{array}$ & Materiais informativos sobre a Campanha do Dia Mundial de Luta contra às Hepatites Virais - 2017 \\
\hline $\begin{array}{l}\text { Campanha de Prevenção } \\
\text { da Sífilis Congênita - } \\
2017\end{array}$ & Materiais informativos sobre a Campanha de Prevenção à Sífilis Congênita - 2017 \\
\hline $\begin{array}{l}\text { Campanha Dia de } \\
\text { Combate à Sífilis } 2017\end{array}$ & Campanha que incentiva a participação do parceiro durante o pré-natal. \\
\hline $\begin{array}{l}\text { Campanha Dia Mundial } \\
\text { de Luta contra a Aids - } \\
\text { Vamos combinar? - 2017 }\end{array}$ & $\begin{array}{l}\text { Materiais informativos sobre o Dia Mundial de Luta contra a Aids } 2017 \text { Slogan da campanha: } \\
\text { "Vamos combinar?" }\end{array}$ \\
\hline $\begin{array}{l}\text { Dia Nacional de } \\
\text { Combate à Sífilis } 2017\end{array}$ & Proteja o seu futuro e o futuro do seu filho Sífilis \\
\hline $\begin{array}{l}\text { Campanha de Carnaval - } \\
2018\end{array}$ & $\begin{array}{l}\text { \#VamosCombinar, Prevenir é Viver o Carnaval é o tema da campanha de prevenção ao HIV/Aids } \\
\text { 2018. A campanha dá continuidade a nova abordagem adotada pelo Ministério intitulada Prevenção } \\
\text { Combinada, lançada durante o Dia Mundial de Luta Contra a Aids, em } 1^{\circ} \text { de dezembro de } 2017 \text {, e } \\
\text { visa fortalecer às diversas formas de prevenção às infecções sexualmente transmissíveis como o } \\
\text { HIV/Aids junto ao público jovem. São utilizadas diferentes manifestações musicais de cada local, } \\
\text { tais como o samba, axé, frevo, marchinhas e forró. Além de lançar mão de mídias segmentadas para } \\
\text { cada grupo específico como a população gay e população trans. }\end{array}$ \\
\hline
\end{tabular}

Fonte: (47) 


\section{REFERÊNCIAS}

1. UNAIDS. Estatísticas. 2017.

2. AYRES JRdCMea. O conceito de vulnerabilidade e as práticas de saúde: novas perspectivas e desafios. In: Czeresnia D, de Freitas CM, (Orgs.), editors. Promoção da saúde: conceitos, reflexões, tendências: SciELO - Editora FIOCRUZ; 2009. p. 117-40.

3. Boletim Epidemiológico Aids/DST 2014. Brasília; 2014. Report No.: 15171159.

4. Prevention and treatment of HIV and other sexually transmitted infections for sex workers in low- and middle-income countries: Recommendations for a public health approach. Geneva: World Health Organization; 2012.

5. Global HIV/AIDS response: epidemic update and health sector progress towards universal access: progress report 2011. Geneva: World Health Organization; 2011.

6. Ministério da Saúde lança campanha de prevenção às DSTs/Aids 2015. Portal Brasil2015.

7. Moderno dicionário da língua portuguesa. 2009.

8. HOUAISS A, VILLAR MS. Dicionário Houaiss conciso. São Paulo: Moderna; 2011.

9. CHIUZI RM, PEIXOTO BRG, FUSARI GL. Conflito de gerações nas organizações: um fenômeno social interpretado a partir da teoria de Erik Erikson. Temas em Psicologia. 2011;19(2):579 - 90.

10. Yelkikalan N, Ayhun SE. EXAMINATION OF THE CONFLICTS BETWEEN X AND Y GENERATIONS: RESEARCH FOR ACADEMICIANS. European Scientific Journal (ESJ). 2013;9(19).

11. Kyles D. Managing Your Multigenerational Workforce. Strategic Finance. 2005;87(6):52 - 5 .

12. LANCASTER L, STILLMAN D. Clashing Generations. Futurist. 2002;36(2):59 -

13. SEÇKİN BÜYÜK S. Biz Kuşağı Geliyor. Capital Monthly Journal of Business and Economics. 2005;10.

14. TULGAN B, MARTIN C. Managing the generation mix. Press H, editor. Amherst, MA2006.

15. SALAHUDDIN MM. Generational Differences Impact On Leadership Style and. Organizational Success. Journal of Diversity Management. 2010;5(3):1 - 6.

16. YELKİKALAN N, ALTIN E. Farklı Kuşakların Yönetimi. Journal of Management Sciences. 2010;2(8). 
17. TSUI B, LAURA Q H. Generation Next. Advertising Age. 2001;3(72):14 - 6.

18. SPITZNAS TJ. Generation X: Why So Glum? Fairfield County Business Journal. 1998;50(37):4-5.

19. WASHBURN ETR. The Five Generations. Physician Executive. 2000;26(1):54-.

20. CRUMPACKER M, CRUMPACKER JM. Succession Planning and Generational Stereotypes: Should HR Consider Age-Based Values and Attitudes a Relevant Factor or a Passing Fad? Public Personnel Management. 2007;4(36):349-69.

21. SENBİR H. Z "son insan" mı?: Z kuşağı ve sonrasına dair düşünceler. İstanbul: "O” Kitaplar; 2004.

22. HAEBERLE K, HERZBERG J, HOBBY T. Leading the Multigenerational Work Force. Healthcare Executive. 2009;24(5):62-7.

23. KELEŞ HN. Y Kuşağı Çalışanlarının Motivasyon Profillerinin Belirlenmesine Yönelik Bir Araştırma. Journal of Organization and Management Studies. 2011;3(2):129-39.

24. MATTHEWS V. Generation Y. Personnal Today. 2008:48-51.

25. KILSZTAJN S. Casos Notificados de AIDS no Estado de São Paulo-A Geração Vulnerável-Nascidos entre 1955-1970. Anais 2000 - População e Saúde. 2000.

26. ROCHA-DE-OLIVEIRA S, PICCININI VC, BITENCOURT BM. Juventudes, gerações e trabalho: é possível falar em geração Y no Brasil? Organizações \& Sociedade. 2012;19.

27. VELOSO EFR, SILVA RCd, DUTRA JS. Diferentes gerações e percepções sobre carreiras inteligentes e crescimento profissional nas organizações. Revista Brasileira de Orientação Profissional. 2012;13(2).

28. VASCONCELOS KCdA, MERHL DQ, GOULART VM, SILVA ARLd. A Geração Y e suas âncoras de carreira. Revista Gestão Organizacional. 2010;8(2):226-44.

29. CAVAZOTTE FSCN, LEMOS AHdC, VIANA MDdA. Novas gerações no mercado de trabalho: expectativas renovadas ou antigos ideais. Cadernos EBAPE. $2012 ; 19(1)$.

30. R. Kupperschmidt B. Multigeneration Employees: Strategies for Effective Management2000. 65-76 p.

31. Boletim Epidemiológico Aids/DST 2016. Brasília; 2016.

32. PAIVA V, PUPO LR, BARBOZA R. O direito à prevenção e os desafios da redução da vulnerabilidade ao HIV no Brasil. Revista de Saúde Pública. 2006;40:109-19.

33. Seade PEDAeF. Dados para repensar a Aids no Estado de São Paulo: resultados da parceria entre Programa Estadual DST/Aids e Fundação Seade2010.

34. SAÚDE MD. 20. O que é população-chave para o hiv? 2018 [Available from: http://www.aids.gov.br/pt-br/faq/20-o-que-e-populacao-chave-para-o-hiv. 
35. Ramos LQ, editor A cara viva da AIDS pós coquetel: a representação social da doença no século XXI. Anais Eletrônicos do $14^{\circ}$ Seminário Nacional de História da Ciência e da Tecnologia - $14^{\circ}$ SNHCT; 2014; Belo Horizonte, Campus Pampulha da Universidade Federal de Minas Gerais - UFMG.

36. PMSP DACdSPSS-. Boletim Epidemiológico de AIDS do Município de São Paulo 2003 [Available from: http://www.prefeitura.sp.gov.br/cidade/secretarias/upload/boletimVII7_1254751678.pdf.

37. SAÚDE MD. Diretrizes para Organização do CTA no Âmbito da Prevenção Combinada e nas Redes de Atenção à Saúde 2017. Available from: http://www.aids.gov.br/pt-br/pub/2017/diretrizes-para-organizacao-do-cta-noambito-da-prevencao-combinada-e-nas-redes-de-atencao.

38. Lomando E, Wagner A. Reflexões sobre Termos e Conceitos das Relações entre Pessoas do Mesmo Sexo. Revista Sociais e Humanas. 2010;22(2):11.

39. Garcia S, Souza FMd. Vulnerabilidades ao HIV/aids no Contexto Brasileiro: iniquidades de gênero, raça e geração. Saúde e Sociedade. 2010;19:9-20.

40. Bertolozzi MR, Nichiata LYI, Takahashi RF, Ciosak SI, Hino P, Val LFd, et al. Os conceitos de vulnerabilidade e adesão na Saúde Coletiva. Revista da Escola de Enfermagem da USP. 2009;43:1326-30.

41. Ayres JRdCM. Saúde e emancipação no Século XXI: reificação e vulnerabilidade no contexto das cibertecnologias** Comentário sobre o artigo "Epidemiologia del siglo XXI y ciberespacio: repensar la teoría del poder y la determinación social de la salud", de Jaime Breilh, para a Revista Brasileira de Epidemiologia. Revista Brasileira de Epidemiologia [online]. 2015.

42. Ayres JRdCM. Organização das ações de atenção à saúde: modelos e práticas. Saúde e Sociedade. 2009;18:11-23.

43. Pellini ACG. Evolução da epidemia de Aids no município de São Paulo - 1980 a 2012: uma análise espacial com múltiplas abordagens. Biblioteca Digital de Teses e Dissertações da USP: Faculdade de Saúde Pública, Universidade de São Paulo; 2016.

44. Barros NB, GuimarÃ£es CM, Borges OdS. Pol⿵̃-ticas de SaÃ de e Preven $\tilde{A} \S \tilde{A} £ o$ ao Hiv/Aids no Brasil 1982-2012. EVS - Estudos Vida e SaÃ ${ }^{\circ}$ de. 2013;39(4):10.

45. Marques MCdC. Saúde e poder: a emergência política da Aids/HIV no Brasil. História, Ciências, Saúde-Manguinhos. 2002;9:41-65.

46. Villarinho MV, Padilha MI, Berardinelli LMM, Borenstein MS, Meirelles BHS, Andrade SRd. Políticas públicas de saúde face à epidemia da AIDS e a assistência às pessoas com a doença. Revista Brasileira de Enfermagem. 2013;66:271-7.

47. Ministério da Saúde - Departamento de Vigilância PeCdI, do HIV/Aids e das Hepatites Virais. Campanhas.

48. Sepkowitz KA. AIDS - The First 20 Years. New England Journal of Medicine. 2001;344(23):1764-72. 
49. Social MdP. Diretrizes de apoio à decisão médico-pericial em clínica médica em HIV/AIDS. 2011 [Available from: http://www.previdencia.gov.br/arquivos/office/4_110831-181722-268.pdf.

50. Aids. BMdSSdVeSPNdDe. Critérios de definição de casos de aids em adultos e crianças. 2004.

51. Boletim Epidemiológico Aids/DST. 2013. Brasília; 2013. Report No.: 15171159.

52. Boletim Epidemiológico Aids/DST 2015. Brasília; 2015.

53. Boletim Epidemiológico Aids/DST. 2012. Brasília; 2012. Report No.: ISSN 15171159.

54. DANCEY CP, \& REIDY, J. Estatística sem Matemática para Psicologia. Porto Alegre: Penso; 2013.

55. Sheskin DJ. Handbook of parametric and nonparametric statistical procedures: crc Press; 2003.

56. Zhao Y. R and data mining: Examples and case studies.

57. Team RC. R Development Core Team. R: A language and environment for statistical computing. R Foundation for Statistical Computing, Vienna, Austria; 2014.

58. Hahsler M, Buchta C, Gruen B, Hornik K. Arules: Mining Association Rules and Frequent Itemsets, Package Version 1.1-6. Michael Hahsler; 2014.

59. Agrawal R, Srikant R. Fast Algorithms for Mining Association Rules in Large Databases. Proceedings of the 20th International Conference on Very Large Data Bases. 672836: Morgan Kaufmann Publishers Inc.; 1994. p. 487-99.

60. Faraway JJ. Extending the Linear Model with R: Generalized Linear, Mixed Effects and Nonparametric Regression Models. 2 ed2016.

61. Ferreira Juliana Carvalho PCM. What is survival analysis, and when should I use it? $\mathrm{J}$ bras pneumol [Internet]. Available from: http://www.scielo.br/scielo.php?script=sci_arttext\&pid=S180637132016000100077\&lng=enAvailable from: http://dx.doi.org/10.1590/S180637562016000000013 .

62. Guibu IA, Barros MBdA, Donalísio MR, Tayra Â, Alves MCGP. Survival of AIDS patients in the Southeast and South of Brazil: analysis of the 1998-1999 cohort. Cadernos de Saúde Pública. 2011;27:s79-s92.

63. Samji H, Cescon A, Hogg RS, Modur SP, Althoff KN, Buchacz K, et al. Closing the Gap: Increases in Life Expectancy among Treated HIV-Positive Individuals in the United States and Canada. PLOS ONE. 2013;8(12):e81355.

64. Saúde. BMd, Saúde. SdVe, Departamento de DST AeHV. Adesão ao tratamento antirretroviral no Brasil: coletânea de estudos do Projeto Atar: Projeto Atar. Saúde SBTBd, editor. Brasília2010. 
65. Departamento de DST AeHV. Nota informativa n. 019/2017- DDAHV/SVS/MS | Departamento de IST, Aids e Hepatites Virais 2017 [updated 09/03/2017. Available from: http://www.aids.gov.br/legislacao/2017/59457.

66. HIV/Aids nos jovens de 15 a 24 anos. BEPA Boletim Epidemiológico Paulista (Online). 2011;8:14-20.

67. IBGE. Estados@ 2017 [Available from: http://www.ibge.gov.br/estadosat/perfil.php?sigla=sp.

68. Emplasa. Sobre a RMSP [Available from: https://www.emplasa.sp.gov.br/RMSP.

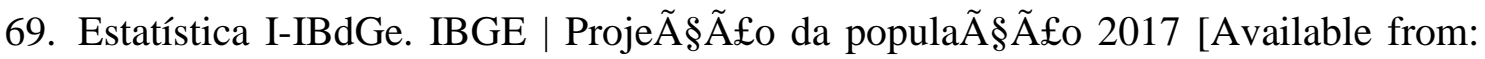
http://www.ibge.gov.br/apps/populacao/projecao/.

70. PAULO SMDSDS, COVISA CDVES-, CCD CDCDD-, TRANSMISSÍVEIS VDDS. Boletim Epidemiológico de Aids HIV e DST do Município de São Paulo. 2014.

71. IBGE IBdGeE-. IBGE divulga as estimativas populacionais dos municípios para 2017. 2017.

72. Paulo PdMdS. Mapa da Cidade | Secretaria Municipal de Prefeituras Regionais | Prefeitura da Cidade de São Paulo. 2010.

73. Kalichman AO. A integralidade no cuidado das pessoas vivendo com HIV e AIDS: a experiência do Centro de Referência e Treinamento em DST/AIDS da SES-SP: Universidade de São Paulo; 2016.

74. Brojan LEF, Muller EV, Brasil D. Mortalidade por AIDS e fatores associados no município de Ponta Grossa, Paraná: 2008-2015. 19. 2018.

75. Fabiola Sulpino V. Evolução do gasto com medicamentos do sistema único de saúde no período de 2010 a 2016. 2018. Contract No.: 2356.

76. Alcalde PR, Kirsztajn GM. Expenses of the Brazilian Public Healthcare System with chronic kidney disease. Brazilian Journal of Nephrology. 2018.

77. Martins T, Kerr LRFS, Kendall C, Mota RMS. CENÁRIO EPIDEMIOLÓGICO DA INFECÇÃO PELO HIV E AIDS NO MUNDO. 3. 2014.

78. Ministério da Saúde SdVeS. PORTARIA N 34, DE 28 DE JULHO DE 20052005 [Available from: http://bvsms.saude.gov.br/bvs/saudelegis/svs/2005/prt0034_28_07_2005.html. 